\title{
3-D Velocity structure of the northern Hikurangi margin: implications for crustal growth
}

\author{
Daniel Graham Bassett
}

VOLUME ONE

A thesis submitted to Victoria University of Wellington in fulfilment of the requirement for the degree

Master of Science - Geology/Geophysics

August 2009

Institute of Geophysics

School of Geography, Environment and Earth Science

Victoria University of Wellington 


\section{ABSTRACT}

Onshore-offshore wide-angle seismic reflection and refraction data are combined with multi-channel seismic reflection profiles to model crustal structure within a $32,000 \mathrm{~km}^{2}$ block of the northern Hikurangi subduction margin, New Zealand. A 3-D onshore-offshore dataset comprising $\sim 250,000$ seismic traces is analysed as a suite of 81 receiver-gathers. These receiver-gathers contain reflected and refracted arrivals and constrain a 3-D P-wave velocity forward model.

Southwest along the strike of the subduction zone, velocity forward models resolve a $>10 \mathrm{~km}$ increase in Moho depth and a $>20 \mathrm{~km}$ increase in basement thickness between Raukumara Basin and the Raukumara Peninsula. Beneath the topographic crest of the East Cape Ridge and Raukumara Peninsula, low velocities (3.0-5.0 $\mathrm{km} / \mathrm{sec})$ are resolved within a triangular prism $\left(>200 \mathrm{~km}^{3} / \mathrm{km}^{-1}\right.$ ie per $\mathrm{km}$ of strike) positioned on top of the subducting slab. The arcward/inboard edge of this prism coincides with the intersection of the subducting slab with the Moho and southward along East Cape Ridge, both the prism and topographic crest are observed migrating arcward, concomitant with the increase in Moho depth beneath the continental shelf.

Second-order seismic-stratigraphic sequences within Raukumara Basin record a southeast-northwest migration of the Neogene depocenter. Internal deformation increases east and south of the central basin at East Cape Ridge and within the continental shelf where strata tilt up toward the topographic crest.

Refracted arrivals place the first controlled-source seismic constraints on the thickness of the about-to-be subducted northern Hikurangi Plateau. The Hikurangi Plateau crust is modelled as two layers with velocities of $4.9-6.3 \mathrm{~km} / \mathrm{sec}$ and $7.1-7.3$ $\mathrm{km} / \mathrm{sec}$ with a combined thickness of $17-18 \mathrm{~km}$. The upper $10 \mathrm{~km}$ of the subducting mantle lithosphere is modelled with velocities of $8.1-8.4 \mathrm{~km} / \mathrm{sec}$. The geometry of the plate interface is also constrained by wide-angle reflections.

Low velocities $(3.0-5.0 \mathrm{~km} / \mathrm{sec})$ beneath the topographic crest of the East Cape Ridge and the Raukumara Peninsula are interpreted as underplated sedimentary and crustal material and a rate of accretion of $10-25 \mathrm{~km}^{3} \mathrm{Myr}^{-1} \mathrm{~km}^{-1}$ is calculated. The migration of the Neogene Raukumara Basin depocenter and what is considered postdepositional internal deformation are associated with uplift and protuberant growth at East Cape Ridge and Raukumara Peninsula in response to lower crustal underplating. The underplating process appears modulated by Moho depth and a cyclical crustal dynamic is proposed to provide a viable means of maintaining or increasing the netvolume of the forearc in the presence of trench slope collapse and subduction erosion.

At present, a discrepancy exists between published estimates of continental creation at volcanic arcs and continental destruction at subduction margins. $\mathrm{Nd}$ isotopic evidence and continental freeboard arguments require a constant volume of continental crust throughout the Phanerozoic. The crustal dynamic developed in this thesis highlights the importance of lower crustal underplating as a means of retaining subducted sediment within the forearc, thus reducing the flux of continental material to the mantle. The calculated rates at which subducted sediment is underplated and accreted to the upper plate $\left(10-25 \mathrm{~km}^{3} \mathrm{Myr}^{-1} \mathrm{~km}^{-1}\right)$ are considered sufficient to solve the discrepancy between the inputs and outputs at subduction margins within analytical uncertainty. 


\section{ACKNOWLEDGMENTS}

For providing a young scientist with the opportunity to work on a project so well aligned with his own personal interests, my primary thanks are directed to my supervisors Rupert Sutherland, Tim Stern and Stuart Henrys. I am grateful for the freedom, guidance, and endless references I have received over the last 2 years.

This thesis has contributed to a collaborative research effort comprising GNS Science, Victoria University, IFM Geomar and MED Crown Minerals. Martin Scherwath (IFM Geomar) has been an integral member of this research group and is thanked for his constructive input and the provision of data for this thesis.

Adrian Benson is thanked immensely for his tireless assistance with programming. A great deal of the code produced with Adrian was essential to the forward modelling methodology developed in this thesis. Mark Henderson, Zara Rawlinson, Sandra Bourguignon and Chris Le Blanc are also acknowledged for assistance with programming. Nick Rawlinson (ANU) and Nicolas Brikke are thanked for software support and expertise concerning the application of FMTOMO.

Mark Henderson, Suzannah Toulmin, Rosanne Simes, Yanik Behr and Nicolas Henrys are thanked for the deployment and retrieval seismometers from the East Cape. Sam Nowland, Mark Henderson, Sam Hemming-Sykes, Mark Bassett, Zara Rawlinson and Matt Ryan are all thanked for helpful reviews of specific chapters of this thesis. A final review was provided by John Townend and Vaughan Stagpoole. The helpful comments stemming from this review have improved the readability of this thesis.

From GNS Science, Stephen Bannister, Mike Milner, Guy Maslen, Martin Reyners and Hannu Seebeck are thanked for general assistance, the provision of data and helpful discussion. NIWA is acknowledged for the provision of bathymetric and seismic data and Geoffroy Lamarche and Simon Bardsley are specifically thanked for their role in facilitating this exchange.

Throughout the course of this thesis, I have been financially supported by scholarships from Victoria University, The Todd Foundation, The Freemasons and have received annual contributions from my grandparents for which I am extremely grateful.

Lower Hutt City Football Club are thanked for their financial support and patience during the latter stages of this thesis. Gill Ruthven is thanked for her assistance with binding the final product.

Finally, I am extremely grateful for the support and encouragement received from my friends and colleagues, and particularly from my family and partner, Vita. 


\section{TABLE OF CONTENTS}

\section{VOLUME ONE}

Abstract .................................... ii

Acknowledgments .............................. iii

Table of Contents .............................

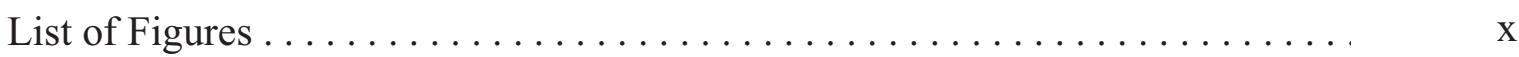

List of Tables $\ldots \ldots \ldots \ldots \ldots \ldots \ldots \ldots \ldots \ldots \ldots \ldots \ldots \ldots \ldots \ldots \ldots \ldots \ldots$

\section{CHAPTER 1 - INTRODUCTION}

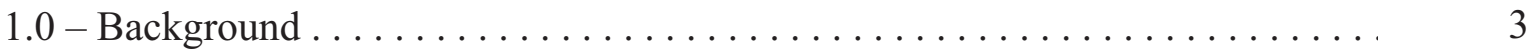

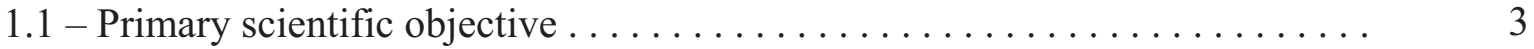

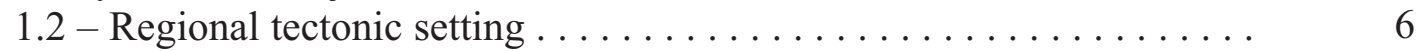

1.2 .1 - Plate Boundary . . . . . . . . . . . . . . . . . . . . . . . 6

1.2 .2 - Forearc crustal structure . . . . . . . . . . . . . . . 8

1.2.3 - Raukumara Basin structure, onshore geology and tectonics . . . . 9

1.3 - Relationships with other work . . . . . . . . . . . . . . . 12

1.4 - Thesis outline . . . . . . . . . . . . . . . . . . . . . . . . 13

CHAPTER 2 - SEISMIC REFLECTION

2.1 - Introduction . . . . . . . . . 17

2.2 - Seismic Reflection

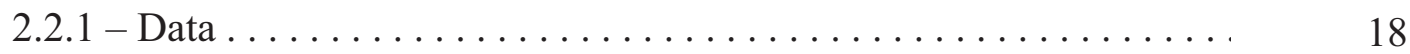

2.2 .2 - Interpretation . . . . . . . . . . . . . . 20

2.3 - Seismic Reflection Stratigraphy

2.3 .1 - Sequences within Megasequence $Z \ldots \ldots \ldots \ldots \ldots \ldots . \ldots \ldots$

2.3.2 - Sequences within Megasequence Y . . . . . . . . . . . . . . . . . 29

2.3.3 - Sequences within Megasequence X ................. 30

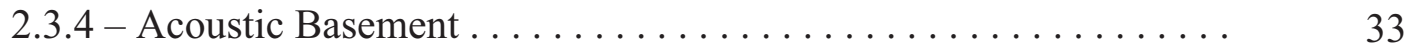

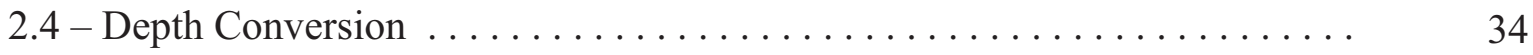

2.5 - Results

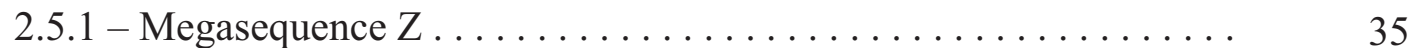

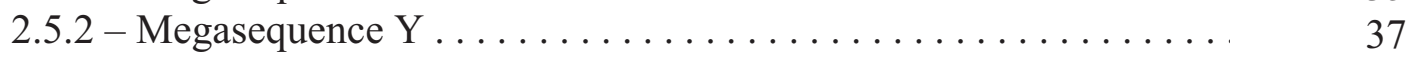

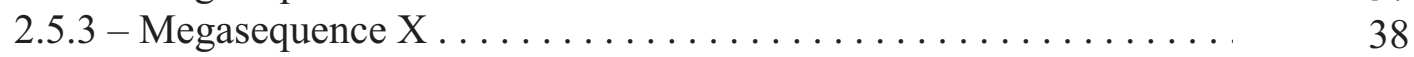

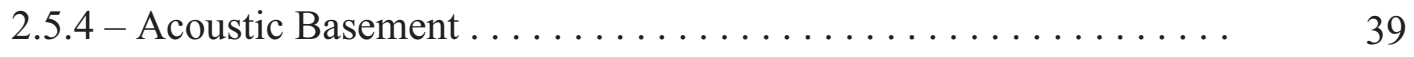

2.6 - Discussion

2.6.1 - Mass-balance of Forearc . . . . . . . . . . . . . . . . . 40

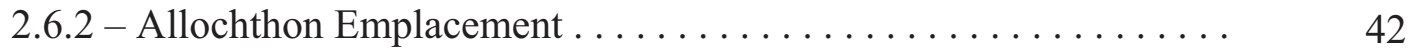

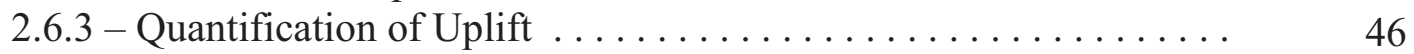

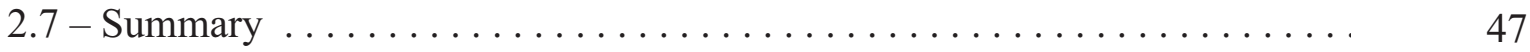




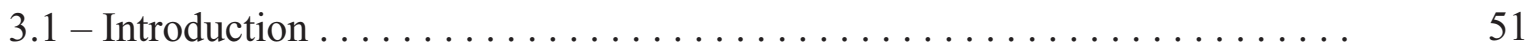

3.2 - Seismic Refraction

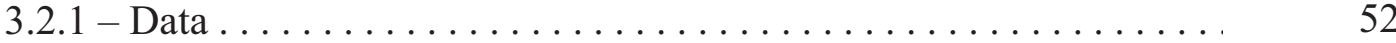

3.2.2 - Onshore offshore seismic profiling ........... 54

3.2 .3 - Processing and Interpretation . . . . . . . . . . 57

3.3 - Observations

3.3.1 - Regional observations . . . . . . . . . . . . . . . . . . . . . . 58

3.3 .2 - Raukumara Plain . . . . . . . . . . . . . . . . . . . . 62

3.3.2.1 - Central Basin . . . . . . . . . . . . . . . . . . . 62

3.3.2.2 - Northern Basin . . . . . . . . . . . . . . . . . . . 65

3.3.2.3 - Western Basin - Kermadec Ridge / Harve Trough . . . . . 66

3.3 .3 - Trench-slope - Subducting Slab. . . . . . . . . . . . . . . . . 68

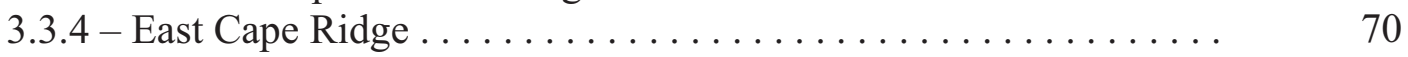

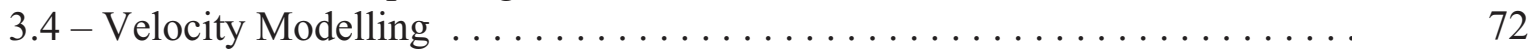

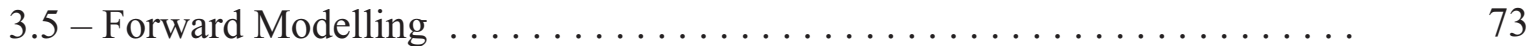

3.5.1 - Forward Modelling Methodology . . . . . . . . . . . . . . . . . . 73

3.5.2 - Forward Modelling Strategy . . . . . . . . . . . . . . . . . . . . . 75

- Constraints incorporated into forward modelling . . . . . . . . . 77

3.5.3.1 - Onshore velocity structure . . . . . . . . . . . . . 78

3.5.3.2 - Velocity structure along RAU07-05 . . . . . . . . . . . . . . . . 79

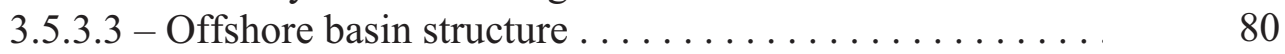

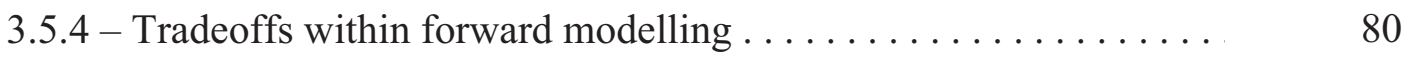

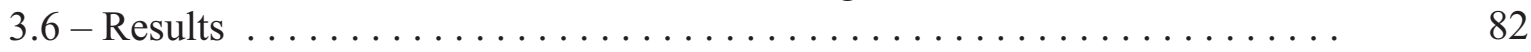

3.6.1 - Raukumara Plain / Harve Trough . . . . . . . . . . . . . . . . 87

3.6.2 - Raukumara Peninsula / continental Shelf . . . . . . . . . . . . . . . 89

3.6.3 - Trench-Slope / Subducting Slab . . . . . . . . . . . . . . . . . . . . . 90

3.6 .4 - East Cape Ridge . . . . . . . . . . . . . . . . . . . . . . . . . 91

3.7 - Discussion

3.7.1 - Model fit . . . . . . . . . . . . . . . . . . . . . . . . . . . . . 92

3.7 .2 - Problematic arrivals during forward modelling . . . . . . . . . 92

3.7.3 - Model resolution . . . . . . . . . . . . . . . . . . . . . . . . . . . . . . . . 94

3.7 .4 - Errors . . . . . . . . . . . . . . . . . . . . . . . . . . . 94

3.7.4 - Comparison with constraining datasets . . . . . . . . . . 95

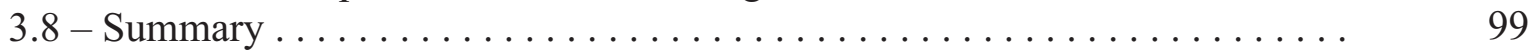


4.1 - Introduction . . . . . . . . . . . . . . . . . . . . . . . . . . . . . . . 103

4.2 - Data and Methodology .......................... 105

4.3 - Observations

4.3 .1 - Structure of the downgoing plate . . . . . . . . . . . . 106

4.3.2 - Structure of the subduction interface . . . . . . . . . . . . . 108

4.3 .3 - Structure of the Moho . . . . . . . . . . . . . . . . 110

4.3.4 - Forearc Crustal Structure

4.3.4.1 - Basement Thickness . . . . . . . . . . . . . . . . . . . . 112

4.3.4.2 - Low-velocity forearc high . . . . . . . . . . . . . . . 114

4.3.4.3- Structure of Raukumara Basin . . . . . . . . . . . . . . . 114

4.4 - Regional Implications

4.4.1 - Seismic constraints on Hikurangi Plateau structure

4.4.1.1 - Crustal Thickness . . . . . . . . . . . . . . . . . . . 119

4.4.1.2 - Upper Mantle Velocities . . . . . . . . . . . . . . . 119

4.4.1.3 - Conclusions with regard to the Hikurangi Plateau . . . . 121

4.4.2 - Subduction interface

4.4.2.1 - Interface Geometry . . . . . . . . . . . . . . . . . . . 123

4.4.2.2 - Physical Properties . . . . . . . . . . . . . . . 123

4.4 .3 - Crustal Growth Processes . . . . . . . . . . . . . . . . . 125

4.5 - Global Implications

4.5.1 - Quantification of the fluxes at convergent margins . . . . . . . . . 130

4.5.2 - Sediment recycling and crustal underplating ........... 132

4.5.3 - Implications for the fluxes at convergent margins . . . . . . . . . . 134

4.6 - Future Research . . . . . . . . . . . . . . . . . . . . 137

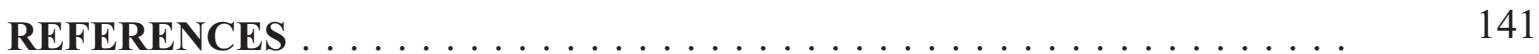




\section{VOLUME TWO - APPENDICIES}

APPENDIX ONE - ACQUISITION, PROCESSING AND INTERPRETATIO] ONSHORE-OFFSHORE SEISMIC DATA

Page

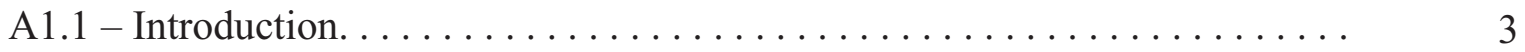

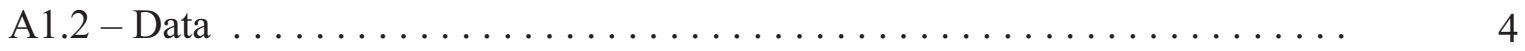

A1.3 - Data Processing

A1.3.1 - Data extraction and Conversion

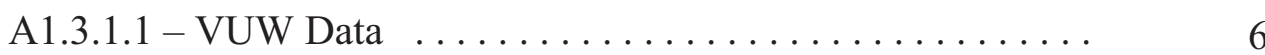

A1.3.1.2 - GNS Data ...................... 6

A1.3.2 -Compilation of navigation and shot time data

A1.3.2.1 - Shot times. ..................... 7

A1.3.2.2 - Shot positions . . . . . . . . . $\ldots \ldots \ldots \ldots . \ldots$

A1.3.3 - Data preparation ........................ 12

A1.3.3.1 - VUW Data . . . . . . . . . . . . . . . . . . 12

A1.3.3.2 - GNS Data ...................... 13

A1.3.4 - Cutting Receiver Gathers. . . . . . . . . . . . . . . 14

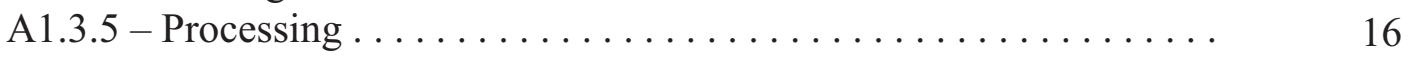

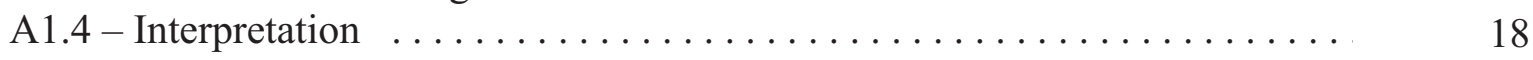

A1.5 - Results

A1.5.1 - Data and travel times . . . . . . . . . . . . . . . 19

A1.5.2 - Shot timing errors . . . . . . . . . . . . . . . . 20

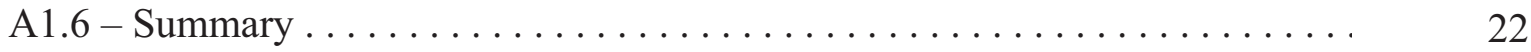

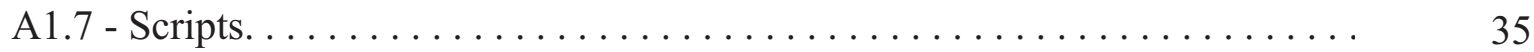

APPENDIX TWO - 3-D FORWARD MODELLING

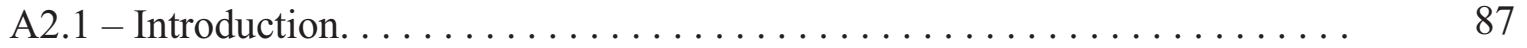

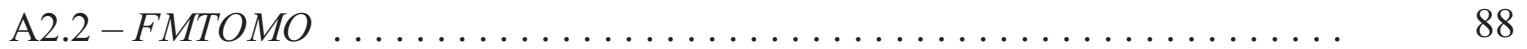

A2.2.1 - Fast Marching Method ... . . . . . . . . . . . . . . . . . 88

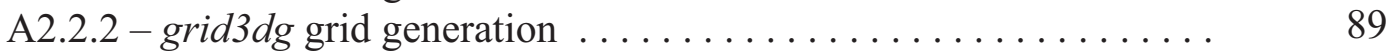

A2.2.2.1 - Interface grids $\ldots \ldots \ldots \ldots \ldots \ldots \ldots \ldots \ldots \ldots . \ldots \ldots$

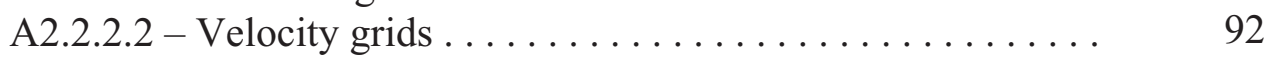

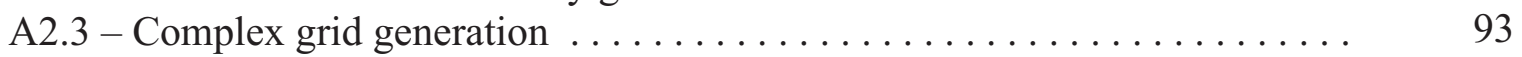

A2.3.1 - Grid Space ....................... 93

A2.3.2 - Interface Grids . . . . . . . . . . . . . . . . 94

A2.3.3 - Velocity Grids ........................ 95

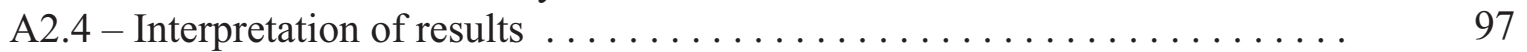

A2.4.1 - Collation of synthetic data . . . . . . . . . . . . . . . 97

A2.4.2 - Collation of observational data . . . . . . . . . . . . . . . 99

A2.4.3 - Plotting results . . . . . . . . . . . . . . . . . . . . 100

A2.4.4 - Visualising raypaths $\ldots \ldots \ldots \ldots \ldots \ldots \ldots \ldots \ldots \ldots \ldots$

A2.5 - Model resolution .................................. 104

A2.6-Results . . . . . . . . . . . . . . . . . . . . . . . . . . . . 106

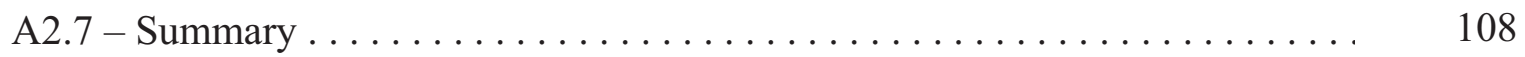

A2.8 - Scripts. . . . . . . . . . . . . . . . . . . . . . . . 109 


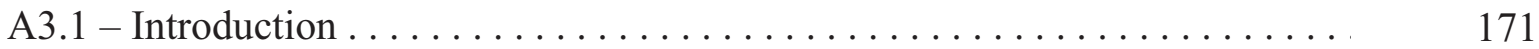

A3.2 - Unconstrained Inversion . . . . . . . . . . . . . . . . . . . 173

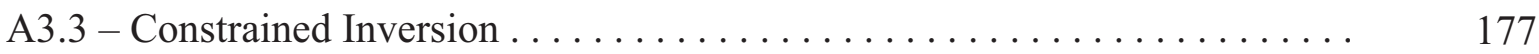

A3.4 - Inversion of final forward model . . . . . . . . . . . . . . 181

APPENDIX FOUR - SUPPLEMENTARY FIGURES

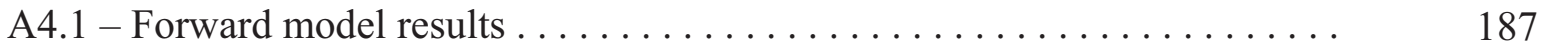

A4.2 - Model ray coverage plots

A4.2.1 - Cross-sections . . . . . . . . . . . . . . . . . . . . . . . . . . . . . . . 197

A4.2.2 - Depth-slices . . . . . . . . . . . . . . . . . . . . 199

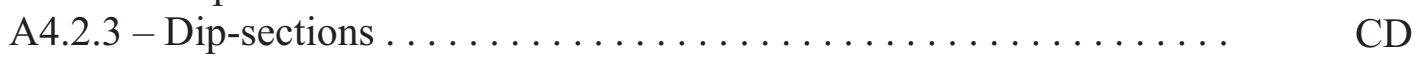

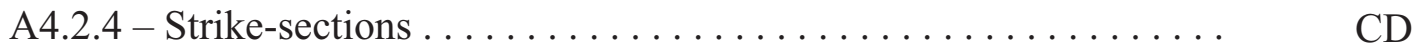




\section{LIST OF FIGURES}

\section{Volume 1}

Introduction

1.1 - Transitions in plate boundary configuration through New Zealand ...... 4

1.2 - Regional tectonic setting of the North Island of New Zealand . . . . . . . . 7

1.3 - Onshore geology of the northern Raukumara Peninsula . . . . . . . . . . 10

\section{Seismic Reflection}

2.1 - Distribution of MCS reflection data across Raukumara Basin . . . . . . . . . .

2.2 - Interpreted seismic reflection profile RAU07-09 . . . . . . . . . . .

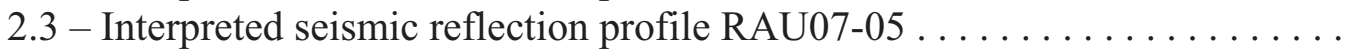

2.4 - Interpreted seismic reflection profile RAU07-03 . . . . . . . . .

2.5 - Second-order sequence isopach maps for Megasequence $Z \ldots \ldots \ldots \ldots$

2.6 - Isopach map for Megasequence Y. . . . . . . . . . . . . . . . . . . . . 29

2.7 - Second-order sequence isopach maps for Megasequence X . . . . . . . . . 31

2.8 - Migration of the Neogene Raukumara Basin depocenter . . . . . . . . . . 40

2.9 - Cartoon illustrating depocenter migration in response to forearc growth ... 41

2.10 - Emplacement directions of North Island allochthons . . . . . . . . . . . 44

\section{Seismic Refraction}

3.1 - Acquisition geometries of onshore-offshore seismic data . . . . . . . . . .

3.2 - Summary of the onshore-offshore seismic profiling technique . . . . . . . .

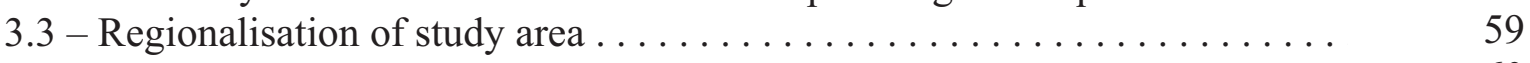

3.4 - Average velocity plots of observational data . . . . . . . . . . . 60

3.5 - Interpreted receiver gathers from the central and southern basin . . . . . . 63

3.6 - Interpreted receiver gathers from the western basin and Harve Trough . . . . 67

3.7 - Interpreted receiver gather from the central and eastern basin and . . . . . . 69 trench-slope

3.8 - Interpreted receiver gathers from RAU07-07. . . . . . . . . . . . . . 71

3.9 - Grid constructed within Seisware for the manipulation of model interfaces $\quad 74$

3.10 - Constraints incorporated into velocity forward models . . . . . . . . . . . 77

3.11 - Vp cross-sections from Reyners et al (1999) traversing the northern . . . . . 78 Raukumara Peninsula

3.12 - Vp cross-section along RAU07-05 constructed from OBH/S data . . . . . . (Scherwath et al, submitted manuscript)

3.13 - Vp depth-slices displaying the results of the 3-D forward model . . . . . . .

3.14 - Cross-sections displaying the velocity structure and ray coverage . . . . . . . through the 3-D forward model

3.15 - Residual travel times for the 3-D forward model . . . . . . . . . . . .

3.16 - Comparison between forward model results and earthquake ......... tomography (Reyners et al, 1999)

3.17 - Comparison between forward model results and OBH/S cross-section . . . (Scherwath et al, submitted manuscript) 
4.1 - Vp velocity structure along RAU07-05 from forward modelling . . . . . . .

4.2 - Structure of the subduction interface . . . . . . . . . . . . . . .

4.3 - Structure of the Moho . . . . . . . . . . . . . . . . . . .

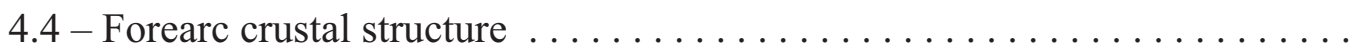

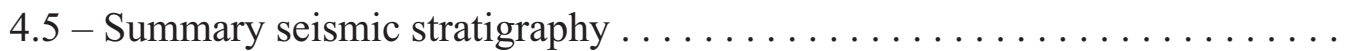

4.6 - Cartoon of cyclical crustal underplating . . . . . . . . . . . .

4.7 - Arcward migration of slab-moho intersection . . . . . . . . . . .

4.8 - Trench-slope uplift and deformation . . . . . . . . . . . . .

4.9 - Relative proportions of subduction zone inputs and outputs . . . . . . .

4.10 - Models of convergent margins . . . . . . . . . . . . . . .

4.11 - Southern region of Raukumara forearc block . . . . . . . . . . . .

\section{Volume 2}

\section{Appendix One - Refraction Processing}

A1.1 - Map displaying the geometry of onshore-offshore data . . . . . . . . .

A1.2 - Schematic cartoon illustrating GPS receiver - air gun position correction

A 1.3 - Illustration of reciprocal raypaths $\ldots \ldots \ldots \ldots \ldots \ldots \ldots \ldots \ldots$

A1.4 - Cartoon displaying a methodology of correcting the time base . . . . . . .

A1.5 - Flowchart summarizing onshore-offshore processing methodology .....

\section{Appendix Two}

A2.1 - FMTOMO grid parameterization . . . . . . . . . . . . . . .

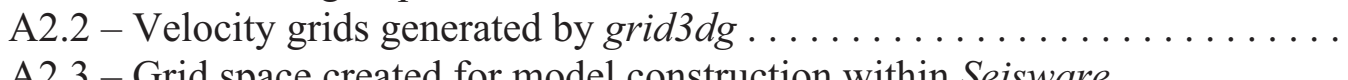

A2.3 - Grid space created for model construction within Seisware . . . . . . . . . 94

A2.4 - Plot of observed vs calculated travel times for RAUK-02 . . . . . . . . 101

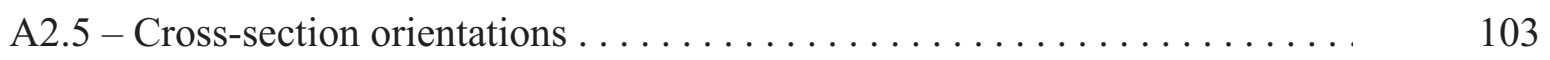

A2.6 - Cross-section p3 generated by create_X_sections . . . . . . . . . . . 104

A2.7 - Comparison between velocity grids generated grid3dg and my scripts . . . 107

A2.8 - Flow chart detailing forward modeling methodology . . . . . . . . . . 108 
A3.1 - Depth slices displaying the results of the unconstrained $\ldots \ldots \ldots \ldots$ tomographic inversion

A3.2 - Cross-section and travel time residuals for the unconstrained . . . . . . . . tomographic inversion

A3.3 - Depth slices displaying the results of the constrained tomographic . . . . . inversion

A3.4 - Cross-section and travel time residuals for the constrained . . . . . . . . tomographic inversion

A3.5 - Depth slices displaying the results of the inversion starting with the .... final forward model

A3.6 - Cross-section and travel time residuals for the inversion starting . . . . . . with the final forward model

Appendix Four - Supplementary Figures

A4.1 - Forward model results . . . . . . . . . . . . . . . . . .

A4.2 - Model ray-coverage plots

A4.2.1 - Cross-sections . . . . . . . . . . . . . . . . . . . . .

A4.2.2 - Depth-slices . . . . . . . . . . . . . . . . . . .

A4.2.3 - Dip-sections . . . . . . . . . . . . . . . . . . .

\section{LIST OF TABLES}

Volume One

3.1 - RMS residuals for forward model and final tomographic inversion . . . . . .

4.1 - Crust-mantle tradeoff for the Hikurangi Plateau . . . . . . . . . . . . .

Volume Two

A1.1 - Locations of onshore sesismometers . . . . . . . . . . . . . .

A1.2 - Sequence files associated with each RAU07 profile . . . . . . . . . . . 7

A1.3 - Sequence file extract displaying erroneous files . . . . . . . . . . . . . 8

A1.4 - Summary of travel time interpretations . . . . . . . . . . . . . . . . . . . . 19 


\section{CHAPTER 1 - INTRODUCTION}

\section{TEXT}

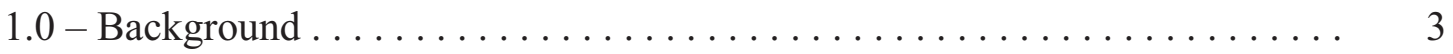

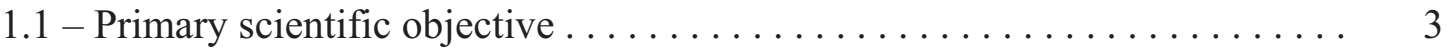

1.2 - Regional tectonic setting ........................ 6

1.2 .1 - Plate Boundary ............................... 6

1.2 .2 - Forearc crustal structure . . . . . . . . . . . . . . 8

1.2.3 - Raukumara Basin structure, onshore geology and tectonics .... 9

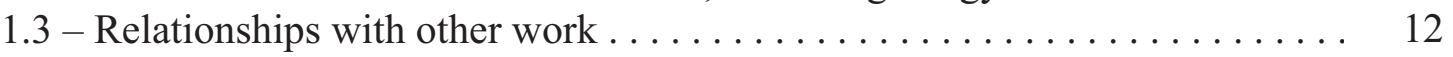

1.4 - Thesis outline ................................. 13 


\section{0 - Background}

Subduction zones are the dominant physical and chemical systems of the Earth's interior [see review paper by Stern, 2002]. The sinking of subducted lithosphere provides most of the force required to drive plate tectonics [Forsyth \& Uyedaf, 1975; Davies \& Richards, 1992] and subduction zones are the most obvious locations where continental material could be recycled back into the mantle [Clift \& Vannucchi, 2004]. In addition to destructive processes, subduction zones play a key role in the formation of continental crust through arc volcanism and the accretion of sediment from the downgoing plate. Documenting the relative fluxes of subduction zone inputs and outputs has implications for the growth and recycling of continental crust and is central to our understanding of how the Earth has chemically differentiated over long periods of geological time [Stern, 2002].

\section{1 - Primary scientific objective}

The New Zealand continent sits astride the plate boundary between the Pacific and Australian tectonic plates (Figure 1.1). The character of the plate boundary changes through New Zealand, in response to variations in the crustal structure of tectonic plates in juxtaposition. Opposing senses of subduction are observed south of Fiordland and north of Kaikoura along the Puysegur and Hikurangi subduction margins respectively. Coincident with increases in the thicknesses of the Australian (Challenger Plateau) and Pacific (Chatham Rise) plates, the plate boundary moves onshore and propagates through the South Island as the transpressive dextral Alpine Fault [Walcott, 1998; Sutherland et al., 2007].

Variations in crustal structure clearly have a profound influence on plate boundary dynamics through New Zealand and northeast along the Hikurangi margin, the anomalously high topography of the Raukumara Peninsula [Walcott, 1987] is replaced by the deep $(\sim 12 \mathrm{~km})$ Raukumara forearc basin. Crustal thicknesses determined onshore ( $35 \mathrm{~km}$, [Reyners et al., 1999]) and offshore $(<15 \mathrm{~km}$ [Sutherland et al., 2009; Scherwath et al., submitted manuscript]) require a transition in crustal structure between the Raukumara Basin and Raukumara Peninsula and implicate a transition in tectonic regime from oceanic-oceanic to oceanic-continental subduction. 
Resolving the geometry of the crustal transition between these regions through the application of onshore-offshore seismic profiling techniques and three-dimensional (3-D) forward velocity modelling is a primary objective of this thesis.

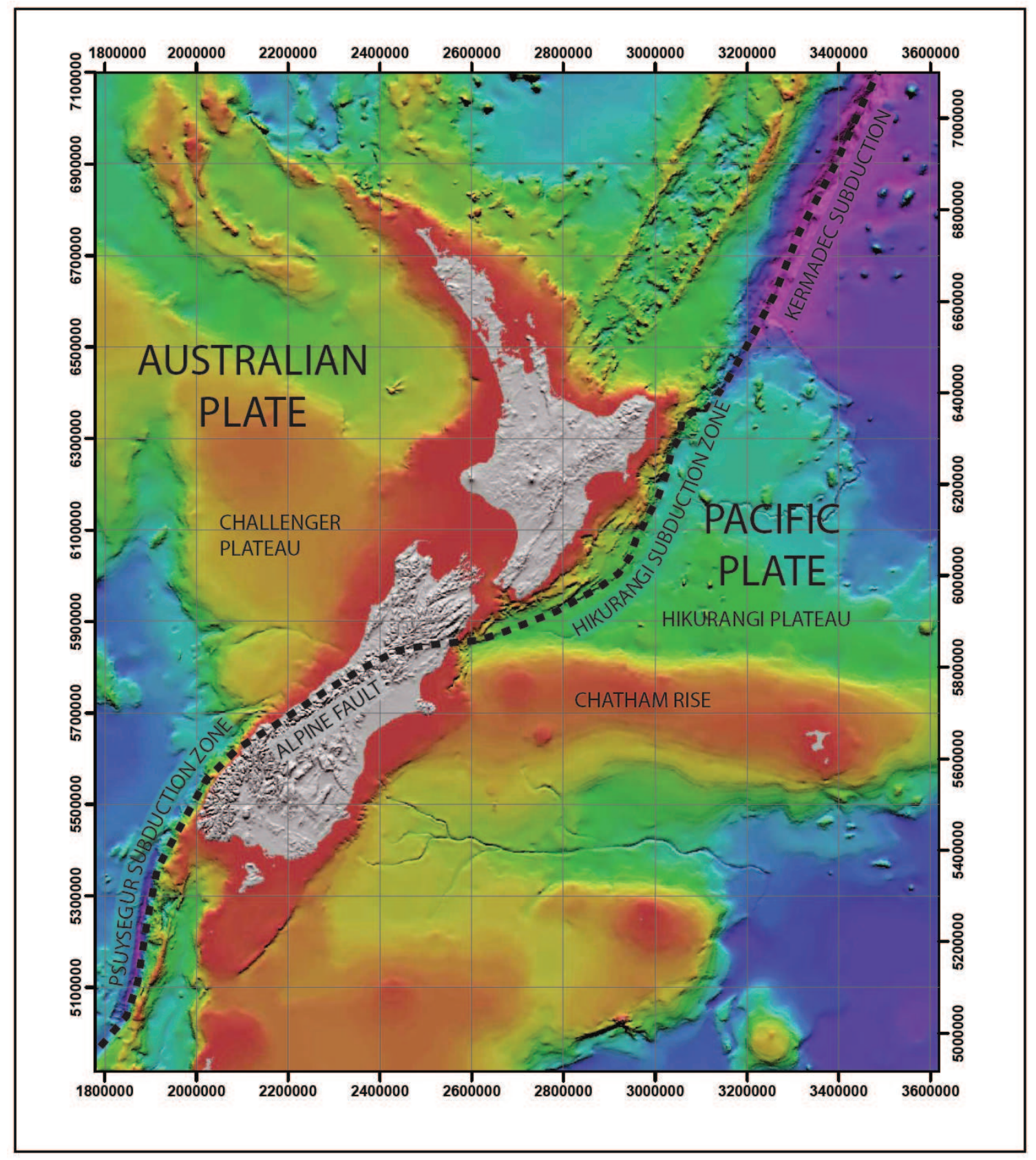

Figure 1.1 - Bathymetric map displaying margin parallel transitions in plate boundary configuration through New Zealand. Bathymetric map courtesy of NIWA

The anomalously high topography [Walcott, 1987], Vp velocity structure [Reyners et al., 1999], uplift rates [Litchfield et al., 2007], Pliocene strain estimates [Nicol et al., 2007] and deformation of Pleistocene marine terraces [Wilson et al., 2007] 
which characterise the northern Raukumara Peninsula have been interpreted as manifestations of lower crustal underplating. The recent acquisition of high-fold seismic reflection data (RAU07) from Raukumara Basin facilitates investigation into the role of crustal underplating beneath the Raukumara Plain. Despite evidence of persistent trench slope collapse and thus subduction erosion [von Huene \& Scholl, 1991; Collot \& Davy, 1998; Clift \& Vannucchi, 2004], Neogene stratal relationships suggest the Raukumara forearc is in a state of zero or positive mass-balance. Sutherland et al. [2009] develop a cyclical crustal dynamic model operating between the trench and the intersection of the subducting slab and the Moho as a mechanism of crustal underplating, which counteracts ongoing subduction erosion and thus maintains the volume of the forearc.

Through the development of a 3-D velocity forward model, this thesis places constraints on parameters (Moho depth, crustal thickness, slab geometry) considered to modulate the dynamic model of Sutherland et al. [2009]. Alongstrike variations in crustal structure provide a controlled experiment from which to study the underplating process. The second primary objective of this thesis is to investigate the influence pre-existing crustal structure exerts on the underplating process and to test the model of Sutherland et al. [2009] in 3-D. This thesis makes an additional contribution toward the underplating hypothesis in the form of seismic reflection observations which provide further evidence of Neogene forearc growth.

To address these objectives, $\sim 250,000$ onshore-offshore seismic traces occupying $\sim 32,000 \mathrm{~km}^{2}$ of the northern Hikurangi subduction margin (Figure 3.1) have been integrated with multi-channel seismic $(\mathrm{MCS})$ reflection profiles totalling $\sim 10,000$ line $\mathrm{km}$ (Figure 2.1). Refraction and wide-angle reflection data are acquired using the onshore-offshore seismic profiling technique in which airgun shots associated with the offshore acquisition of MCS reflection profiles are recorded onshore. Conventional onshore-offshore data are largely 2-D with offshore airgun shots inline with the onshore distribution of seismometers. The data acquired in this study originate from offshore reflection profiles largely perpendicular to the distribution of onshore seismometers and this thesis documents one of the first studies analysing onshore-offshore data with this unique geometry. 


\section{2 - Regional tectonic setting}

The regional focus of this thesis is the Hikurangi subduction margin and specifically encompasses the $150 \mathrm{~km}$ of strike between the northern Raukumara Peninsula and the central Raukumara Plain (Figure 1.2). The majority of newly acquired data occupy the forearc region although small proportions are located within the Harve Trough and east of the Hikurangi Trench.

\subsection{1 - Plate Boundary}

Near-orthogonal subduction of the Pacific plate beneath the Raukumara Peninsula occurs at $\sim 60 \mathrm{~mm} / \mathrm{yr}$; accommodated through a combination of oblique AustraliaPacific relative plate motion trending $50^{\circ}$ to the trend of the margin $(\sim 47 \mathrm{~mm} / \mathrm{yr}$ [DeMets et al., 1994; Beavan et al., 2002]), and backarc extension within the Taupo Volcanic Zone and Harve Trough ( 13-16 mm/yr [Wallace et al., 2004; Lamarche et al., 2006]).

The subducting Hikurangi Plateau has estimated crustal thicknesses of 10-23 km (10-15 km east of Raukumara Peninsula [Henrys et al., 2006; Scherwath et al., submitted manuscript]) and the subduction of this anomalously thick crust has been causally related to the sub-aerial exposure of the forearc along the East Coast of the North Island [Davy and Wood, 1994; Davy et al., 2008]. Higher (2-4 $\mathrm{mm} / \mathrm{yr}$ ) uplift rates of the central and northern axial ranges are attributed to crustal underplating [Walcott, 1987; Litchfield et al., 2007]. Plate convergence is principally accommodated on the subduction thrust $(>80 \%)$ with the remaining margin-normal, and the majority of margin-parallel displacement accommodated in the upper plate via a combination of reverse faulting, strike slip faulting and vertical-axis clockwise rotations [Nicol et al., 2007 and references therein]. The plate interface at $15-20 \mathrm{~km}$ depth is identified as a 1-2 km thick zone with Vp of $5.0-5.35 \mathrm{~km} / \mathrm{sec}$ and $\mathrm{Vp} / \mathrm{Vs}$ of 2 , which is interpreted as a subducting sediment channel containing fluids at near-lithostatic pressures [Reyners et al., 1999; Eberhart-Phillips \& Reyners, 1999].

A major objective of this thesis is to place the first controlled source seismic constraints on the thickness of the northern Hikurangi Plateau. Onshore-offshore 
data place further constraints on the geometry of the plate interface and wide-angle reflections may be of future use to study its physical properties through an analysis of waveforms.

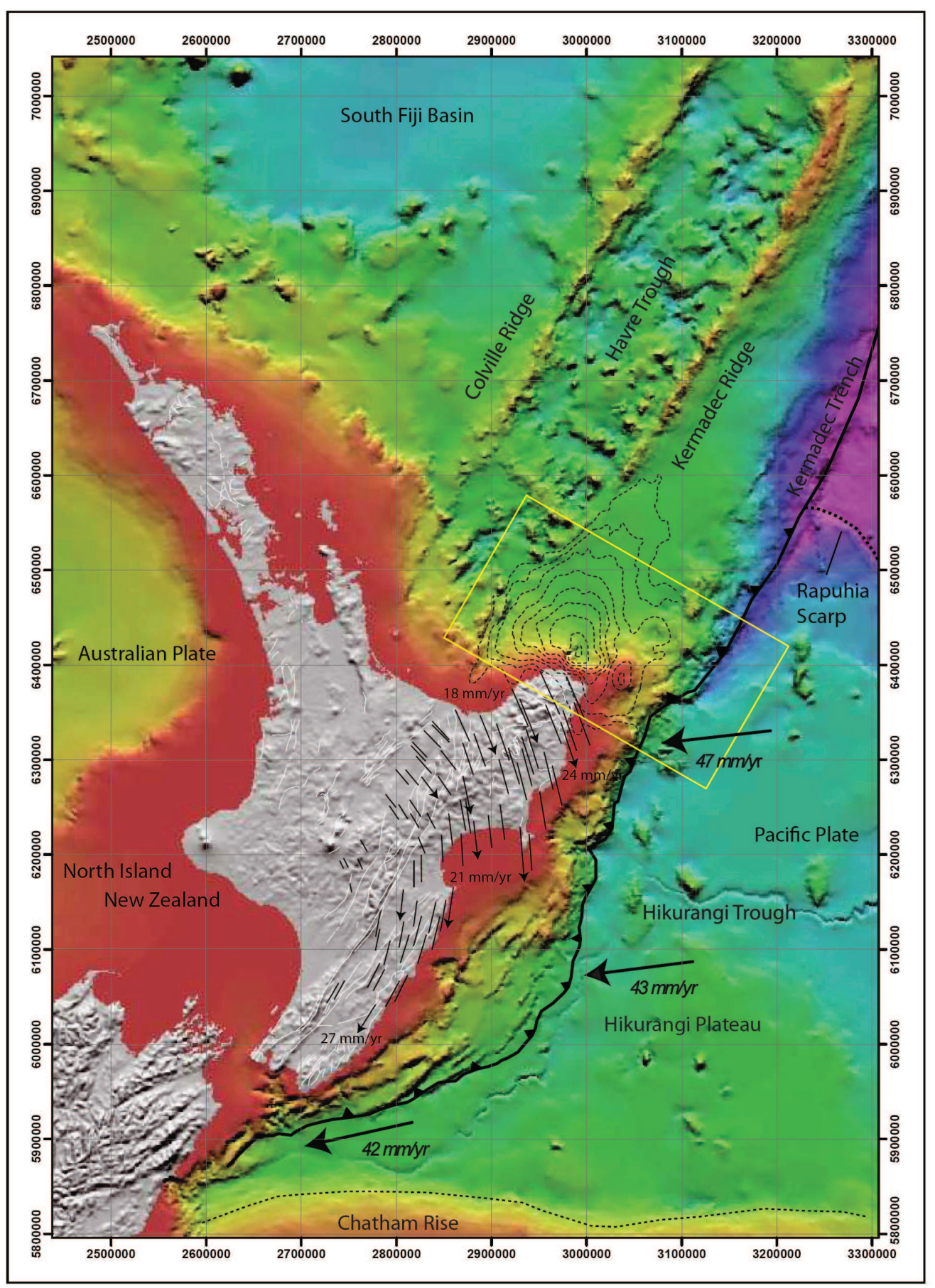

Figure 1.1 - Bathymetric map displaying the regional tectonic setting of the North Island, New Zealan [NIWA]. Subduction of the Hikurangi Plateau (onboard the Pacific plate) beneath the North Islan occurs at rates increasing northward along strike [Beavan et al., 2002]. Long term forearc rotatio relative to the Australian Plate (black vectors onshore, rates displayed) results in near orthogon: subduction beneath the East Cape [Wallace et al., 2004]. Yellow box denotes the study area of thi thesis. Dashed contour (intervals 20 mgal, innermost contour $-150 \mathrm{mgal}$ ) illustrates the geometry of th Raukumara free air gravity anomaly. The Rupuhia Scarp marks the northern boundary between th Hikurangi Plateau large igneous province [Davy \& Collot 2000] and Mesozoic oceanic crust. Onshor active faults plotted in white [GNS Science, active fault database]. 


\subsection{2 - Forearc crustal structure}

Onshore crustal structure, as constrained by tomography and receiver function analysis of naturally occurring earthquakes, suggests a crustal thickness of 30-40 $\mathrm{km}$ beneath the east coast of the North Island [Reyners et al., 1999; Bannister et al., 2004; Reyners et al., 2006; Horspool et al., 2006]. Crustal structure beneath the north-eastern Raukumara Ranges is characterised by a low-velocity (5.5-6.5 $\mathrm{km} / \mathrm{sec}$ ) region extending to $\sim 30 \mathrm{~km}$ depth. These velocities are interpreted as underplated sediment and are not observed south of Tolaga Bay suggesting a possible transition in forearc crustal thickness [Reyners et al., 1999].

Offshore, crustal structure within the Raukumara Plain is dominated by the Raukumara forearc basin [Katz, 1974; Dickinson \& Seely, 1979; Gillies, 1984; Gillies \& Davey, 1986; Davey et al., 1997; Sutherland et al., 2009; Scherwath et al., submitted manuscript]. Sediment cover of the Raukumara Plain was revealed by low fold seismic reflection and sonobuoy seismic refraction surveys conducted in the 1970's and 1980's, however, the full thickness of sedimentary fill (>10 km) was not appreciated until a high fold seismic reflection profile spanning the forearc, arc and backarc was acquired in 1990 [Davey et al., 1997]. Raukumara Basin has since been imaged in its southern region by the $\mathrm{O} 5 \mathrm{CM}$ seismic reflection survey and has been the recent focus of both a high-fold seismic reflection survey (RAU07 [Sutherland et al., 2009]) and an Ocean Bottom Seismometer/ Hydrophone $(\mathrm{OBS} / \mathrm{H})$ wide-angle seismic reflection and refraction profile [Scherwath et al., submitted manuscript]. The Moho beneath Raukumara Basin is imaged at $\sim 17 \mathrm{~km}$ depth and excluding sedimentary basin fill from calculations of basement thickness, the crustal basement beneath the Raukumara Plain is $\sim 4-7 \mathrm{~km}$ thick and thus likely of oceanic origin [Gillies, 1984; Sutherland et al., 2009; Scherwath et al., submitted manuscript].

Onshore-offshore data are well suited to studying crustal structure beneath the ocean-land boundary and I reiterate that resolving the location and geometry of the transition in crustal thickness between Raukumara Basin and the Raukumara Peninsula is a primary objective of this thesis. 


\subsection{3- Raukumara Basin structure, onshore geology and tectonics}

Strata within Raukumara Basin are subdivided into three megasequences, which can be correlated with the geology of the Raukumara Peninsula (Figure 1.3) [Sutherland et al., 2009]. These megasequences each represent a distinct phase of North Island tectonics and provide insights into the anomalous tectonic history of Raukumara Basin since the Late Cretaceous.

The deepest megasequence (X) within Raukumara Basin is correlated onshore with Late Cretaceous and Paleogene marine passive margin sediments (Tinui and Mangatu Groups) (Figure 1.3). This megasequence was deposited between 85-25 Ma, during which Raukumara Basin was clearly a significant depocenter with the thickness of acquired sediments one of the greatest known for this period in New Zealand [Sutherland et al., 2009].

Between 30-20 Ma, a change in Australia-Pacific relative plate motions [Cande \& Stock, 2004] initiated subduction beneath northern New Zealand resulting in volcanic activity in the Northland Arc from 23-16 Ma [Herzer, 1995; Hayward et al., 2001], and the obduction of the Northland [Ballance \& Spörli, 1979; Brook et al., 1988; Rait et al., 1991; Isaac, 1988; Herzer et al., 1994; Isaac, 1994; Brook et al., 1994; Rait, 2000] and East Coast allochthons [Stoneley, 1968; Moore, 1988; Rait et al., 1991; Field et al., 1997]. Megasequence Y within Raukumara Basin is imaged as a layer of chaotic and variably-dipping discontinuous reflections and Sutherland et al. [2009] suggest a correlation with the East Coast Allochthon.

Megasequence $\mathrm{Z}$ was deposited in an active subduction forearc, displays a depocenter located predominantly within the western Raukumara Basin and has onshore correlatives in Neogene forearc marine sandstones, siltstones and mudstones of the Tolaga and Mangaheia groups [Sutherland et al., 2009].

Forearc tectonics of the Raukumara Peninsula and Raukumara Basin during deposition of Megasequence $\mathrm{Z}$ are anomalous with respect to regions now south along the strike of subduction. Onshore paleomagnetic declination anomalies suggest that the Raukumara Peninsula has not undergone vertical axis rotations relative to the Australian plate since ca. 24 Ma [Nicol et al., 2007]. The 
Raukumara Peninsula is also a site of contemporary margin normal extension [Thornley, 1996] and has experienced $\sim 6 \pm 3 \mathrm{~km}$ of extension since the Pliocene [Nicol et al., 2007]. These observations contrast with large rates of vertical axis rotation $\left(3^{\circ}-5^{\circ} / \mathrm{Myr}\right)$ and bulk forearc shortening observed south of the Raukumara Peninsula [Nicol et al., 2007]. Recent tectonics are manifest through a distinct northwest tilt of Pleistocene marine terraces mapped around the northern Raukumara Peninsula [Wilson et al., 2007].

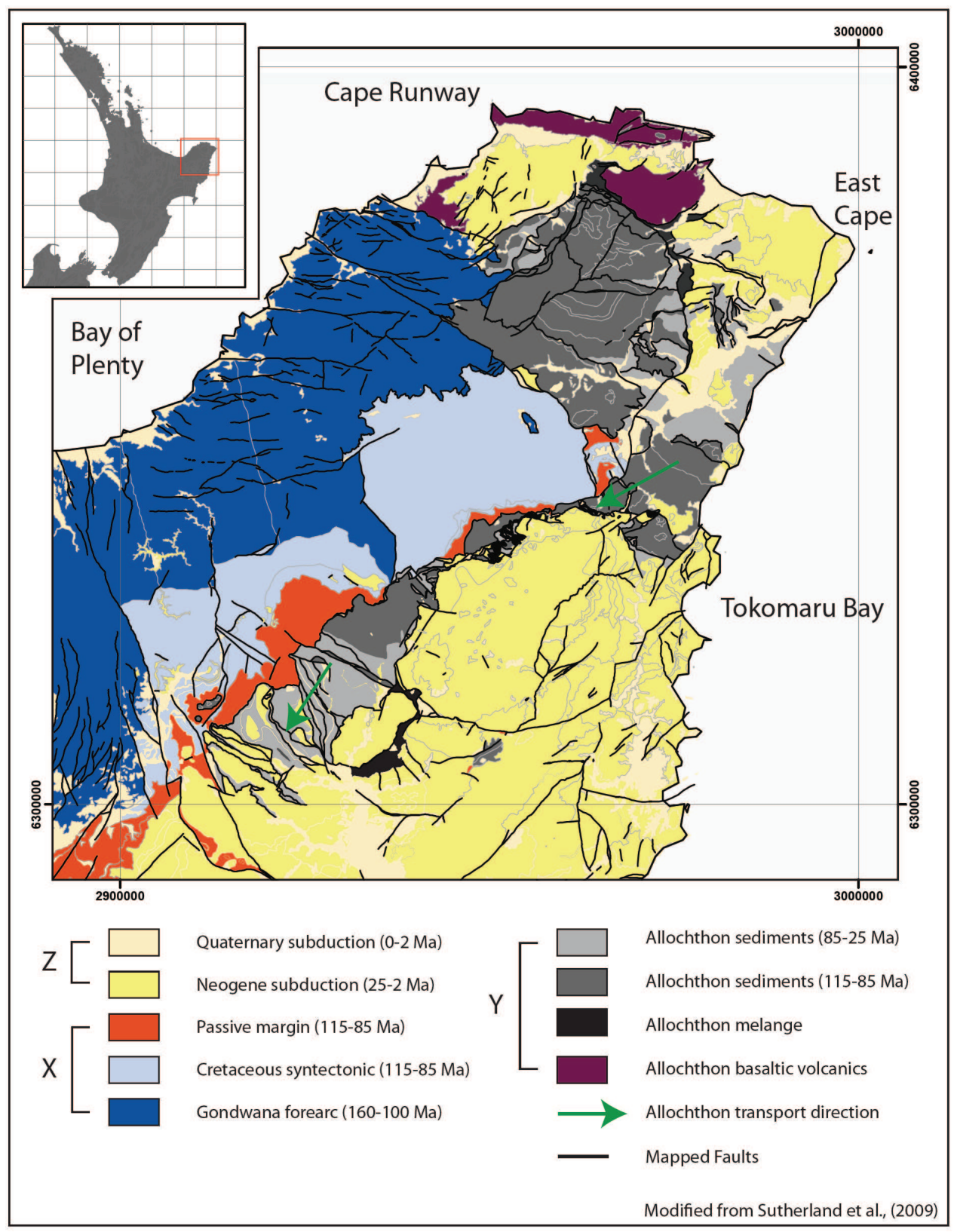

Figure 1.3 - Onshore geology of the Northern Raukumara Peninsula [modified from Sutherlan et al., 2009 using data from Mazengarb and Speeden, 2000]. Correlations between geologic: units observed onshore, and seismic reflection megasequences mapped offshore are displaye in the key. Green arrows denote allochthon emplacement directions determined from detaile structural analysis [Stonley, 1968; Rait et al., 1991] Mapped faults are displayed in blac [Mazengarb and Speeden, 2000]. 
The correlation between the East Coast and Northland Allochthons [Ballance \& Spörli, 1979; Brook et al., 1988; Isaac, 1988; Rait et al., 1991, Herzer et al. 1994; Isaac, 1994; Brook et al., 1994; Rait, 2000] forms an integral component of Miocene-present tectonic reconstructions of the northern Hikurangi forearc [Walcott, 1984; Lamb, 1988; Rait et al., 1991; King \& Thrasher, 1996; Nicol et al., 2007]

The East Coast Allochthon consists of highly deformed pre-Miocene rocks and is predominantly recognised through differences in structural style relative to underlying strata [Stoneley, 1968; Moore, 1988; Rait et al., 1991; Field et al., 1997]. Biostratigraphic ages of strata deposited pre (25-22 Ma) and post (22-16) allochthon emplacement constrain the timing of obduction to the early Miocene [Field et al., 1997; Mazengarb \& Speden, 2000]. Detailed mapping and structural interpretations suggest a direction of emplacement toward the SSW [Stoneley, 1968; Kenny, 1984; Rait et al., 1991].

Within Raukumara Basin, Megasequence $\mathrm{Y}$ is observed as a single unit of chaotic and variably-dipping discontinuous reflections and is interpreted as a single large $\left(10,000 \mathrm{~km}^{3}\right)$ submarine landslide. The thinned frontal edge of Megasequence $\mathrm{Y}$ trends northeast-southwest over a distance of 100-150 km and maintaining a correlation with the East Coast Allochthon, the tipline geometry has been interpreted as suggesting a regional emplacement direction of both the East Coast and offshore allochthons toward the west or northwest [Sutherland et al., 2009].

To studies concerning the structure of Raukumara Basin, this thesis contributes an independent interpretation of all seismic reflection data acquired over this region. An alternative geometry of the Megasequence $\mathrm{Y}$ tipline is presented, as are hypotheses concerning the origin and emplacement direction of this megasequence. Also provided is a discussion of the merits and implications of correlations between Megasequence Y and the East Coast Allochthon. 


\section{3 - Relationships with other work}

The northern Hikurangi subduction margin has been studied during the last three years by a research group from Victoria University of Wellington, GNS Science and IFM-Geomar (Germany). Two surveys were conducted during 2007. The first was seismic-reflection survey RAU07, which was designed by the NZ Ministry of Economic Development and GNS Science to delineate a putative petroleum basin north of Raukumara Peninsula. The RAU07 survey was acquired using petroleum industry specifications: an 86.51 (5280 cu in) airgun source and $7.3 \mathrm{~km}$ streamer, with $37.5 \mathrm{~m}$ shotpoint spacing and $13.3 \mathrm{~s}$ record length for all lines except RAU07-05, which had $50 \mathrm{~m}$ shotpoint spacing and 15.3 s record length. The RAU07 survey was acquired under contract by CGGVeritas and processed by Fugro Seismic Imaging. The second survey was conducted in 2007 by IFM-Geomar and GNS Science using $R V$ Sonne and was designed to acquire refraction data using an array of ocean-bottom hydrophones (OBHs) and seismographs (OBSs) along a transect (MANGO-P11) that was coincident with reflection line RAU07-05. The combined research group has produced one published manuscript [Sutherland et al, 2009 ${ }^{1}$ ] that provides an overview of the seismic stratigraphy and tectonic history of Raukumara Basin. A second manuscript [Scherwath et al, submitted manuscript ${ }^{1}$ ] details results of the MANGO-P11 profile and has been submitted for publication in the Journal of Geophysical Research. The work presented in this thesis has contributed to both manuscripts and will be the focus of two further publications currently in review.

Seismographs were deployed onshore by Victoria University and GNS Science during 2007 to record the shots of survey RAU07. The primary contribution presented in this thesis relates to the organisation, interpretation, and analysis of this dataset. During the course of this thesis, 81 onshore-offshore receiver gathers were collated and processed, from which $\sim 275,000$ travel time interpretations were made (Appendix One). 3-D velocity forward models were developed (Appendix Two) and travel time interpretations constrain a 3-D velocity model spanning $\mathrm{a} \sim 32,000 \mathrm{~km}^{2}$ region of the northern Hikurangi subduction margin (Chapter 3). The 3-D velocity model is constrained by $\sim 10,000$ line $\mathrm{km}$ of multichannel seismic-reflection (MCS) data (Chapter 2), which provide control on the shallow $(<10 \mathrm{~km})$ velocity structure of Raukumara Basin. All reflection data were inspected and reinterpreted during work on this thesis. 


\section{4 - Thesis Outline}

This thesis integrates analysis of newly acquired onshore-offshore wide-angle seismic reflection and refraction data, with an interpretation of marine multichannel seismic reflection profiles. Volume One presents the observations and conclusions deduced from each dataset and is organised as four chapters: (1) Introduction, (2) Seismic Reflection, (3) Seismic Refraction, (4) Synthesis.

Volume Two is supplementary to Chapter Three and documents the acquisition, processing, interpretation and modelling methodology developed to analyse onshore-offshore seismic wide-angle reflection and refraction data. This volume is organised as two primary appendices: Acquisition, processing and interpretation of onshore-offshore seismic data (Appendix 1); and 3-D forward modelling (Appendix 2). Also presented within Volume Two are the results of several experiments involving tomographic inversion (Appendix Three) and a catalogue of supplementary figures not included within the main text (Appendix Four $+\mathrm{CD})$.

\section{Chapter Two - Seismic Reflection}

Chapter Two analyses the structure of Raukumara Basin through an interpretation of $\sim 10,000$ line $\mathrm{km}$ of multi-channel seismic reflection data. Seismic-reflection Megasequences X, Y and Z are defined within Sutherland et al. [2009]. In this thesis, Megasequences $Z$ and $X$ are subdivided into six and four second-order sequences, respectively. The distribution of secondorder sequences is used to analyse temporal changes in depocenter shape and are interpreted with a view toward forearc tectonics and mass-balance since the inception of modern subduction $(\sim 22 \mathrm{Ma})$.

\section{Chapter Three - Seismic Refraction}

Chapter Three focuses on the velocity structure of the northern forearc of the Hikurangi subduction margin and documents the complete analysis of newly acquired onshore-offshore wide-angle seismic reflection and refraction data. Travel-time observations from 81 receiver gathers are presented in conjunction with the results obtained via construction of a 3-D velocity forward model. Velocity models presented span an area of $\sim 32,000 \mathrm{~km}^{2}$ and a depth range of 0-40 km. 


\section{Chapter Four - Synthesis}

Chapter Four synthesises the primary observations from preceding chapters and discusses the regional and global implications of the present thesis. Regional implications pertain to the geometry of the subduction interface, crustal growth processes and this thesis places the first controlled-source seismic constraints on the thickness of the Hikurangi Plateau. Local observations concerning crustal underplating and crustal growth processes are of global implication and are discussed further with regard to the growth and formation of continental crust and the global fluxes of inputs and outputs at subduction margins. Several recommendations of future research conclude this chapter.

Appendix One - Acquisition, processing and interpretation of onshore-offshore seismic data

Appendix One details the sequential steps by which raw onshore-offshore wide-angle seismic reflection and refraction data are acquired, cut into common receiver-gathers, processed and interpreted to create a travel time dataset.

Appendix Two - 3-D Forward modelling

Appendix Two is focused on forward modelling and presents the methodology developed to interactively create and modify 3-D velocity forward models. Also detailed are techniques of analysing model results against observational data and assessing the spatial resolution of models through an analysis of raypath density.

Scripts developed throughout the processing and modelling of onshoreoffshore data are presented at the back of each appendix and also provided on the attached CD.

\section{Appendix Three - Tomographic Inversion}

Appendix Three presents the details and results of three tomographic inversion experiments conducted throughout the analyses of onshore-offshore seismic data. 


\section{CHAPTER 2 - SEISMIC REFLECTION}

\section{TEXT}

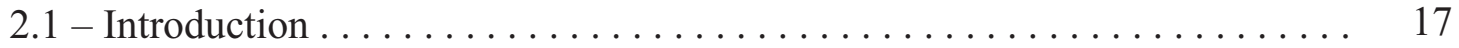

2.2 - Seismic Reflection

2.2 .1 - Data . . . . . . . . . . . . . . . . . . . . . . . . . . . . . 18

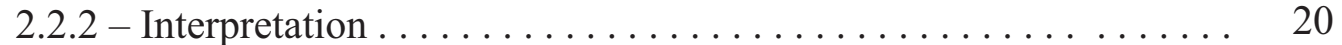

2.3 - Seismic Reflection Stratigraphy

2.3 .1 - Sequences within Megasequence $Z \ldots \ldots \ldots \ldots . \ldots 25$

2.3.2 - Sequences within Megasequence Y . . . . . . . . . . . . . . 29

2.3.3 - Sequences within Megasequence X . . . . . . . . . . . 30

2.3 .4 - Acoustic Basement . . . . . . . . . . . . . . . . . . . . 33

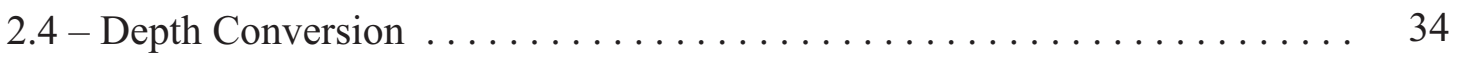

2.5 - Results

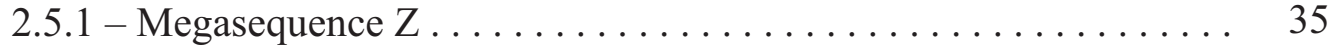

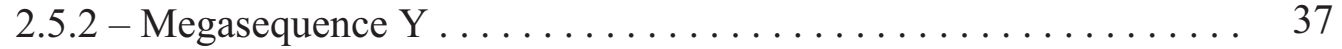

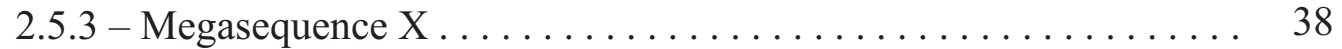

2.5.4 - Acoustic Basement . . . . . . . . . . . . . . . . . . . . . . . . . 39

2.6 - Discussion

2.6.1 - Mass-balance of Forearc . . . . . . . . . . . . . . . . . . . . . . 40

2.6.2 - Allochthon Emplacement . . . . . . . . . . . . . . . 42

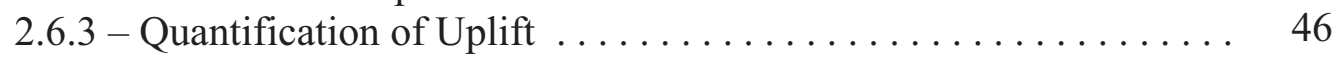

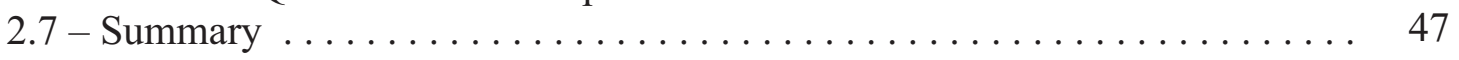




\section{1 - Introduction}

Raukumara Basin is one of the most prospective frontier basins of New Zealand. The Raukumara Peninsula has been the site of numerous oil and gas seeps (three commercial) and the observation of oil slicks from satellite synthetic aperture radar (SAR) images testify to the presence of an active petroleum system [Field et al., 1997; Field et al., 2004; Stagpoole et al., 2008]. The identification of offshore sedimentary fill exceeding $10 \mathrm{~km}$ in thickness beneath the Raukumara Plain [Davey et al., 1997] has driven a decade of speculation regarding the hydrocarbon prospectivity of Raukumara Basin and most recently lead to the acquisition of two industry standard seismic reflection datasets in 2005 (05CM) and 2007 (RAU07) respectively.

In total, Raukumara Basin has been the subject of seven marine seismic reflection surveys and these data are compiled and interpreted in this study. Structural observations made from this analysis are used to constrain a 3-D Pwave velocity forward model constructed from onshore-offshore wide-angle seismic data (Chapter Three). Twelve second-order sequences are mapped through a seismic-stratigraphic subdivision of previously defined megasequences. The spatial distribution and stratal relationships between these sequences place constraints on forearc mass-balance and the tectonic genesis of Raukumara Basin. 


\section{2 - Seismic Reflection}

\subsection{1 - Data}

Seismic reflection data from seven geophysical surveys (Figure 2.1) conducted between 1972 and 2007 have been assembled and interpreted. The most recent dataset, RAU07, was acquired in 2007 using an 86.5 litre (5280 cu in) airgun source and $7.3 \mathrm{~km}$ streamer. Shot point spacing was $37.5 \mathrm{~m}$ for all lines other than RAU07-05 $(50 \mathrm{~m})$ generating record lengths of $13.3 \mathrm{~s}$ and $15.3 \mathrm{~s}$ respectively [Fugro Seismic Imaging, 2008]. The 05CM dataset was acquired in 2005 using a 67.8 litre (4140 cu in) source and a streamer which varied in length between $12 \mathrm{~km}$ and $4 \mathrm{~km}$ (due to shark attacks). Shotpoint spacing was $37.5 \mathrm{~m}$ generating a record length of 8-12 seconds [Maslen, 2005; Multiwave, 2005]. The OGS90 line was acquired in 1990 using a 45.2 litre (2756 cu in) source and a $3 \mathrm{~km}$ streamer. Shotpoint spacing was $50 \mathrm{~m}$, generating a record length of 16 seconds [Davey et al., 1997]. OGS90 was reprocessed with the RAU07 dataset [Fugro Seismic Imaging, 2008]. Data from cruises TAN0113 and TAN0314 were supplied courtesy of NIWA. These data were acquired in 2001 and 2003 respectively using a single GI airgun (45/105 cu in), $25 \mathrm{~m}$ shot spacing and a $587.5 \mathrm{~m}$ streamer resulting in a 7 second record length. The Mobil72 and Gulf72 datasets were also incorporated and in the absence of GPS positioning, these surveys were shot on time (rather than offset) with variable shot spacing. 


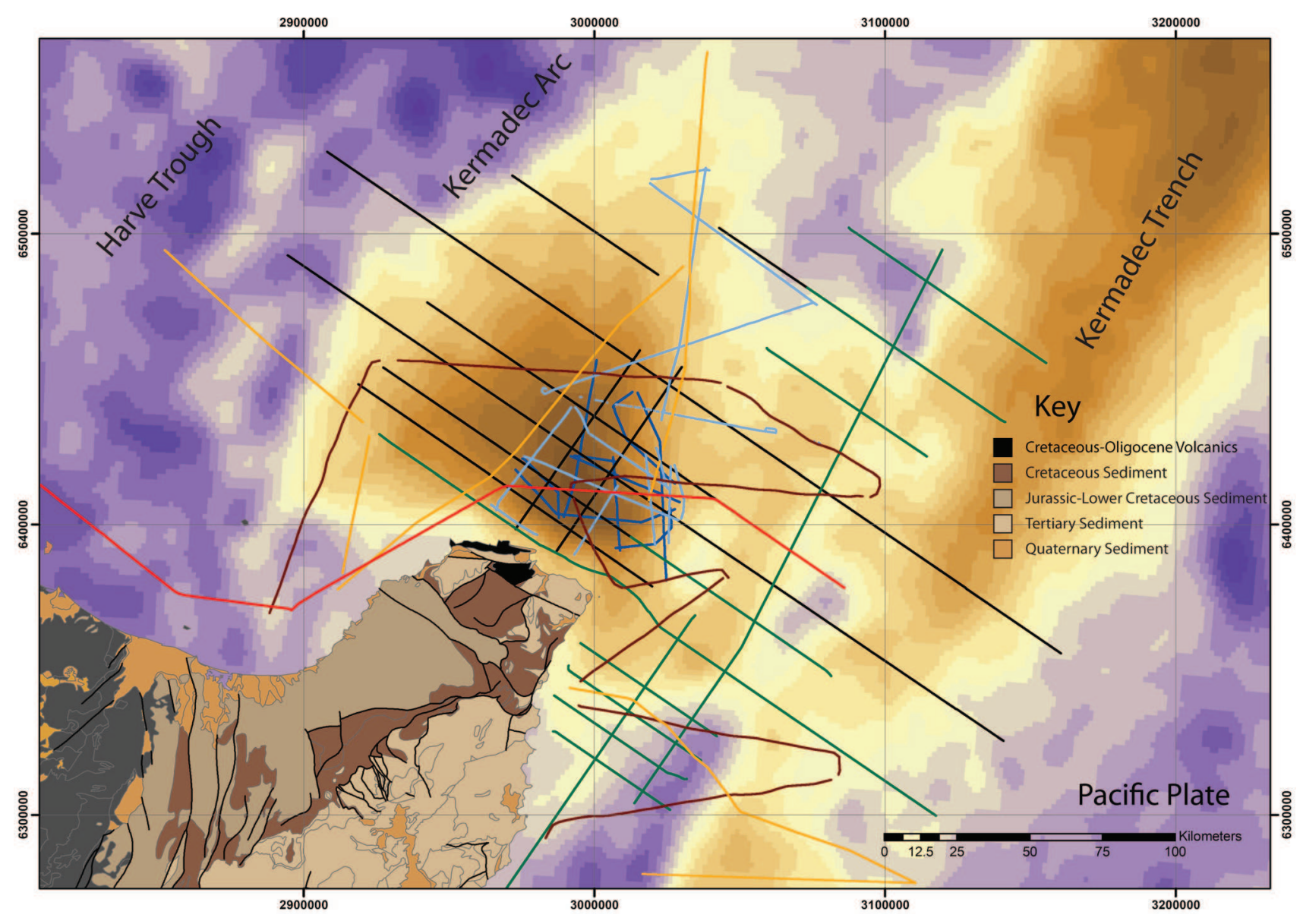

Figure 2.1 - Map displaying the distribution of multi-channel seismic reflection data across the forearc and backarc of the northern Hikurangi subduction margin. Seismic reflection surveys are coloured as follows: Black - RAU07, Green - 05CM, Red - OGS90, Yellow - Mobil72, Dark Red - Gulf72, Light Blue - TAN0113 and Dark Blue - TAN314. Free-air gravity anomaly offshore illustrates the position of Raukumara Basin. Brown shades represent negative gravity anomalies with the darkest brown denoting a -150 mgal anomaly. Onshore, simplified geology and mapped active faults (black) are displayed [Mazengarb and Speeden, 2000; GNS Science Active Fault Database]. TAN data supplied courtesy of NIWA. 


\subsection{2 - Interpretation}

Preliminary interpretations of major seismic-stratigraphic boundaries were made on the RAU07 dataset through the identification of megasequence boundaries defined by Sutherland et al. [2009]. These horizons were extrapolated throughout the wider seismic grid with local and regional loop ties implemented to ensure consistency between datasets. Interpretation of second-order sequences was initially undertaken on the RAU07 dataset and reflection profiles of comparable quality before attempting to extend these interpretations across the additional profiles in this dataset. Reflection data acquired with a comparatively small source and short shot spacing (TAN0113, TAN314, Mobil72, Gulf72) were of a quality and record length only conducive to the interpretation of shallow horizons. Further processing of these data to remove the effects of multiples and increase the quantity of interpretable data was beyond the scope of this study.

The stratigraphic nomenclature adopted consists of three megasequences termed $\mathrm{X}, \mathrm{Y}$ and $\mathrm{Z}$ in order of decreasing stratigraphic age. In this thesis, Megasequences $\mathrm{Z}$ and $\mathrm{X}$ are subdivided further into six and four second-order sequences respectively, which are labelled by attaching a numeral to the megasequence name, also in order of decreasing age (e.g. Z1 is older than Z2).

Figure 2.2 (overleaf) - Interpreted seismic profile RAU07-09 illustrating the along strike structure of Raukumara Basin. Profile location is given in the insert. Note the rough seafloor topography and steep dip of horizons at the southern end of the profile. Dashed Red line displays the interpreted position of the Moho. In key, black x denotes interpreted sequences which are not visible on this profile. 


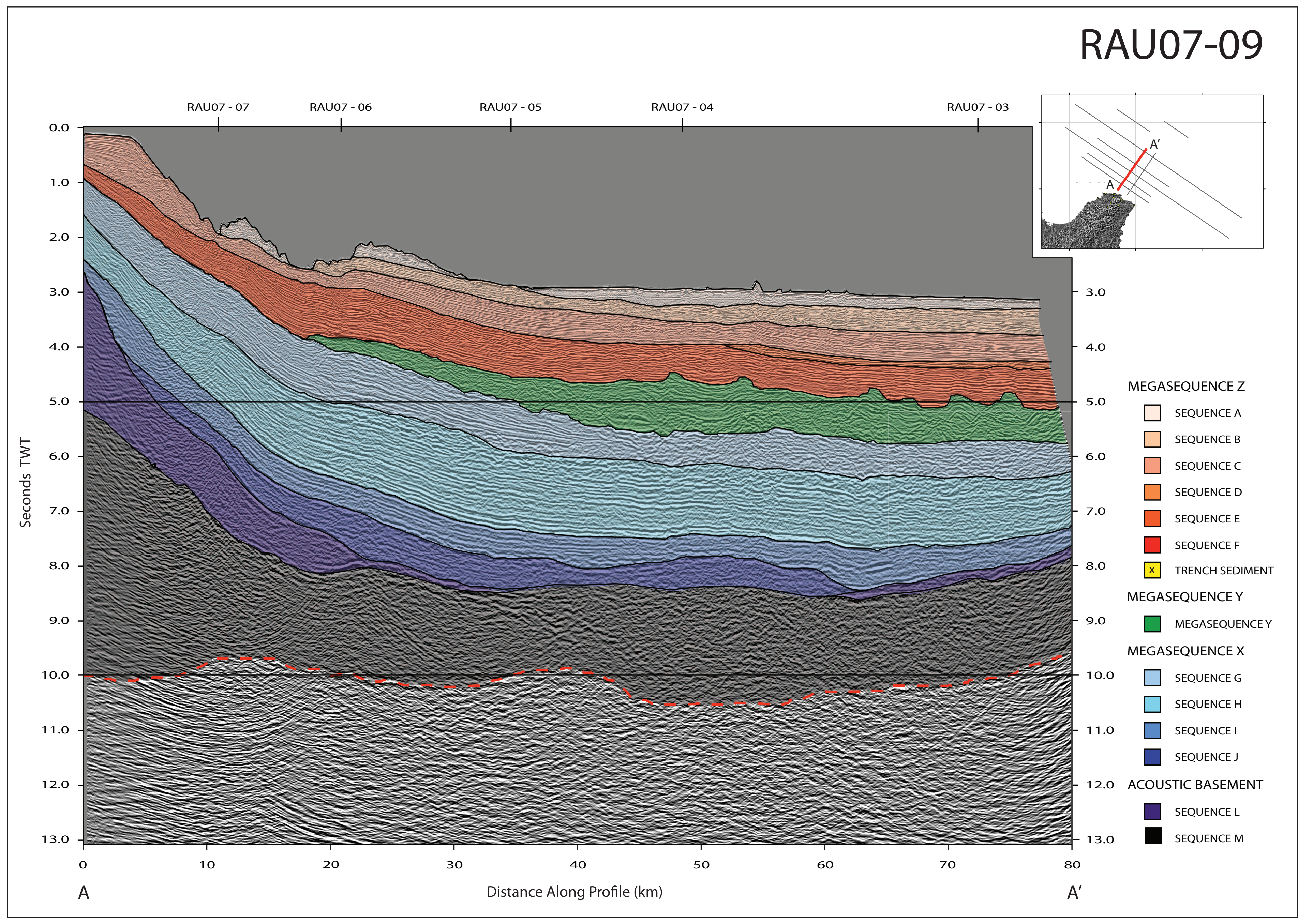




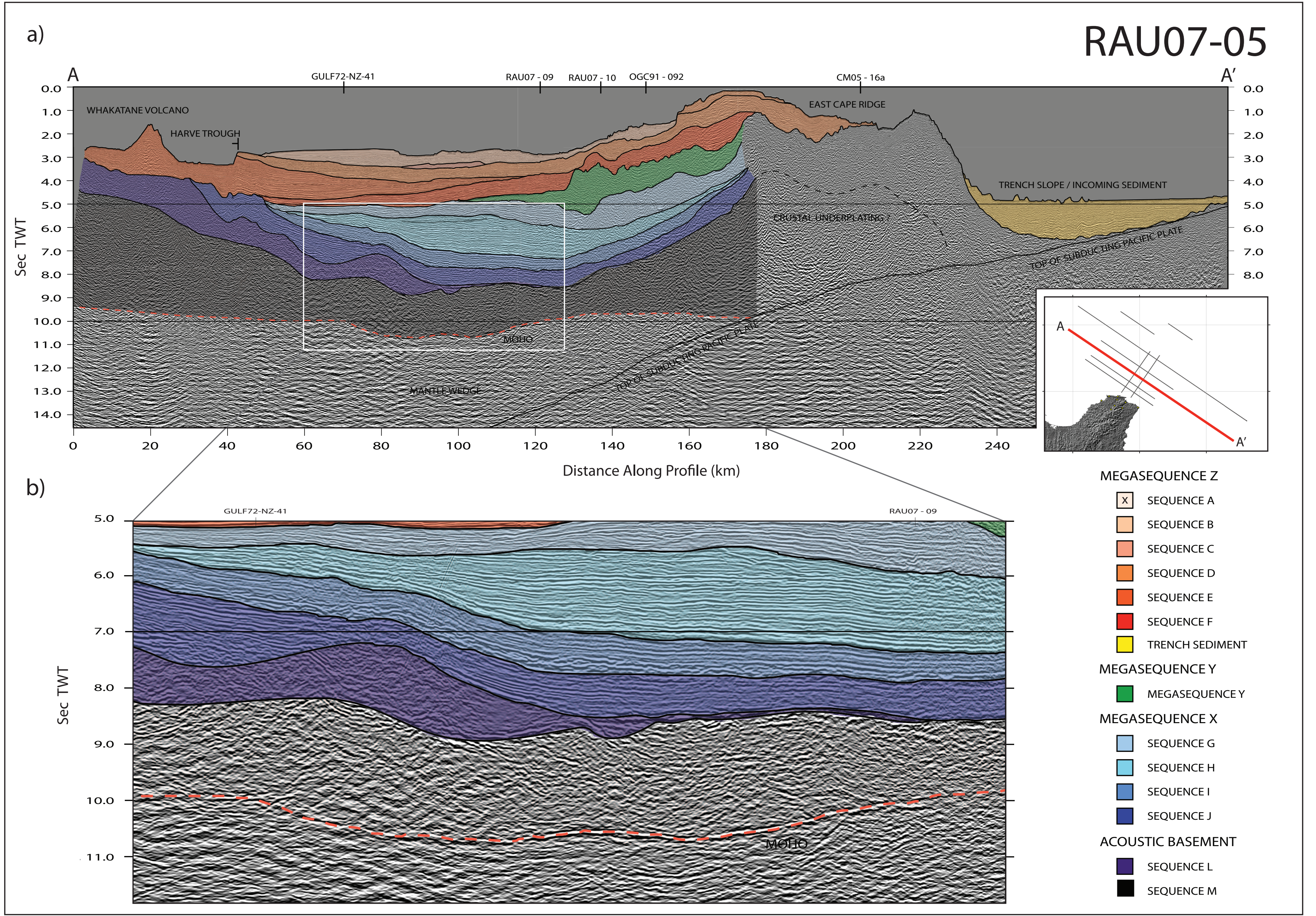




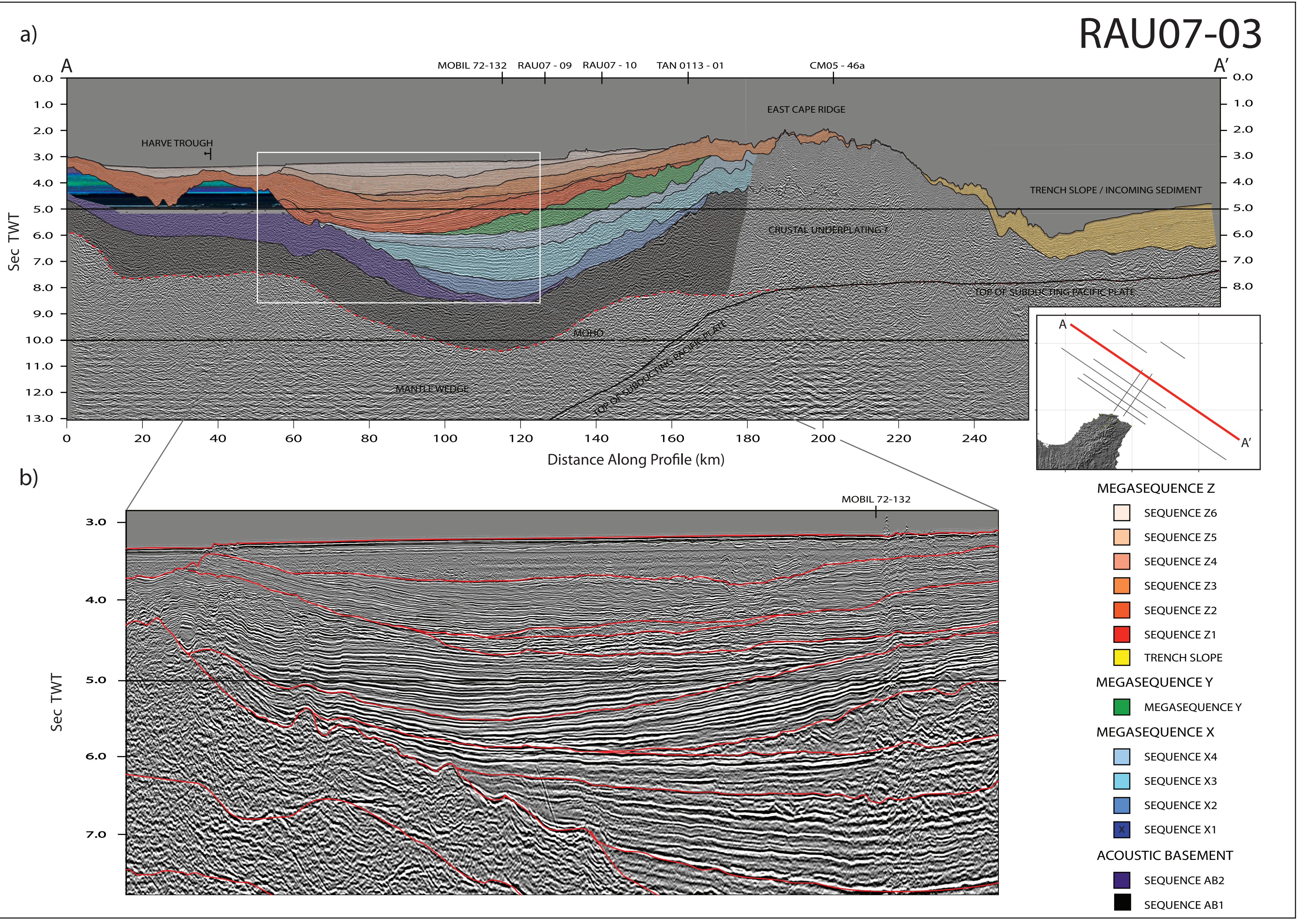




\section{3 - Seismic Reflection Stratigraphy}

As outlined in Chapter One, the compilation and interpretation of seismic reflection data across Raukumara Basin was undertaken to fulfil two primary objectives. The first was to map the broad distribution of major stratigraphic facies and resolve the seismic architecture of Raukumara Basin. These interpretations provide initial structural constraints which are incorporated into the development of a 3-D velocity forward model (Chapter Three).

The interpretation of second-order seismic-stratigraphic sequences and analysis of the stratal relationships between these sequences was carried out to fulfil the second objective of this interpretation. Undertaken between and within stratigraphic megasequences, the results of this analysis provide insights into the genesis and evolution of Raukumara Basin and the tectonic processes which have shaped this region. These observations also place constraints on mass-balance at the forearc since the inception of subduction $(\sim 22 \mathrm{Ma})$. A detailed discussion of previously defined megasequences, age interpretations and lithostratigraphic correlations with onshore geology are given by Sutherland et al. [2009].

\subsection{1 - Sequences within Megasequence $Z$}

Six second-order sequences are interpreted within Megasequence Z. 


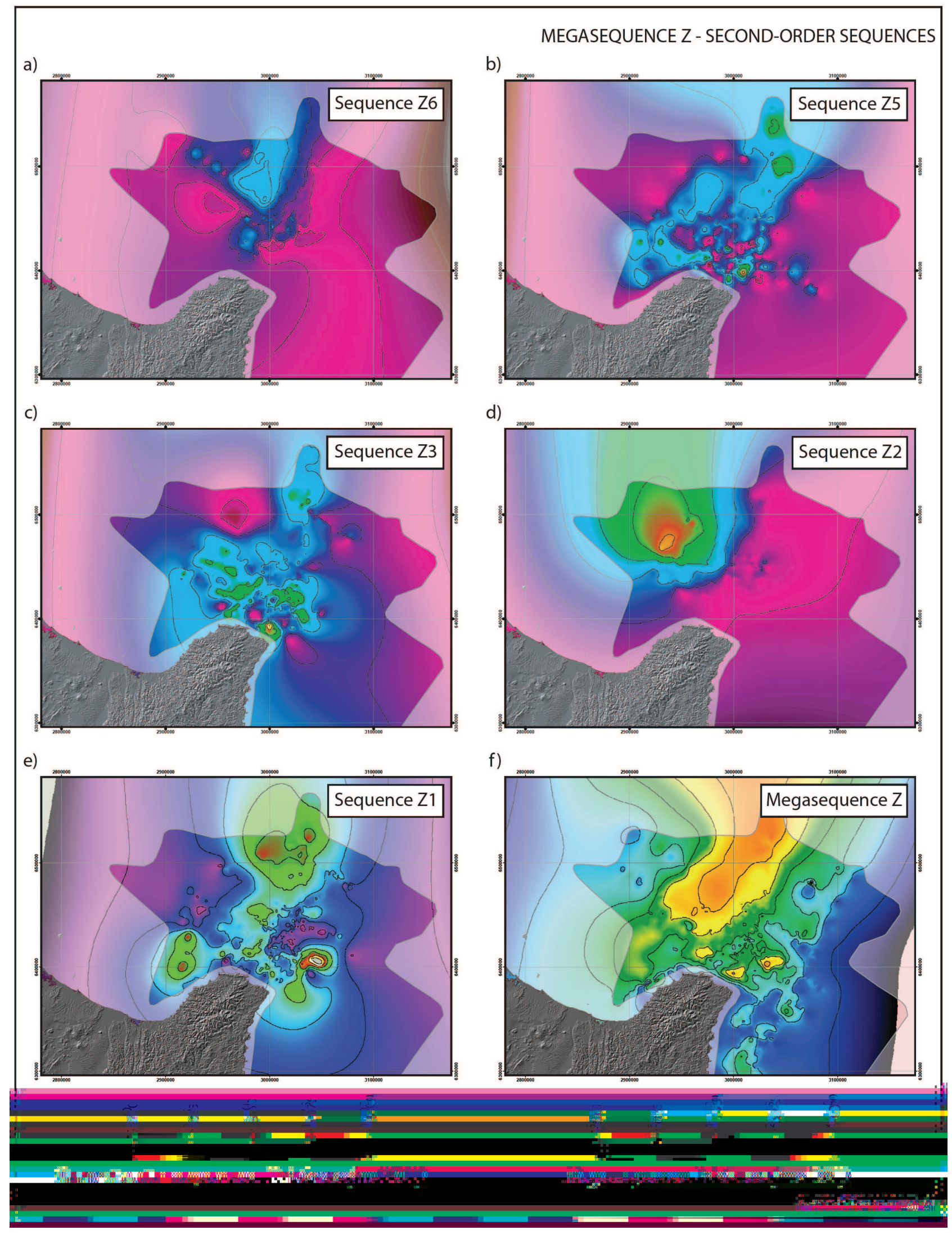

Figure 2.5a-e - Sediment isopach maps (as labelled) illustrating the thickness distribution (in two-way time) of second-order sequences interpreted within Megasequence Z. Contour interval in plots a-e is $250 \mathrm{~ms}$. f) As above but for the full thickness of Megasequence Z. Note the change in scale for plot $\mathrm{f}$, contour interval is $500 \mathrm{~ms}$. Faded area denotes regions unconstrained by MCS seismic reflection data. 
The deposition of all second-order sequences within Megasequence $\mathrm{Z}$ appears modulated by seafloor topography and a strong correlation is generally observed between the geometry of basal sequence boundaries and the topography of the East Cape Ridge and continental slope/shelf.

The shallowest second-order sequence in Raukumara Basin (Z6) is characterised by a largely transparent acoustic structure within which several coherent blocks of high amplitude, variably dipping reflectors are observed (Figures 2.2-2.4b). Sequence Z6 onlaps the western flank of East Cape and has been deposited almost exclusively in deep water $(>2000 \mathrm{~m}$ ) within the northern and western regions of Raukumara Basin (Figures 2.2, 2.4 and 2.5a). This sequence has been correlated with the Matakaoa Submarine Instability Complex (MSIC, 600-40 ka, [Lamarche et al., 2008]) and a rough and scoured reflector observed towards the top of this sequence separating gently dipping, weakly deformed and continuous reflectors from variably dipping and transparent material is interpreted as the upper surface of this mass failure (Figure 2.4b).

Sequence Z5 displays a higher amplitude acoustic structure than the overlying sequence and while still relatively chaotic, several large blocks of coherent reflectors are observed in the northern and western regions of Raukumara Basin (Figures $2.4 \mathrm{~b}$ and 2.5b). This sequence displays an approximately uniform thickness (0.4-0.6 sec two way time, [twt]) throughout the distal regions of Raukumara Basin, with a reduced and variable thickness observed in the central basin (Figure 2.5b). The central basin is characterised by rough seafloor topography and the general absence of Sequence Z6. A spatial correlation exists between the MSIC and the near shore region of reduced and variable thickness and it is possible that this sequence has been scoured and eroded during the evolution of this mass failure.

Sequence Z3 is imaged as a high amplitude, high frequency packet of sediments bounded by angular unconformities (Figures 2.2, 2.3 and 2.4a). Reflectors are predominantly parallel to the basal unconformity and this sequence is interpreted up the western flank of East Cape Ridge, occupying an area largely southwest of shallower second-order sequences. The basal unconformity of sequence Z3 displays a particularly strong correlation with seafloor topography and along 
RAU07-05 this sequence appears bounded to the west by the Harve Trough (Figure 2.3a).

Within the north-western Raukumara Basin and within the Harve Trough, Sequence Z3 is underlain by (Sequence Z2) a wedge of thick, strong and continuous reflectors (Figures 2.3a, 2.4a-b and 2.5d). These reflectors are generally parallel to the basal sequence boundary in the central and western basin and are observed onlapping to the east, against both the basal unconformity and internal reflectors (Figure 2.4a-b). In the western Raukumara Plain and within the Harve Trough, Sequence Z2 becomes imbricately faulted by extensional faults presumably associated with backarc rifting (Figure 2.4b). Thicknesses exceeding $\sim 1.2 \mathrm{sec}$ twt are observed between Whakatane Volcano and Clark Volcano and thicknesses $>0.8 \mathrm{sec}$ twt are implied within the north-western Raukumara Basin although this region is poorly constrained (Figures 2.1 and 2.5d). The origin of strata within Sequence Z2 is unknown, however, isopach maps and the mantling of the basal unconformity by reflectors may be interpreted as suggesting a volcaniclastic origin (Figure 2.5d).

The position of Raukumara Basin within an active subduction forearc makes it likely that volcaniclastic sediment would be widely deposited throughout Megasequence Z. Sequence Z2 is capped by an erosional unconformity which progressively truncates west-dipping reflectors until the sequence pinches out in the central basin. Shallow second-order (Z6-Z4) sequences within Megasequence $\mathrm{Z}$ display erosional and/or depositional characteristics consistent with submarine landslides. The erosion and reworking of strata associated with these debris flows may play a key role modulating where Sequence Z2, as well as all other sequences throughout Raukumara Basin, are preserved. The region where Sequence $\mathrm{Z} 2$ is observed with maximum thickness $(\sim 1.2 \mathrm{sec}$ twt $)$ is a considerable distance $(\sim 70 \mathrm{~km})$ from both the continental shelf and East Cape Ridge which are hypothesised to be the primary source regions of (gravitational) submarine failure.

Sequence Z1 is localised in the central and eastern regions of Raukumara Basin. Internal reflections which are thick, high amplitude and continuous in the central basin become increasingly fragmented toward the East Cape Ridge (Figure 2.3a). 


\subsection{2 - Sequences within Megasequence $Y$}

Megasequence $\mathrm{Y}$ displays an acoustic structure which is chaotic and characterised by discontinuous reflections of variable dip and amplitude (Figures 2.2, 2.3a, 2.4a-b). The complicated internal structure prevented any finer scale sequences from being resolved.

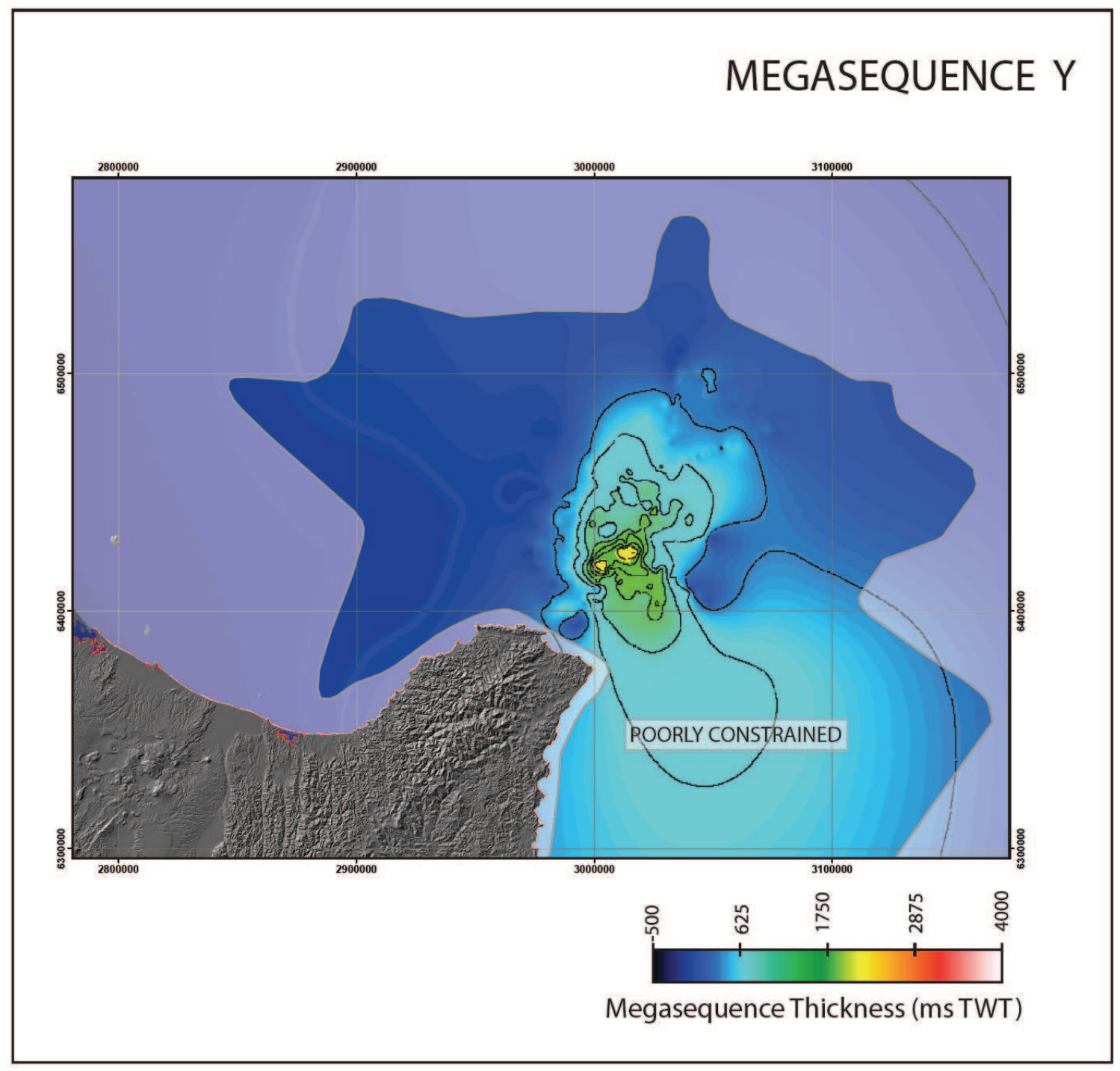

Figure 2.6 - Sediment isopach map illustrating the thickness distribution (in two way time) of Megasequence Y. Note the geometry of the outermost contour - referred to as the tipline. The geometry of this contour may provide information regarding emplacement direction and source region of this megasequence. Contour interval is $250 \mathrm{~ms}$. Faded area denotes regions unconstrained by MCS seismic reflection data. 
Down dip, Megasequence $\mathrm{Y}$ is only observed between the East Cape Ridge, where it displays an average thickness of $\sim 0.9 \mathrm{~s}$ twt and the centre of the Raukumara Plain where it pinches out beneath Megasequence Z (Figure 2.6). The upper and lower contacts are rough and along RAU07-03 (Figure 2.4a) a correlation is observed between topographical highs and depressions on both surfaces (Figure 2.4a). This may suggest deposition as a moving body and coupled with the internal acoustic structure, Megasequence $\mathrm{Y}$ is interpreted as a single large $\left(\sim 10,000 \mathrm{~km}^{3}\right)$ submarine slope failure (Figure 2.6).

Megasequence $\mathrm{Y}$ downlaps to the west and onlaps to the south against a well defined basal unconformity which caps Megasequence X (Figures 2.2 and 2.3a). This unconformity can be reliably traced across Raukumara Basin and is an important chronostratigraphic marker. The contrasting styles of sedimentation above and below this horizon are compelling and this observation forms a key component of hypotheses concerning the evolution of Raukumara Basin (Section 2.6).

The megasequence isopach map displays a maximum thickness $(\sim 1.6 \mathrm{~s}$ twt $)$ immediately west of East Cape Ridge with thinning observed in all directions, most dramatically to the west and south (Figure 2.6). Given the evidence in support of deposition as a single submarine slope failure, the distribution of Megasequence $\mathrm{Y}$ and specifically the geometry of the thinned frontal edge may constrain emplacement direction and possible source regions (Section 2.5.2).

\subsection{3 - Sequences within Megasequence X}

Megasequence $\mathrm{X}$ is defined as all strata positioned between Megasequence $\mathrm{Y}$ (or the equivalent stratigraphic level at which Megasequence Y was emplaced) and the deepest packet of continuous reflectors [Sutherland et al., 2009]. Four second-order sequences are interpreted within Megasequence $\mathrm{X}$ on the basis of reflection amplitude and onlap relationships. The base of Megasequence $\mathrm{X}$ is interpreted as the basin bounding unconformity which separates Raukumara Basin fill from Mesozoic basement (Figures 2.2a, 2.3a and 2.4a-b). 


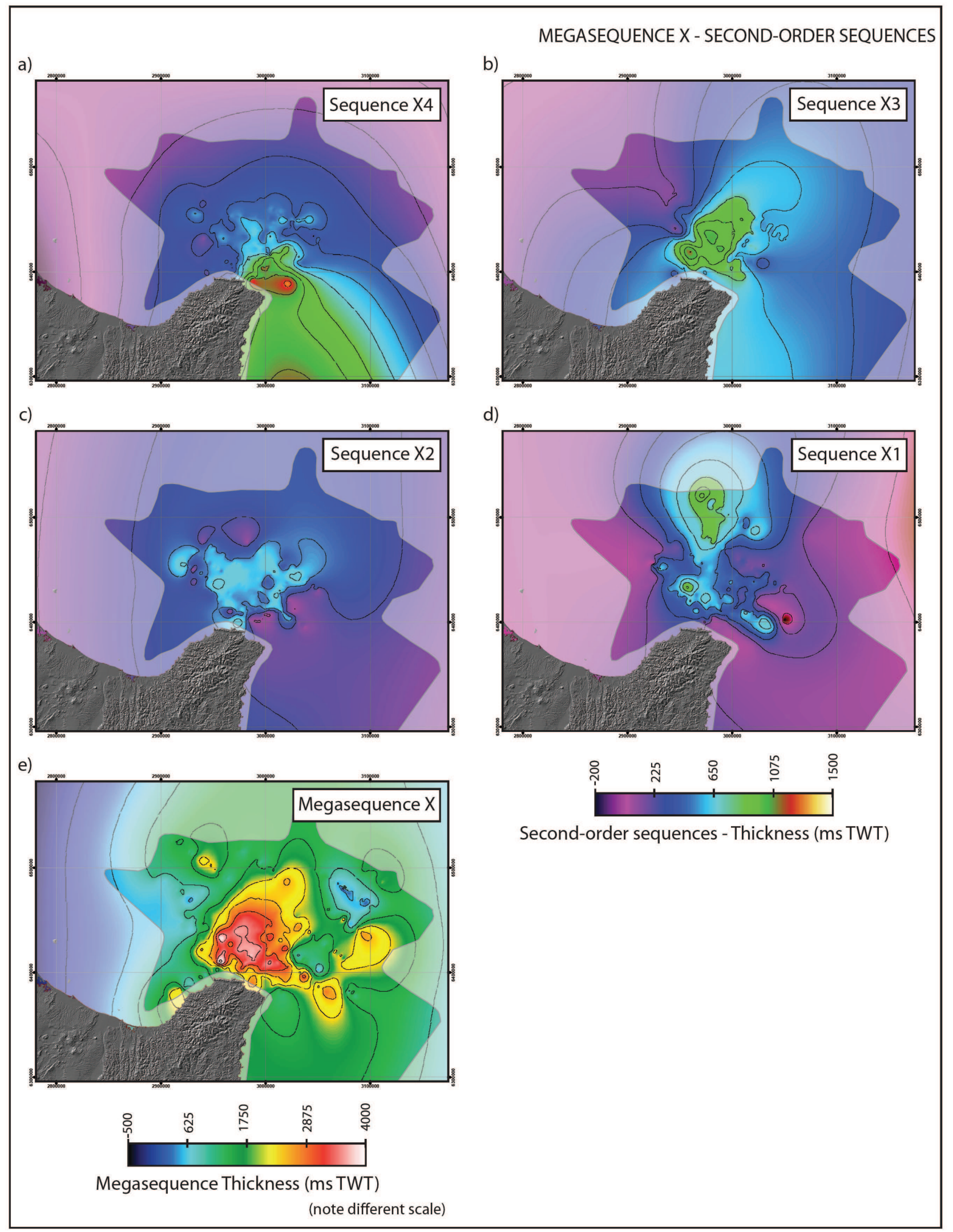

Figure 2.7a-d - Sediment isopach maps (as labelled) illustrating the thickness distribution (in two way time) of second order sequences interpreted within Megasequence X. Note the localisation of strata within the central basin. Contour interval in plots a-d is $250 \mathrm{~ms}$. e) as above but for the full thickness of Megasequence X. Note the change in scale for plot e, contour interval is $500 \mathrm{~ms}$. Faded area denotes regions unconstrained by MCS seismic reflection data. 
In contrast to second-order sequences interpreted within Megasequence $\mathrm{Z}$, second-order sequences interpreted within Megasequence $\mathrm{X}$ are predominantly localised within the central and southern Raukumara Basin (Figures 2.7a-d). Megasequence $\mathrm{X}$ displays a total thickness of $\sim 3.5 \mathrm{sec}$ twt $(\sim 7 \mathrm{~km})$ in the central basin with second-order sequences displaying individual thicknesses up to $2.0 \mathrm{sec}$ twt (Sequence $\mathrm{Z} 4$ ). The Megasequence isopach displays a wedge geometry which is correlated with the central and southern Raukumara Plain (Figure 2.7e).

In the central basin, reflectors are planar, laterally continuous and generally parallel to basal sequence boundaries (Figures 2.2-2.4b). Sequences are separated by angular unconformities and stratigraphic onlap is observed in the western basin where Mesozoic basement shallows toward the Harve Trough.

In the eastern basin where basal surfaces (and the seafloor) shallow toward the East Cape Ridge, reflectors are immediately fragmented and second-order sequences are characterised by short discontinuous reflections of moderate amplitude and variable dip. This observation is consistent throughout Megasequence $\mathrm{Z}$ and beneath East Cape Ridge, basal surfaces are interpreted to shallow by up to $4.5 \mathrm{sec}$ twt from positions within the central basin.

A similar shallowing of strata is observed south of the central basin beneath the continental shelf. Second-order sequences shallow by up to $5.0 \mathrm{sec}$ twt and although internal reflectors are less continuous than those imaged within the central basin, the degree of fragmentation is not as severe as observed at East Cape Ridge and along RAU07-09, it is possible to trace reflectors to within $5 \mathrm{~km}$ of the coast (Figure 2.2).

The basal surface of Sequence X1 is a basin bounding unconformity separating acoustic (Mesozoic) basement from Raukumara Basin fill. 


\subsection{4 - Acoustic Basement}

The observation of a sub-basin reflector at 9.5-10.5 sec twt (Figures 2.2 and 2.3ab) permits the interpretation of Acoustic Basement. Within this layer, a high amplitude and continuous reflection is observed branching off the base of Megasequence $\mathrm{X}$ around the western and southern perimeter of Raukumara Basin. This reflection displays a similar geometry to the basal unconformity of Megasequence $\mathrm{X}$ and facilitates the distinction of second-order sequences AB2 (above) and AB1 (below). Acoustic Basement and the second-order sequences interpreted within it are resolved through the observation of sub-basin reflections rather than any internal acoustic structure.

Reflections observed between 9.5-10.5 sec twt are interpreted by Sutherland et al. [2009] to be originating from the Moho. This interpretation is supported by forward modelling of $\mathrm{OBS} / \mathrm{H}$ wide-angle seismic reflection and refraction data [Scherwath et al., submitted manuscript] and preliminary forward modelling of onshore-offshore refraction data [this study]. Beneath the central basin, the Moho is observed flexing down by $\sim 1.0-3.0 \mathrm{sec}$ twt (Figures 2.3a and 2.4a).

West-dipping reflectors between 13-15 sec twt beneath the central basin are interpreted as the top of the subducting slab (Figures 2.3a and 2.4a). These reflectors are geometrically continuous and are aligned with reflectors observed beneath East Cape Ridge, which are in turn, aligned with the top of the subducting slab where it is imaged at shallower depths $(<7.3 \mathrm{sec}$ twt $)$ closer to the Hikurangi Trench (Figure 2.3a). 


\section{4 - Depth Conversion}

For the purposes of refraction modelling (Chapter Three), depth conversion of interpreted horizons was carried out through a layer cake method combining tools within Petrosys and Seisware. Horizon grids were constructed and exported from Seisware and loaded into Petrosys in conjunction with stacking velocities derived during the processing of the RAU07 dataset [Fugro Seismic Imaging, 2008]. Interval velocities between horizons were calculated along RAU07 profiles and interpolated across the seismic grid using interface constraints from interpreted horizons to construct 3-D velocity grids. Velocity grids were imported back into Seisware where a layer cake method was implemented to iteratively calculate the vertical distance between horizons, thus performing an approximate depth conversion. For the purposes of quality control, depth converted horizons were plotted against RAU07 depth profiles [Fugro Seismic Imaging, 2008]. Depth converted horizons display a strong correlation with sequence boundaries and provide initial constraints on the architecture of Raukumara Basin. 


\section{5 - Results}

\subsection{1 - Megasequence $\mathrm{Z}$}

Megasequence $\mathrm{Z}$ is interpreted as a prograding Neogene sedimentary succession deposited between the inception of subduction in the early Miocene (ca. $22 \mathrm{Ma}$ ) and the present day. Sutherland et al. [2009] correlate Megasequence Z with Neogene forearc marine sandstones, siltstones and mudstones observed onshore within the Tolaga and Mangaheia groups (Figure 1.3) [Mazengarb \& Speden 2000].

Megasequence $\mathrm{Z}$ contains at least six second-order sequences, the deposition of which appears strongly modulated by seafloor topography (Figures 2.5a-f). Isopach maps reveal a distinct SE-NW migration of sedimentary depocenters (Figure 2.8). A geometrical correlation exists between the basal surfaces of second-order sequences and the topographical highs of the East Cape Ridge and continental shelf. The migration of the Neogene depocenter is thus interpreted as recording the progressive broadening of the zone of uplift in both areas and is a key observation placing constraints on forearc mass-balance since the inception of subduction (Section 2.6.2).

Active faulting within Megasequence $\mathrm{Z}$ is predominantly observed around the perimeter of Raukumara basin. Sequence Z2 becomes imbricately faulted adjacent to (within $15 \mathrm{~km}$ ) and within the Harve Trough (Figures 2.3a and 2.4b). Where second-order sequences are interpreted up the western flank of East Cape Ridge, internal deformation increases and pervasive normal faulting and several fault bounded basins are observed (Figure 2.4a). Internal deformation is also observed to accompany the shallowing of strata within the continental shelf and the reduction in reflector continuity in both regions is attributed to progressive Neogene uplift. East of the East Cape Ridge, widespread faulting is observed on the upper part of the trench slope, which appears comprised of collapsed imbricately faulted rock rather than accreted sediment [Collot et al., 1996; Collot \& Davy., 1998; Sutherland et al., 2009]. 
Shallow second-order sequences display a transparent and/or internally chaotic acoustic structure and appear preferentially preserved in the northern and western regions of Raukumara Basin. The seafloor and second-order sequences adjacent to East Cape Ridge and the northern continental slope of the Raukumara Peninsula appear scoured and eroded with stranded debris blocks observed on the seafloor. Submarine landslides originating from the East Cape Ridge and continental shelf may be relatively common and play a key role in modulating the deposition and preservation of shallow strata within Raukumara Basin. Based on the relative proportions of internally chaotic and acoustically transparent sequences (indicative of mass transport deposits) between the upper and lower regions of Megasequence $Z$, it is suggested that the frequency of submarine failures within Raukumara Basin may be greater in recent times than periods contemporaneous with the deposition of second-order sequences Z2 and Z1. 


\subsection{2 - Megasequence $Y$}

Megasequence $\mathrm{Y}$ is interpreted as a single gravity induced submarine landslide. The chaotic internal structure, geometry of bounding interfaces and the inability to resolve any second-order sequences support this interpretation.

This Megasequence is only observed between the East Cape Ridge where it displays an average thickness of $0.9 \mathrm{sec}$ twt and the centre of the Raukumara Plain (Figures 2.2, 2.3a and 2.4a). It is observed thinning most rapidly to the west with the frontal tipline trending approximately NNE in the central and northern basin, before progressively arcing around to a NNW orientation within the continental shelf north of the East Cape (Figure 2.6). This geometry may be interpreted as reflecting a regional emplacement direction from east-west and the elevated East Cape Ridge appears a likely source region for a submarine landslide of this geometry.

A geometrical correlation exists between the angular unconformity upon which Megasequence $\mathrm{Y}$ was deposited and the base of the onshore allochthon. This observation suggests both Megasequence $\mathrm{Y}$ and the East Coast Allochthon were deposited at approximately the same time (latest Oligocene - earliest Miocene). 


\subsection{3 - Megasequence $X$}

Megasequence $\mathrm{X}$ is interpreted as a Cretaceous-Paleogene marine passive margin sequence and may represent one of the thickest sedimentary sections for this period in New Zealand [Uruski, 2008; Sutherland et al., 2009]. The upper region is correlated with clay-rich and calcareous Paleogene mudstones (Mangatu Group) with deeper strata correlated with passive margin fine-grained sandstones and organic-rich mudstones (Tinui Group) [Sutherland et al., 2009].

Second-order sequences are localised and well preserved in the central and southern areas of Raukumara Basin (Figures 2.7a-e). Toward the East Cape Ridge and continental shelf, flat lying and continuous reflectors become fragmented as strata are tilted up toward the topographic crest (Figure 2.3a). The reduction in reflector continuity is not as severe beneath the continental shelf as observed along the East Cape Ridge (Figure 2.2).

Where basal surfaces tilt up toward the Harve Trough, reflectors within Megasequence $\mathrm{X}$ are undeformed and stratigraphic onlap is observed (Figure 2.3a). The preserved nature of strata may suggest that this interface geometry may have existed at the time of deposition. Following the same reasoning, the immediate disruption of reflectors observed to accompany the increase in dip of second-order sequences at East Cape Ridge, may suggest these horizons were originally flat lying and have been subjected to deformation some time after deposition $(<25 \mathrm{Ma})$.

The lower intensity of deformation observed within the continental shelf, relative to the East Cape Ridge, may suggest that lesser amounts and/or more distributed uplift has occurred in this region. If the Raukumara Peninsula has experienced less uplift than the East Cape Ridge, a relative topographic high between the Raukumara Peninsula and the East Cape Ridge must have existed at the time of deposition, which has implications concerning correlations between onshore and offshore (Megasequence Y) allochthons (Section 2.6.3). Alternatively, the contemporary relative topographic high may reflect higher rates of erosion and trench slope collapse at East Cape Ridge, which although counter intuitive, is 
feasible given the transition in Moho depth between these regions (Figure 4.8, Section 4.4.3).

\subsection{4 - Acoustic Basement}

Beneath the central Raukumara Basin, a continuous sub-basin reflector interpreted as the Moho is observed to flex down beneath the region displaying the thickest sedimentary section by $0.5-1 \mathrm{sec}$ twt along RAU07-05 and $\sim 3.0 \mathrm{sec}$ twt along RAU07-03. This apparent flexure may represent a velocity pull down effect generated by the thickness $(\sim 10 \mathrm{~km})$ of overlying strata. Alternatively, it may represent a flexural downwarp within the basin floor crust in response to sedimentary loading and uplift around the eastern (East Cape Ridge), southern (Raukumara Peninsula) and western (Kermadec Ridge) boundaries of Raukumara Basin. Such a response might be expected given the thin $(\sim 5 \mathrm{~km})$ crust and the high apparent rates of uplift on bordering regions. Lithospheric flexure of this nature has been modelled in 2-D for the Wilkes Basin adjacent to the Transantarctic Mountains, Antarctica and in 3-D for the Kalahari Basin within the Great Escarpment in Southern Africa [Brink et al., 1993; Ten Brink \& Stern, 1992]. 


\section{6 - Discussion}

\subsection{1 - Mass-balance of forearc}

Strata between the central Raukumara Basin and the Harve Trough are well preserved and shallow second-order sequences (Z6-Z3) interpreted within Megasequence $\mathrm{Z}$ record a SE-NW migration of the Neogene sedimentary depocenter (Figures 2.5a-f and 2.8). No volcanic intrusions are observed east of the active arc.

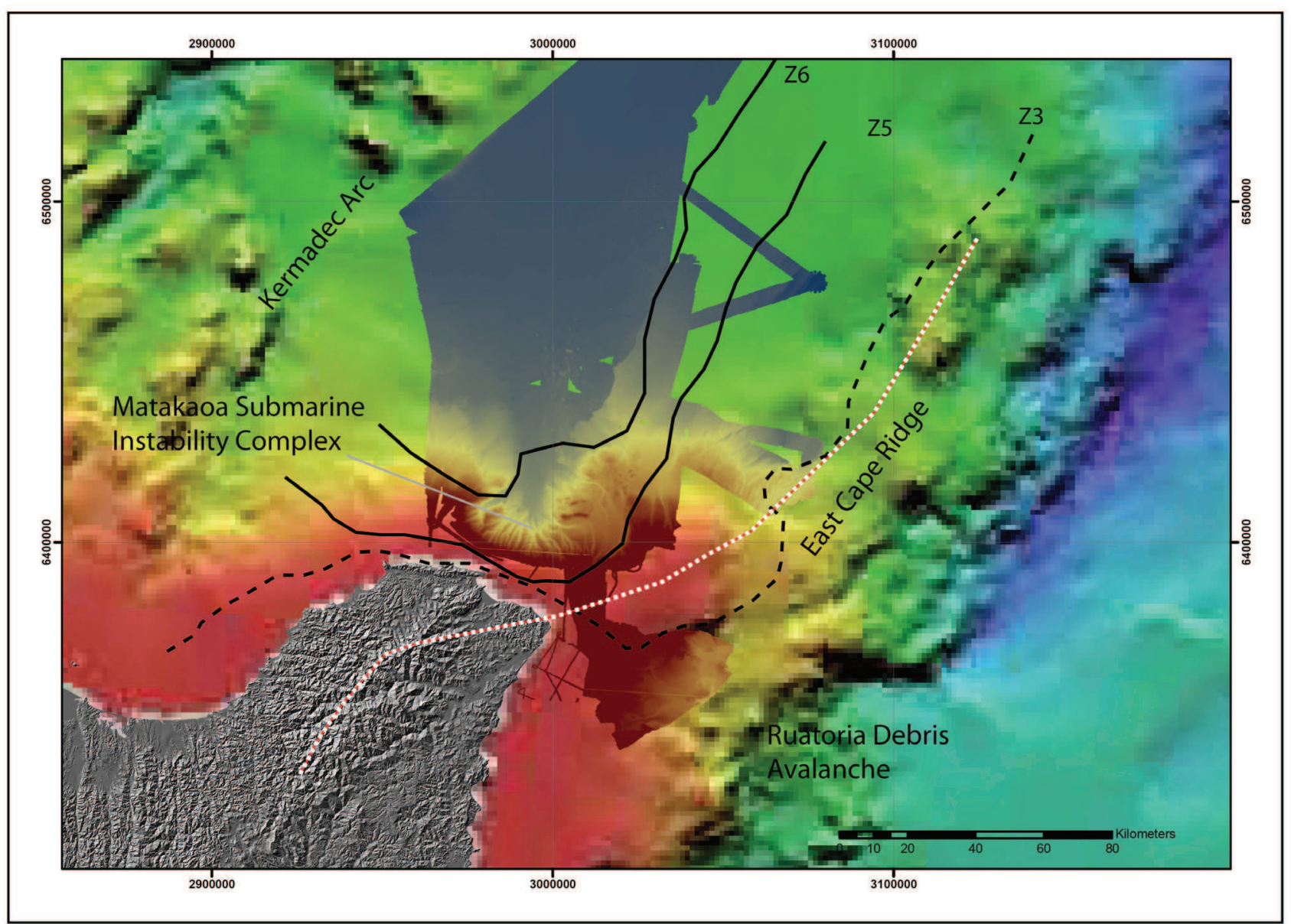

Figure 2.8 - Bathymetric map displaying the migration of the Neogene sedimentary depocenter. Black lines denote the eastern and southern extents of shallow second-order sequences (as labelled) interpreted within Megasequence Z. Full and dashed lines distinguish depositional and erosional extents respectively. Red and White dashed line marks the inferred position of the topographic crest. Note the positions of the Matakaoa Submarine Instability Complex and the Ruatoria Debris Avalanche on either side of this lineation. Bathymetric datasets supplied courtesy of NIWA. 
These observations effectively rule out a net decrease in the volume of the forearc. The removal of forearc material via tectonic erosion at the plate interface would be accompanied by a trenchward advection of the entire forearc. Assuming a constant distance between the trench and the volcanic front [Lallemand, 1995], if such a process had occurred, ancient arc volcanoes would likely be preserved within the western Raukumara Basin. Abandoned volcanoes east of the Kermadec Arc are not observed and it is proposed that large scale removal of forearc material by tectonic erosion has not occurred in the region of Raukumara Basin at any time since $\sim 22 \mathrm{Ma}$.

This conclusion is contrary to interpretations of an erosional subduction margin [Collot \& Davy, 1998] and stratigraphic observations (Section 2.3.1, Figure 2.8) suggest a net crustal growth of the forearc. The SE-NW migration of Neogene sedimentary depocenters is interpreted as tracking the protuberant growth and arcward migration of the zone of uplift at the East Cape Ridge and Raukumara Peninsula. Crustal growth is driven by accretion of subducted sediment to the over-riding plate; however, the trench slope in this region is highly faulted and consists of indurated rock rather than accreted sediment [Collot \& Davy, 1998; Collot et al., 1996]. This observation effectively rules out frontal accretion as a mechanism of increasing the volume of the forearc wedge and lower crustal underplating is a viable alternative.

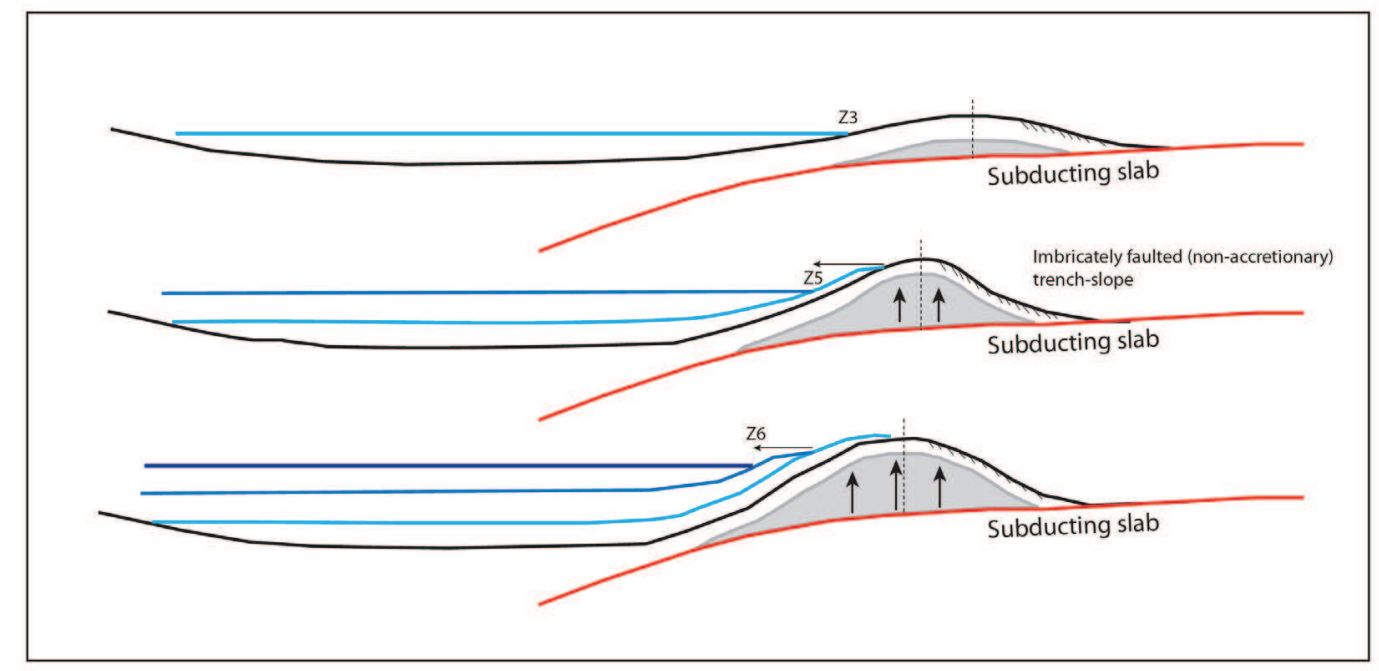

Figure 2.10 - Schematic cartoon illustrating how lower-crustal underplating is hypothesised to result in a migration of the sedimentary depocenter. Note the migration of the locus of underplating (dashed black line). 


\subsection{2 - Allochthon Emplacement}

The East Coast Allochthon is observed onshore and was first recognised by Stoneley [1968] who mapped 15 south-southwest directed thrust sheets throughout the northern Raukumara Peninsula (Figures 1.3 and 2.9). It has since been suggested that the onshore allochthon was emplaced toward the SSW during the Early Miocene, with the timing of obduction constrained by relationships between allochthonous units and syn-tectonic deposits [Ballance \& Spörli, 1979; Isaac et al., 1994; Field et al., 1997].

Offshore, within the central and eastern regions of Raukumara Basin, a thick chaotic packet of sediment (Megasequence $\mathrm{Y}$ ) is interpreted as a single submarine landslide (Figures 2.2a, 2.3a and 2.4a). Sutherland et al. [2009] propose a correlation between Megasequence $\mathrm{Y}$ and the East Coast Allochthon and resolve a NE-SW trending tipline, which they interpret as suggesting a regional emplacement direction of both allochthons toward the west or northwest. This interpretation appears inconsistent with emplacement directions structurally derived onshore for the East Coast Allochthon [Kenny, 1984; Rait et al., 1991; Stoneley, 1968], however, Sutherland et al. [2009] suggest that the emplacement direction onshore, may have locally been toward the southwest as suggested by previous workers.

The tipline for Megasequence Y resolved in this thesis trends NNE within the central and northern basin before progressively arcing around to a NNW orientation within the continental shelf, north of East Cape (Figure 2.6). This tipline geometry appears consistent with the suggestion of Sutherland et al. [2009] and would produce a local emplacement direction toward the southwest if extrapolated onshore.

The East Coast Allochthon is most commonly correlated with the Northland Allochthon, which is comprised of obducted Cretaceous to earliest Miocene oceanic igneous and sedimentary rocks located $>350 \mathrm{~km}$ northwest of the Raukumara Peninsula in Northland, New Zealand [Balance and Sporli, 1979]. 
Regional emplacement directions form a key component of correlations between these allochthons and it is necessary to consider how the implications of linking Megasequence $\mathrm{Y}$ with the East Coast Allochthon propagate through to correlations between the East Coast and Northland Allochthons (Figure 2.10).

The Northland Allochthon was emplaced in the earliest Miocene [Balance, 1976, 1988; Balance and Sporli, 1979; Herzer 1995]. The most widely accepted emplacement direction is toward the southwest, a direction supported by recognition of the thrust front southwest of Northland [Isaac et al., 1994], the distribution of sub-units and stratal ages [Rait, 1991] and the orientations of macroscopic and minor structures within the allochthon [Rait, 2000]. Rait [2000] resolve a consistent transport direction $\left(220^{\circ} \pm 10^{\circ}\right)$ along the exposed length of the allochthon $(>250 \mathrm{~km})$ at all structural levels suggesting a relatively constant emplacement direction throughout obduction.

In support of correlations with the East Coast Allochthon, the range of lithologies, ages of displaced strata, structural style and both the direction and timing of emplacement of the Northland Allochthon are all similar or identical to those of the East Coast Allochthon [Balance and Sporli., 1979; Brook et al., 1988; Isaac et al., 1994; Isaac, 1996; Mazengarb and Speeden., 2000]. 


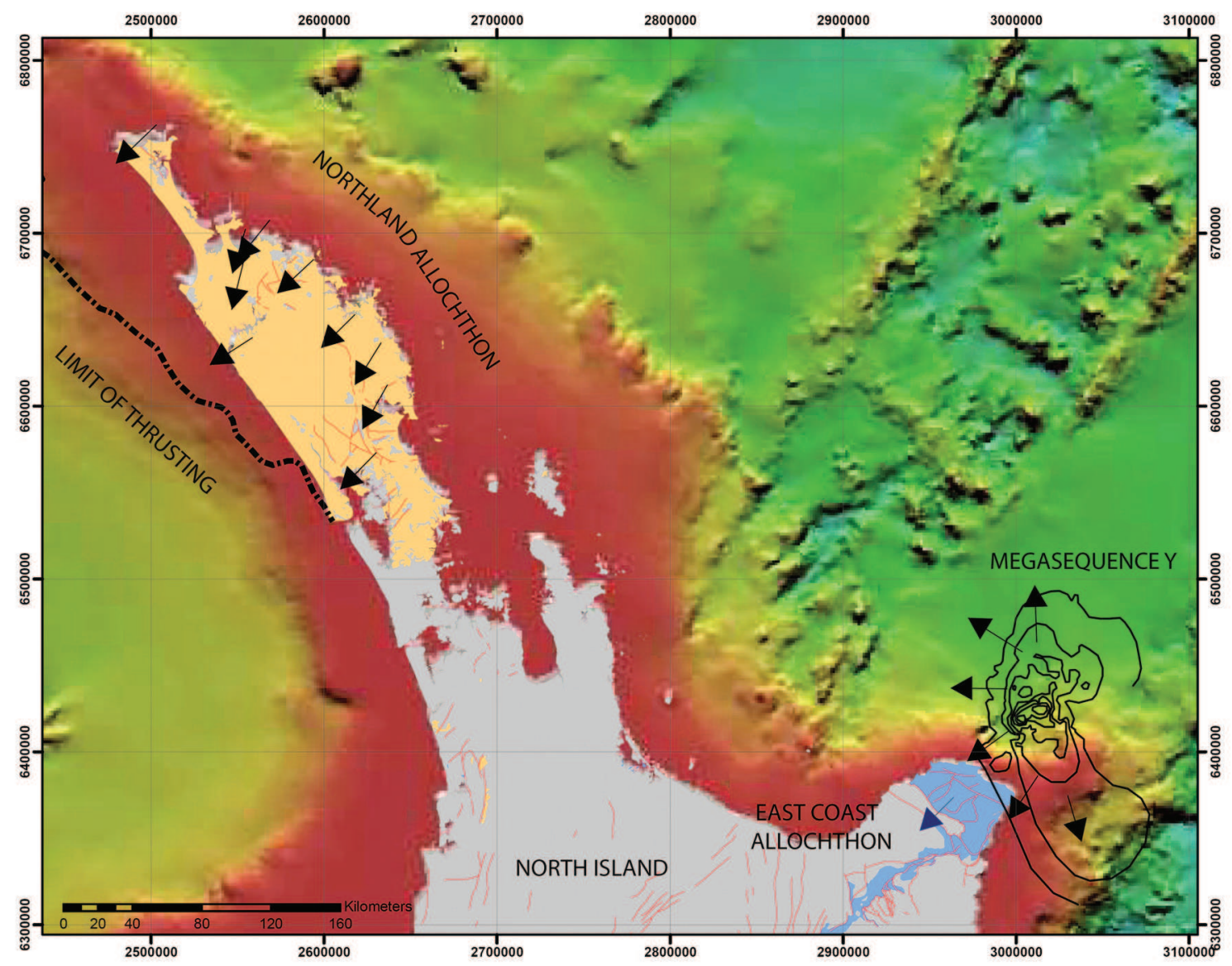

Figure 2.10 - Map of the northern North Island, New Zealand, displaying the locations and emplacement directions of the Northland (Yellow) and East Coast (Blue) Allochthons [Mazengarb \& Speden, 2000]. Contour illustrates the thickness of Megasequence Y (Figure 2.6). Contours are spaced at $0.25 \mathrm{sec}$ twt and range from 0 (outermost) to $1.75 \mathrm{sec}$ twt. Black arrows illustrate calculated emplacement directions for the Northland Allochthon [Rait, 2001] and estimated emplacement direction for Megasequence Y. Dark Blue arrow onshore denotes the regional emplacement direction for the East Coast Allochthon [Kenny, 1984; Rait et al., 1991; Stoneley, 1968]. Dashed black line southwest of Northland illustrates the thrust front [Isaac et al., 1994]. Mapped active faults are displayed onshore in Red [GNS Science, active fault database]. Background colour illustrates bathymetry [NIWA].

Onshore paleomagnetic declination anomalies indicate that the Raukumara Peninsula has not experienced vertical axis rotations relative to the Australian plate [Mumme et al., 1989; Rowan et al., 2005; Rowan \& Roberts, 2008]. This suggests that if the Northland and East Coast Allochthons were deposited contemporaneously, similar emplacement directions should be preserved in both 
areas. Linking the East Coast Allochthon with Megasequence $\mathrm{Y}$ suggests a regional emplacement direction of both units toward the west or northwest. As this emplacement direction is inconsistent with that observed within the Northland Allochthon, this interpretation effectively decouples the East Coast and Northland Allochthons (Figure 2.10).

The angular unconformity upon which Megasequence $\mathrm{Y}$ and the East Coast Allochthons are emplaced is $5 \mathrm{~km}$ higher at the northern Raukumara Peninsula than the position of Megasequence $\mathrm{Y}$ within the central Raukumara Basin. Megasequence $\mathrm{Y}$ is interpreted as a submarine landslide and thus correlations between the onshore and offshore allochthons require a much $(>5 \mathrm{~km})$ lower elevation for the Raukumara Peninsula than is presently observed. A further consequence of correlations between the East Coast and offshore allochthons is thus a higher rate uplift and/or a lower rate of erosion at Raukumara Peninsula relative to the East Cape Ridge.

As an alternative hypothesis, Sutherland et al. [2009] suggest that the East Coast and offshore allochthons may have been deposited as separate entities with the East Coast Allochthon deposited slightly earlier than Megasequence Y.

It is acknowledged that it is difficult to discern between the two alternatives presented within Sutherland et al. [2009] and the data analysed here are unable to conclusively distinguish between these hypotheses. The alternative hypothesis in which Megasequence $\mathrm{Y}$ and the East Coast Allochthon are similar although separate entities appears more consistent with onshore studies of the East Coast Allochthon and the numerous datasets suggesting a correlation between the Northland and East Coast Allochthons [e.g. Balance \& Sporli, 1979; Brook et al., 1988; Rait, 1992; Isaac et al., 1994; Isaac, 1996; Rait, 2000; Black et al., 2002]. This scenario is also more compatible with observations of internal deformation within Megasequence X which suggest higher rates of uplift at East Cape Ridge. The correlation between the Northland and East Coast Allochthons is compelling and for this reason the alternative (separate emplacement) scenario of Sutherland et al. [2009] is preferred. 


\subsection{3 - Quantification of Uplift}

The reflection continuity of second-order sequences within Megasequence $\mathrm{X}$ diminishes as sequence boundaries tilt up toward the East Cape Ridge (Figures 2.3a and 2.4a). This is interpreted as internal deformation accompanying Neogene uplift. Assuming the depths of sequence boundaries prior to deformation were approximately similar to those presently observed beneath the central basin, may allow estimation of the total rock uplift at East Cape Ridge. These calculations may place constraints on the rate at which subducted sediment is accreted to the upper plate, and the geometrical relationship between the seafloor and uptilted passive markers may offer insights into rates of erosional denudation and the ability of erosive processes to keep pace with uplift. A similar calculation may be possible for the Raukumara Peninsula, however, relative to East Cape Ridge, strata are less deformed within the continental shelf. A relative topographic high may have existed between the Raukumara Peninsula and the East Cape Ridge prior to deposition of Megasequence $\mathrm{X}$ and the undeformed depth of strata is considered more uncertain.

It is noted that appropriate depth conversion is required and it is likely large errors will be associated with these calculations. The preferential erosion of regions of anomalous topography makes this approach of calculating rock uplift preferable to using seafloor topography. 


\section{7 - Summary}

Analyses of seven seismic reflection datasets allow the identification and mapping of 3 Megasequences and 12 second-order sequences throughout Raukumara Basin. The stratigraphic column reaches a maximum thickness of $(\sim 10.5 \mathrm{~km}) 35 \mathrm{~km}$ offshore and along strike of the Raukumara Peninsula.

Megasequence $\mathrm{Z}$ is interpreted as a Neogene sedimentary succession deposited following the onset of subduction beneath the East Cape and is correlated onshore with the Tolaga and Mangaheia Groups. Within this megasequence, a north-westward migration of sedimentary depocenters is observed and interpreted as tracking the progressive broadening and migration of the locus of contemporary uplift at the East Cape Ridge and Raukumara Peninsula (Figure 2.8).

Megasequence $\mathrm{Y}$ is interpreted as a single submarine landslide $(\sim 10,000 \mathrm{cu} \mathrm{km})$. The tipline geometry of this megasequence suggests an emplacement direction toward the west-northwest and the East Cape Ridge appears a likely source region for a submarine failure of this geometry. Correlating Megasequence $\mathrm{Y}$ with the East Coast Allochthon suggests a regional emplacement direction toward the west (Figure 2.10). This emplacement direction appears inconsistent with that derived for the Northland Allochthon [Rait, 2000]. Given the volume of published data supporting correlations between the East Coast and Northland Allochthons, interpretations involving Megasequence $\mathrm{Y}$ and the East Coast Allochthon as separate lithostratigraphic entities are preferred.

Megasequence $\mathrm{X}$ is interpreted as a Late Cretaceous and Paleogene marine passive margin sequence and is correlated onshore with the Mangatu Group and the Tinui Group. Reflector continuity within this megasequence becomes increasingly fragmented toward the East Cape Ridge and marginally deformed toward Raukumara Peninsula. Internal deformation is interpreted to be associated with Neogene uplift of the Raukumara Peninsula and East Cape Ridge and it may be possible to use the deflection of marker beds within this sequence to quantify the rates and amounts of rock uplift for these regions. 
The observations presented in this chapter place constraints on the mass-balance of the forearc since the inception of subduction (22 Ma). Contrary to suggestions of an erosive margin [Clift and Vanucchi, 2004; Von Huene and Scholl, 1991], the Neogene migration of the depocenter suggests that the forearc in the vicinity of East Cape Ridge and the Raukumara Peninsula has been a site of net crustal growth. The imbricately faulted physiography of the trench slope [Collot and Davy, 1998] suggests crustal growth is facilitated predominantly through lower crustal underplating as opposed to frontal accretion. 


\section{CHAPTER 3 - SEISMIC REFRACTION}

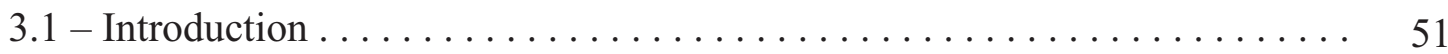

3.2 - Seismic Refraction

3.2 .1 - Data ................................ 52

3.2.2 - Onshore offshore seismic profiling ............ 54

3.2 .3 - Processing and Interpretation $\ldots \ldots \ldots \ldots \ldots \ldots . \quad 57$

3.3 - Observations

3.3 .1 - Regional observations . . . . . . . . . . . . . . . . . 58

3.3 .2 - Raukumara Plain ............................ 62

3.3.2.1 - Central Basin .......................... 62

3.3.2.2 - Northern Basin ..................... 65

3.3.2.3 - Western Basin - Kermadec Ridge / Harve Trough .... . 66

3.3.3 - Trench-slope - Subducting Slab. .................. 68

3.3 .4 - East Cape Ridge .............................. $\quad 70$

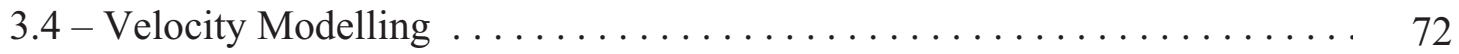

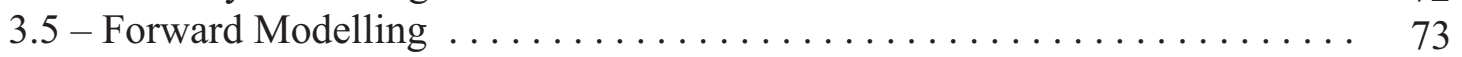

3.5.1 - Forward Modelling Methodology . . . . . . . . . . . . . 73

3.5 .2 - Forward Modelling Strategy .................... 75

3.5.3 - Constraints incorporated into forward modelling .......... 77

3.5.3.1 - Onshore velocity structure ................. 78

3.5.3.2 - Velocity structure along RAU07-05 _......... 79

3.5.3.3 - Offshore basin structure .................. 80

3.5.4 - Tradeoffs within forward modelling $\ldots \ldots \ldots \ldots \ldots \ldots \ldots, 80$

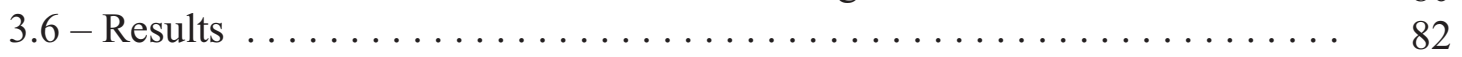

3.6.1 - Raukumara Plain / Harve Trough .................... 87

3.6.2 - Raukumara Peninsula / continental Shelf . . . . . . . . . . . 89

3.6.3 - Trench-Slope / Subducting Slab . . . . . . . . . . . . . . . . 90

3.6 .4 - East Cape Ridge ............................. 91

3.7 - Discussion

3.7 .1 - Model fit ............................. 92

3.7.2 - Problematic arrivals during forward modelling ........... 92

3.7 .3 - Model resolution . . . . . . . . . . . . . . . . . . . . . . . . . . 94

3.7 .4 - Errors ............................... 94

3.7.4 - Comparison with constraining datasets ............. 95

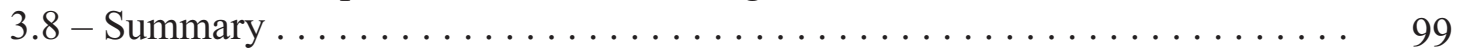




\section{1 - Introduction}

Transition zones between continental and oceanic environments and the coastlines of landmasses often play host to one, or several, first order tectonic settings. These include passive and active continental margins, ocean-continent subduction zones and arc systems, and plate boundaries situated near coastlines [Okaya et al. 2003]. Conventional land or marine based seismic methods are unable to image the region of crust beneath land-ocean transitions however onshore-offshore seismic profiling techniques are well suited to studying these environments.

Along the strike of the northern Hikurangi subduction margin, the anomalously high forearc topography of the Raukumara Ranges [Walcott, 1984] drops away south of the submarine Raukumara Plain (water depths $>2.0 \mathrm{~km}$ ) (Figure 3.1). A transition in forearc crustal thickness is hypothesised to accompany this physiographic transformation and may implicate a northward transition from continental-oceanic to oceanic-oceanic subduction.

To address this hypothesis, an onshore-offshore wide-angle seismic reflection and refraction dataset has been acquired through the temporary deployment of nine short-period seismometers around the northern Raukumara Peninsula, at a time contemporaneous with the offshore RAU07 seismic reflection survey (Figure 3.1). These data are processed, interpreted and modelled using a technique of forward velocity modelling developed in this thesis to produce a 3-D P-wave velocity (Vp) model occupying $\sim 32,000 \mathrm{~km}^{2}$ of the northern Hikurangi subduction margin.

This chapter presents travel-time observations from onshore-offshore receivergathers and focuses on the velocity modelling of these data. The interpretation and implications of model results are presented within Chapter Four. Supplementary to this chapter are Appendices One and Two which detail the processing of onshore-offshore data and the technique by which 3-D velocity forward models are created. The results of several experiments involving tomographic inversion are presented in Appendix Three. Figures supplementary to this chapter are presented within Appendix Four and on CD. 


\section{2 - Seismic Refraction}

\subsection{1 - Data}

For the duration of the RAU07 multi-channel-seismic (MCS) reflection survey nine three-component short-period seismometers were deployed around the northern Raukumara Peninsula by GNS Science and Victoria University (Figure 3.1). These seismometers recorded the onshore arrival of reflected and refracted energy emanating from offshore air-gun shots (Figure 3.2).

RAU07 consisted of nine seismic reflection lines totalling $1228 \mathrm{~km}$ acquired by CGG Veritas onboard CGG Duke in July 2007 (Figure 3.1). The seismic source was a 5280 cu.in air-gun array charged to a pressure of 2000 pounds per square inch (psi). Shot intervals were $37.5 \mathrm{~m}$ with the exception of RAU07-05, which had a $50 \mathrm{~m}$ shot spacing [Fugro, 2007].

As a result of the finely spaced acquisition parameters associated with the MCS reflection survey and the distribution of onshore receivers (average spacing $\sim 15$ $\mathrm{km})$, a large dataset has been acquired $(30,000$ shots $\mathrm{x} 9$ receivers $\approx 270,000$ unique seismic traces). In the analyses of these data only the vertical component of recorded seismograms is considered. 


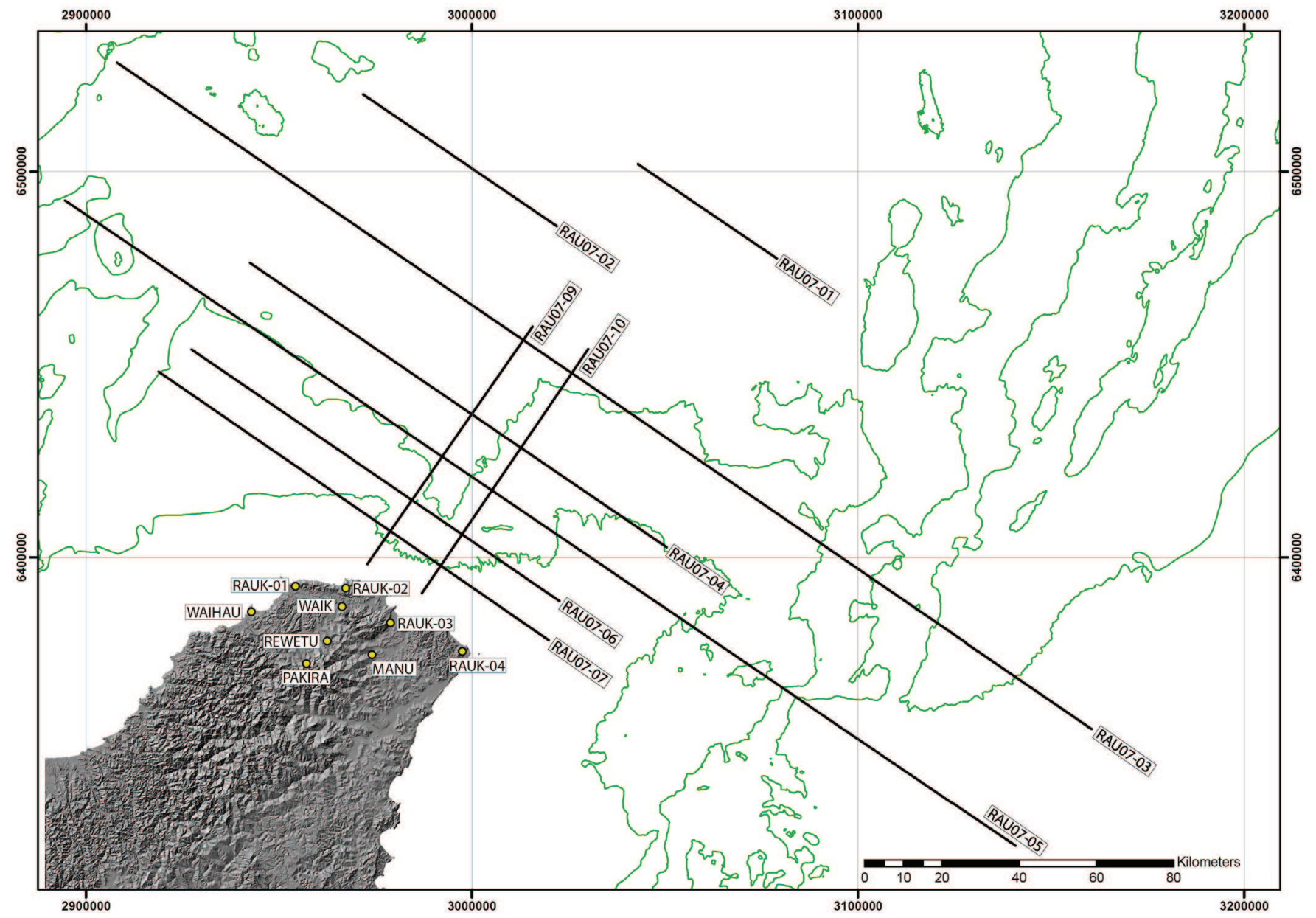

Figure 3.1 - Map illustrating the acquisition geometries of onshore-offshore wide-angle seismic refraction and refraction data. Black lines illustrate the position of RAU07 seismic reflection profiles (as labelled). Shots along these profiles were recorded onshore by nine three-component short-period seismometers (Yellow dots, as labelled). Shot spacing was $37.5 \mathrm{~m}$ along all profiles with the exception of RAU07-05, which had a shot interval of $50 \mathrm{~m}$. Bathymetric contours at $1000 \mathrm{~m}$ intervals are displayed in green with a digital elevation model (DEM) used to display the Raukumara Peninsula. 


\subsection{2 - Onshore-offshore seismic profiling}

Seismic profiling across the land-ocean transition is a known challenge that requires a combination of data collection techniques [Okaya et al., 2003]. The primary advantage of onshore-offshore seismic profiling is that seismic energy is recorded that undershoots the coastline and this technique is able to image subsurface regions which cannot be examined using either marine or land-based seismic profiles.

The onshore-offshore seismic profiling technique uses moderately spaced land instruments to record densely spaced marine air-gun shots. Offshore air-gun shots are generally associated with the acquisition of MCS reflection data and the onshore arrival of each air-gun shot is recorded by land based seismometers deployed for the duration of the offshore survey.

Seismograms are extracted from continuously recorded data using precise GPS shot-times and plotted on the basis of shot-number for each profile in the MCS survey. These plots are referred to as receiver-gathers (Figures 3.5-3.8) and seismic reciprocity theory [Knopoff \& Gangi, 1959] predicts that receivergathers will be identical to the shot-gather that would be recorded if a single explosion positioned at the land seismometer was recorded simultaneously at the location of each offshore air-gun shot. In contrast to land-based refraction surveys, the air-gun source associated with onshore-offshore data is relatively small. The rich resolution observed on onshore-offshore receiver-gathers is thus attributed to the fine shot spacing and the high trace density, which allows comparatively weak signals to be visually detected. 
Onshore-offshore profiling has inherent ocean-land ray-path geometries and complete onshore-offshore experiments may also employ land based refraction profiling and the deployment of Ocean Bottom Seismometers and Hydrophones (OBS/H) [Okaya et al., 2003]. These additional data and the reversed profiles they provide can assist in overcoming the refraction-velocity versus dip ambiguity which often arises with unidirectional shooting. In the absence of these additional data, a large number of land instruments and the use of modern ray tracing methods [Zelt \& Smith, 1992; Hole, 1992; Rawlinson \& Sambridge, 2004] can overcome this trade-off and compensate for data incomplete in its azimuthal coverage.

The orientation of MCS reflection profiles, relative to the onshore distribution of seismometers, exerts a strong influence on the apparent velocities observed on receiver-gathers (Figure 3.2a-d). This influence specifically relates to the obliquity of the raypath relative to the profile orientation and thus the variation in source-receiver offset between adjacent traces. 
a)
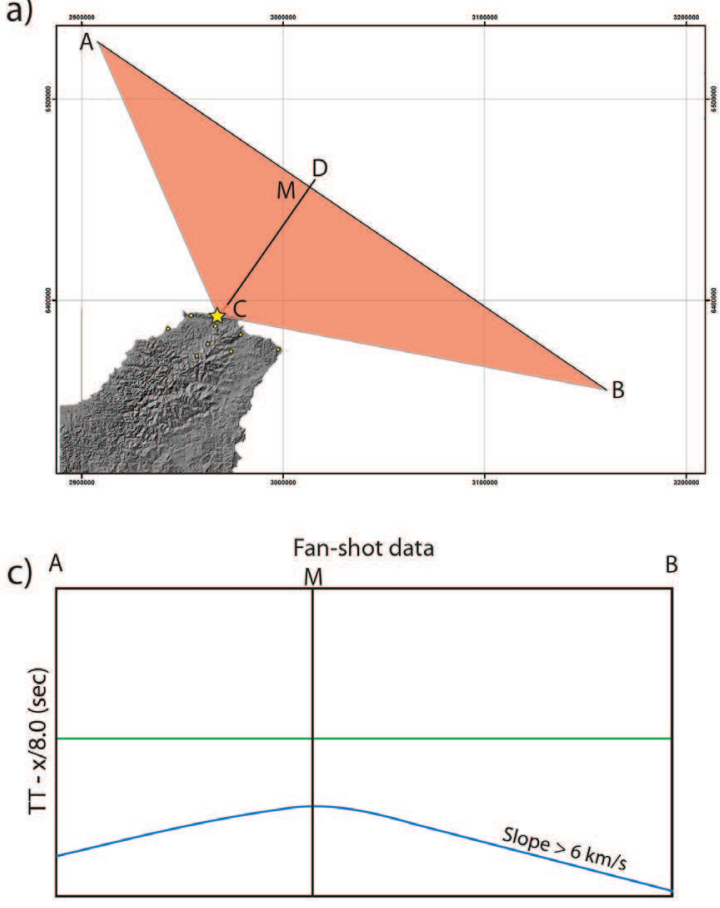

$x$ offset $(\mathrm{km})$ b)

Onshore seismometer

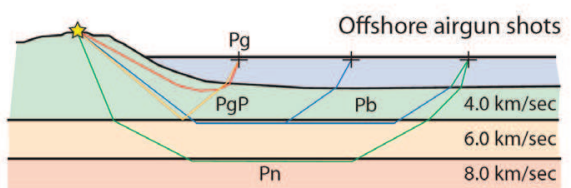

- PgP-P wave reflecting off the lower crust

- Pg - P wave turning in upper crust

— $\mathrm{Pb}$ - $\mathrm{P}$ wave turning in lower crust

_ Pn- $\mathrm{P}$ wave turning in upper mantle

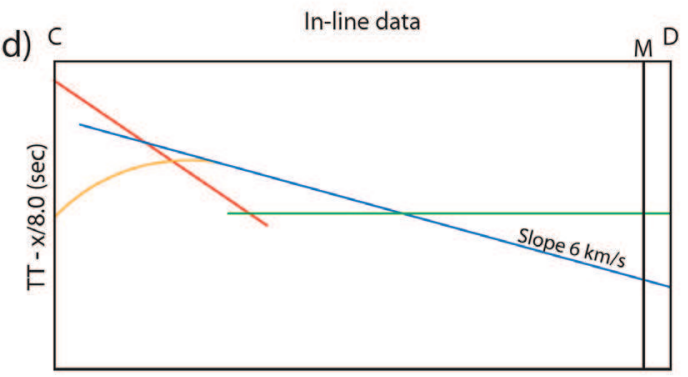

$\mathrm{x}$ offset $(\mathrm{km})$

Figure 3.2 - Schematic cartoon illustrating the onshore-offshore seismic profiling technique and the effect of along profile variations in ray - profile obliquity on the apparent velocities observed. a) Map displaying the contrasting geometries of cross-line (A-B) and in-line (C-D) MCS profiles. The red area displays the region sampled by raypaths originating from the cross-line profile. $\mathrm{b}$ ) Cartoon displaying the phases and raypaths commonly observed on onshore-offshore seismic profiles. c) Hypothetical receiver-gather for cross-line profile A-B. d) Hypothetical receivergather for in-line profile C-D. Note the increase in apparent velocity observed toward the centre of profile A-B. This is due to an increase in the obliquity of the raypath relative to the profile orientation. Variations of this nature are not observed on profile C-D as all rays originating from this profile travel a common azimuth.

For in-line profiles this obliquity is negligible with all arrivals travelling a common azimuth (Profile C-D in Figure 3.2a). The receiver-gather generated for data with this geometry is similar to conventional 2-D single-ended shot-gathers. In contrast, for cross line profiles (Profile A-B in Figure 3.2a), each arrival travels a unique azimuth with both absolute offset and the relative offset between adjacent shots decreasing as the obliquity between ray-azimuth and profile orientation increases. 
The reduction in the relative offset between adjacent traces as a function of rayazimuth - profile obliquity effectively increases the apparent velocity observed. It is thus important that the orientation of MCS reflection profiles is considered when interpreting receiver-gathers, especially where travel-time gradients are being used to estimate interval velocities within turning layers.

\subsection{3 - Processing and Interpretation}

Data were processed into a series of 81 receiver-gathers using utility codes and scripts provided by IRIS Passcal [www.passcal.nmt.edu].

Minimal processing was applied to receiver-gathers with minor frequency filtering and altering the aspect ratio of the visual display of data the most useful methods of enhancing data quality and identifying arrivals. The poorest quality data were recorded by the two stations aligned with the onshore projection of the East Cape Ridge (RAUK04 and MANU - Figure 3.1).

Travel-time interpretations were limited to P-waves and of the 81 receivergathers constructed, first-arrivals were identified on 69, with 174 discrete phase segments identified and $\sim 275,000$ travel-time picks made.

Throughout the interpretation process, the errors associated with each pick were visually estimated and recorded. The degree of confidence in interpreted traveltimes ranged from $70 \mathrm{~ms}$ to 1 second although the vast majority of picks had associated errors below $200 \mathrm{~ms}$. Travel-time interpretations were generally limited to data where picks could be made within a useful degree of uncertainty $( \pm 500 \mathrm{~ms})$.

A comprehensive discussion of the methodology by which raw data were processed and reduced to an observed travel-time dataset is presented in Appendix One. Scripts developed throughout this process are provided both within this appendix and on the attached CD. 


\section{3 - Observations}

\subsection{1 - Regional observations}

Regional travel-time observations are presented in a series of figures illustrating the spatial distribution of average velocities calculated for first-arrivals recorded at six stations in this deployment (Figures 4a-f). The three stations not plotted (RAUK04, MANU and WAIHAU) displayed lower quality data and the picks made were limited in their spatial coverage and not conducive to analyses in this manner.

In generating these plots, the curvature of the raypath with depth is not accounted for and average velocities are calculated by dividing offset by the observed travel-time. The true average velocity will always be higher than the estimates presented in these plots which assume a linear, horizontal and thus shortest possible raypath between source and receiver.

Average velocities are plotted at their shot-point rather than the mid-point between source and receiver. Consideration of the receiver position is therefore crucial to the correct interpretation of these plots, especially when observations are compared between stations.

The discussion of travel-time observations is not intended to be exhaustive, but rather to present a general overview of the data and some of the interesting observations from receiver-gathers. Variations in ray-azimuth obliquity along dip-parallel profiles exerts a strong influence on the apparent velocities resolved (Section 3.2.2) and for this reason the discussion below focuses predominantly on average velocities. 


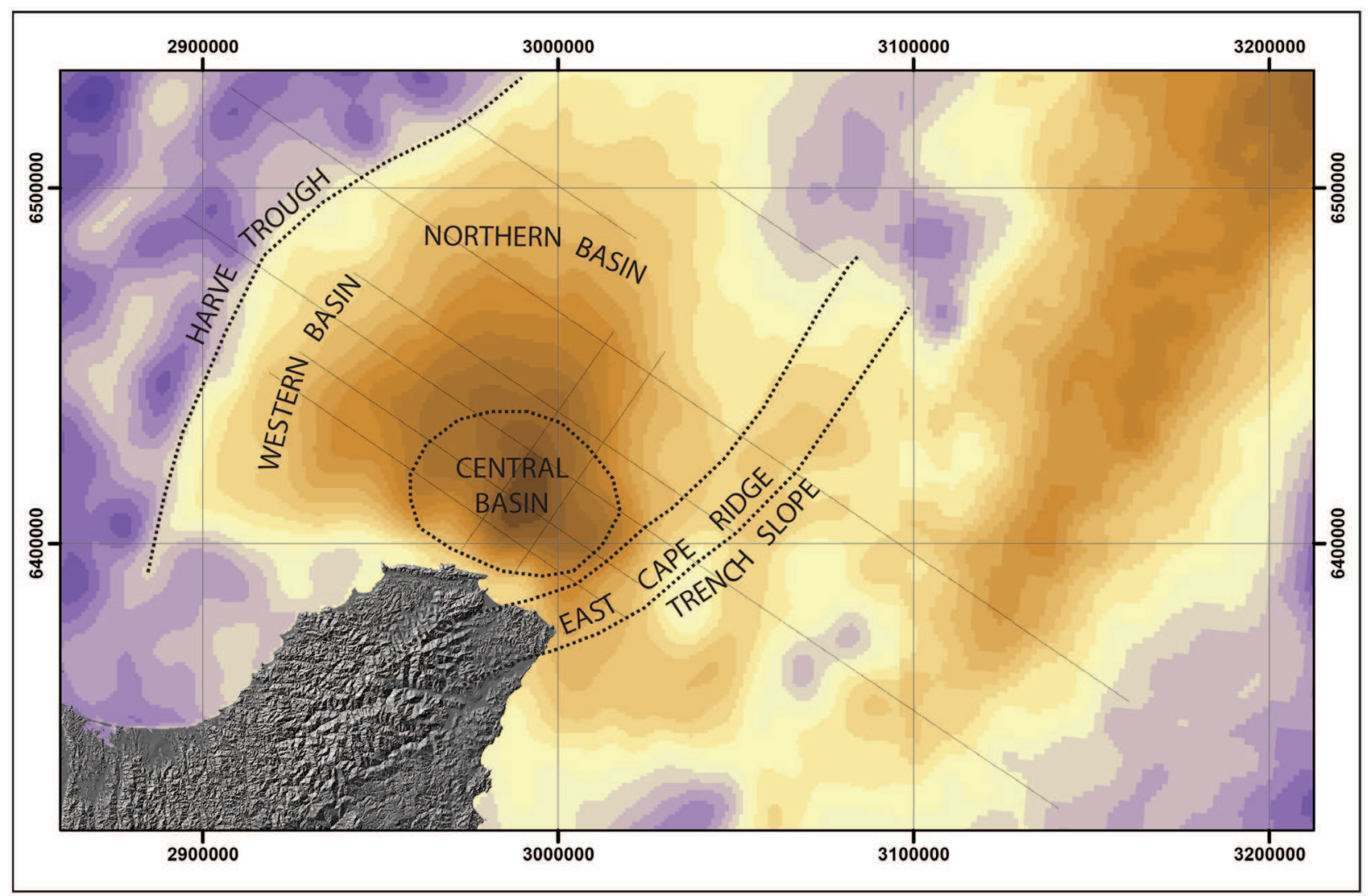

Figure 3.3 - Free-air gravity map displaying the general domains which the study area is subdivided into. The Raukumara Peninsula is displayed as a Digital Elevation Model (DEM). RAU07 seismic reflection lines are displayed in black. Free-air gravity anomaly displayed at 10 mgal intervals. The darkest browns are negative -150 mgal anomalies.

Figure 3.4a-g (overleaf) - Maps displaying average velocities of interpreted first-arrivals, calculated by dividing offset by travel-time for a) RAUK-02, b) WAIK, c) Rewetu, d) Pakira, e) RAUK-01 f) RAUK-03. Velocities are plotted at the shot point which makes consideration of the receiver position (Red Star) important when viewing these plots. Thin and thick average velocity contours are plotted at $0.25 \mathrm{~km} / \mathrm{sec}$ and $0.5 \mathrm{~km} / \mathrm{sec}$ intervals respectively (as labelled). The other stations in this deployment are denoted by yellow dots. g) Average synthetic velocities calculated through a 1-D velocity model using the same source and receiver positions as in $3.4 \mathrm{a}$. This plot is provided for comparison with observational data and to further illustrate the anomalously slow nature of arrivals originating from the East Cape Ridge region h) 1-D velocity model (used to construct 3.4g) for the central Raukumara Basin calculated from the depth distribution of velocities at the point of intersection between RAU07-05 and RAU07-09 (Figure 3.1). 

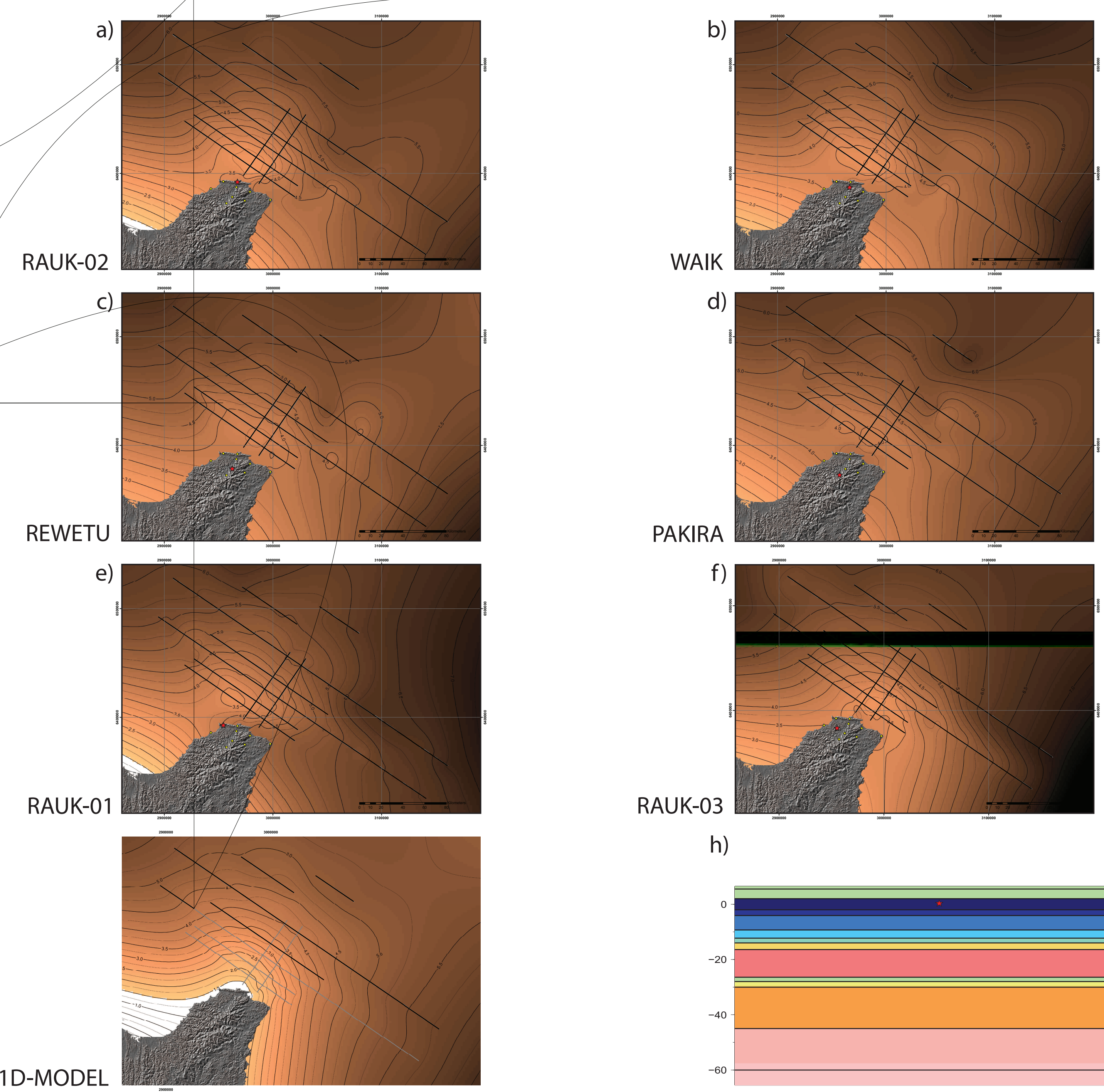

h)

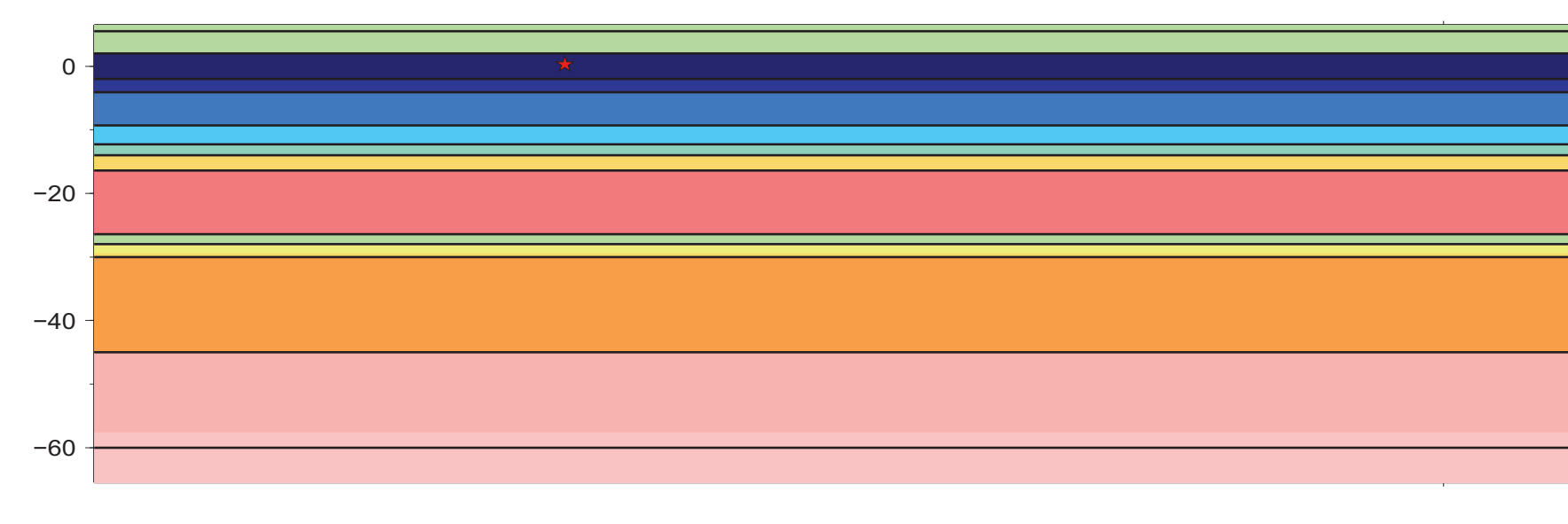




\subsection{2 - Raukumara Plain}

Arrivals with origins within the Raukumara Plain are largely unaffected by structures related to subduction tectonics and are considered the simplest amongst the data recorded.

\subsubsection{1 - Central Basin}

The central region of Raukumara Basin is defined by the geometry of the free-air gravity anomaly (Figure 3.3 ).

Arrivals from this region display a bulls-eye pattern of average velocities ranging from $\sim 3.0$ to $\sim 4.0 \mathrm{~km} / \mathrm{sec}$. This pattern is centred near the intersection of lines RAU07-09 and RAU07-07 (Figure 3.4a-g). Offsets associated with arrivals from the central basin range from $8-60 \mathrm{~km}$ and it is likely most arrivals from this region turn within forearc sedimentary and basement layers. The majority of phases identified from the central basin arrive within a narrow time band. This makes the distinction of discrete phases difficult with later arriving phases masked by the coda of the first arrival. Most phase interpretations are made from gathers constructed for shots from in-line profiles (RAU07-09 and RAU07-10).

For RAUK-02, arrivals from the central basin display apparent velocities of $\sim 5.4$ $\mathrm{km} / \mathrm{sec}$. Moving south along RAU07-09, phases displaying apparent velocities of $\sim 4.6 \mathrm{~km} / \mathrm{sec}, 3.0 \mathrm{~km} / \mathrm{sec}$ and $2.8 \mathrm{~km} / \mathrm{sec}$ are observed (Figure $3.5 \mathrm{a}$ ).

For Pakira and the same section of RAU07-09, a slightly different pattern of phase arrivals is observed (Figure 3.5b). Arrivals from the centre of RAU07-09 display apparent velocities of $6.2 \mathrm{~km} / \mathrm{sec}$. To the south, phases with apparent velocities of $5.2 \mathrm{~km} / \mathrm{sec}$ and $3.8-2.6 \mathrm{~km} / \mathrm{sec}$ are observed. Arrivals from the southern limit of RAU07-09 display an increase in apparent velocity to 3.5 $\mathrm{km} / \mathrm{sec}$ (Figure 3.5b). This may be due to a dip effect with subsurface stratigraphic layers shallowing toward the coast, or alternatively, the observed increase in velocity may represent rays sampling the Matakaoa Volcanic Group. 


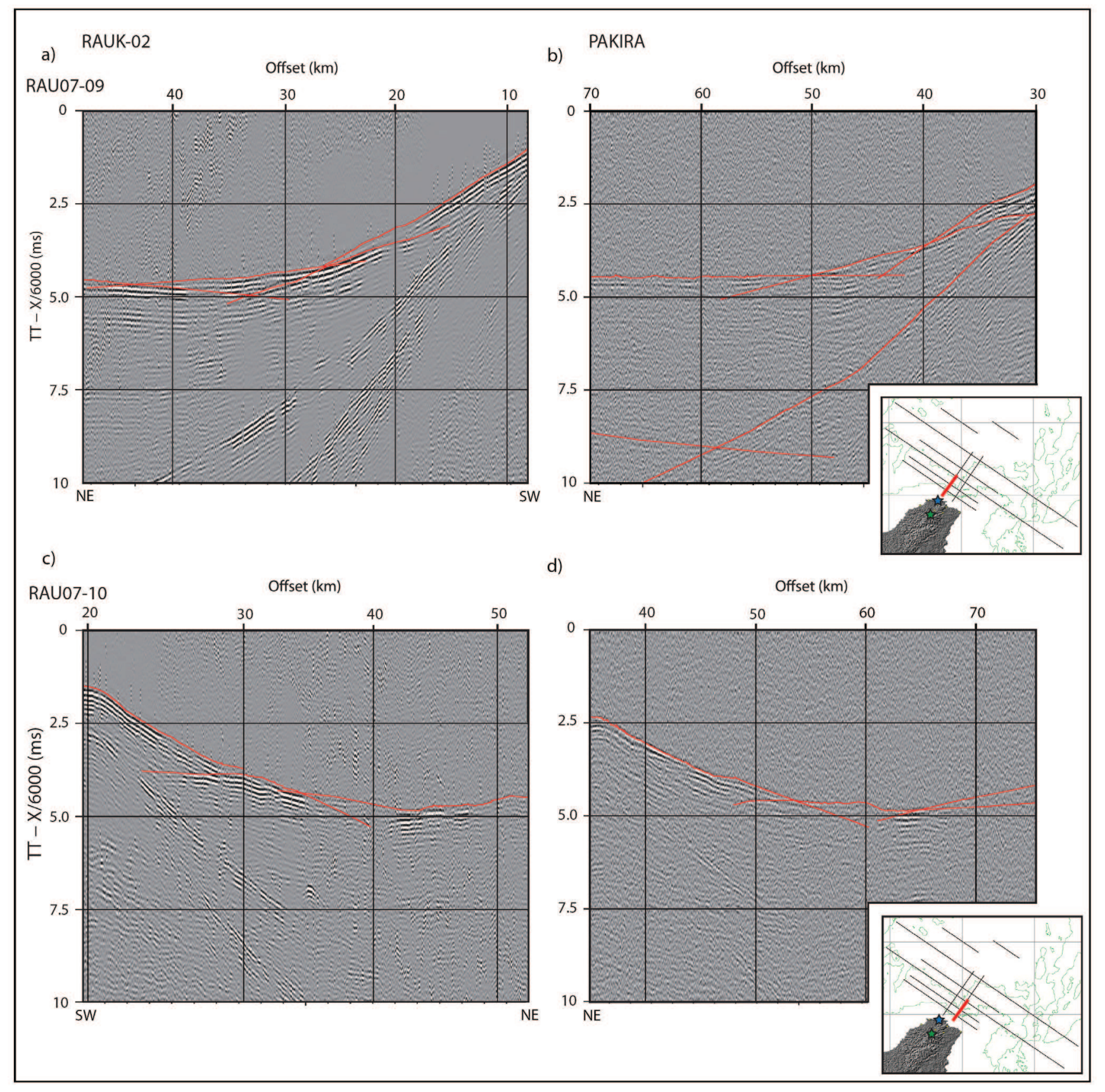

Figure 3.5 - Interpreted receiver-gathers for onshore-offshore data with shot points from the southern half of RAU07-09 (See insert) recorded at a) RAUK-02 (blue) and b) Pakira (green). c) As above but for data with shot points from the southern half of RAU07-10 (See insert) recorded at RAUK-02 and d) Pakira. Station positions are presented in Figure 3.1 and as stars in insert. Receiver-gathers are reduced to $6.0 \mathrm{~km} / \mathrm{sec}$ and interpreted arrivals are plotted in red. Traces are plotted with uniform spacing however offset markers are also plotted and provide a useful guide for observing variations in ray azimuth along receiver-gathers. Note the approximately constant number of traces plotting within each offset range along RAU07-09 (a-b) and the contrast with the trace-offset distribution along RAU07-10 (c-d). This difference arises as RAU07-09 is approximately in-line with both RAUK-02 and Pakira, with RAU07-10 more oblique (Figure 3.1). The number of shots within a given offset range is directly proportional to the angle between the ray-azimuth and the profile-orientation which explains why a larger number of shots are observed within lower offset ranges at the southern end of RAU07-10 (c). A gradual reduction in the number of shots within each offset range is observed to the northeast as the obliquity of the ray-azimuth relative to the profile orientation decreases. 


\subsubsection{2 - Northern Basin}

The northern region of Raukumara Basin contains all profile segments north of RAU07-05 which lie within the Raukumara Plain (Figure 3.3).

Arrivals from this region display average velocities which increase with offset from $4.0 \mathrm{~km} / \mathrm{sec}$ to $>6.0 \mathrm{~km} / \mathrm{sec}$ (Figures $3.4 \mathrm{a}-\mathrm{g}$ ). Apparent velocities range from $6.5 \mathrm{~km} / \mathrm{sec}$ to $>12.0 \mathrm{~km} / \mathrm{sec}$ (Mean $8.0 \mathrm{~km} / \mathrm{sec}$ ) and are thus likely influenced by variations in ray-azimuth and possibly 3-D structural effects. Offsets for shots within the northern basin are $>60 \mathrm{~km}$ and both average and apparent velocities suggest arrivals from this region turn within the mantle wedge.

A common feature on gathers constructed for shots from RAU07-01 and RAU07-02 (Figure 3.1) is the presence of a phase approximately 5 seconds after the first arrival. This phase displays apparent velocities from $5.0 \mathrm{~km} / \mathrm{sec}$ to $>9.0$ $\mathrm{km} / \mathrm{sec}$, a stronger signal and continuity across traces than observed for earlier arriving phases, and is interpreted as a refracted phase turning within forearc basement. 


\subsubsection{3 - Western Basin - Kermadec Ridge / Harve Trough}

Average velocities within the western basin (Figure 3.3) increase with offset from $4.0 \mathrm{~km} / \mathrm{sec}$ to $>6.0 \mathrm{~km} / \mathrm{sec}$ (Figures $4 \mathrm{a}-\mathrm{g}$ ). Apparent velocities ranging from $6.1-13.0 \mathrm{~km} / \mathrm{sec}$ are observed.

The boundary between the western Raukumara Basin and the Harve Trough is marked by a sharp gradient in the free-air gravity anomaly (Figure 3.3). Shots from the westernmost regions of RAU07-05 and RAU07-03 lie within the Harve Trough back-arc rift (Figure 3.3). Data from stations displaying sufficiently strong arrivals from RAU07-05 effectively record the transition from the forearc to the back-arc (Figure 3.6a-b).

Along RAU07-05 the western boundary of the Raukumara Plain is marked on the seabed by a normal fault with over $500 \mathrm{~m}$ vertical relief (Figure 2.3a). Whakatane Volcano is observed $\sim 20 \mathrm{~km}$ northwest from this fault as a $>1 \mathrm{~km}$ reduction in water depth. These bathymetric observations are correlated with abrupt variations in travel-time and are considered to dominate the local signal recorded by receiver-gathers (Figure 3.6a-b)

This interpretation is supported by receiver-gathers constructed for the western regions of RAU07-03. The forearc to backarc transition is less apparent on both receiver-gathers and bathymetric maps which display a distinct absence of arc volcanoes in the vicinity of RAU07-03 (Figure 3.10). 

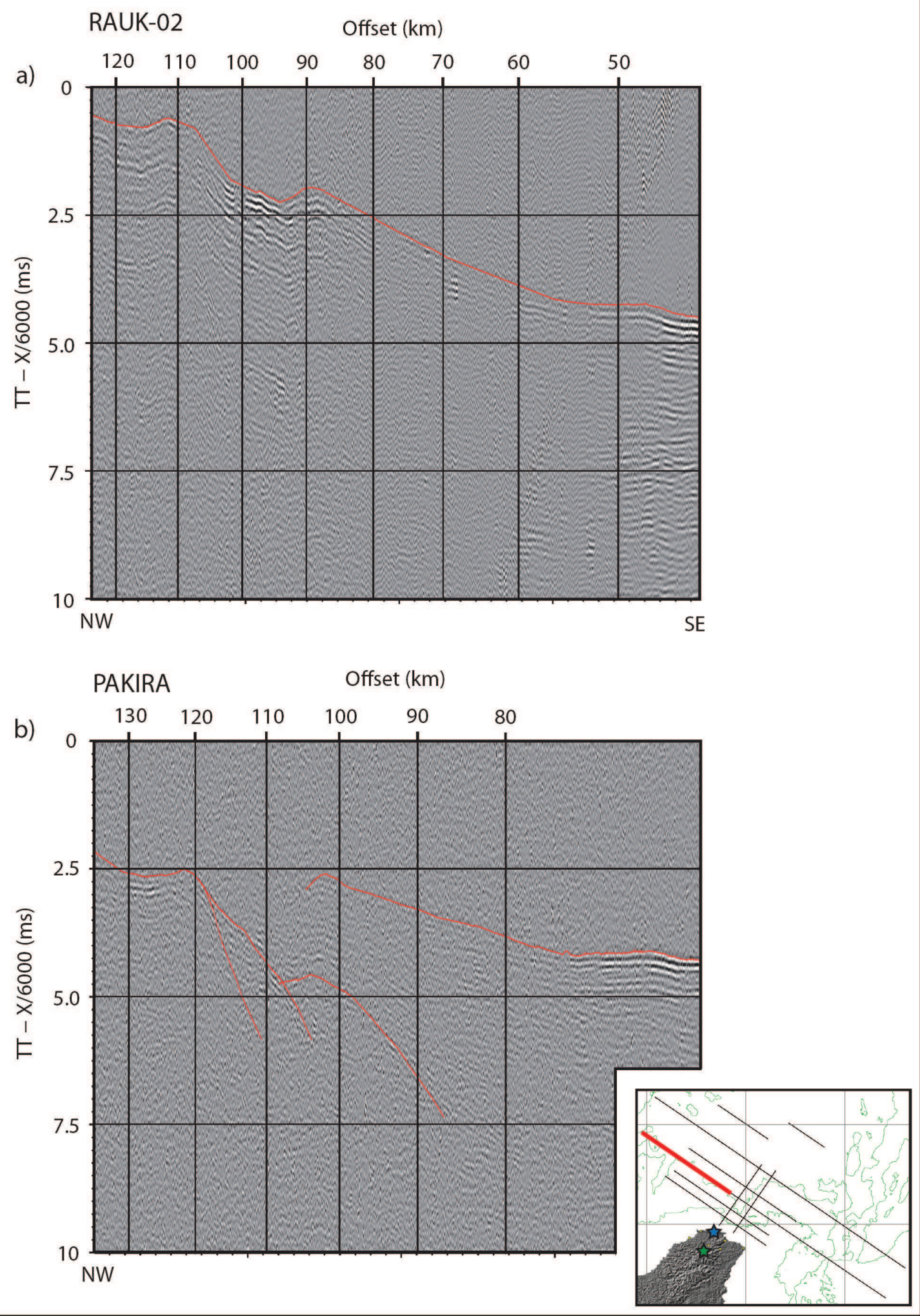

Figure 3.6 - Interpreted receiver-gathers for onshore-offshore data with shot points from the north-western $100 \mathrm{~km}$ of RAU07-05 (See insert) recorded at a) RAUK-02 (blue) and b) Pakira (green). Station positions are presented in Figure 3.1 and as stars in insert. Receiver-gathers are reduced to $6.0 \mathrm{~km} / \mathrm{sec}$ with interpreted arrivals plotted in red. Note the abrupt increase then decrease in travel-time moving northwest along both gathers. These travel-time variations are spatially correlated with a normal fault marking the eastern boundary of the Harve Trough, and Whakatane Volcano within the Kermadec Arc. 


\subsection{3 - Trench-slope - Subducting slab}

RAU07-05 and RAU07-03 extend $>100 \mathrm{~km}$ southeast of the East Cape Ridge (Figures 3.1 and 3.3). Arrivals originating from this region are important as they are well positioned to sample the subducting slab.

Apparent velocities range from 8.4-11.0 km/sec (RAU07-05) and 6.5-11.0 $\mathrm{km} / \mathrm{sec}$ (RAU07-03). The azimuth of rays potentially sampling the subducting slab range from almost dip parallel orientations $\left(293^{\circ}\right)$ to azimuths closer to the strike of subduction $\left(235^{\circ}\right)$ (Figure 3.1). The effects of increasing obliquity between ray-azimuth and profile-orientation are gradual and localised regions displaying apparent velocities $>10 \mathrm{~km} / \mathrm{sec}$ are likely caused by variations in bathymetry, the thickness of the trench-slope and/or the topography and dip of the subducting slab. In general, the fastest apparent velocities are observed in the southeast $(>9.6 \mathrm{~km} / \mathrm{sec})$ and, where sufficiently long segments of arrivals could be identified, average apparent velocities for the south eastern $100 \mathrm{~km}$ 's of RAU07-05 and RAU07-03 are approximately 8.4-8.9 km/sec and 8.2-8.9 km/sec respectively. For regional estimates, the influence of 3-D effects and varying raypath obliquity on apparent velocities is reiterated and the velocities presented here will be systematically higher than those within the upper mantle of the subducting slab.

Typically only one phase is interpreted from arrivals east of East Cape Ridge, however it was often possible to track this phase from regions east of the trench, over $150 \mathrm{~km}$, to locations beneath the East Cape Ridge and/or the central Raukumara Basin (Figure 3.7). On receiver-gathers this phase is hummocky and it is not uncommon for arrivals from the extremities of RAU07-05 and RAU0703 to display more coherent data than arrivals with lower offsets originating adjacent to East Cape Ridge. 


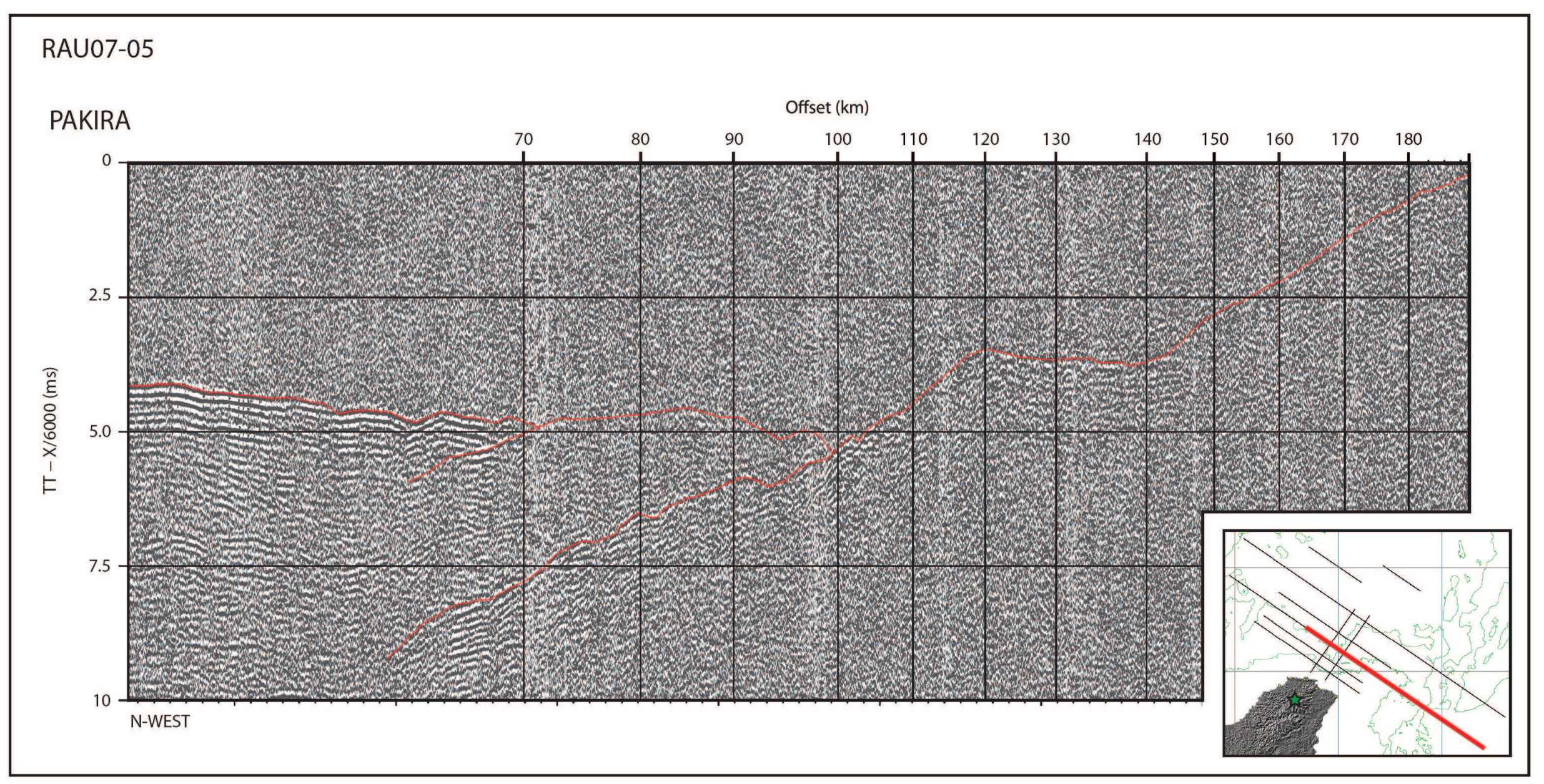

Figure 3.7 - Interpreted receiver-gather for onshore-offshore data originating from the eastern $220 \mathrm{~km}$ of RAU07-05 (See Insert) recorded at Pakira (green). Data is reduced to $6.0 \mathrm{~km} / \mathrm{sec}$ and displayed as a variable area plot. Interpreted phases are plotted in Red. The phase extending from the top-right to bottom-left is interpreted as a refraction through the subducting slab. Data proximal to (In figure, 75-100 km) and east of East Cape Ridge contains a weaker signal which makes the display of data from this region difficult. Station positions are presented in Figure 3.1 and as stars in insert. 


\subsection{4 - East Cape Ridge}

Average velocities calculated for arrivals with origins within the East Cape Ridge region range from $4.25-5.0 \mathrm{~km} / \mathrm{sec}$. These velocities are slower than those which would be expected if the offset-velocity relationship observed in the central basin were to continue throughout this region (Figure 3.4a-g). Anomalously low average velocities for arrivals which sample the East Cape Ridge is an observation consistent across most stations and is one of the most compelling features of average velocity plots.

At the East Cape Ridge phases interpreted from the central basin are abruptly reduced in amplitude (Figure 3.8a-b). This observation is considered consistent with RAU07 seismic reflection data which displays an internally chaotic seismic structure and the absence of internal reflectors within the East Cape Ridge (Figures 2.3a and 2.4a). The rough seafloor in this region may cause a higher proportion of seismic energy to be scattered away although it is also possible the material which makes up the ridge has a comparatively high degree of seismic attenuation.

Later arriving phases from the eastern limits of RAU07-07, RAU07-06 and RAU07-04 display a geometry consistent with reflection events and these arrivals may represent reflections from the top of the subducting slab (Figure 3.8a-b). 


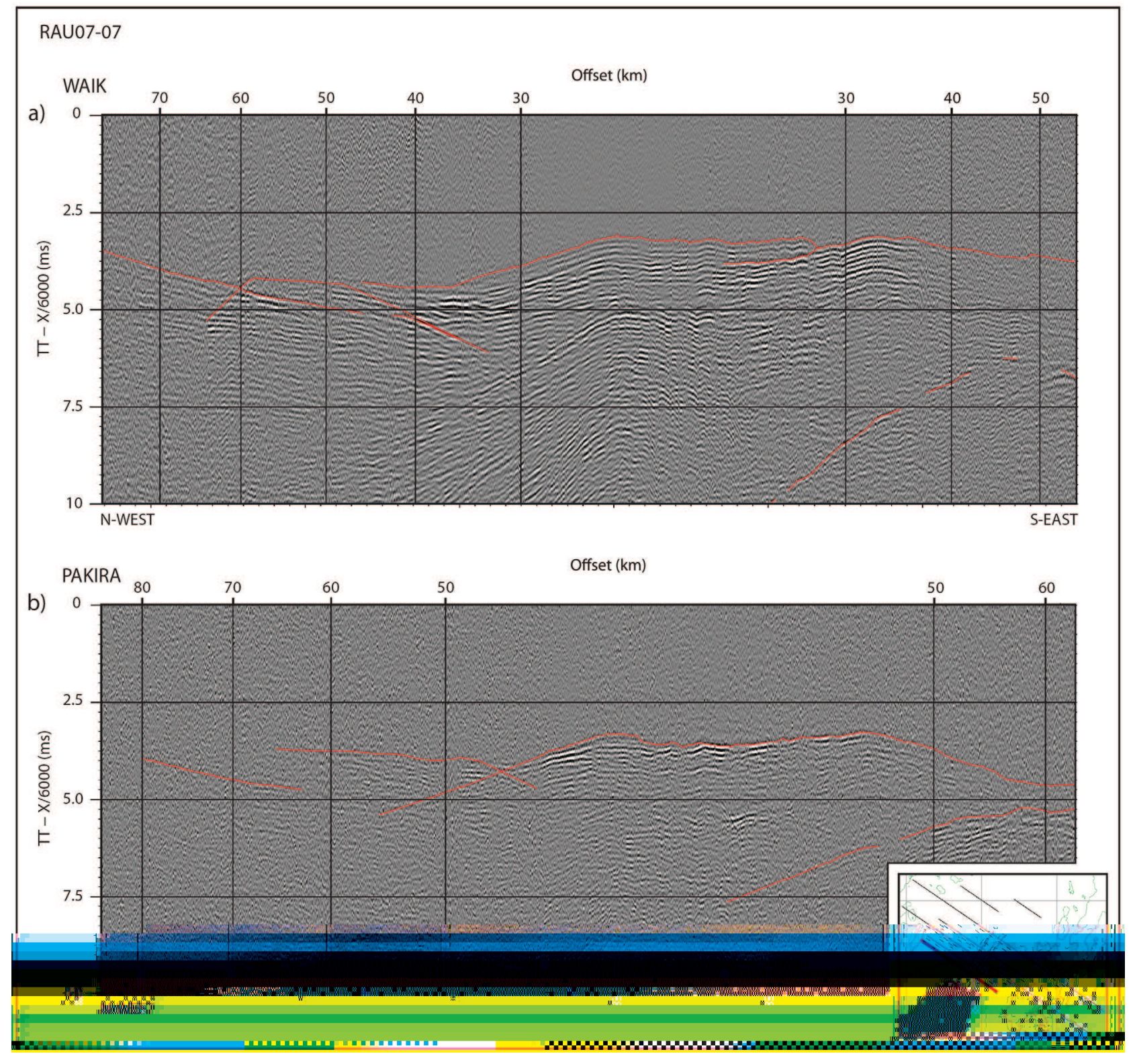

Figure 3.8 - Interpreted receiver-gathers for onshore-offshore data from RAU07-07 (See Insert) recorded at a) WAIK (yellow) and b) Pakira (green). Receiver-gathers are reduced to $6.0 \mathrm{~km} / \mathrm{sec}$ with interpreted arrivals plotted in red. Note the reduction in the amplitude and coherency of arrivals in the southeast where shots are positioned above the East Cape Ridge. Also note the later arriving phase observed in the southeast on both gathers which is interpreted as a reflection from the top of the subducting slab. Station positions are presented in Figure 3.1and as stars in insert. 


\section{4 - Velocity Modelling}

The primary method by which onshore-offshore data are analysed is through the construction of a 3-D velocity forward model. The model produced in this thesis encompasses $32,000 \mathrm{~km}^{2}$ of the northern Hikurangi subduction margin and is developed combining tools within Seisware and FMTOMO with code developed in this thesis to generate the forward model and analyse model results.

In addition to velocity forward modelling, several experiments involving tomographic inversion were conducted throughout the analyses of these data. Initial inversions consisted of simple (3-4 layer) starting models and, while firstorder structures such as the Raukumara sedimentary basin and the East Cape Ridge were broadly resolved, the inversion problem was underdetermined due to the limited azimuthal-coverage of data.

Multilayer velocity inversions require a priori information concerning the phase of observed travel-times to enable the specification of a precise ray-path through the model region. The delineation of phase information from apparent velocities is complicated in this study due to the influence of variations in ray azimuth along receiver gathers. Velocity forward modelling is a viable alternative means of determining phase identity and the final velocity inversion is a complex multilayer inversion in which a 3-D velocity forward model is used to resolve phase identity and then incorporated as the starting model.

The same ray-coverage limitations which rendered the initial inversion experiments as underdetermined problems persist in this final tomographic inversion. Within FMTOMO it is not possible to restrict the inversion to regions unconstrained by other data (e.g. OBS/H profiles) and thus preserve incorporated constraints. Without this ability, it is difficult to produce meaningful results from tomographic inversion alone and for this reason, the modelling of data acquired in this thesis is focussed on velocity forward modelling.

Further detail and the results of inversion experiments are provided in Appendix Three. 


\section{5 - Forward Modelling}

Forward modelling allows specific assumptions to be made and a clearly defined modelling strategy to be developed, which in part, compensates for the limited azimuthal coverage of data. Moreover, the additional control associated with forward modelling allows constraints from MCS reflection data, offshore $\mathrm{OBS} / \mathrm{H}$ seismic profiling and earthquake tomography to be incorporated and preserved into forward models.

\subsection{1 - Forward Modelling Technique}

Controlled-source seismic reflection and refraction data are predominantly acquired along 2-D profiles. Software developed for the forward modelling of seismic data is thus almost exclusively restricted to 2-D and 3-D forward modelling relies on code developed for the forward step within tomographic inversion algorithms. Most tomographic inversions are initiated with simple starting models comprised of a small number of layers $(<5)$, within which 1-D velocity gradients are present. Simple script based methods of constructing the model region accompany inversion algorithms and these techniques are poorly suited for the development of complex 3-D forward models.

In this thesis a simple methodology is developed which allows complex forward models to be constructed in an interactive manner, tested using modern 3-D raytracing algorithms and visually assessed by analyses of the spatial distribution of travel-time residuals. The degree to which model regions are constrained by seismic data is determined through analyses of the spatial distribution of raypaths. 
Velocity forward models are created within software developed for the interpretation of MCS reflection data (Seisware). A grid of hypothetical (or real if present) seismic profiles is created and the forward model is constructed interactively by adjusting the position of model interfaces along each profile in the grid (Figure 3.9).

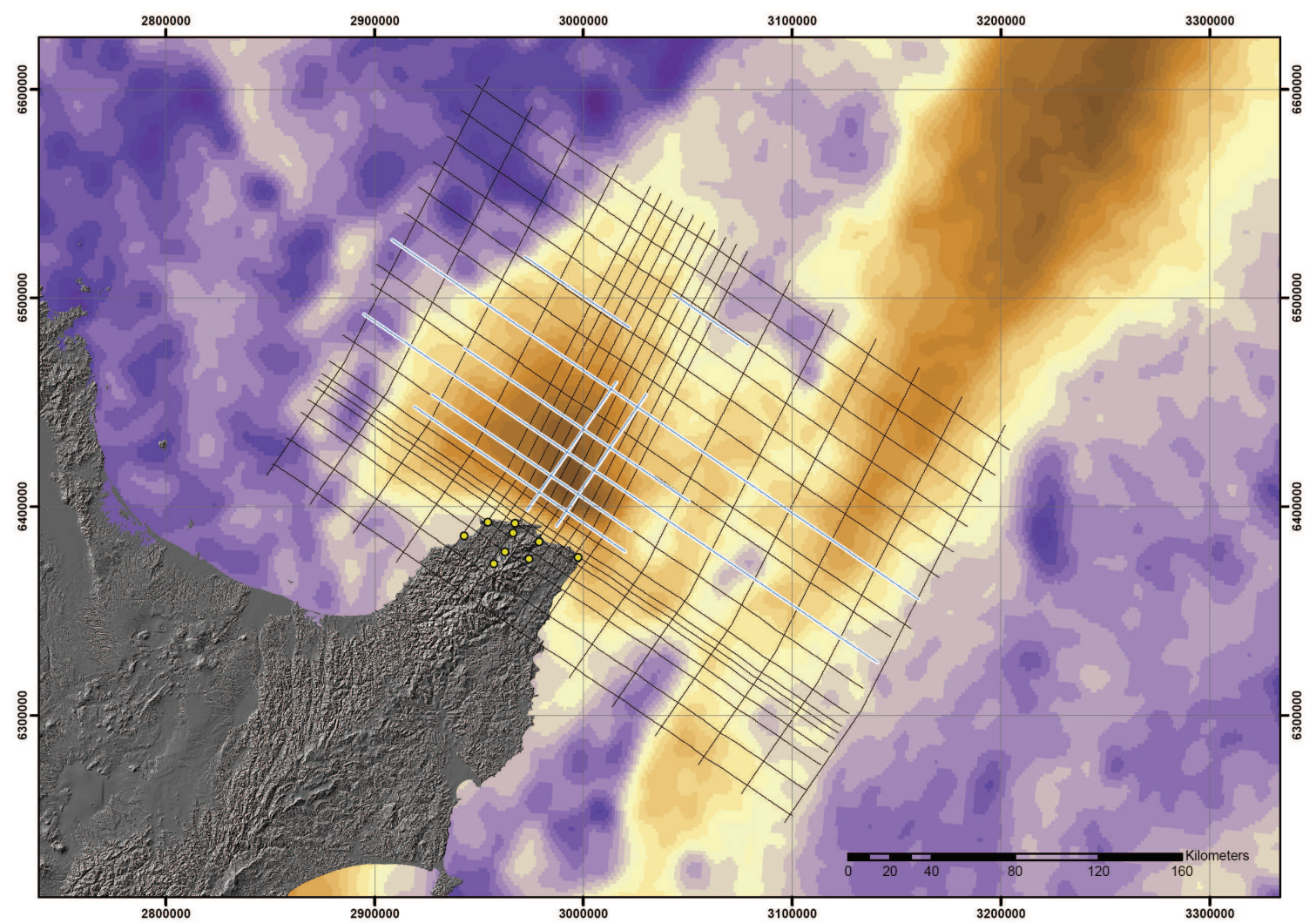

Figure 3.9 - Grid constructed within Seisware for the manipulation of interface positions. This grid was constructed from hypothetical seismic profiles (Black) and depth converted RAU07 MCS reflection data (Blue). Yellow dots onshore denote station locations. Background colour represents the free-air gravity anomaly at 10 mgal intervals. The darkest browns are negative (150 mgal) anomalies.

Grids of interface positions are exported from Seisware and used by several scripts to create interface and velocity grids in the format required by FMTOMO. Within FMTOMO, the grid3dg and $f m 3 d$ utilities are combined to re-create the model region and calculate synthetic travel-times [Rawlinson \& Sambridge, 2005; de Kool et al., 2006]. 
Forward models are analysed by plotting observed and synthetic travel-times for each receiver-gather on a station by station basis (Figures A2.4 and A4.1). This analysis provides the spatial information necessary to adjust the forward model and is supplemented by the construction of cross-sections displaying the interactions between modelled structures and raypaths (Figure 3.14). Model resolution is assessed by exporting raypath geometries from FMTOMO and calculating ray density within each region of the model (Figure A4.2).

A comprehensive discussion of the forward modelling technique developed in this thesis and the scripts required to perform the tasks outline above is presented in Appendix Two.

\subsection{2 - Forward Modelling Strategy}

The onshore-offshore data acquired in this study are spatially incomplete. Arrivals from offshore air-gun shots were recoded exclusively onshore and this dataset is characterised by unidirectional shooting and the absence of reversed profiles. To overcome limitations in ray-coverage this forward model is created following a carefully designed sequence of logical steps, in which well constrained regions are analysed first and used to calibrate specific parameters of the model.

The assumption is made that lateral velocity variations within layers are negligible. This assumption is inherent with the forward modelling strategy and the extrapolation of velocities resolved in well constrained regions throughout the model. Furthermore, this assumption is implicit within the technique of forward modelling developed in this thesis. Layer velocity grids are constructed through linear interpolation between layer bounding interfaces and it is not possible to introduce lateral variations in velocity independent of variations in layer geometry. 
The forward modelling strategy applied in this thesis is as follows:

1 - Profile RAU07-09 is in-line with four onshore stations and is the most densely sampled profile acquired. These data are used to constrain an initial 2-D forward model and calibrate model parameters independent of structural and azimuthal 3-D effects. This model is constructed incorporating a 1-D velocity constraint obtained at the point of intersection between RAU07-09 and RAU0705 , which is constrained by a coincident $\mathrm{OBS} / \mathrm{H}$ profile [Scherwath et al., submitted manuscript].

2 - Building on the 2-D model resolved above, initial 3-D models include shots from the cross-line profile RAU07-05 (constrained by the results OBS/H forward modelling). Shots are progressively incorporated west, then east of the intersection with RAU07-09 and at this stage, arrivals are limited to those with origins within the Raukumara Plain.

3 - Structural observations from depth converted RAU07 MCS reflection data are integrated with velocities resolved along RAU07-05 and RAU07-09 to model arrivals originating within the Raukumara Plain. Initial focus is on the in-line profile RAU07-10, followed by cross-line profiles progressively offset from the Raukumara Peninsula. Arrivals from the Raukumara Plain are less complicated than those originating east of Raukumara Basin and place further constraints on the near shore/onshore velocity structure of the Raukumara Peninsula.

4 - Refracted arrivals from east of East Cape Ridge are first modelled in the east where the top of the slab is well constrained and overlain by a thinner sedimentary section. RAU07-05 is considered first in recognition of the additional constraints imposed by the OBS/H profile and followed by RAU07-03 adopting the same approach.

5 - The East Cape Ridge region is poorly constrained by both OBS/H and MCS data and is thus considered last. In modelling these arrivals, the majority of travel-time residuals are reconciled beneath the shot-points as the velocity structure beneath the Raukumara Peninsula is by this stage, comparatively well constrained. 


\subsection{3 - Constraints incorporated into forward modelling}

The incorporation of constraining datasets places limitations on the methods and regions in which travel-time residuals can be reconciled and is a key component of the modelling strategy outlined above. Constraints incorporated into this forward model (Figure 3.10) come from the interpretation of offshore seismic reflection data (Chapter Two), onshore 3-D Vp earthquake tomography [Reyners et al., 1999] and the offshore acquisition of an $\mathrm{OBS} / \mathrm{H}$ wide-angle seismic reflection and refraction profile along RAU07-05 [Scherwath et al., submitted manuscript].

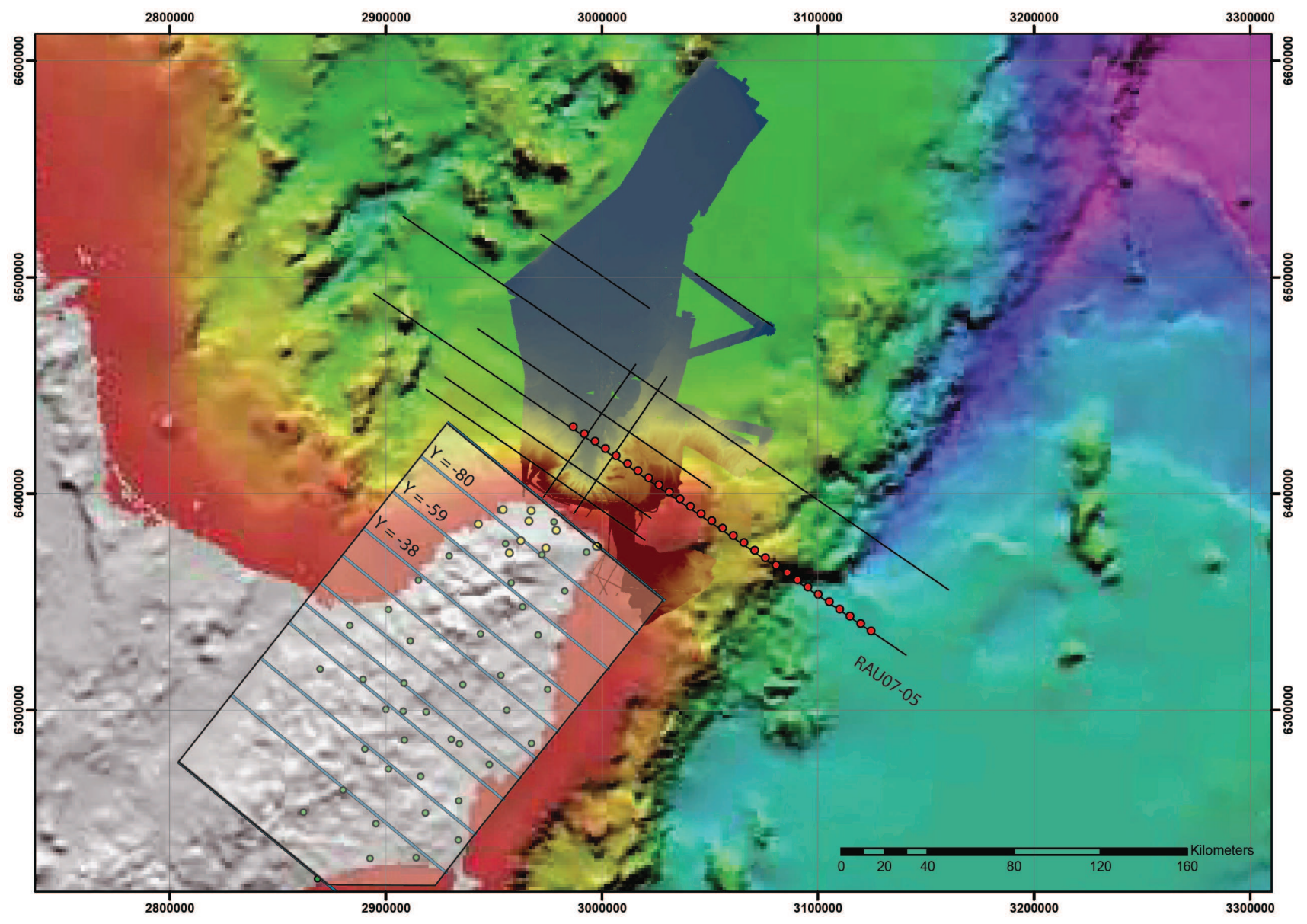

Figure 3.10 - Bathymetric map illustrating the constraints incorporated into velocity forward models. Black lines denote RAU07 seismic reflection profiles. These profiles were depth converted (Fugro, 2008) and included within the hypothetical grid of seismic lines (Figure 3.9) used to construct the forward model. RAU07-05 (labelled) was also the location of a coincidental $O B S / H$ wide-angle seismic reflection and refraction profile and the red dots display the locations of ocean bottom instrumentation (Scherwath et al., submitted manuscript). Onshore velocity structure is constrained by Vp velocity profiles (Blue) calculated from 3-D Vp earthquake tomography (Reyners et al., 1999). These profiles are slices from a 3-D grid (faded box) extending to $80 \mathrm{~km}$ depth (Figure 3.11). Green circles illustrate the station distribution used in generating this grid. Background colours represent two bathymetric datasets supplied courtesy of NIWA. 


\subsubsection{Onshore velocity structure}

From data acquired during a five month deployment of 36 digital seismometers around the Raukumara Peninsula, Reyners et al. [1999] perform a simultaneous inversion for hypocenters, 3-D $V p$ and $V p / V s$ ratios down to $80 \mathrm{~km}$ depth. The three northern profiles traverse the Raukumara Peninsula close to the seismometers deployed in this study and provide initial constraints on the velocity structure beneath on-land stations (Figure 3.11). Profile $Y=-100$ is excluded as it resides on the edge of the onshore station distribution and is poorly resolved [M.Reyners, pers comm. 2009].

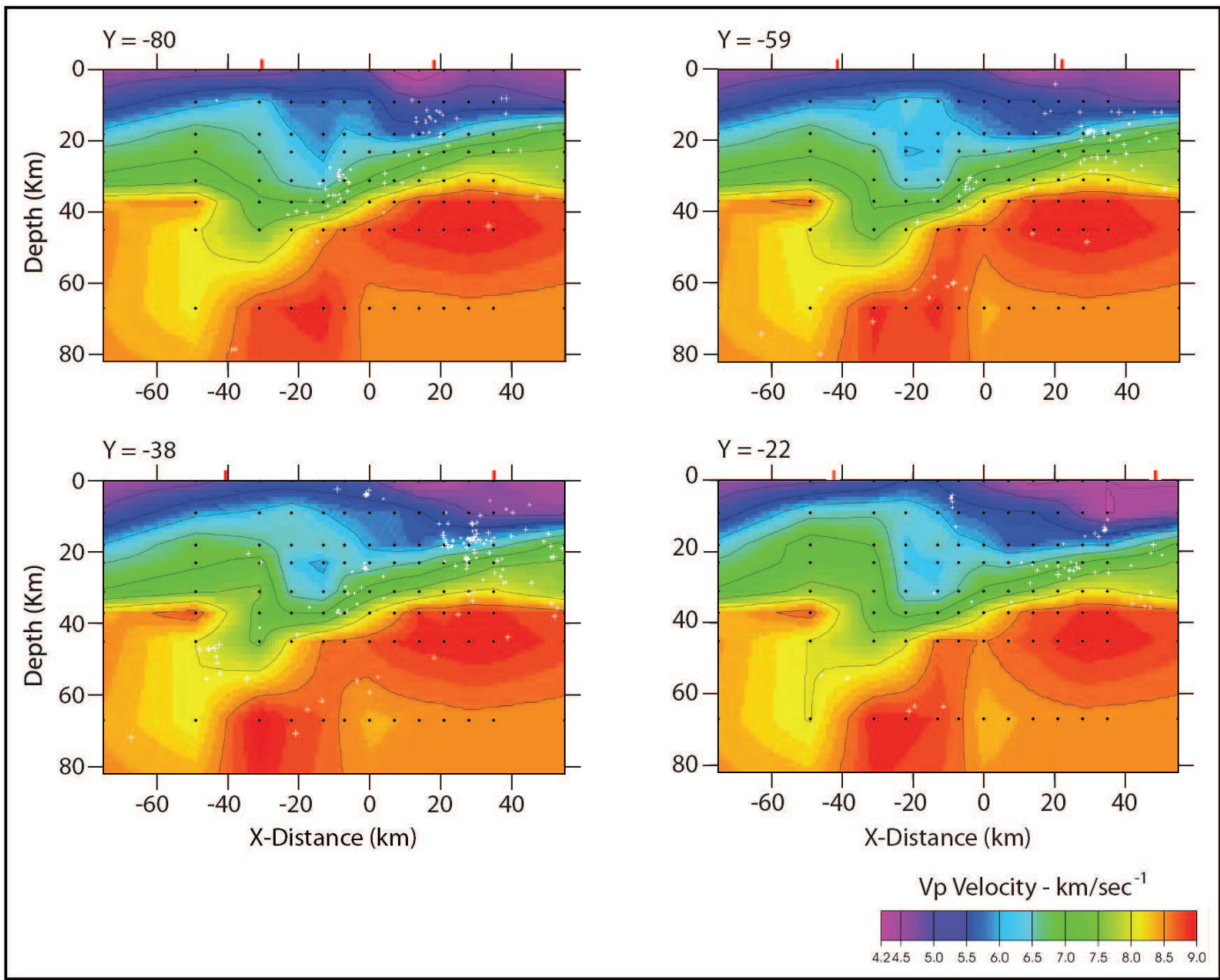

Figure 3.11 - Dip-parallel cross-sections for the four northern slices of the 3-D Vp model of Reyners et al. [1999]. Profile locations displayed in Figure 3.10. Inversion nodes are shown by black dots with relocated hypocenters of all events denoted by white pluses. Events are extrapolated along strike onto the nearest profile and are not all used in the inversion [Reyners et al., 1999]. Red bar gives the position of the coastline on each profile. 


\subsubsection{2 - Velocity structure along RAU07-05}

The velocity structure along RAU07-05 is constrained by a coincident OBS/H wide-angle seismic reflection and refraction profile collected in early 2007 onboard the $R V$ Sonne (MANGO P11; cruise SO192). OBS/H instrumentation (29 deployed) extends along RAU07-05 from 40km east of the Hikurangi trench, to $8 \mathrm{~km}$ west of RAU07-09 (Figures 3.10 and 3.12). The airgun source was a 64 litre (3905 cu in) G-gun cluster with shots nominally spaced at $150 \mathrm{~m}$ encompassing the full length of RAU07-05 [Scherwath et al., submitted manuscript]. This model is constructed using the ray-tracing and travel-time inversion method of Zelt and Smith [1992] and is structurally constrained by RAU07-05 seismic reflection data [Scherwath et al., submitted manuscript].

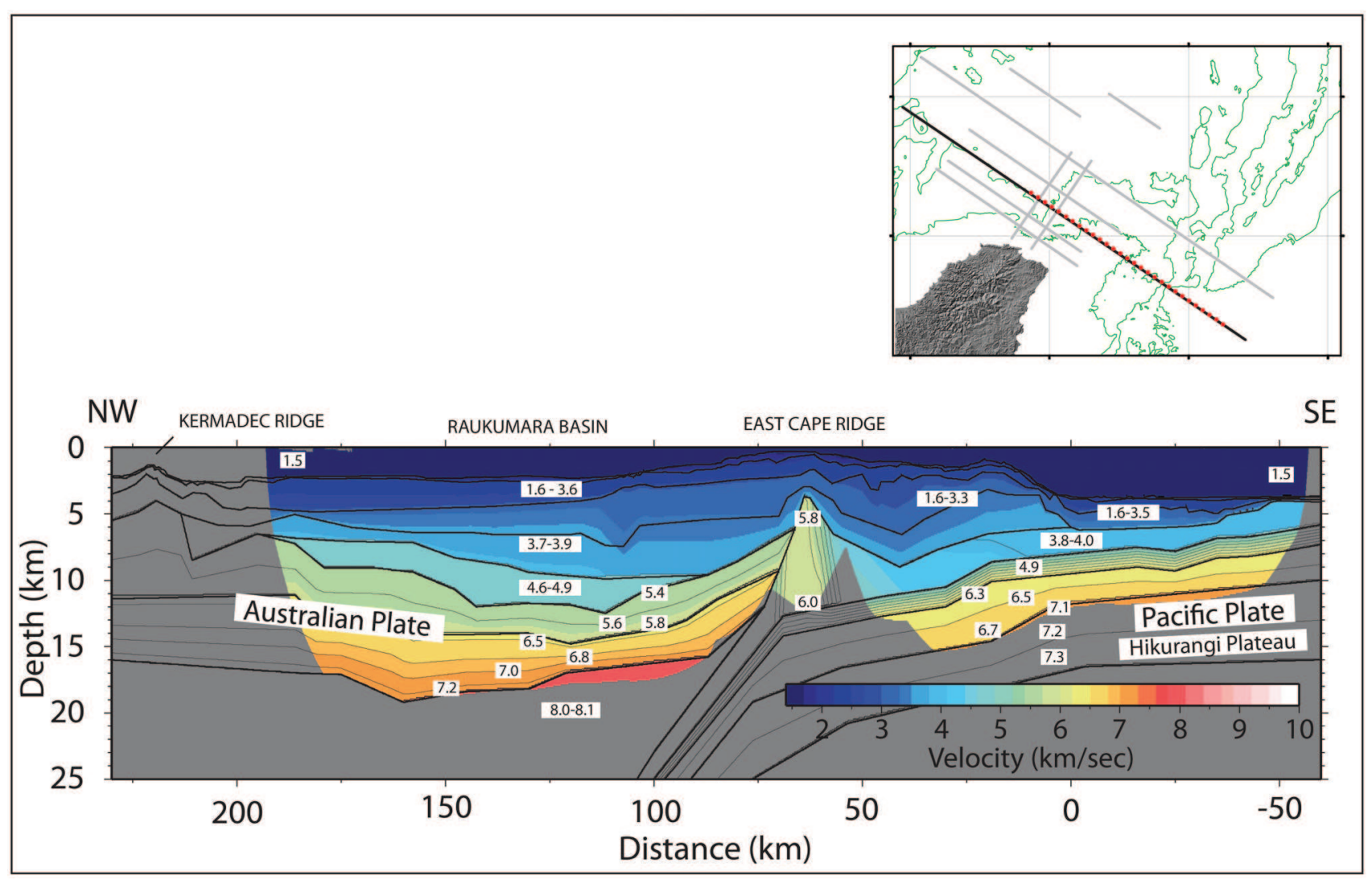

Figure 3.12- Final Vp velocity forward model for MANGO P11 (along RAU07-05), derived by raytracing wide-angle seismic reflection and refraction data recorded by $29 \mathrm{OBS} / \mathrm{H}$ instruments (Modified from Scherwath et al., submitted manuscript). Grey areas represent regions unresolved by seismic data. The geometry of layers in these areas is constrained by MCS reflection data (RAU07-05, Sutherland et al. [2009]) and gravity modelling. Insert displays profile geometry and positions of $O B S / H$ instrumentation (red dots). This velocity model has been re-plotted using a colour scale consistent with that used to display the results generated in this study (Courtesy of Martin Scherwath, IFM GEOMAR). 


\subsubsection{3 - Offshore basin structure}

The broad geometry and distribution of seismic-stratigraphic sequences within Raukumara Basin is constrained by observations from MCS reflection data (Chapter 2). Depth converted RAU07 data place constraints on the seismic structure directly beneath offshore shot-points and are included within the grid of hypothetical profiles used to manipulate the model region (Figure 3.9). Depth converted sequence boundaries (Section 2.4) are combined with velocities modelled in 2-D along RAU07-09 and RAU07-05 (OBS/H profile) to define the initial 3-D seismic structure of the forward model.

\subsection{4 - Trade offs inherent with velocity forward modelling}

The primary objective of velocity modelling is to minimise residual travel-times. This can be achieved by adjusting interval velocities and/or the geometry of interfaces either within discrete regions, or along the entire length of the raypath. The multitude of ways in which a residual travel-time can be reconciled introduces non-uniqueness into model results.

The degree of uncertainty introduced due to trade-off between interval velocities and interface geometry, and trade-offs between discrete regions along the raypath is highest where data are spatially incomplete, as is the case in this study. This uncertainty heightens the importance of both constraining datasets and the careful development of a strategy to guide forward modelling.

Complete onshore-offshore experiments often include $\mathrm{OBS} / \mathrm{H}$ data and land based refraction profiles. These additional data are acquired to generate reversed profiles, increase the azimuthal coverage of data and ultimately minimise the effects of the trade-offs discussed above. 


\section{6 - Results}
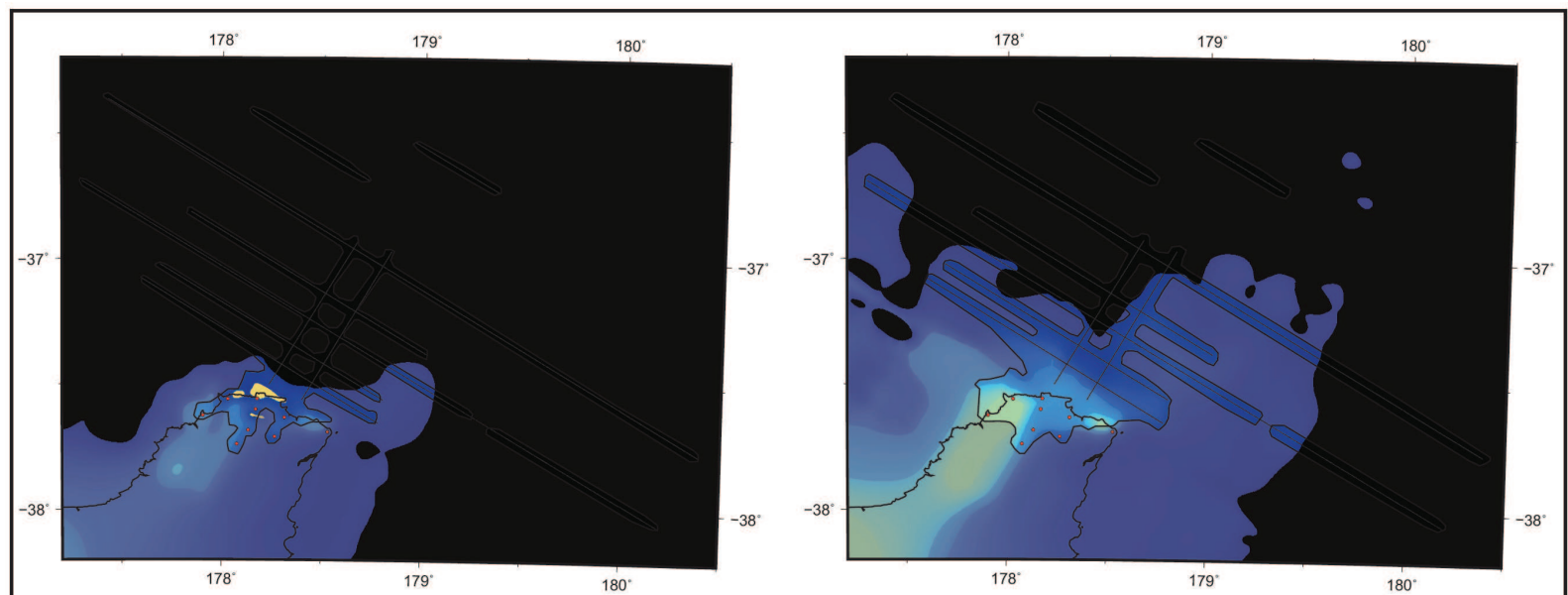

$\mathrm{DEPTH}=0.5 \mathrm{~km}$

$179^{\circ}$

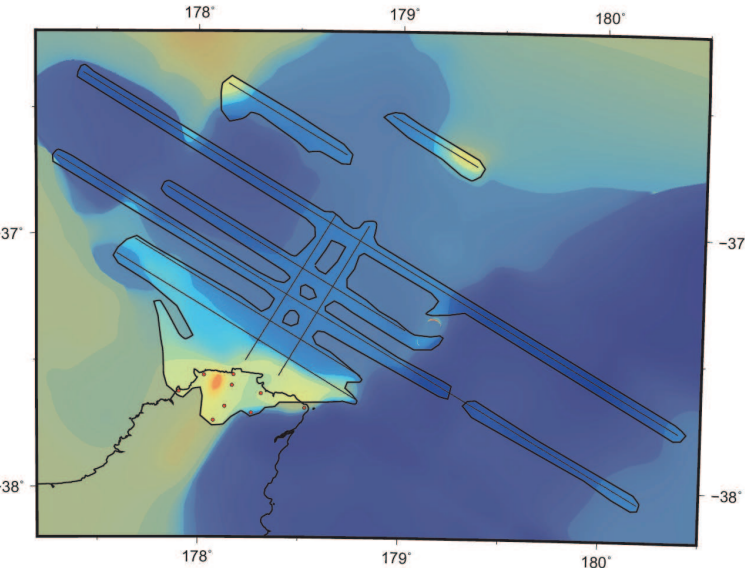

$\mathrm{DEPTH}=5.0 \mathrm{~km}$

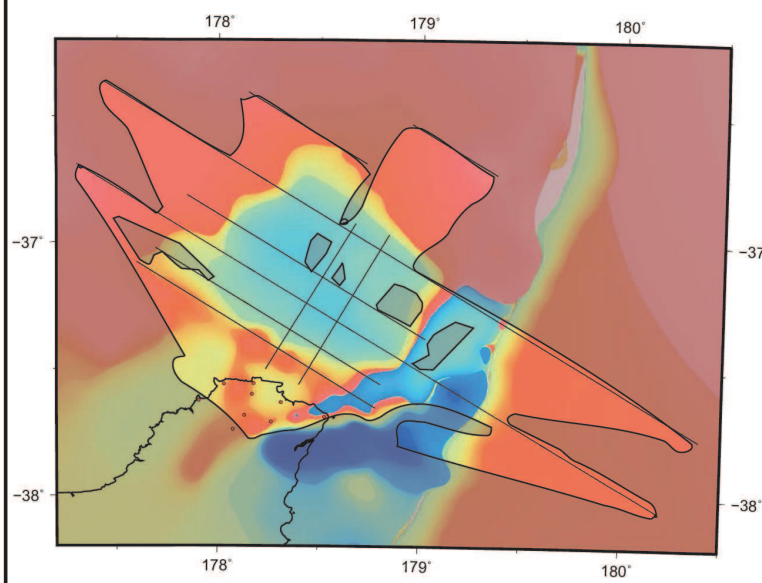

$\mathrm{DEPTH}=10.0 \mathrm{~km}$

\section{$\mathrm{DEPTH}=2.0 \mathrm{~km}$}

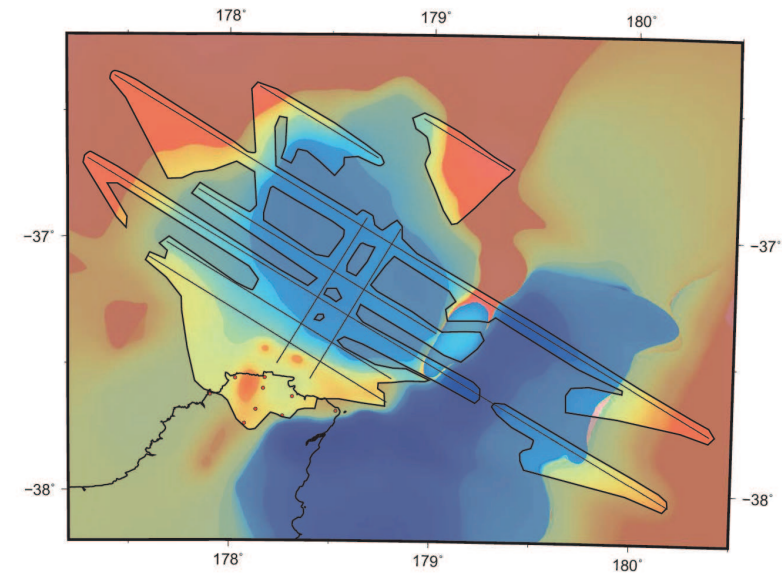

$\mathrm{DEPTH}=7.5 \mathrm{~km}$

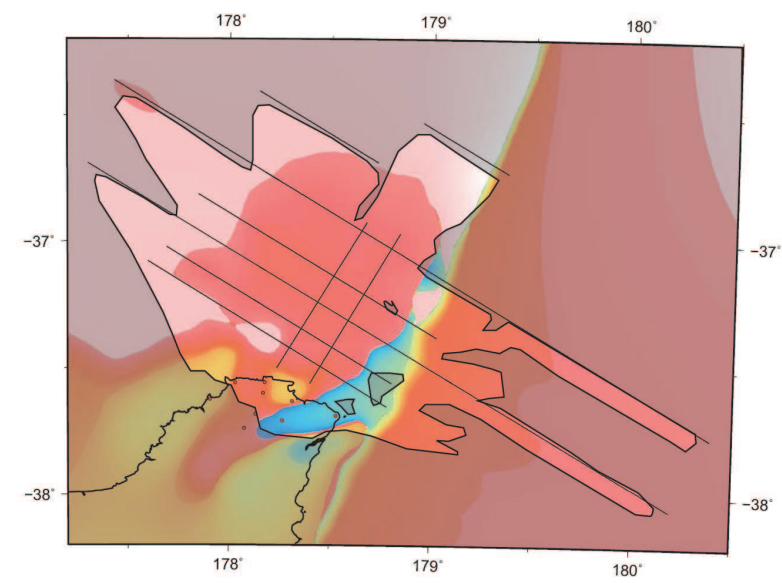

$\mathrm{DEPTH}=15.0 \mathrm{~km}$

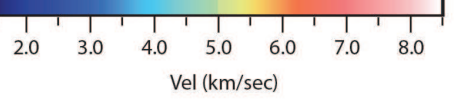

Figure 3.13 - Depth slices (as labelled) displaying the distribution of P-wave velocities within the final forward model. Darker areas represent regions not sampled by seismic data (Figure A4.2.2). Black lines offshore display RAU07 reflection profiles and the source of interpreted arrivals. Coastline of the Raukumara Peninsula displayed in Black. Note the prevalence of low velocities in the East Cape Ridge region.

Continued overleaf. 

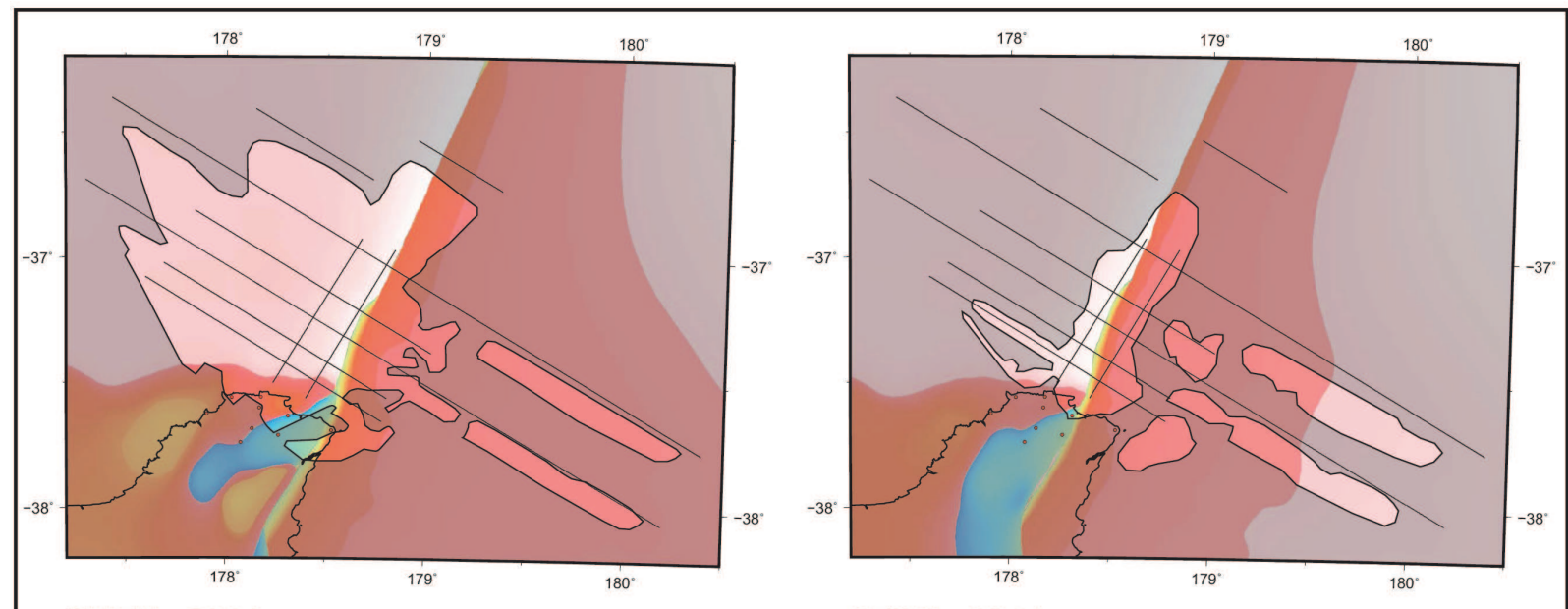

DEPTH $=20.0 \mathrm{~km}$

DEPTH $=25.0 \mathrm{~km}$
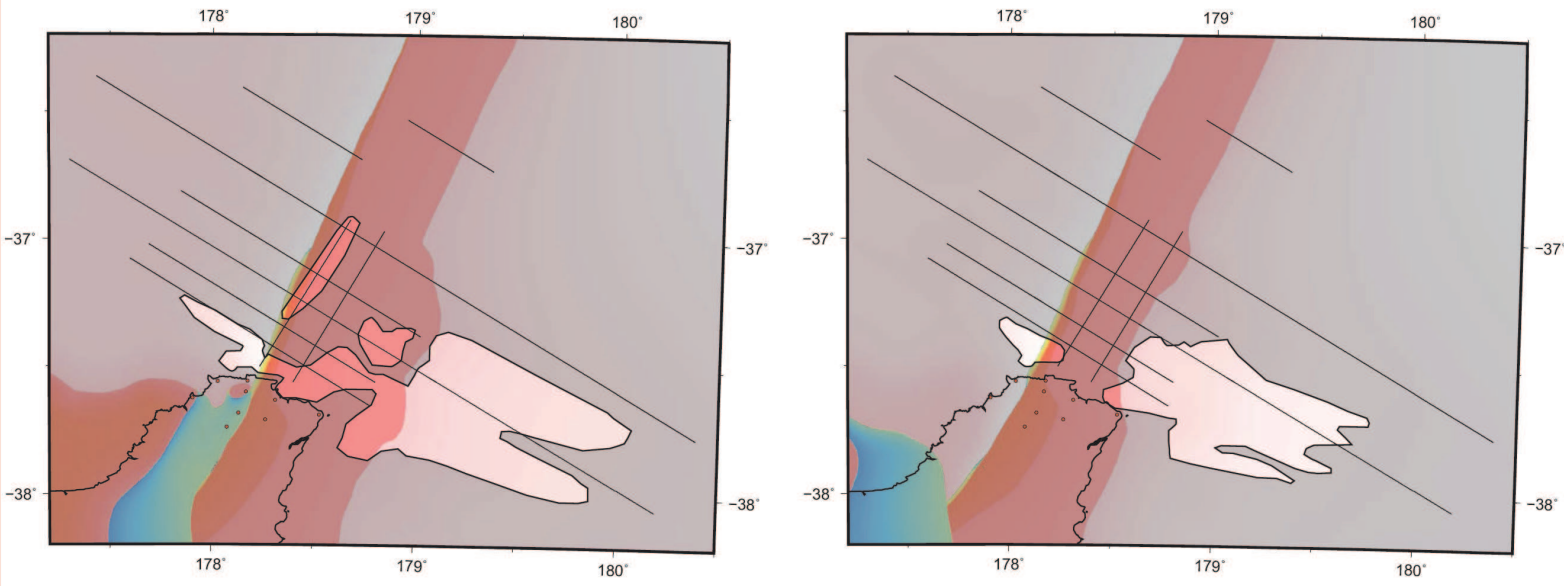

DEPTH $=30.0 \mathrm{~km}$

$\mathrm{DEPTH}=35.0 \mathrm{~km}$

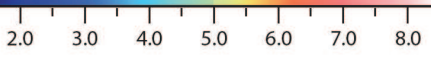

Vel $(\mathrm{km} / \mathrm{sec})$

Figure 3.13 - Continued

Figure 3.14 (Overleaf) - Cross-sections along profiles 1 - 11 displaying the distribution of Pwave velocities within the final forward model. Also plotted are the locations of shot points (blue triangles), onshore receivers (red stars) and the raypaths for in-plane phases calculated along each profile. Masked areas illustrate regions not sampled by seismic data (Figures A4.2.1). Profile positions (Black) displayed in insert in conjunction with RAU07 seismic reflection profiles (White). 

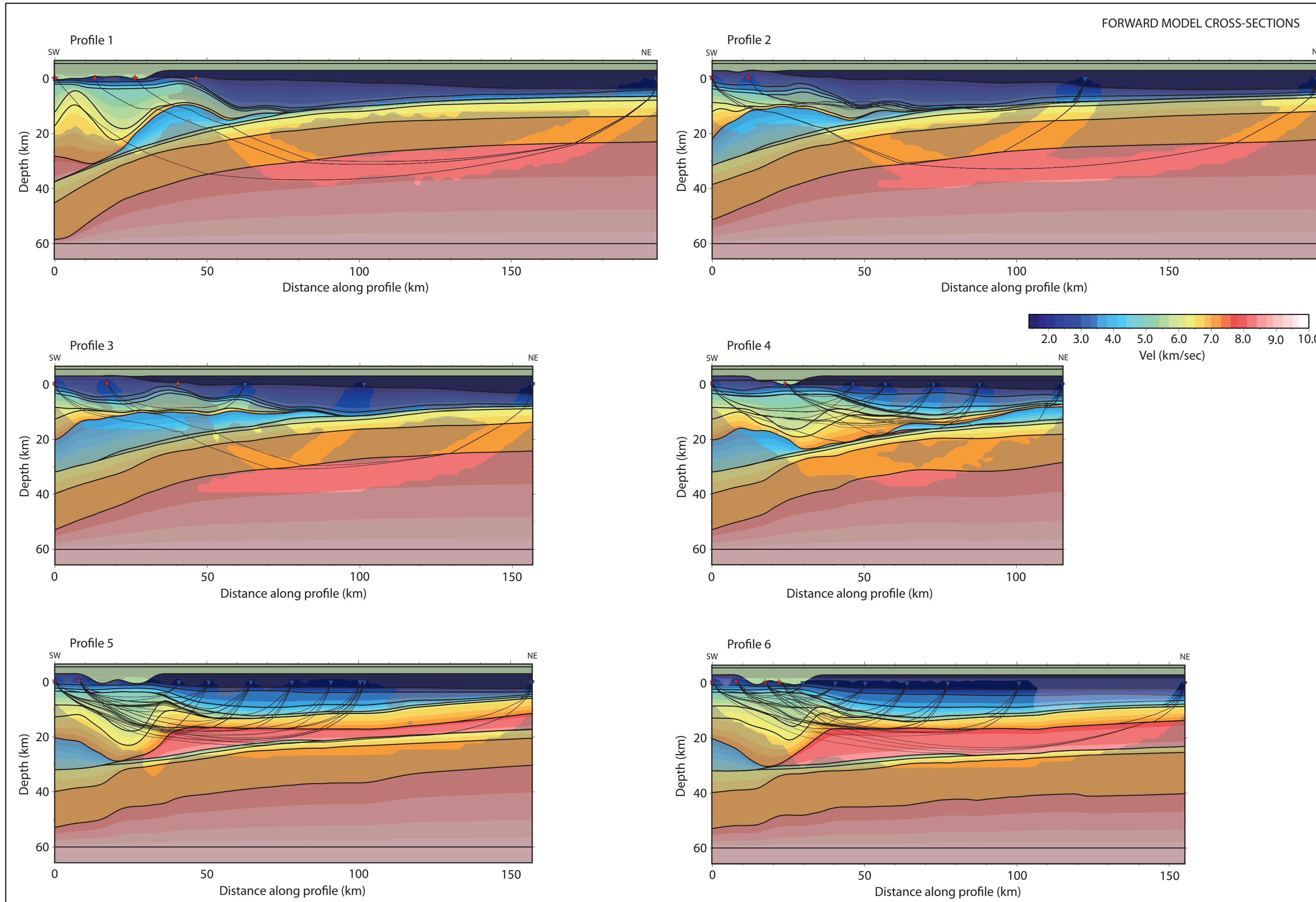

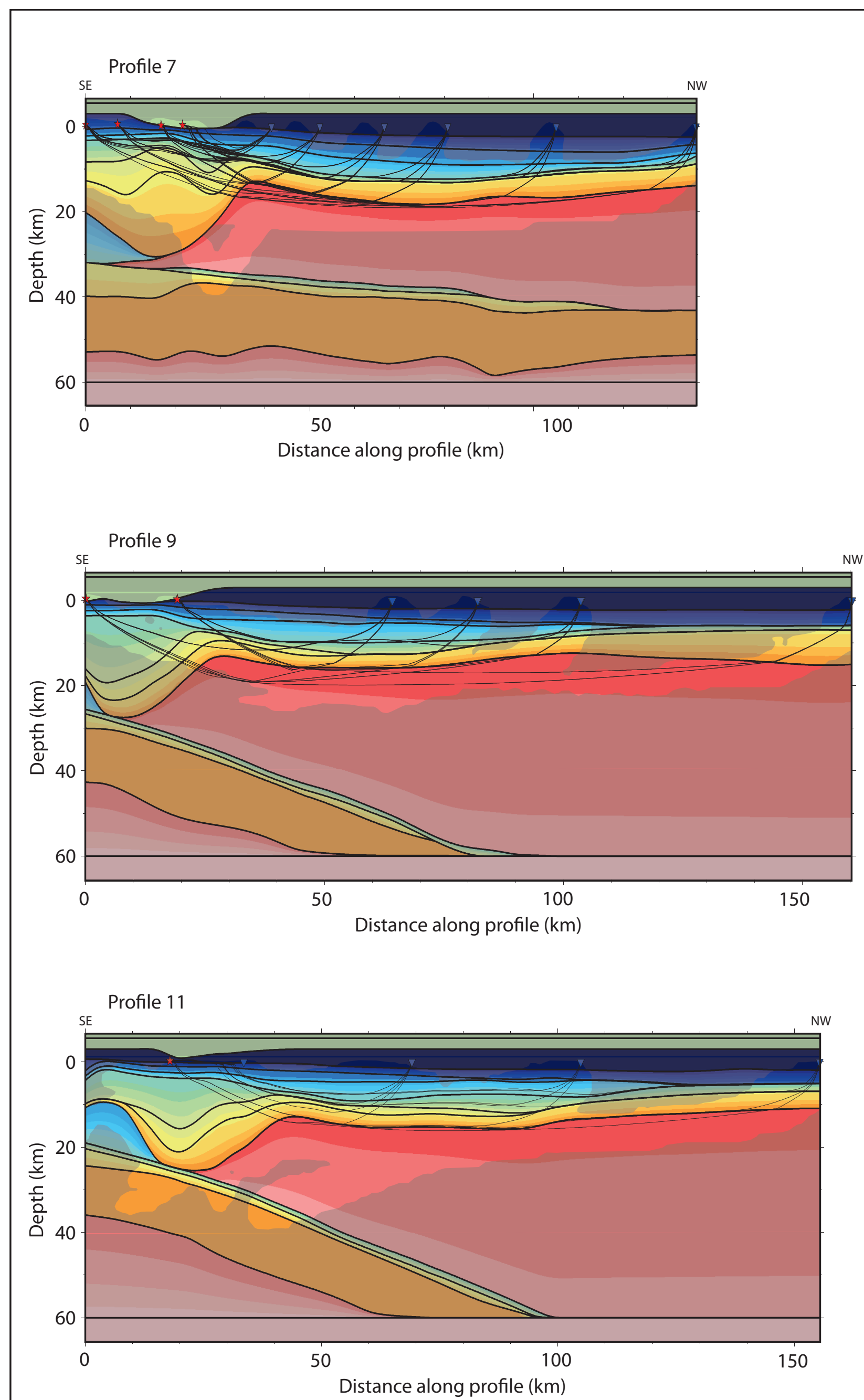
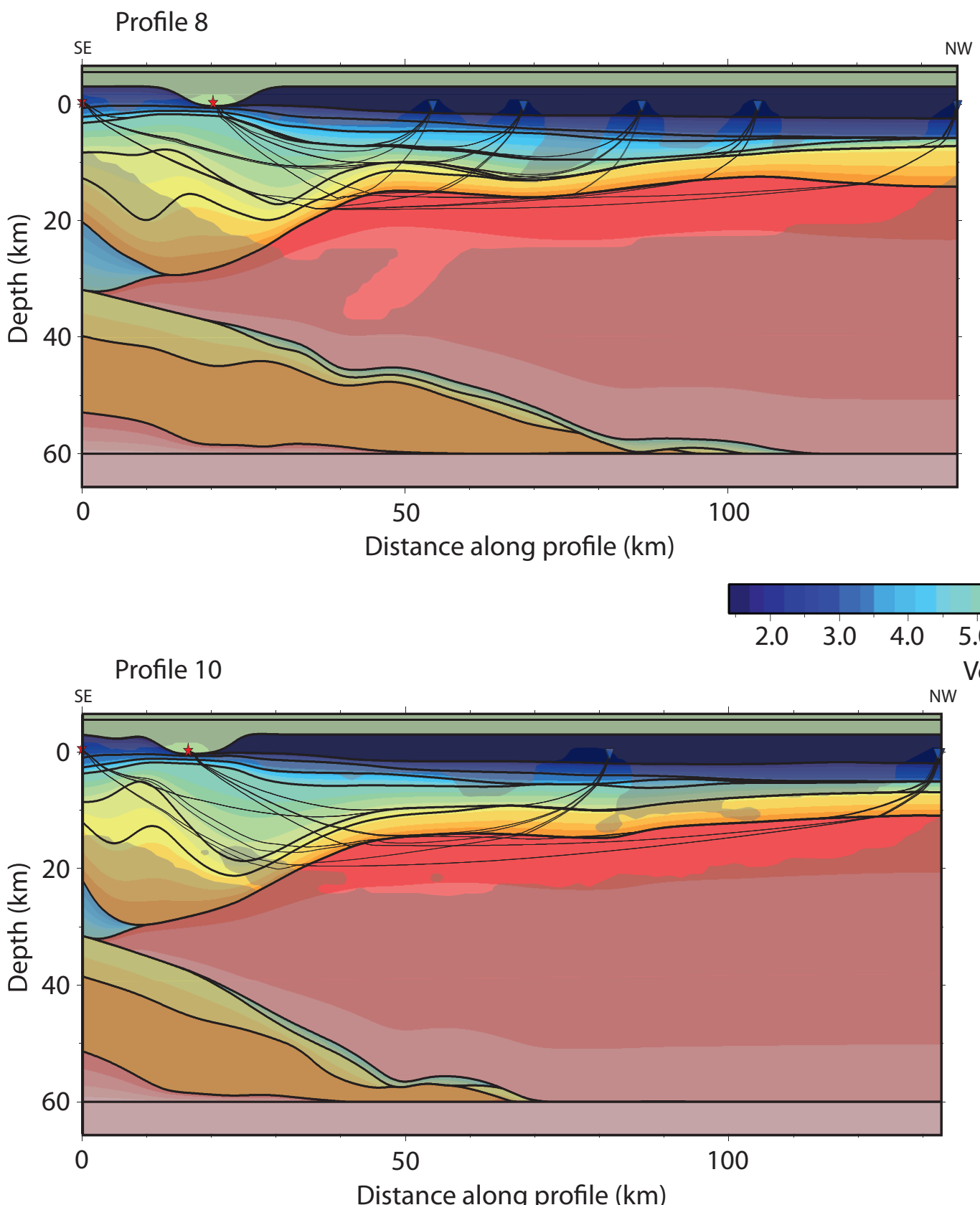
$\begin{array}{llllll}5.0 & 6.0 & 7.0 & 8.0 & 9.0 & 10.0 \\ \begin{array}{l}\text { Vel }(\mathrm{km} / \mathrm{sec}) \\ \end{array} & & & \end{array}$

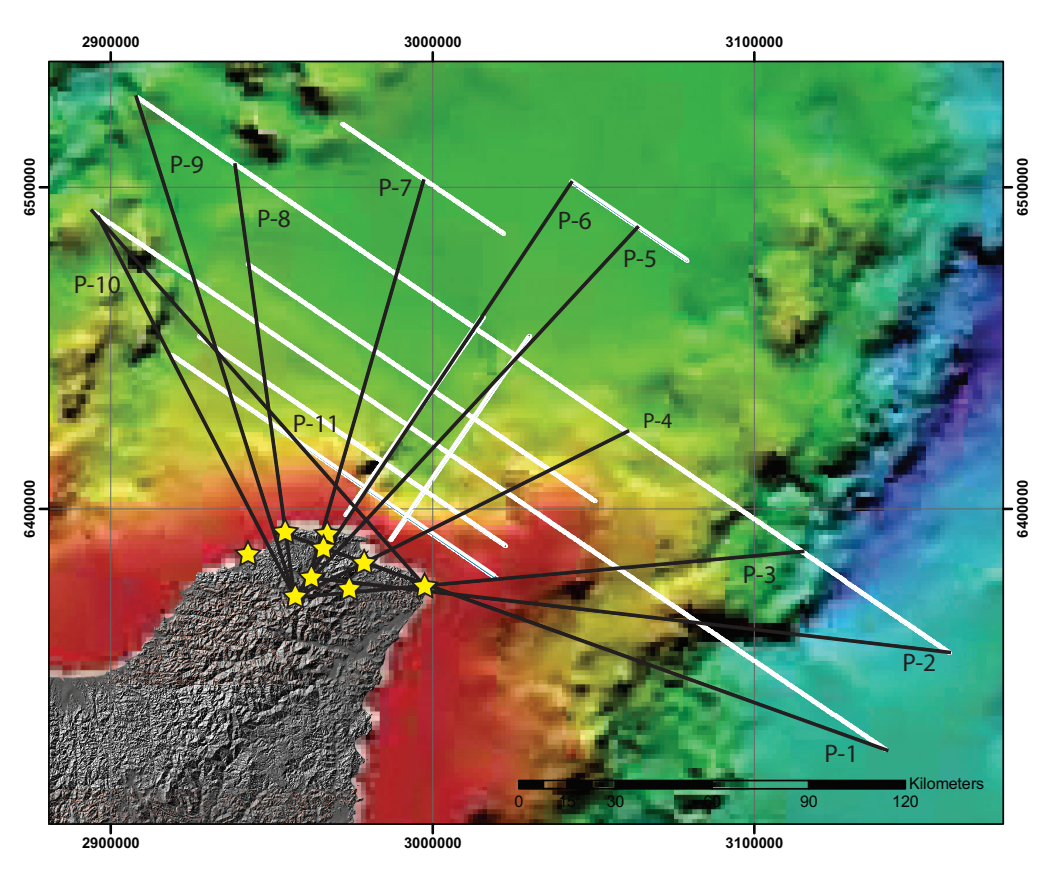




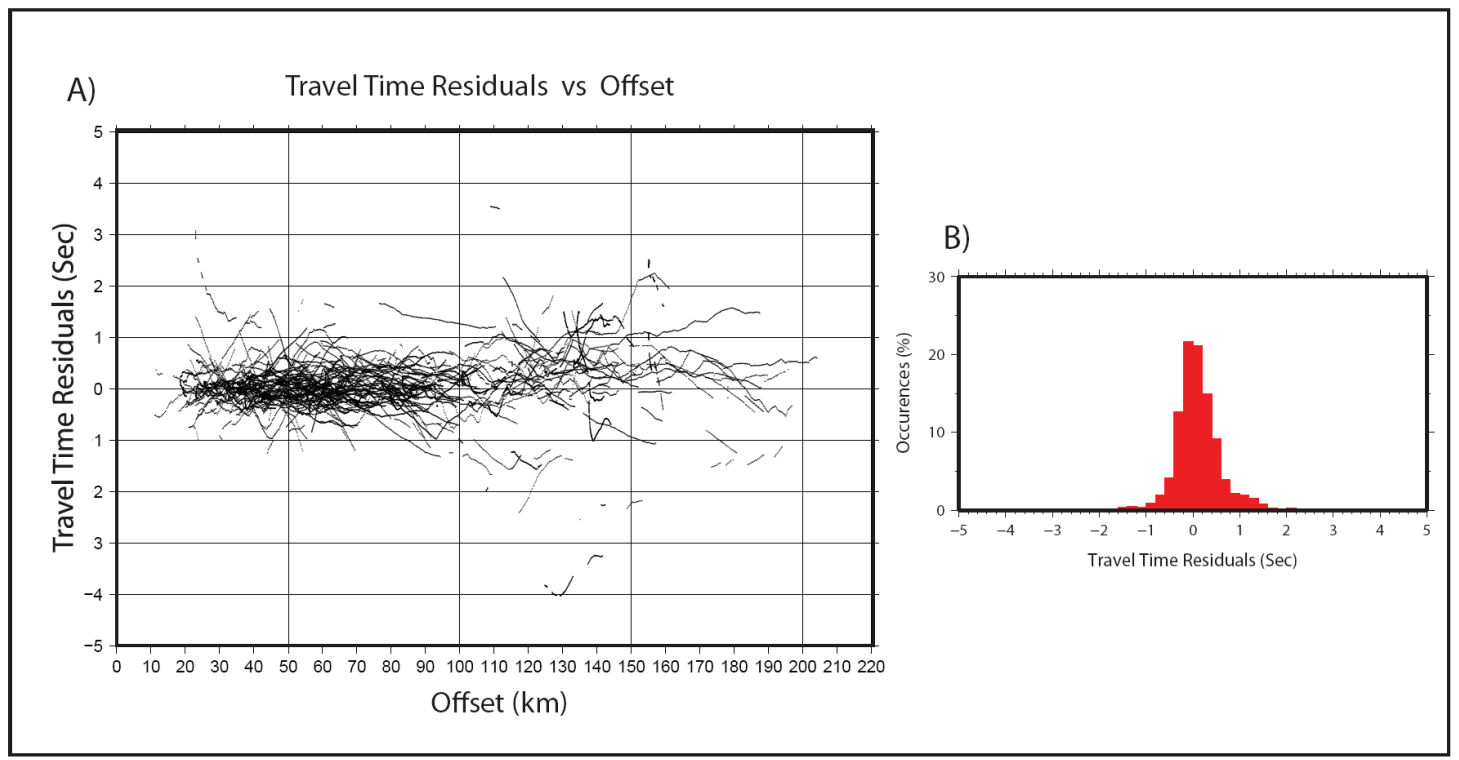

Figure 3.15 - a) Plot of travel-time residuals ( $\mathrm{T}$ obs $-\mathrm{T}$ calc) vs. offset calculated for the final velocity forward model. b) The same data as in (a) however plotted as a histogram displaying the distribution of residual travel-times.

\subsection{1- Raukumara Plain / Harve Trough}

\section{- Central Raukumara Basin}

The Raukumara Basin is modelled as a low-velocity region $(1.9-4.9 \mathrm{~km} / \mathrm{sec})$ reaching a maximum depth of $12.5 \mathrm{~km}$ beneath the southern Raukumara Plain (Figure 3.13-14). The perimeter of the basin is best resolved at depths greater than $5 \mathrm{~km}$ due to the velocity contrast between sedimentary basin fill and the forearc basement which floors the Raukumara Plain (Figure 3.17). Raukumara Basin fill is modelled as three layers containing sedimentary velocities with thicknesses in the central basin of $\sim 2.5 \mathrm{~km}(1.9$ to $3.2 \mathrm{~km} / \mathrm{sec}), 4.5-6 \mathrm{~km}(3.3-$ $3.6 \mathrm{~km} / \mathrm{sec})$ and $2-3 \mathrm{~km}(3.9-4.9 \mathrm{~km} / \mathrm{sec})$ respectively (Figure 3.14$)$.

Forearc basement underlying the central basin is thin $(\sim 5.0 \mathrm{~km})$ and is modelled as two layers containing velocities of $4.9-5.9 \mathrm{~km} / \mathrm{sec}$ and $6.4-7.2 \mathrm{~km} / \mathrm{sec}$. Beneath the central basin, $80 \%$ of basement thickness is comprised of the lowermost layer. A spatial correlation exists between the thinnest basement flooring Raukumara Basin $(\sim 4 \mathrm{~km})$ and the thickest overlying sedimentary column $(10.5 \mathrm{~km})$, located at the intersection of RAU07-05 and RAU07-09.

The Moho is modelled as an approximately planar horizon in the depth range of $16-17 \mathrm{~km}$ and is constrained by both MCS reflection and $O B S / H$ data. 


\section{- Western Raukumara Basin / Harve Trough}

In the western region of the Raukumara Plain, a systematic reduction in the thickness of layers containing sedimentary velocities and an accompanying reduction in the depth to the Moho is observed. While the upper sedimentary layer $(1.9-3.2 \mathrm{~km} / \mathrm{sec})$ maintains an approximately constant thickness $(\sim 2.5$ $\mathrm{km}$ ), deeper sedimentary layers observed beneath the central basin shallow toward the northwest, eventually pinching out at the eastern boundary of the Harve Trough (Figure 3.17a).

The thickness of forearc basement beneath the western basin varies from 4-7 km. This range is comparable to thicknesses modelled within the central basin and the Moho is observed shallowing toward the Harve Trough (Figure 3.18). At the eastern boundary of the Harve Trough the dip on the Moho subsides into an approximately planar interface modelled at 11-12 km depth. Within the backarc, basement thickness is modelled at $\sim 6 \mathrm{~km}$ which is overlain by $3-5 \mathrm{~km}$ of sediment (1.9-3.2 km/sec).

This forward model does not resolve any displacement on sub-seafloor horizons, or any variation in velocity structure which correlates with the normal fault observed marking the boundary between the Raukumara Plain and the Harve Trough.

\section{- Northern Raukumara Basin}

The northern region of Raukumara Basin is modelled displaying several characteristics similar to those observed in the western basin.

Moving north from the central basin, a gradual reduction in the thickness of sedimentary layers is observed. Basement thickness increases from $\sim 5 \mathrm{~km}$ in the central basin to $\sim 7 \mathrm{~km}$ at the northern limits of RAU07-09 and RAU07-10. The gradual increase in basement thickness along these profiles offset a reduction in sediment thickness resulting in a relatively flat Moho maintained at $\sim 17 \mathrm{~km}$ depth (Figure 3.14, Profile 6). 
Further north beneath RAU07-01 and RAU07-02, basement thickness is $\sim 6-7$ $\mathrm{km}$ and the Moho shallows to an average depth of $14 \mathrm{~km}$.

NW-SE along RAU07-01, the combined thickness of layers containing sedimentary velocities is reduced from $\sim 5 \mathrm{~km}$ at the north-western limit of this profile to $<3 \mathrm{~km}$ at the profile mid point. A similar reduction, although in the opposite direction (SE-NW), is resolved along RAU07-02 from $\sim 7 \mathrm{~km}$ in the southeast to $\sim 2.0 \mathrm{~km}$ adjacent to the eastern boundary of the Harve Trough.

These stratigraphic observations are accompanied by a reduction in Moho depth to the east along RAU07-01 and to the west along RAU07-02. The western region of RAU07-02 lies in close proximity to the boundary between the Raukumara Plain and the Harve Trough, and the eastern segment of RAU07-01 is located inboard of the East Cape Ridge (Figures 3.1 and 3.3). This model displays the crust being flexed up in the vicinity of the Harve Trough and East Cape Ridge respectively.

\subsection{2 - Raukumara Peninsula / continental shelf}

The continental shelf between the central basin $(\sim 17.0 \mathrm{~km})$ and the Raukumara Peninsula $(>27.5 \mathrm{~km})$ is characterised by a $>10 \mathrm{~km}$ increase in depth to the Forearc Moho. This transition is inversely correlated with the topography of the continental slope and is accompanied by a systematic tilting of sedimentary and basement layers modelled as flat lying within the central basin. Toward the Raukumara Peninsula, these layers progressively increase in dip displaying a dip direction broadly orthogonal to the swinging topographic crest of the East Cape Ridge and the northern coastline of the Raukumara Peninsula. Collectively, the tilting of forearc strata and the increase in Moho depth result in a $>20 \mathrm{~km}$ transition in basement thickness between the central basin $(\sim 5 \mathrm{~km})$ and the Raukumara Peninsula ( $>25 \mathrm{~km})$.

Coincident with basement tilting, a low-velocity $(3.0-5.0 \mathrm{~km} / \mathrm{sec})$ layer is modelled progressively increasing in thickness along strike from the central basin. This layer is localised beneath the topographic crest and is geometrically 
continuous with its modelled position offshore along the East Cape Ridge. The region beneath the East Cape and the central Raukumara Peninsula is characterised by the absence of a mantle wedge and this layer occupies all the space between the base of forearc basement and the top of the subducting slab (Figures 3.13-14).

The northern tip of the Raukumara Peninsula and the continental shelf are modelled displaying a localised region of high velocities $(5.0-6.0 \mathrm{~km} / \mathrm{sec})$ at the surface (Figure 3.13 , depth slice $0.5 \mathrm{~km}$ ). This high velocity anomaly is modelled as a thin $(<2 \mathrm{~km})$ layer which is correlated with the onshore distribution and offshore magnetic signature of the Matakaoa Volcanics. The thickness of layers containing sedimentary velocities onshore ranges from $<2.0 \mathrm{~km}$ in the western peninsula, to $>5.0 \mathrm{~km}$ in the central and northern regions.

\subsection{3 - Trench-slope / Subducting Slab}

The trench-slope is modelled with velocities from $1.9-3.9 \mathrm{~km} / \mathrm{sec}$ and reaches maximum thickness $(\sim 19 \mathrm{~km})$ immediately east of the East Cape Ridge. The subducting slab is overlain by $\sim 5.0 \mathrm{~km}$ of sediment at the trench which is reduced to $\sim 3.5 \mathrm{~km}$ at the south-eastern limit of RAU07-05 (Figure 4.1).

The crust of the subducting slab is modelled as two layers with velocities of 4.9$6.7 \mathrm{~km} / \mathrm{sec}$ and $7.1-7.3 \mathrm{~km} / \mathrm{sec}$ respectively. The uppermost crustal layer is modelled as two layers $(4.9-6.3 \mathrm{~km} / \mathrm{sec}$ and $6.3-6.7 \mathrm{~km} / \mathrm{sec})$ to represent the change in velocity-gradient with depth through this layer (Figure 4.1).

East of the trench, the upper and lower crustal layers display thicknesses of $\sim 8.0$ $\mathrm{km}$ and 10-12 km respectively (combined thickness $17-18 \mathrm{~km}$ ) and dip NW at 2$5^{\circ}$, striking $25-30^{\circ}$ (Figures 3.17 ). The dip of the subducting slab is modelled increasing at locations $\sim 15 \mathrm{~km}$ down-dip from the trench $\left(\sim 3^{\circ}\right.$ to $\left.5-7^{\circ}\right)$, beneath the central basin $\left(7^{\circ}\right.$ to $\left.10-15^{\circ}\right)$ and is modelled dipping $25-32^{\circ}$ at depths greater than $30 \mathrm{~km}$. The thickness of the upper crustal layer thins gradually down-dip from $7 \mathrm{~km}$ east of the trench to $<2 \mathrm{~km}$ beneath the central basin. 
The upper $10 \mathrm{~km}$ of the subducting mantle lithosphere is constrained and modelled with velocities from $8.1-8.4 \mathrm{~km} / \mathrm{sec}$.

\subsection{4 - East Cape Ridge}

Seismic velocities within the upper 5-7 km of the East Cape Ridge range from $1.9-4.9 \mathrm{~km} / \mathrm{sec}$. These velocities are associated with up-tilted sedimentary layers modelled beneath the central basin. Basement velocities $(6.0-7.2 \mathrm{~km} / \mathrm{sec})$ are modelled at intermediate depths and similarly interpreted (Figure 3.17a).

The main volume of East Cape Ridge is composed of a low-velocity triangular prism (3.0-5.0 km/sec) located between the subducting slab and up-tilted forearc basement. This prism reaches maximum thickness beneath the topographic crest and is not observed beneath the central basin to the west or above the subducting slab to the east.

Southwest along strike, the topographic crest (and the low-velocity prism) is observed migrating arcward and intersects the coast at East Cape before linking up with the Raukumara Ranges. A spatial correlation suggests this migration may be in response to the transition in Moho depth between the central basin and Raukumara Peninsula (Figures 4.2 and 4.3). Further correlations exist between the elevation of the East Cape Ridge and the thickness of forearc basement, and between the arcward limit of the low-velocity prism and the point of intersection between the subducting slab and forearc Moho (Figure 4.4b). These correlations are important and form a key component of hypotheses concerning the dynamics of lower crustal underplating (Section 4.4.3). 


\section{7 - Discussion}

The discussion and interpretation of model results is presented in Chapter Four.

\subsection{1 - Model fit}

The ability of forward models to replicate observational data is spatially analysed by creating plots of observed vs. calculated travel-times for each RAU07 profile on a station by station basis (Figure A4.1). The overall fit of the model is quantified by calculation of RMS residuals, Variance and Chi squared values. Performing a tomographic inversion of the final forward model (Appendix Three) resulted in a $25 \%$ reduction in residual travel-times (Table 3.1).

\begin{tabular}{|l|l|l|l|}
\hline & RMS Residuals (ms) & Variance (Seconds squared) & Chi squared value \\
\hline Starting model & 568.78 & 0.32351 & 29.27675 \\
\hline Iteration 1 & 453.85 & 0.20599 & 13.48845 \\
\hline Iteration 2 & 578.67 & 0.33487 & 18.43572 \\
\hline Iteration 3 & 506.09 & 0.25613 & 16.15335 \\
\hline Iteration 4 & 443.70 & 0.19688 & 11.79345 \\
\hline Iteration 5 & 445.90 & 0.20354 & 12.36718 \\
\hline
\end{tabular}

Table 3.1 - RMS Residuals, Variance and Chi Squared Value of the final velocity forward model and these values after subjecting this model to a tomographic inversion containing 5 iterations.

The residuals calculated both before and after tomographic inversion are dependent on the accuracy at which interpreted phases are matched with discrete ray identities through the model region.

\subsection{2 - Problematic arrivals during forward modelling}

The forward modelling methodology developed in this thesis (Appendix 2) provides only simple control over the distribution of velocities within layers. The resolution of this method is thus proportional to degree of control over the 3-D velocity structure, which is predominantly governed by the number and velocity range of layers incorporated into the model and the spacing of hypothetical profiles used to adjust the model region. 
Limitations concerning the 3-D control on velocity structure outweigh inaccuracies in raytracing within FMTOMO and the limited resolution of the technique makes it unlikely a forward model created using this methodology will fit all interpreted arrivals within observational error (Figures 3.15 and A4.1).

In general, a direct relationship is observed between the degree of difficulty interpreting arrivals, and the degree of difficulty modelling them. The most difficult arrivals to model were those with origins from the western half of RAU07-04, the East Cape Ridge region and the northern Raukumara Basin (Figure 3.3).

Synthetic arrivals from the western half of RAU07-04 into RAUK-02, Rewetu and RAUK-03 (Figures 3.1 and A4.1) were consistently slower than observed travel-times. RAU07-04 is well constrained by MCS data and to replicate these arrivals, a high velocity $(\mathrm{Vp}>6.4 \mathrm{~km} / \mathrm{sec})$ region was introduced within the shallow forearc crust extending along strike from the western Raukumara Ranges into the continental shelf (Figure 3.17, depth slices 5-7.5 km).

Initial difficulty was experienced replicating arrivals into RAUK-02 and WAIK in unison (Figure 3.1). Although these stations are only $\sim 5 \mathrm{~km}$ apart, they display remarkably different travel-times with arrivals into RAUK-02 from several regions up to 2.5 seconds faster than those into WAIK. This travel-time difference was resolved through the introduction of a high velocity (5.0-6.0 $\mathrm{km} / \mathrm{sec}$ ) surface layer within the continental shelf and northern Raukumara Peninsula extending beneath RAUK-02.

The degree of constraint at East Cape Ridge from MCS and OBS/H datasets is comparatively low. Over five phases are modelled originating from this region and high (> $200 \mathrm{~ms}$ ) errors are associated with interpreted travel times. Difficulty was experienced in modelling arrivals from this region into RAUK-01, RAUK03 and Pakira (Figures A4.1). 


\subsection{3 -Model resolution}

The degree to which velocities and structures presented in forward models are constrained by observational data is visualised through an analyses of the spatial density of raypaths (Section A2.5). The geometries of all synthetic raypaths are exported from FMTOMO and used to calculate the number of rays intersecting each cell within the model thus creating a 3-D ray-density grid. In this thesis, slices from this grid (Figures A4.2.1 and A4.2.2) are plotted on depth slices and cross-sections of model results to discriminate between constrained and unconstrained regions (Figures 3.13-14).

\subsection{4 - Errors}

One of the advantages of using active source data is the precise information attained concerning the origin and total travel-time of the seismic data recorded.

The primary source of error is considered to be associated with travel-time picks, introduced during the processing and interpretation of receiver-gathers. Throughout the interpretation process, the degree of uncertainty was visually estimated and recorded for each station. These values were incorporated into velocity modelling using the script Error_script (Script A1.9) which allocates errors to observed travel-times on the basis of station ID and shotnumber.

Pick uncertainties are incorporated within the script used to analyse forward model results (Plot_all_lines_loop, Script A2.7) and behind each observed travel-time (black), a second point scaled to the degree of error associated with that arrival is plotted (grey) (Figures A4.1). Most errors were between 70 - 200 $\mathrm{ms}$ and below the resolution of the forward modelling methodology. For experiments involving tomographic inversion (Appendix Three), errors are included within the observational data file as required by FMTOMO. 


\subsection{4 - Comparison with constraining datasets}

In most regions, constraints incorporated from MCS reflection data and $\mathrm{OBS} / \mathrm{H}$ wide-angle seismic profiling are preserved within the forward model. It was more difficult to maintain constraints from onshore $\mathrm{Vp}$ earthquake tomography and although similar structures are resolved within the forward model, the velocities resolved by Reyners et al. [1999] are consistently faster than those determined in this study (Figure 3.16).

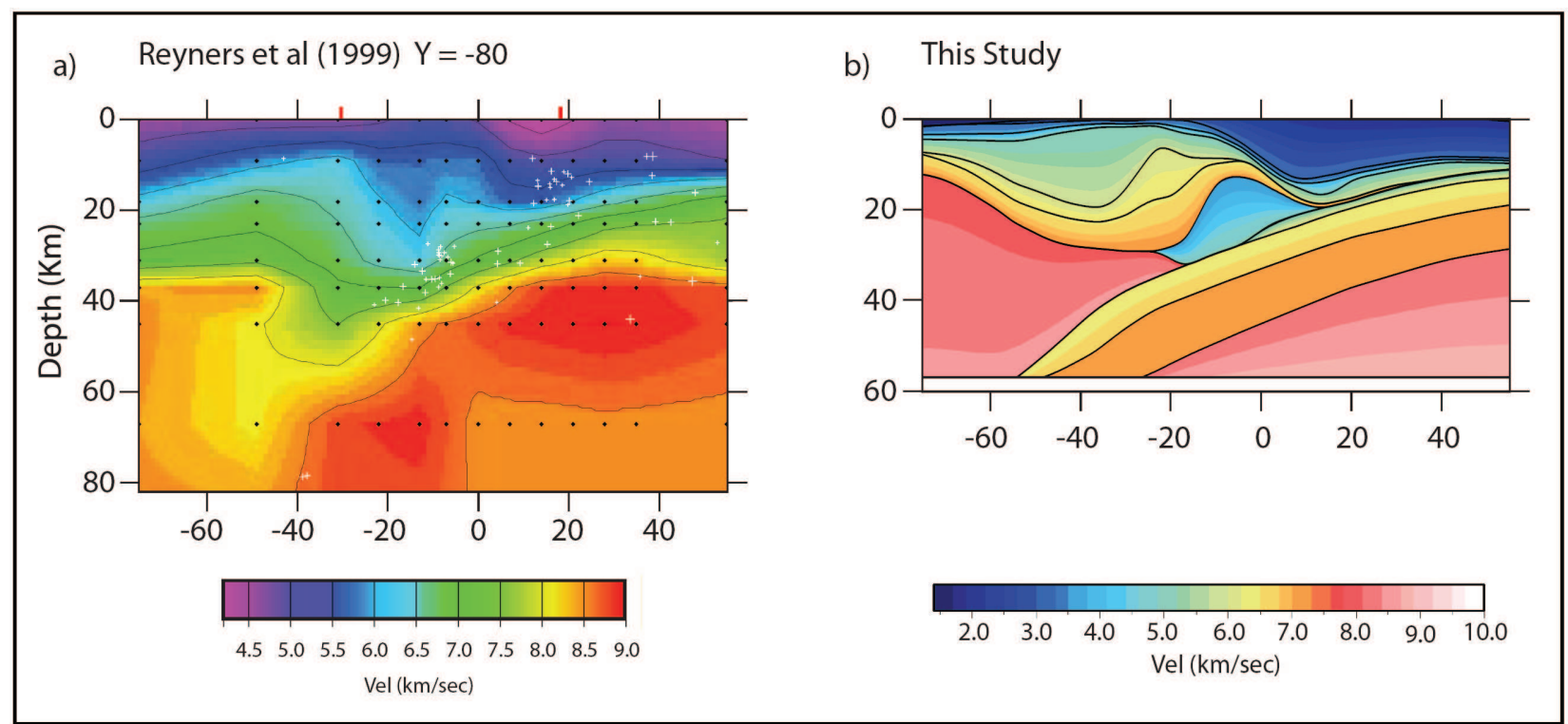

Figure 3.16 - Cross-sections traversing the northern Raukumara Peninsula (profile $\mathrm{Y}=-80$, Reyners et al, 1999) displaying a) the velocity structure derived by 3-D Vp earthquake tomography [Reyners et al., 1999] and b) forward modelling of onshore-offshore seismic data [this study]. The position of this profile is displayed in Figure 3.10.

The geometry of the trench slope and subducting slab is broadly consistent between these models although the velocities derived from forward modelling are consistently slower. The low velocity $(5.5-6.5 \mathrm{~km} / \mathrm{sec})$ region resolved beneath the western Raukumara Ranges (Figure 3.16a) is modelled in this study as a region of thick $(>25 \mathrm{~km})$ forearc basement which is juxtaposed against a low velocity $(3.0-5.0 \mathrm{~km} / \mathrm{sec})$ prism extending from the plate interface to a depth of $\sim 12 \mathrm{~km}$ (Figure 3.16b). The upper mantle velocity for the subducting slab resolved by Reyners et al. [1999] is $>0.5 \mathrm{~km} / \mathrm{sec}$ faster than the upper mantle velocities modelled in this study. The eastern $10 \mathrm{~km}$ and western $30 \mathrm{~km}$ of both models are considered poorly constrained. 


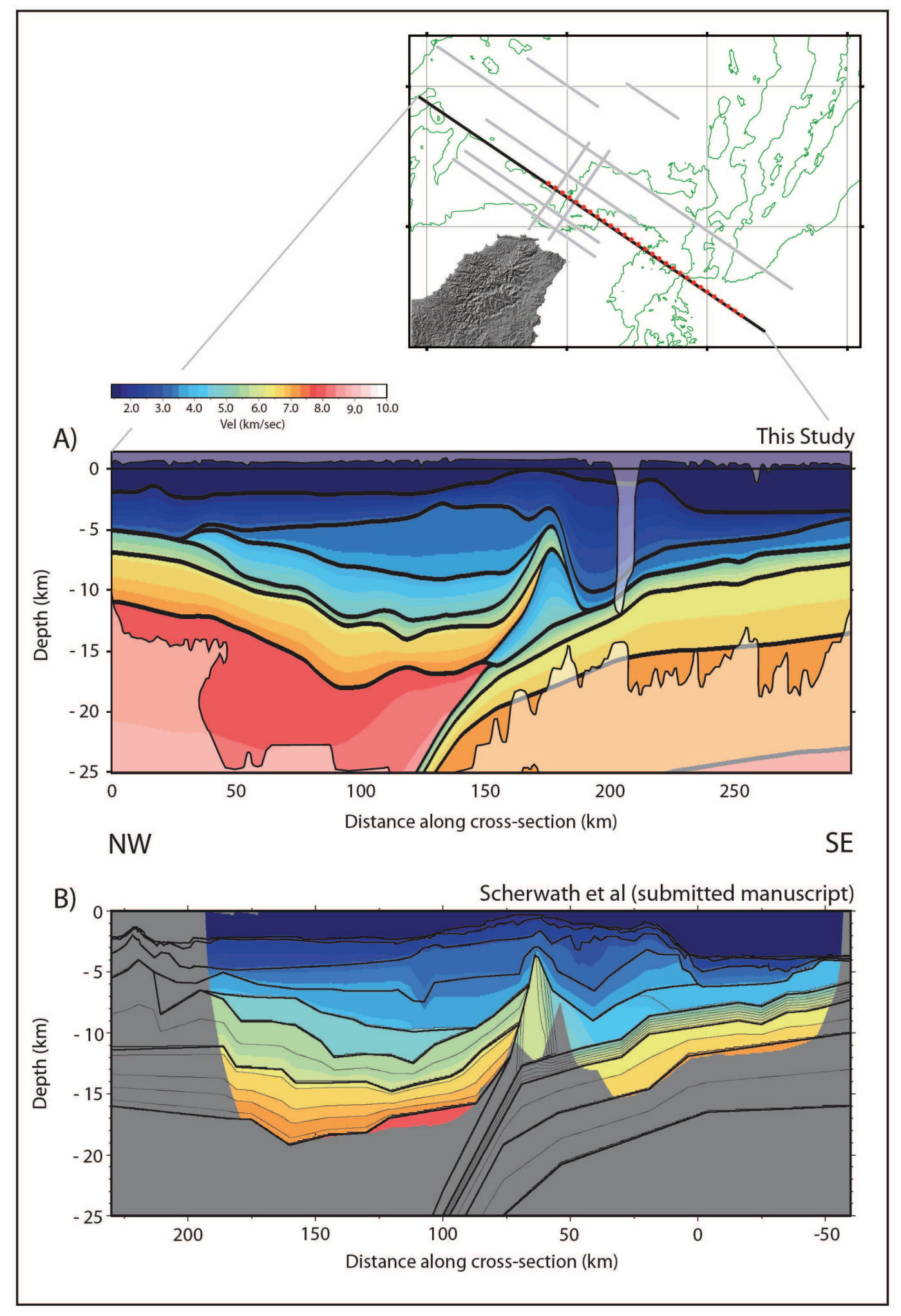

Figure 3.17 - Cross-sections along RAU07-05 displaying the results of a) 2-D Velocity forward modelling of OBS/H wide-angle seismic data [Scherwath et al., submitted manuscript] and b) 3D forward modelling of onshore-offshore wide-angle seismic data [this study]. Dull regions in both models denote areas along each profile not sampled by seismic data. Although it appears only the upper $5 \mathrm{~km}$ of the subducting slab is sampled by either model, in the 3-D model (b) developed in this thesis, shots originating from this profile (RAU07-05) sample the full thickness of the subducting slab, however, do so at a position closer to the station and are therefore not displayed on this plot. 
The areas of divergence between the 3-D onshore-offshore forward model [this study] and the 2-D OBS/H model of Scherwath et al. [submitted manuscript] predominantly occur at regions which are poorly constrained.

Beneath the East Cape Ridge, the model developed in this thesis resolves the presence of a low-velocity prism $(3.0-5.0 \mathrm{~km} / \mathrm{sec})$ located above the subducting slab and below up-tilted basement and sedimentary layers (Figure 3.17a). Scherwath et al. [submitted manuscript] model an anomaly of slightly higher relief with a velocity gradient of $5.8-6.0 \mathrm{~km} / \mathrm{sec}$ (Figure $3.17 \mathrm{~b}$ ). Plots of ray coverage through the model of Scherwath et al. [submitted manuscript] show that aside from a small number of rays modelled reflecting off the plate interface, only the shallowest portions $(4-7 \mathrm{~km})$ of this anomaly is sampled. It is suggested that the high velocities observed at intermediate depths are related to up-tilted forearc crust and do not extend down to the plate interface.

The second area of divergence between these models concerns the thickness of the subducting slab. Scherwath et al. [submitted manuscript] model the crust of the subducting slab as upper and lower crustal layers with thicknesses of $4 \mathrm{~km}$ $(4.9-6.7 \mathrm{~km} / \mathrm{sec})$ and $6 \mathrm{~km}(7.1-7.3 \mathrm{~km} / \mathrm{sec})$ respectively. Only the upper $1 \mathrm{~km}$ of the lower crustal layer is sampled by refracted rays and Scherwath et al. [submitted manuscript] calculate the thickness of this layer via gravity modelling. The full crustal thickness of the subducting slab is sampled by refracted rays in the data analysed in this thesis and using the same layer velocities as Scherwath et al. [submitted manuscript], thicknesses at the trench for these layers of 7.0 and $\sim 10 \mathrm{~km}$ are resolved (Figure 3.17a). 


\section{8 - Summary}

- The East Cape Ridge is resolved as a region of anomalously low velocity. The majority of the ridge's volume is modelled as a localised lowvelocity $(3.0-5.0 \mathrm{~km} / \mathrm{sec})$ triangular prism centred beneath the topographic crest and positioned above the subducting slab. A geometrical correlation is observed between the eastward limit of this low-velocity layer and the intersection of the subduction thrust and the forearc Moho.

- Velocity forward models resolve a $>10 \mathrm{~km}$ increase in Moho depth between the central Raukumara Basin $(17 \mathrm{~km})$ and the Raukumara Peninsula $(>30 \mathrm{~km})$, which is accompanied by an increase in the thickness of forearc basement $(\sim 5$ to $>25 \mathrm{~km})$. The increase in Moho depth is inversely correlated with topography and is spatially concomitant with an along strike clockwise rotation of the topographic crest and an arcward migration of the intersection between the subducting slab and the forearc Moho. The increase in basement thickness is correlated with a reduction in bathymetry along the East Cape Ridge.

- The subducting slab is modelled as two layers with velocities from 4.9 $6.3 \mathrm{~km} / \mathrm{sec}$ and $7.1-7.3 \mathrm{~km} / \mathrm{sec}$, with a combined thickness of $\sim 17-18$ $\mathrm{km}$. Wide-angle reflections are observed and modelled from the plate interface and provide further constraints on interface geometry. These reflections may be of future use to study the physical properties of the plate interface. The upper $10 \mathrm{~km}$ of the subducting mantle lithosphere is constrained and modelled with velocities from $8.1-8.4 \mathrm{~km} / \mathrm{sec}$.

The geodynamic interpretation and regional and global implications of these observations are presented in Chapter Four. 


\section{CHAPTER 4 - SYNTHESIS}

\section{TEXT}

4.1 - Introduction . . . . . . . . . . . . . . . . . . . . . . . . . . . . . . . . 103

4.2 - Data and Methodology . . . . . . . . . . . . . . . . . . . . 105

4.3 - Observations

4.3 .1 - Structure of the downgoing plate . . . . . . . . . . . 106

4.3 .2 - Structure of the subduction interface . . . . . . . . . . 108

4.3 .3 - Structure of the Moho . . . . . . . . . . . . . . . . 110

4.3.4 - Forearc Crustal Structure

4.3.4.1 - Basement Thickness . . . . . . . . . . . . . . . 112

4.3.4.2 - Low-velocity forearc high . . . . . . . . . . . . . . . . 114

4.3.4.3- Structure of Raukumara Basin . . . . . . . . . . . . 114

4.4 - Regional Implications

4.4.1 - Seismic constraints on Hikurangi Plateau structure

4.4.1.1 - Crustal Thickness . . . . . . . . . . . . . . . . . . . . . . . 119

4.4.1.2 - Upper Mantle Velocities . . . . . . . . . . . . . . . . . . 119

4.4.1.3 - Conclusions with regard to the Hikurangi Plateau . . . . 121

4.4.2 - Subduction interface

4.4.2.1 - Interface Geometry . . . . . . . . . . . . . . . . . 123

4.4.2.2 - Physical Properties . . . . . . . . . . . . . . 123

4.4 .3 - Crustal Growth Processes . . . . . . . . . . . . . . . . . . . . . . 125

4.5 - Global Implications

4.5.1 - Quantification of the fluxes at convergent margins . . . . . . . . 130

4.5.2 - Sediment recycling and crustal underplating . . . . . . . . . . . 132

4.5.3 - Implications for the fluxes at convergent margins . . . . . . . . . . 134

4.6 - Future Research . . . . . . . . . . . . . . . . . . . . . . . . . . 137 


\section{1 - Introduction}

This thesis integrates high-fold seismic reflection data $(\sim 10,000$ line $\mathrm{km})$ and onshore-offshore wide-angle seismic reflection and refraction data $(\sim 250,000$ seismic traces) to study in detail the northern Hikurangi subduction margin. Onshore-offshore data constrain a three-dimensional (3-D) P-wave velocity (Vp) model occupying an area of $\sim 32,000 \mathrm{~km}^{2}$ and a depth range down to $40 \mathrm{~km}$.

This chapter provides a brief summary of the onshore-offshore data acquired, observations of seismic reflections (Chapter 2) and refractions (Chapter 3) and the implications of interpretations on local and global geodynamic processes.

Seismic constraints on the thickness and velocity structure of the Hikurangi Plateau are presented here, which are the first controlled-source constraints to be made. Local conclusions pertain to the 3-D velocity structure of the forearc, subduction zone mass-balance and the influence of pre-existing crustal structure on crustal growth processes. These later conclusions may be general to all subduction zones and are discussed with a view toward global estimates of crustal growth and destruction at subduction margins. This thesis suggests an explanation for the discrepancy between published estimates of continental creation and destruction [Reymer \& Schubert, 1984; Clift \& Vannucchi, 2004]. 


\section{2 - Data and Methodology}

The RAU07 seismic reflection survey consisted of nine lines totalling 1128 line $\mathrm{km}$ of high fold seismic data with $\sim 30,000$ shot points (Figure 3.1). The arrival of body-waves emanating from each of these shots was recorded onshore by nine three-component short-period seismometers and over 250,000 unique onshoreoffshore raypaths have been analysed. These data are processed and interpreted as a suite of 81 receiver-gathers, from which, first arrivals are identified on 69, with 174 discrete phase segments interpreted and in total, 275,000 travel-time picks made.

In contrast to the majority of onshore-offshore datasets [e.g. Dowling 1968; Spence et al. 1985; Tréhu et al. 1995; Lafond \& Levander 1995; Stern et al. 2001; Scherwath et al. 2003], the data acquired in this thesis predominantly originate from MCS reflection profiles perpendicular the distribution of onshore seismometers (Figure 3.1). These data are analysed through the construction of a 3-D velocity forward model. Forward modelling allows specific assumptions to be made, constraining datasets to be maintained and a clearly defined modelling strategy to be developed (Section 3.5.2). Forward modelling is thus better suited to overcoming ray-coverage deficiencies than tomographic inversion techniques (Appendix Three).

This thesis demonstrates that onshore-offshore seismic profiling need not be restricted to 2-D profiles and is a viable method of producing coarse 3-D images of crustal velocity beneath the ocean-land boundary. This is true even where the spatial distribution of receivers is restricted to a few stations. If such images are desired, then routine marine reflection surveys, similar in geometry to the survey associated with this study (RAU07), can be augmented by the on-land deployment of seismometers. 


\section{3 - Observations}

\subsection{1 - Structure of the downgoing plate}

East of the trench along profile RAU07-05 (Figure 4.1, profile km 210-290), the subducting slab is modelled with a crustal thickness of $17-18 \mathrm{~km}$. The crystaline crust is modelled as two layers with velocities of 4.9-6.3 $\mathrm{km} / \mathrm{sec}$ (upper layer) and 7.1-7.3 km/sec (lower layer) respectively. The upper and lower crustal layers have thicknesses of $\sim 8 \mathrm{~km}$ and $10-12 \mathrm{~km}$, are dipping NW at $2-5^{\circ}$ and are overlain by $3-5 \mathrm{~km}$ of seismically slow $(\mathrm{Vp}<3.6 \mathrm{~km} / \mathrm{sec})$ material. West of the

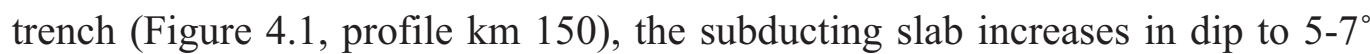
and the upper crustal layer thins from 7 to $<4 \mathrm{~km}$ (Figure 4.1, Section 4.1.2). West of East Cape Ridge, the dip of the subducting slab increases to $10-15^{\circ}$ and progressively steepens to $25-32^{\circ}$ at depths greater than $30 \mathrm{~km}$ (Figure 4.1 ). The upper crustal layer is modelled with a thickness $<2.5 \mathrm{~km}$ west of East Cape Ridge. The velocity structure of the downgoing plate is constrained southwest of reflection profiles RAU07-05 and RAU07-03 in the offshore regions east of the intersection of the plate interface with the forearc Moho (Figure 4.2).

The upper $10 \mathrm{~km}$ of the subducting mantle lithosphere is modelled with a $\mathrm{Vp}$ from 8.1-8.4 km/sec (Figures 3.19, 3.20 and 4.1). The constrained region is restricted to areas southwest of RAU07-03 and RAU07-05, diminishing with depth to a $\sim 5,000 \mathrm{~km}^{2}$ region northeast of the East Cape at $35 \mathrm{~km}$ depth (Figure A4.2.2) 


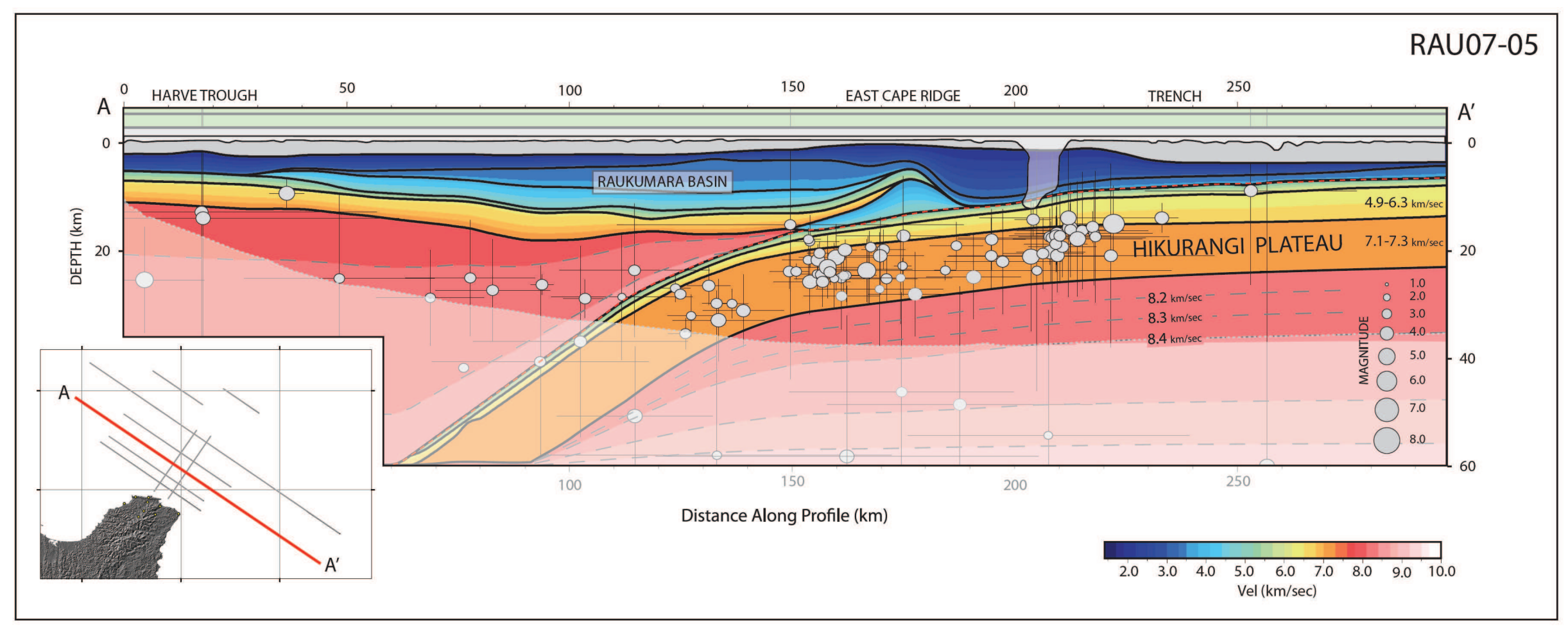

Figure 4.1 - Cross-section along RAU07-05 (see insert) displaying the dip parallel Vp structure through the southern Raukumara Plain derived by forward modelling onshore-offshore wide-angle reflection and refraction data (Chapter 3). Earthquakes with $\mathrm{Mw}>2$ and hypocenters within $5 \mathrm{~km}$ of this profile are plotted and scaled to magnitude. Earthquake locations are downloaded from Geonet and not located using this velocity model. The upper crustal layer of the subducting slab is modelled as two layers to represent the change in velocity gradient within the shallow crust. The top of the slab is denoted by a dashed red line. Note the reduction in thickness of the upper crustal layer and the clusters of hypocenters coincident with modelled increases in slab dip east and west of East Cape Ridge. Faded area displays regions unconstrained by onshore-offshore seismic data. 


\subsection{2 - Structure of the subduction interface}

The subduction interface is sampled by refracted arrivals turning within the subducting slab and phases modelled as reflections from the plate interface. These arrivals and thus constraints on the geometry of the plate interface are restricted predominantly to the East Cape Ridge, trench-slope and continental shelf north of the Raukumara Peninsula (Figures 4.2 and A4.2.2). The strike of the subduction thrust is $25-30^{\circ}$ and dip increases from $2-5^{\circ}$ east of the trench to $>25^{\circ}$ beneath the central Raukumara Basin (Figures 4.1 and 4.2). Two distinct increases in dip are observed east $\left(\sim 2^{\circ}\right.$ increase $)$ and west $\left(\sim 5^{\circ}\right.$ increase $)$ of East Cape Ridge along RAU07-05 (Figure 4.1). 


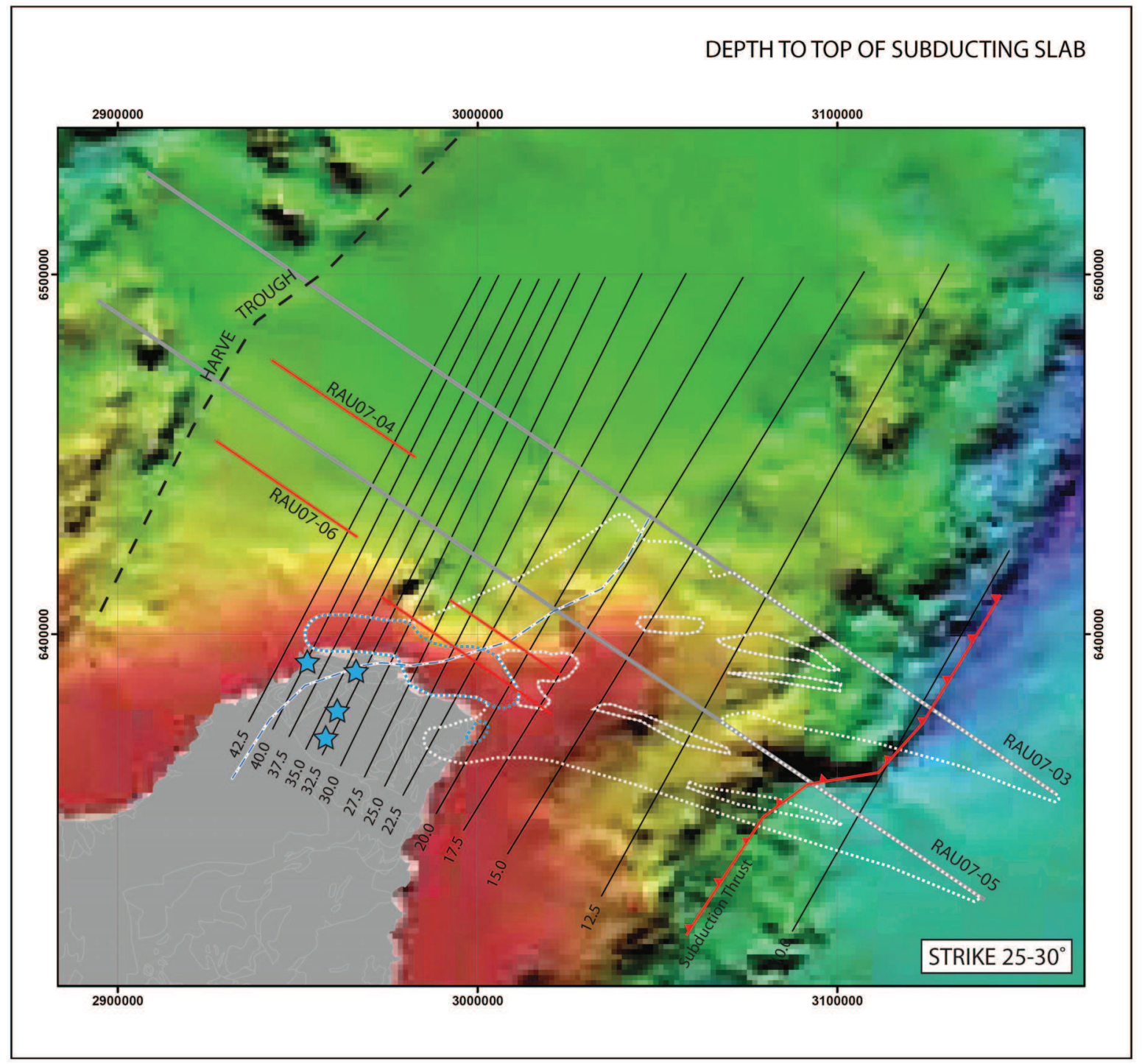

Figure 4.2 - Bathymetric map displaying contours of the subduction interface (as labelled). Dashed white line demarcates regions where the plate interface is constrained by onshoreoffshore seismic data. Dashed blue areas show regions where the plate interface is sampled by wide-angle reflections (Figure A4.2.2). Red lines and blue stars denote the line positions and recording stations of wide-angle plate interface reflections. White and blue line illustrates the point of intersection between the subduction interface and the Forearc Moho (Section 3.3, Figure 4.3). Bathymetry courtesy of NIWA. 


\subsection{3 - Structure of the Moho}

Between the Raukumara Plain and the Raukumara Peninsula, velocity forward models resolve a $>10 \mathrm{~km}$ increase in depth to the base of the forearc crust (Moho) (Figure 4.3). The Moho beneath the Raukumara Plain is approximately planar and modelled between $15-17.5 \mathrm{~km}$ depth. In contrast, the western Raukumara Peninsula is characterised by a Moho depth $>25 \mathrm{~km}$ [Reyners et al., 1999]. The geometry of the transition in Moho depth trends west-east and is inversely correlated with topography (Figures 4.2 and 4.3). The structure of the Moho is constrained predominantly offshore of the Raukumara Peninsula in regions landward of RAU07 profiles (Figure A4.2.2)

Around the perimeter of the Raukumara Plain, the Moho is modelled to shallow from its position within the central basin $(\sim 17 \mathrm{~km})$, occupying depths of $<12.5 \mathrm{~km}$ within the Harve Trough, $<15 \mathrm{~km}$ within the northern Raukumara Plain and 10-15 km within the East Cape Ridge region (Figure 4.3). In contrast to the central basin, the Moho at East Cape Ridge is not constrained by either MCS reflection or $\mathrm{OBS} / \mathrm{H}$ wide-angle data and uncertainties of $\pm 5 \mathrm{~km}$ are assigned. Within the Harve Trough a region of increased Moho depth $(12.5$ to $>15 \mathrm{~km})$ is correlated with a bathymetric trough and a break in the volcanic arc (Figures 4.2 and 4.3).

The intersection between the Moho and the subduction interface shallows toward the northeast and is located closer to the trench (Figure 4.3). 


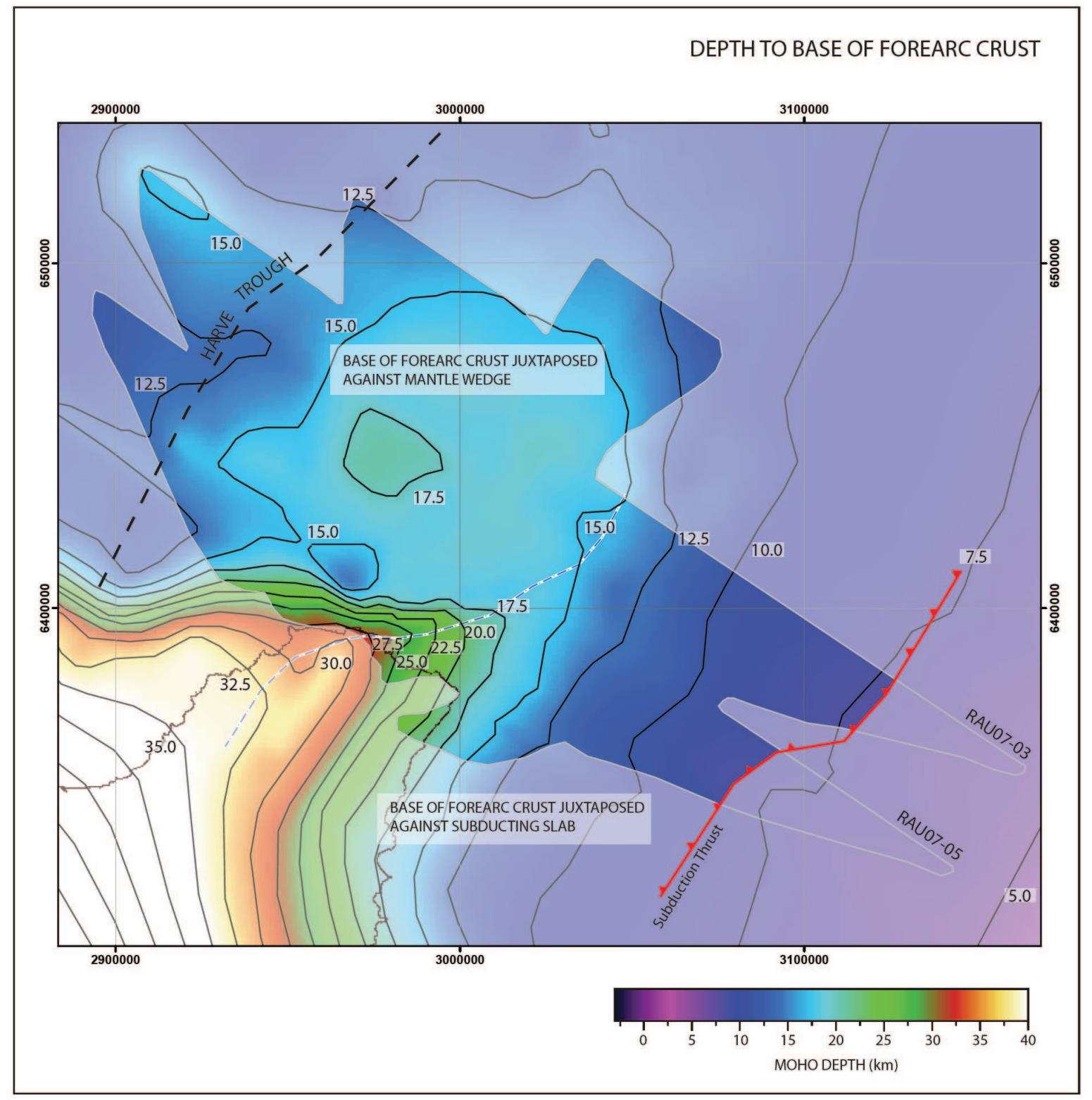

Figure 4.3 - Map displaying the depth to the base of forearc crust (Moho). Contours are at $2.5 \mathrm{~km}$ intervals (as labelled). White and blue line illustrates the point of intersection between the Moho and the subduction interface (Section 3.2, Figure 4.2). Surface trace of the subduction thrust displayed in red. Note the region of increased Moho depth within the Harve Trough and the correlation this feature has with a break in the volcanic arc (Figure 4.2). Faded area demarcates regions where the Moho is not constrained by onshore-offshore seismic data. 


\subsection{4 - Forearc Crustal Structure}

\subsubsection{1 - Basement Thickness}

In this thesis, forearc basement is defined as material positioned above the Moho/subducting slab and below sedimentary fill $(\mathrm{Vp}<5.0 \mathrm{~km} / \mathrm{sec})$ of Raukumara Basin. Accreted material with $\mathrm{Vp}>5.0 \mathrm{~km} / \mathrm{sec}$ near to the trench is also treated separately.

Accompanying the increase in Moho depth between the Raukumara Plain and the Raukumara Peninsula (Section 3.3, Figure 4.3) is a $>20 \mathrm{~km}$ increase in the thickness of forearc basement. Basement thickness beneath the central Raukumara Basin is $<6.0 \mathrm{~km}$ and reaches a minimum thickness of $3.8 \mathrm{~km}$ in a region correlated with the thickest overlying sedimentary section $(10.5 \mathrm{~km}$, approximately at intersection of RAU07-05 and RAU07-09) (Figure 4.4a-b).

Onshore, the thickness of forearc basement is greatest $(>25 \mathrm{~km})$ in the northern and western Raukumara Peninsula and within the continental shelf offshore from these regions [Reyners et al., 1999; this study]. The increase in basement thickness modelled around the Raukumara Peninsula is correlated with the topography of the continental shelf. The eastern and central Raukumara Peninsula are characterised by steep thickness gradients as forearc basement is replaced by strata of a lower velocity (3.0-5.0 km/sec, Section 4.3.4.2).

Constraints on basement thickness are the same as those for Moho structure (Section 4.3.3). Constraints on the distribution of basement material extend further onshore and although arrivals do not sample the full thickness of the forearc crustal-column, the distribution of basement rock beneath the northern 15 $\mathrm{km}$ of the Raukumara Peninsula at depths shallower than $17 \mathrm{~km}$ is constrained (Figure A4.2.2) 


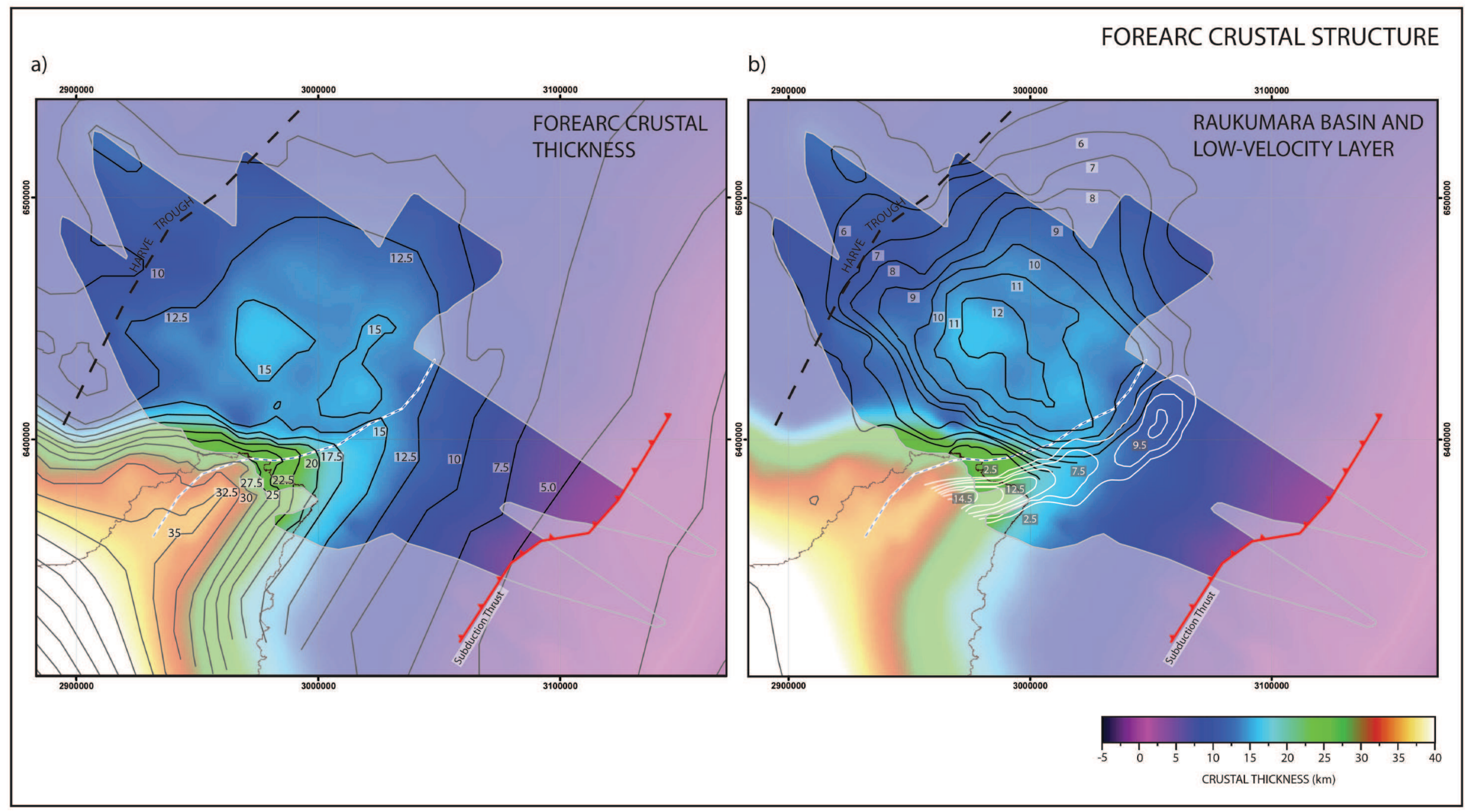

Figure 4.4 - Maps displaying a) forearc crustal thickness and b) the discrete components of the forearc crustal column in this region. Depth contour of the base of Raukumara Basin sediments is displayed in black (values labelled in $\mathrm{km}$ ). White contour displays the thickness (labelled in $\mathrm{km}$ ) of the low velocity $(3.0-5.0 \mathrm{~km} / \mathrm{sec})$ prism modelled between forearc basement and the top of the subducting slab. Basement thickness can be calculated by 


\subsubsection{2 - Low-velocity forearc high}

The East Cape Ridge marks the eastern boundary of Raukumara Basin. In this region, a low-velocity $(3.0-5.0 \mathrm{~km} / \mathrm{sec})$ triangular prism is modelled between the base of forearc basement and the top of the subducting slab (Figure 4.1). This layer is localised beneath the topographic crest and is observed tracking the arcward migration of the East Cape Ridge crest within the continental shelf, before taking up position beneath the Raukumara Ranges (Figure 4.4b).

Beneath the East Cape Ridge and the eastern and central Raukumara Peninsula, this low-velocity layer is modelled coincident with a reduction in thickness and a shallowing of forearc basement layers from positions modelled beneath the central Raukumara Basin and western Raukumara Peninsula respectively (Figure 4.1). The eastern limit of sub-basement low velocities $(3.0-5.0 \mathrm{~km} / \mathrm{sec})$ coincides with the intersection of the Moho with the subducting slab and thus the trenchward limit of the forearc mantle wedge (Figure 4.4b).

\subsubsection{3 - Structure of Raukumara Basin}

Raukumara Basin is a triangular depocenter bounded to the south, east and west by the Raukumara Peninsula, East Cape Ridge and Harve Trough respectively. The base of Raukumara Basin is defined by the deepest packet of continuous reflectors (i.e. base of Megasequence X). The basin reaches $\sim 12.5 \mathrm{~km}$ depth (below sea-level), $40 \mathrm{~km}$ along strike from the northern coastline of the Raukumara Peninsula, shallowing to $3 \mathrm{~km}, 7 \mathrm{~km}$ and $6 \mathrm{~km}$ at the southern, eastern and western boundaries respectively (Figure 4.5c). To the northeast, the reduction in basin floor depth is gradual and the northern boundary of Raukumara Basin is not constrained by existing data.

Raukumara Basin fill comprises three clearly defined Megasequences which are hypothesised to correlate with the onshore geology (Figure 1.3) of the Raukumara Peninsula: X - interpreted as Late Cretaceous and Paleogene passive margin sediments; Y - The East Coast Allochthon (Early Miocene); Z - Neogene marine sedimentary rocks [Sutherland et al., 2009]. 
Second-order seismic-stratigraphic sequences are interpreted throughout Raukumara Basin (Chapter Two). Within Megasequence X, second-order sequences are localised within the central basin (Figure 4.5a). This is in contrast to Megasequence $\mathrm{Z}$ in which shallow second-order sequences record a progressive southeast-northwest migration of the Neogene sedimentary depocenter (Figure 4.5a-c). Along RAU07-03, the depocenter for the youngest second-order sequence (Z6) is located $22 \mathrm{~km}$ down-dip from the depocenter for $\mathrm{Z} 3$ and $\sim 35 \mathrm{~km}$ from the depocenter for Megasequence X (Figure 4.5a).

In the central Raukumara Basin, Megasequence $X$ is thick $(\sim 7 \mathrm{~km})$ and characterised by continuous moderate-amplitude reflections approximately parallel to the basal interface. Toward the East Cape Ridge, both forearc basement and overlying strata tilt-up toward the topographic crest and reflector continuity diminishes, becoming fragmented and chaotic (Figure 4.5a). A reduction in basin depth and a shallowing of strata is also observed along strike between the central Raukumara Basin and the Raukumara Peninsula (Figure $4.5 b)$. Here, diminishing reflection continuity is also observed to accompany this increase in dip however this is not as severe as imaged at East Cape Ridge.

In the western Raukumara Plain, where the basin shallows toward the Harve Trough, there is no apparent reduction in reflection continuity within Megasequence $\mathrm{X}$ and onlap at the basin margin is observed.

Figure 4.5 (overleaf) a) Dip-section displaying the distribution of second-order sequences interpreted along seismic reflection profile RAU07-03 (Red profile in insert). Second-order sequences are coloured according to megasequence and labels are plotted at the interpreted position of the depocenter for each sequence. Thin black lines within Megasequence X illustrate internal reflectors which become disrupted where basal surfaces tilt up toward the East Cape Ridge and Raukumara Peninsula.

b) As above however for the strike-section RAU07-09 (green profile in insert). Thick blue line on figures $a-b$ denotes the base of Raukumara Basin (plotted in figure c).

c) Map displaying the depth contour (labelled in $\mathrm{km}$ ) to the top of Forearc basement which floors the Raukumara Plain. Red lines denote the southern and eastern limits of three shallow secondorder sequences interpreted within Megasequence $\mathrm{Z}$ (as labelled). Full and dashed lines distinguish depositional and erosional extents respectively. Note the apparent stability of the depocenter through deposition of Megasequence X (a-b) and the distinct southeast-northwest migration of the depocenter through deposition of Megasequence $Z$ ( $a, b$ and $c)$. 


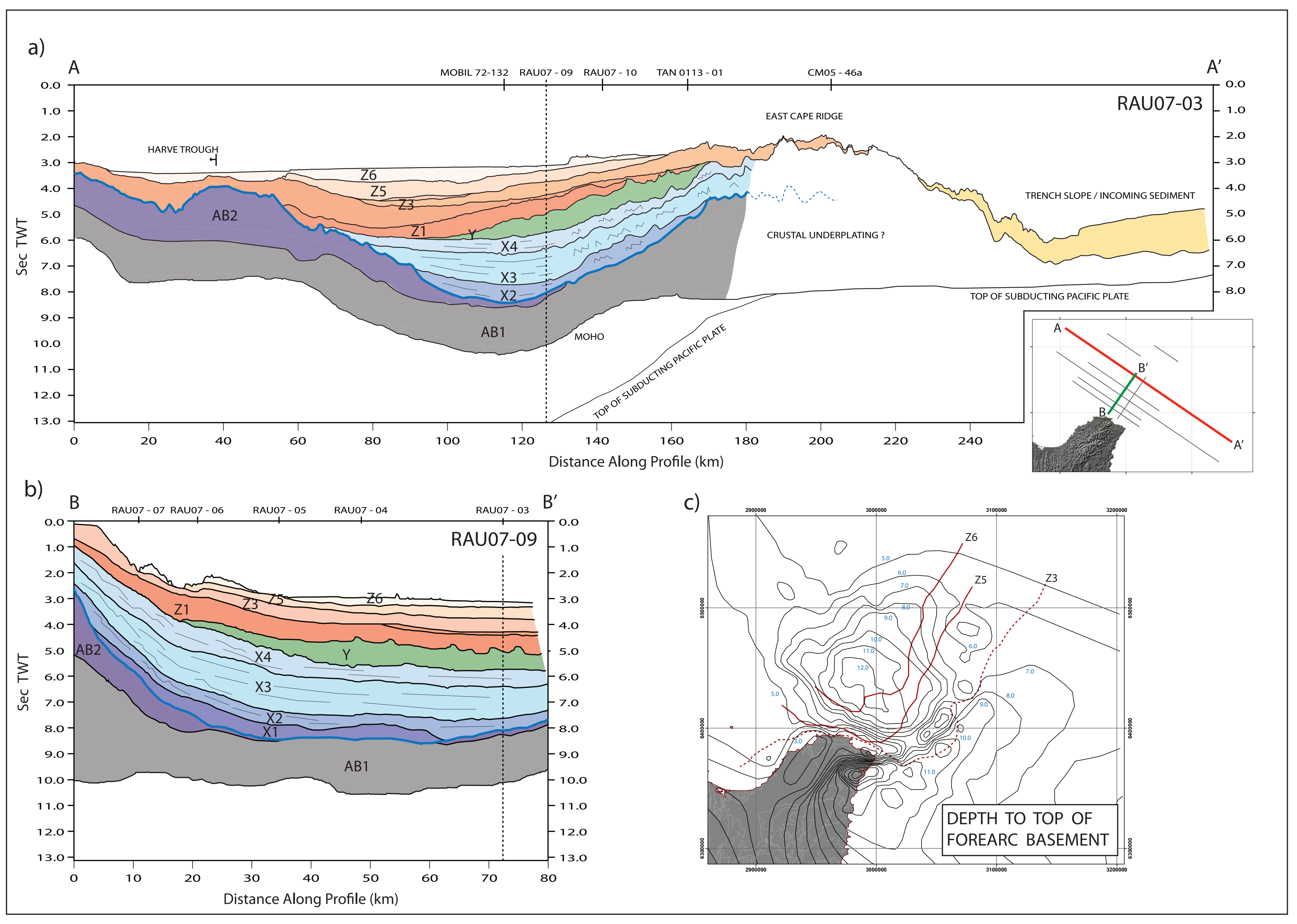




\section{4 - Regional Implications}

\subsection{1 - Seismic constraints on Hikurangi Plateau thickness.}

\subsubsection{1 - Crustal Thickness}

This thesis places the first controlled-source seismic constraints on the thickness of the northern Hikurangi Plateau.

East of the trench, crustal thickness is modelled at $17-18 \mathrm{~km}$ comprised of two layers with thicknesses of $\sim 8 \mathrm{~km}(4.9-6.3 \mathrm{~km} / \mathrm{sec})$ and 10-12 km (7.1-7.3 $\mathrm{km} / \mathrm{sec}$ ) respectively (Figure 4.1 ). Down-dip, the thickness of the upper crustal layer thins from 7 to $<4 \mathrm{~km}$ and two distinct regions where the subducting slab increases in dip, east (2-3 ${ }^{\circ}$ increase) and west (5-7 $7^{\circ}$ increase) of the East Cape Ridge, are observed. These regions appear the site of increased seismicity within the Hikurangi Plateau (Figure 4.1). Tradeoffs are inherent with velocity modelling and the slab geometry presented above represents the simplest possible model subject to initial geometrical constraints imposed by MSC seismic reflection observations and constraints on the shallow velocity structure resolved by $\mathrm{OBS} / \mathrm{H}$ seismic profiling [Scherwath et al., submitted manuscript].

Gravity models spanning the full range of plausible density distributions for the Hikurangi Plateau model the crustal thickness at 10-23 km [Davy, 1992; Davy and Wood, 1994; Davey et al., 1997; Gladczenko et al., 1997; Henrys et al., 2006; Davy et al., 2008]. The thickness resolved by forward models in this thesis is at the upper end of this range and 2-8 $\mathrm{km}$ greater than most previous estimates. A trade off exists between the velocity structure of the crust and mantle of the subducting slab and the increased thickness modelled in this thesis may require a corresponding increase in velocity of the subducting lithospheric mantle.

\subsubsection{2 - Upper Mantle Velocities}

The upper $10 \mathrm{~km}$ of the subducting mantle lithosphere is constrained by one-way refracted arrivals and is modelled with a Vp of $8.1-8.4 \mathrm{~km} / \mathrm{sec}$ (Figure 4.1 ). 
The velocity structure within the uppermost mantle of the Hikurangi Plateau has been the subject of a large quantity of research [Haines, 1979; Kayal and Smith, 1984; Robinson, 1986; Galea, 1992; Chadwick, 1997; Brisbourne \& Stuart, 1998]. Two unifying characteristics become apparent from these studies pertaining to: a) the geometry of experiments and the azimuthal range of raypaths analysed and, b) the suggestion of anomalously high $\mathrm{Vp}(>8.5 \mathrm{~km} / \mathrm{sec})$ at some level within the upper mantle.

The studies mentioned above are restricted to onshore seismometers, local earthquake sources and most conduct their analyses using pairs of receivers. The physiography of New Zealand and the prevalence of earthquake hypocenters within the active plate boundary restrict these studies to the analysis of approximately strike-parallel or near vertical raypaths.

From these studies, the upper mantle structure of the subducting Hikurangi Plateau has been characterised by discrete regions of anomalously fast ( $\mathrm{Vp}>8.5$ $\mathrm{km} / \mathrm{sec}$ ) and more normal (Vp $8.0-8.3 \mathrm{~km} / \mathrm{sec}$ ) mantle velocity [Haines, 1979; Kayal and Smith, 1984; Robinson, 1986; Galea, 1992; Chadwick, 1997; Brisbourne \& Stuart 1998]. Anomalously fast regions are modelled 10-20 km beneath the base of the Hikurangi Plateau crust, above which, more normal mantle velocities are observed [Robinson, 1986; Galea, 1992; Chadwick, 1997]. Analyses of fundamental-mode Rayleigh-wave dispersion velocities do not resolve the anomalous velocities reported above, which may suggest that regions of high velocity are non-pervasive and must be thinner than $10 \mathrm{~km}$ to avoid detection [Brisbourne \& Stuart, 1998]. Brisbourne and Stuart [1998] also propose the presence of a strike-parallel anisotropic fabric within the Hikurangi Plateau, a hypothesis supported by azimuthally dependent velocities from Pn waves emanating from the 1966 Gisborne earthquake [Hamilton, 1969], an easterly rotation of fast orientations relative to the radial axis [Galea, 1992] and SKS splitting results recorded beneath the North Island [Gledhill \& Gubbins, 1996; Greve et al., 2008]. The primary source of anisotropy in the Hikurangi subduction margin is the subducting slab which is modelled with a 5-9 \% anisotropy with a fast axis aligned with the trench [Eberhart-Phillips \& Reyners, 2009]. 
The presence of an anisotropic fabric within the Hikurangi Plateau may be contributing to the high strike-parallel velocities documented in the literature. To discussions of anisotropy, this thesis contributes a controlled source seismic refraction dataset sampling the full thickness of the northern Hikurangi Plateau crust, and the upper $10 \mathrm{~km}$ of the subducting lithospheric mantle across a large azimuthal range $\left(210-293^{\circ}\right)$. A down-dip reduction in the thickness of the upper (slower) crustal layer of the Hikurangi Plateau is required to replicate arrivals less oblique to the strike of subduction (Figure 4.1). It is possible that this reduction may be attempting to compensate for a trench parallel anisotropic fabric within the Hikurangi Plateau lithosphere that cannot be included within this forward model.

Along strike from northeast to southwest, the Hikurangi Plateau shallows in bathymetry and the dip of the subducting plate is reduced [Barker et al., 2009]. It is likely that dip-effects associated with this strike-parallel increase in slab buoyancy are increasing the apparent velocities resolved by the studies discussed above [e.g. Galea, 1992]. Velocities resolved within the subducting mantle lithosphere in this thesis are consistent with models in which regions of anomalous mantle velocity $(\mathrm{Vp}>8.5 \mathrm{~km} / \mathrm{sec})$ are offset from the base of the subducting crust by a $10-20 \mathrm{~km}$ thick mantle cap containing more normal mantle velocities (Vp 8.0-8.3 km/sec) [Galea, 1992; Robinson, 1986; Chadwick, 1997; Brisbourne and Stuart, 1998]. Conversely, forward model results are inconsistent with studies suggesting anomalous mantle velocities $(\mathrm{Vp}>8.5 \mathrm{~km} / \mathrm{sec}$ ) immediately beneath the Hikurangi Plateau crust [Kayal and Smith, 1984; Reyners et al, 1999].

\subsubsection{3 - Conclusions with regard to the Hikurangi Plateau}

This thesis makes two important contributions concerning the structure of the subducting Hikurangi Plateau. The thickness resolved $(17-18 \mathrm{~km})$ is greater than most estimates within the literature and the upper mantle velocities (8.1-8.4 $\mathrm{km} / \mathrm{sec}$ ) are at the slow end of reported values. 
In this study, rays sampling the Hikurangi Plateau have high incidence-angles beneath the Raukumara Peninsula and propagate through crust in close proximity to regions constrained by raypaths from the Raukumara Plain. It is unlikely that the velocity structure of the Raukumara Peninsula has been overestimated and any sub-station velocity anomaly solely effecting rays from the Hikurangi Plateau would require large lateral changes in velocity directly beneath onshore stations and are considered improbable.

The geometry of the experiment from which the thickness and velocities presented above are modelled, is such that the Hikurangi Plateau structure is only constrained by arrivals from two clusters of shots at the south-eastern ends of RAU07-05, and RAU07-03 (Figure 4.2). Trade offs between the crustal seismicstructure (thickness and velocity) and mantle velocity impart uncertainty on the estimates presented above but do not prevent conclusions from being drawn.

This thesis shows the crust of the Hikurangi Plateau to be thicker and the mantle velocity to be slower than most previous estimates. The positive trade-off between these parameters makes it difficult to bring one parameter closer to previously published estimates (e.g. crust thinner) without having to further distance the other parameter (= mantle velocity even slower) to compensate (Table 4.1). The forward model developed in this thesis appears a reasonable compromise between previous estimates of crustal thickness and mantle velocity.

\begin{tabular}{|l|l|}
\hline Crustal Thickness & Mantle Velocity \\
\hline 10 & 7.56 \\
\hline 12 & 7.67 \\
\hline 15 & 7.87 \\
\hline $\mathbf{1 8}$ & $\mathbf{8 . 1}$ \\
\hline 20.23 & 8.3 \\
\hline 22.23 & 8.5 \\
\hline 23.16 & 8.6 \\
\hline
\end{tabular}

Table 4.1 - Crustal thicknesses and mantle velocities to replicate a single observed travel time from the south-eastern limit of RAU07-05 (offset $200 \mathrm{~km}$ ). Parameters in bold italics represent those used in this study. 


\subsection{2 - Subduction Interface}

\subsubsection{1 - Interface geometry}

The geometry of the subduction interface is constrained by deep reflections from RAU07 MCS reflection data and both refracted arrivals and wide-angle reflections from onshore-offshore seismic data (Figure 4.2).

Down dip the subduction interface steepens from 5-7 ${ }^{\circ}$ east of East Cape Ridge to $>25^{\circ}$ beneath the central Raukumara Basin. The point of intersection between the subduction interface and the forearc Moho is located on the western flank of East Cape Ridge and migrates arcward along strike toward the Raukumara Peninsula. The region of the plate interface constrained by onshore-offshore seismic refractions is located predominantly up-dip of the intersection between the subduction interface and the Moho (Figure 4.2).

Wide-angle reflections from the plate interface constrain interface geometry immediately offshore of the northern Raukumara Peninsula (Figure 4.2). The map presented in this thesis (Figure 4.2) represents the first compilation of observations of interface geometry for this margin.

\subsubsection{2 - Physical properties}

Reyners et al. [1999] resolve the subduction interface as a narrow zone of high $\mathrm{Vp} / \mathrm{Vs}$. S-P converted phases constrain this region to a 1-2 $\mathrm{km}$ thick zone at 15 $20 \mathrm{~km}$ depth, overlying the subducting slab with a $\mathrm{Vp}$ of $5.0-5.35 \mathrm{~km} / \mathrm{sec}$ and $\mathrm{Vp} / \mathrm{Vs}$ of 2.0 [Eberhart-Phillips \& Reyners, 1999]. This zone is interpreted as a subducted sediment channel containing fluids at near-lithostatic pressures.

Wide-angle reflected arrivals with modelled origins from the plate interface may be used to further study physical properties. These reflections sample the plate interface up-dip and down-dip of the subducting slab - Moho intersection and the waveforms of these arrivals may be used to investigate changes in plate interface properties accompanying the transition in overlying material from forearc crust to the forearc mantle wedge. These studies have implications for mechanical coupling and hazard assessment and although such analysis was outside the scope of this thesis, it represents an interesting avenue for future study. 


\subsection{3 - Crustal growth processes}

Structural and stratigraphic observations made within Raukumara Basin are proposed to constrain forearc mass-balance in the vicinity of East Cape Ridge and the Raukumara Peninsula. The trench-slope in this region is characterised by highly faulted and indurated rock and it has previously been proposed that subduction erosion is taking place on the plate interface [Collot \& Davy, 1998].

As discussed in Chapter Two, subduction erosion would cause a trenchward advection of the forearc which, assuming a constant distance between the trench and the volcanic front, should result in relict arc volcanoes to be preserved within the western Raukumara Basin. Such volcanoes are not observed and shallow second-order seismic-stratigraphic sequences record a southeast-northwest migration of the Neogene sedimentary depocenter. Collectively, these observations appear to rule out a state of net forearc crustal loss for the northern Hikurangi subduction margin.

Beneath the East Cape Ridge and the eastern and central Raukumara Peninsula, basement and sedimentary layers dip up toward the topographic crest and are progressively underlain by a low-velocity $(3.0-5.0 \mathrm{~km} / \mathrm{sec})$ triangular prism (Figures 4.1 and 4.4). Accompanying the increase in dip, considerable internal deformation and the fragmentation of continuous reflectors is observed (Figures 2.2, 2.3a, 2.4a and 4.5a-b). The same degradation in continuity is not observed in the western basin, which suggests the shallowing of strata beneath the East Cape Ridge and Raukumara Peninsula is related to deformation after the deposition of Megasequence X (since $\sim 22 \mathrm{Ma})$.

This low-velocity $(3.0-5.0 \mathrm{~km} / \mathrm{sec})$ layer is interpreted as underplated sedimentary and crustal strata and the relative buoyancy of this material is proposed to drive local rock-uplift forming the topographic crest. In addition to the confinement of the low-velocity layer beneath the topographic crest, a geometrical correlation is observed between the eastern boundary of the lowvelocity layer and the lineation marking the intersection of the subducting slab and forearc Moho (Figure 4.4b). These observations underpin a cyclical crustal dynamic operating between the trench and the point of intersection between the subducting slab and the forearc Moho (Figure 4.6a-b). 
Sediments on the downgoing plate are incorporated along with material tectonically eroded from the toe of the trench-slope into a subduction channel located above the subducting slab. Accompanying subduction, this material is transported arcward and downward to a position near the forearc Moho. At this location the subduction channel terminates, with entrained material thermally weakened and underplated to the forearc crust. The density contrast between subducted sedimentary and crustal material $\left(\sim 2.3-2.6 \mathrm{~kg} / \mathrm{m}^{3}\right)$ and the mantle wedge $\left(3.4 \mathrm{~kg} / \mathrm{m}^{3}\right)$ prevents further subduction and entrained material is accreted to the upper plate, driving local rock and potentially forming an outer-forearc high. Progressive uplift causes the trench-slope to steepen above its critical angle of stability resulting in episodic gravitational failure. Trench-slope collapse takes place both arcward and trenchward of the locus of underplating, with trenchward collapse creating the trench-slope and returning material to the subduction front completing the cycle (Figure 4.6a-b).

The appreciable difference in crustal structure between the East Cape Ridge and the Raukumara Peninsula (Figures 4.3 and 4.4a-b) provide controlled experiment conditions to study the influence forearc crustal structure exerts on the underplating process. The shallow Moho $(\sim 17 \mathrm{~km})$ beneath the Raukumara Basin places the point of intersection between the Moho and the top of the subducting slab closer to the trench than beneath the Raukumara Peninsula, where forearc basement is $>20 \mathrm{~km}$ thicker and the Moho $>10 \mathrm{~km}$ deeper (Figures 4.3 and 4.6a-b). 


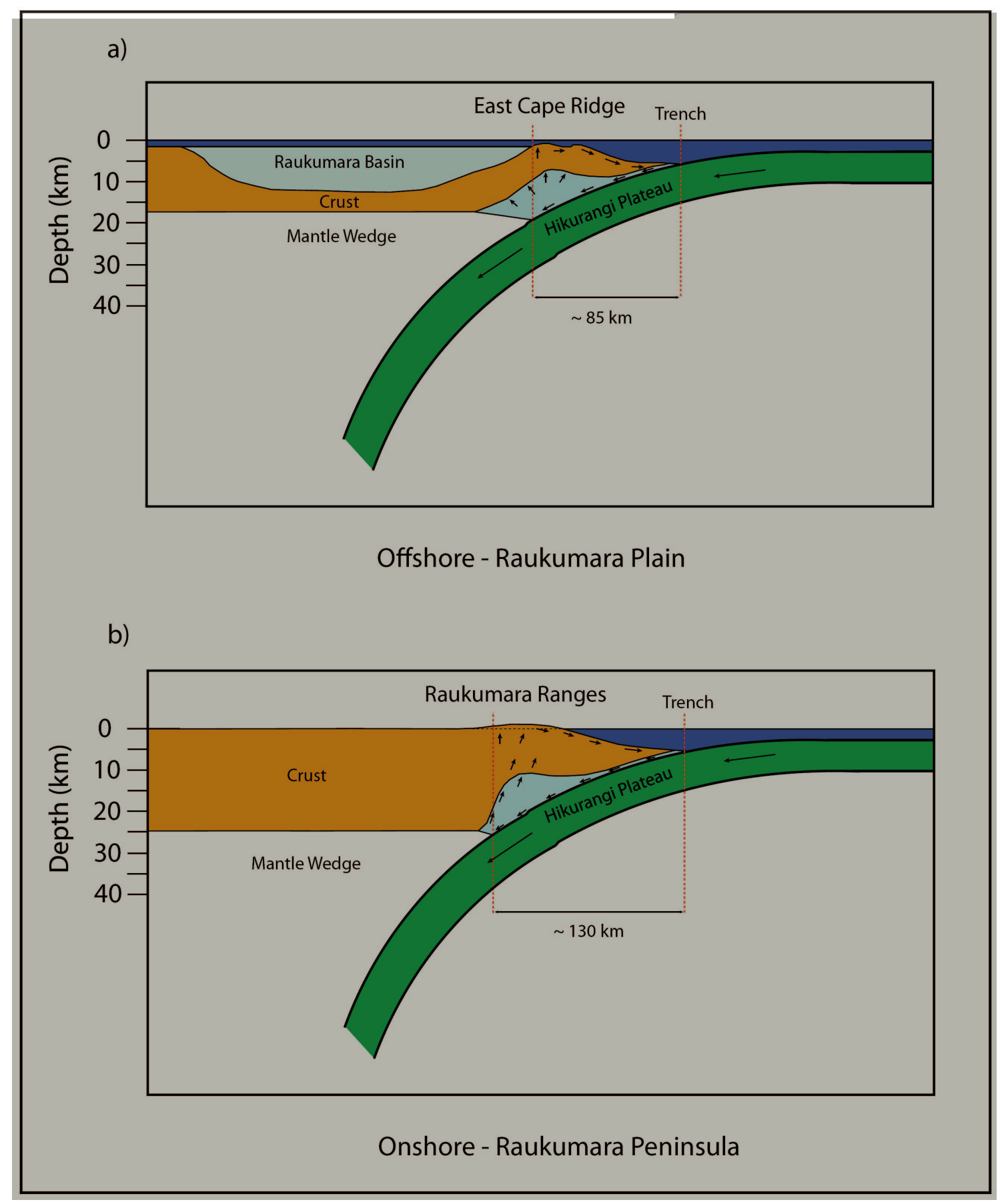

Figure 4.6 - Schematic cartoon illustrating the cyclical underplating process (see text) beneath the a) East Cape Ridge; and b) Raukumara Peninsula (Modified from Sutherland et al. [2009]). Note the difference between the location of underplating and uplift relative to the trench between the two regions. This difference suggests that the Moho modulates the underplating process, effectively limiting the distance (and depth) subducted material can remain within the subduction channel before being accreted to the upper plate. Arrows denote hypothesised particle-motion paths. 
The down-dip extent of the subduction channel is modulated by the forearc Moho (Figure 4.6a-b), the position of which may be dynamic. If the rate of crustal underplating exceeds the rate of tectonic erosion, the forearc crust will thicken, the Moho will deepen and the locus of crustal underplating will migrate away from the trench (Figure 4.7). This sequence of events is suggested to give rise to the migration of the Neogene depocenter observed within Raukumara Basin

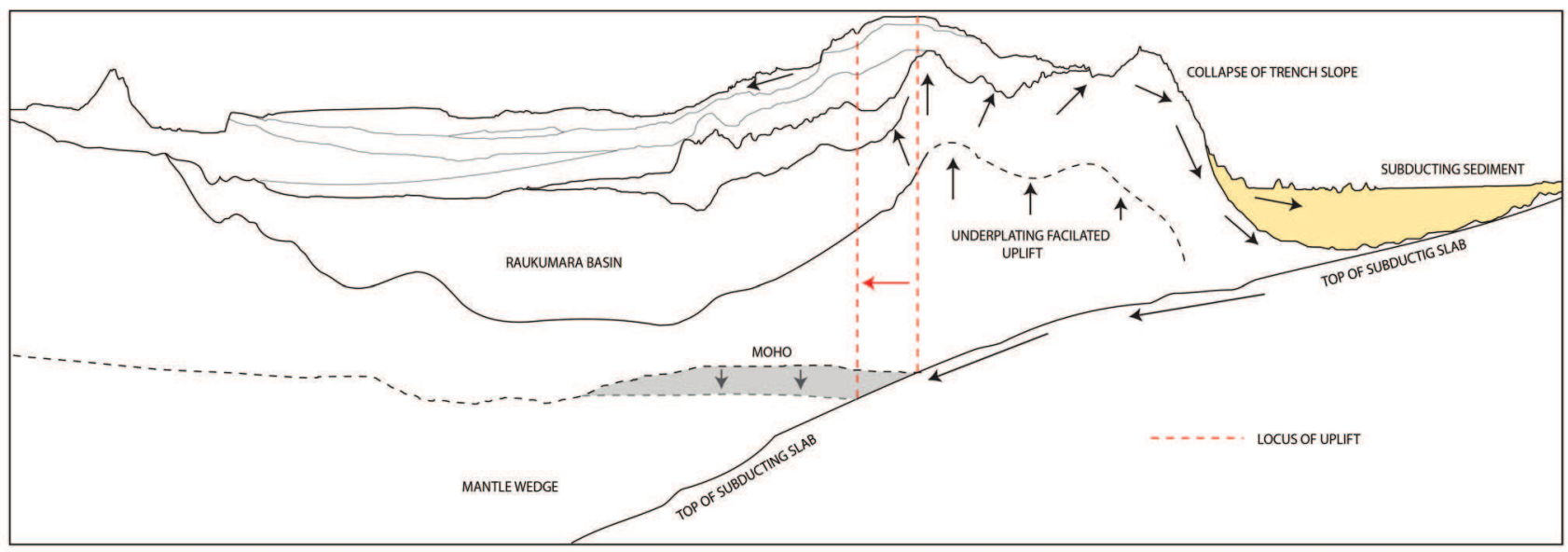

Figure 4.7 - Cartoon illustrating the thickening of forearc crust and the arcward migration of the slab-moho intersection induced by progressive crustal underplating in a state of net forearc growth. The locus of contemporary surface uplift is predicted to migrate toward the arc in response to the increase in Moho depth.

It is hypothesised that the rate of uplift and thus trench-slope collapse at East Cape Ridge will exceed that occurring onshore and adjacent to the Raukumara Peninsula (Figure 4.8). This prediction is based on: A) Higher rates of sediment supply adjacent to East Cape Ridge; B) A shorter down-dip length of the subduction channel causing subducted sediment to be distributed over a smaller (and thus thicker) area; and C) A shorter baseline ( $\mathrm{L}_{1}$ in Figure 4.8) beneath East Cape Ridge, which would give rise to higher rates of angular increase independent of differential uplift rates. 


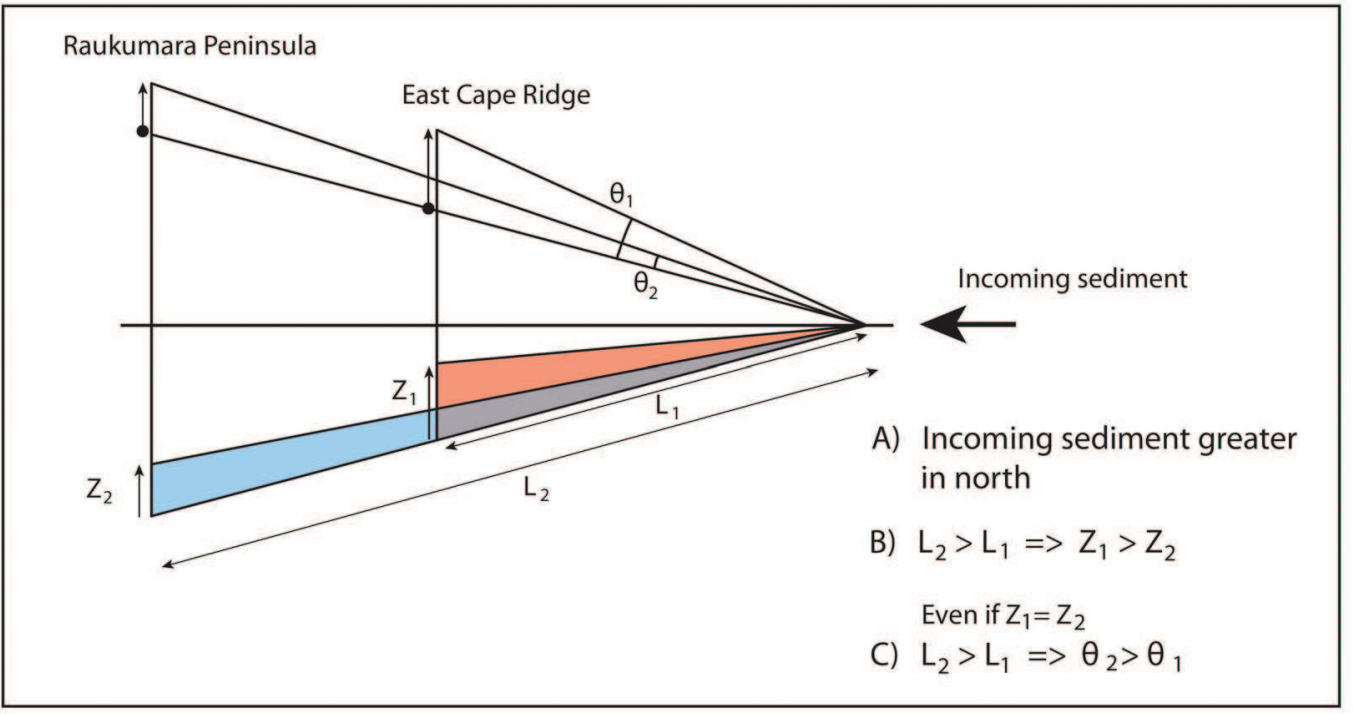

Figure 4.8 - Cartoon illustrating the influence the down-dip length of the subduction channel exerts on rates of uplift and angular increase in the overlying trench-slope (See text).

This hypothesis is consistent with the physiography of the seabed [Sutherland et $a l, 2009]$ and observations of internal deformation within Raukumara Basin strata (Section 2.5).

The cyclical crustal dynamic described above is modulated by the depth of the forearc Moho and provides a viable explanation for the variation in distance between the trench and the topographic crest between the Raukumara Peninsula and the East Cape Ridge. This conclusion is supported by the spatial correlation observed between the Moho-slab intersection lineation and the westward limit of the low-velocity prism modelled beneath the topographic crest (Figure 4.4 and 4.6). This model also provides explanations for the arcward migration of the Neogene Raukumara Basin depocenter (Figure 4.7), the morphology of the trench-slope and the varying degrees of internal deformation adjacent to East Cape Ridge and the Raukumara Peninsula (Figure 4.8). 


\section{5 - Global Implications}

\subsection{1 - Quantification of the fluxes at convergent margins}

From observations of the bathymetry, structure and morphology of the trenchslope and forearc basins at over 30 arcs of known (estimated) Phanerozoic activity, it has been suggested that subduction zones are sites of large scale crustal destruction where considerable quantities of crustal material is mixed back into the mantle [Von Huene and Scholl, 1991; Clift and Vannucchi, 2004].

Recent estimates of the global average rate of crustal loss at subduction zones are $90 \mathrm{~km}^{3} \mathrm{Myr}^{-1} \mathrm{~km}^{-1}$ [Clift and Vannucchi, 2004]. It is suggested that $\sim 85 \%$ of sediment arriving at subduction trenches is subducted into the mantle, exemplifying the inefficiency of frontal accretion to erode and preserve sediment from the downgoing plate [Von Huene and Scholl, 1991; Clift and Vannucchi, 2004]. Contributions from subduction erosion to the mass flux of sedimentary and crustal material to the mantle are significant and although only $57 \%$ of subduction margins are classified as erosive settings, the rate of tectonic erosion at these margins is sufficient to surpass the global flux of sediment derived from the subducting slab (Figure 4.9) [Clift and Vannucchi, 2004].

Using Sm-Nd isotopic data on clastic and chemical sediments in conjunction with the present-day age distribution of continental crustal rocks, Jacobsen [1988] suggest that the volume of continental crust has been steadily growing throughout the Phanerozoic. This growth is hypothesised to offset a deepening of ocean basins in response to waning heat-flow from the mantle, resulting in a generally constant degree of continental freeboard above mean sea-level during the Phanerozoic [Schubert and Reymer, 1985]. In light of these studies, and to preserve the present degree of continental freeboard subject to estimated rates of global crustal loss, Clift and Vannucchi [2004] suggest a global average rate of arc productivity of $91 \mathrm{~km}^{3} \mathrm{Myr}^{-1} \mathrm{~km}^{-1}$. 


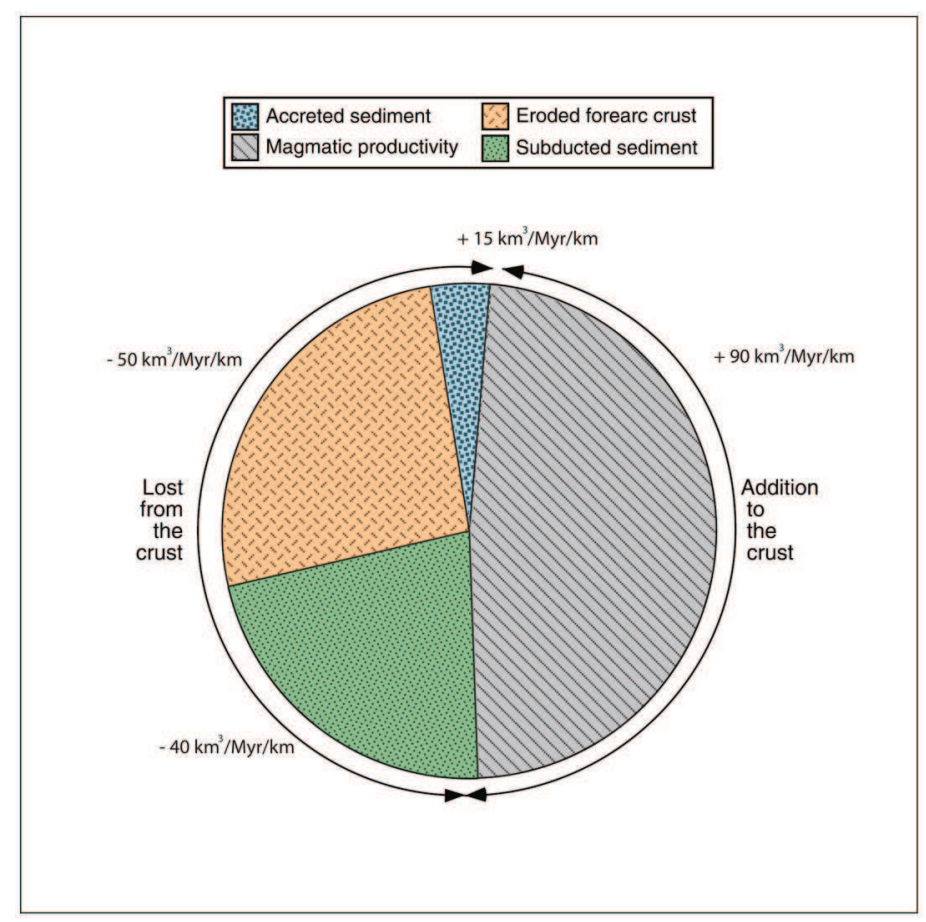

Figure 4.9 - Pie chart from Clift and Vannucchi [2004] illustrating the relative proportions of the major inputs and outputs from global subduction zones. Note the hypothesised dominance of arc volcanism over sediment accretion as the predominant source of new continental crust. 


\subsection{2 - Sediment recycling and crustal underplating}

Using the same classification scheme implemented to estimate the global fluxes presented above, the Hikurangi-Kermadec subduction zone has been classified as an erosional margin and one of net crustal loss [Collot \& Davy, 1998; Von Huene and Scholl, 1991; Clift and Vannucchi, 2004]. This hypothesis is challenged by the observations presented in this thesis (Section 4.4.3), as are several of the assumptions that underpin estimates of global crustal fluxes in subduction zones.

When attempting to quantify subduction fluxes from observable products, direct measurement of accretionary wedges is coupled with estimated average rates of sediment supply to calculate the proportions of sediment delivered to the trenches which are accreted and subducted respectively. Even at accretionary margins, the proportion of sediment subducted is estimated at $\sim 85 \%$ [Von Huene and Scholl, 1991; Clift and Vannucchi, 2004]. The contribution of subduction erosion to rates of crustal loss are estimated from trench slope subsidence histories, which assuming vertical rock trajectories within the forearc wedge, are directly converted to rates of tectonic erosion. We suggest that the use of local evidence of trench slope subsidence to infer widespread states of basal tectonic erosion may result in the systematic calculation of erosion rates which are higher than reality. Moreover, the proportions of subducted and tectonically eroded sediment that is fluxed into the mantle may also be overstated as the retention of this material via lower-crustal underplating is generally not accounted for.

In this thesis, a low-velocity prism occupying $\sim 215 \mathrm{~km}^{3} / \mathrm{km}^{-1}$ is modelled beneath the outer forearc high of the northern Hikurangi subduction margin. This prism is interpreted as underplated material and this volume (and the timing of subduction initiation $\sim 22 \mathrm{Ma}$ ) is used to calculate an average rate of accretion of $\sim 10 \mathrm{~km}^{3} \mathrm{Myr}^{-1} \mathrm{~km}^{-1}$. The assumption that all forearc material trenchward of the topographic crest represents accreted sediment is used to calculate an upper limit to the rate of underplating of $\sim 25 \mathrm{~km}^{3} \mathrm{Myr}^{-1} \mathrm{~km}^{-1}$. The primary difference between the model developed in this thesis, and that previously proposed for non-accreting and erosional margins [Von Huene and Scholl, 1991; Clift and Vannucchi, 2004] pertains to cyclical nature of particle paths within the forearc wedge, the localisation of basal tectonic erosion and the significance of lowercrustal underplating (Figure 4.10). 


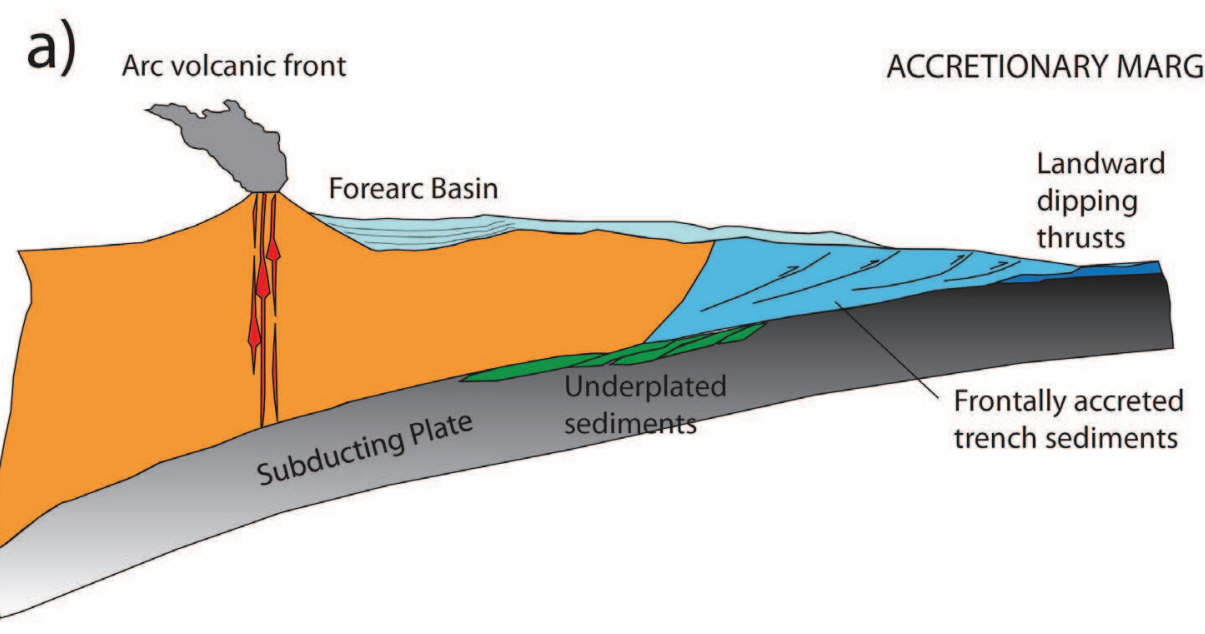

b) Arc volcanic front

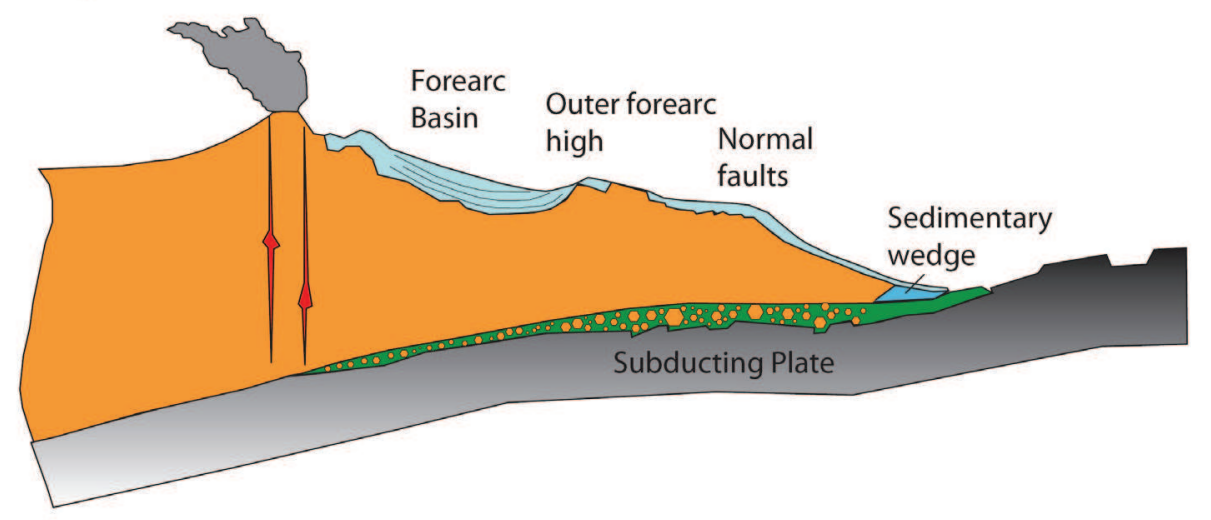

C) Arc volcanic front

OUR MODEL

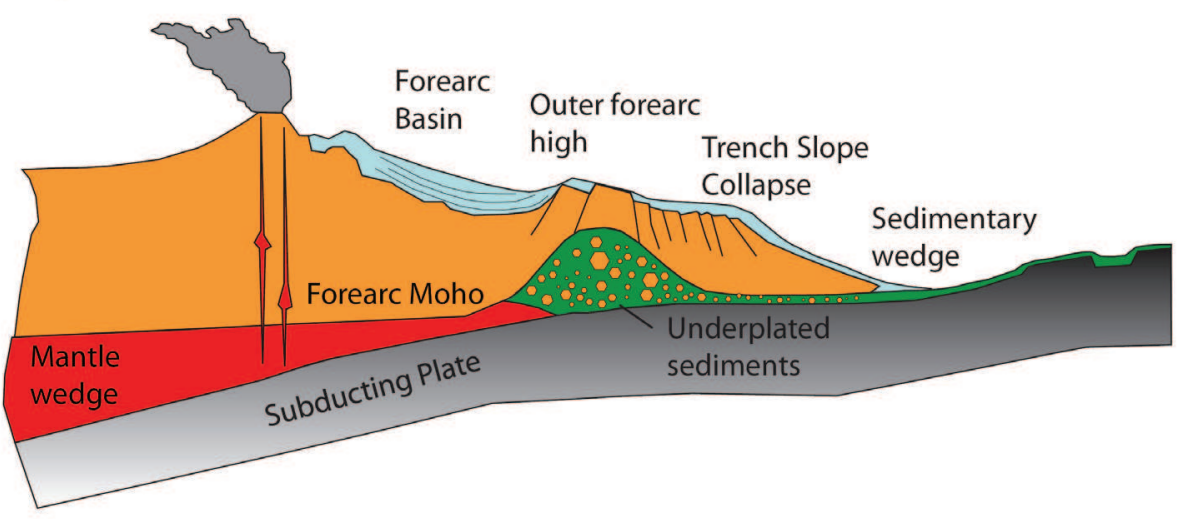

Modified from Clift and Vannucchi (2004)

Figure 4.10 - Schematic cartoons illustrating the features common to the two basic types of convergent margin presented within Clift and Vannucchi, (2004) a) Accretionary and b) Erosive / Non Accretionary c) displays an alternative model which is proposed for margins displaying morphological and structural characteristics consistent with subduction erosion, and stratigraphic evidence for zero net-balance or a net increase in the volume of the forearc wedge. 
North of the Hikurangi margin at the Tonga Trench, Clift et al. [1998] observe pronounced uplift of the outer-forearc high accompanied by subsidence and collapse of the trench-slope. The location of this observation is important to the estimates of crustal loss presented by Clift and Vannucchi [2004] and it is possible crustal underplating has been overlooked in this region.

\subsection{3 - Implications for the fluxes at convergent margins}

A discrepancy exists between estimates of crustal growth at volcanic arcs (20-40 $\mathrm{km}^{3} \mathrm{Myr}^{-1} \mathrm{~km}^{-1}$ [Reymer \& Schubert, 1984]) and crustal destruction at subduction zones (90 $\mathrm{km}^{3} \mathrm{Myr}^{-1} \mathrm{~km}^{-1}$ [Clift \& Vannucchi, 2004]). Taken together, these values imply a steady reduction in the volume of continental crust, a conclusion not supported by $\mathrm{Nd}$ isotopic evidence for continental evolution [Jacobsen, 1988] and the constant degree of continental freeboard suggested throughout the Phanerozoic [Schubert and Reymer, 1985].

To maintain the present degree of continental freeboard, Clift and Vannucchi [2004] propose comparable fluxes $\left(\sim 90 \mathrm{~km}^{3} \mathrm{Myr}^{-1} \mathrm{~km}^{-1}\right)$ between continental material incorporated into the mantle and arc magmatism. Recycling a large proportion of subducted continental material through the magmatic arc would imprint a strong continental signature on arc volcanic output. Isotopic evidence, however, suggests that most arc volcanic output is produced from melting in the upper mantle wedge with only minor degrees of sediment contamination [Woodhead \& Fraser, 1985; Ewart \& Hawkesworth, 1987; Vroon et al., 1993; as cited within Clift and Vannucchi, 2004]. The magmatic fluxes presented by Clift and Vannucchi [2004] are not ideal and are contrived entirely to maintain the present degree of continental freeboard, subject to estimated rates of global crustal loss.

It is difficult to quantify the fluxes of subducted sedimentary and continental material into the mantle. Rates of crustal destruction have progressively increased as more data have become available and although uncertainties associated with published estimates are unquantified, the rate proposed by Clift and Vannucchi [2004] is almost double that of the most recent previous estimate 「von Huene \& Scholl. 19911. 
This thesis demonstrates that lower-crustal underplating is an efficient means of accreting subducted and tectonically eroded material to the forearc. At the northern Hikurangi margin, the rate of accretion $\left(10-25 \mathrm{~km}^{3} \mathrm{Myr}^{-1} \mathrm{~km}^{-1}\right)$ is sufficient to counter-act subduction erosion and facilitate a net crustal-growth of the forearc. Hence, I submit lower-crustal underplating as a viable mechanism of reducing the flux of continental material into the mantle at subduction margins. Such a reduction will bring the rates of arc productivity required to maintain the present degree of continental freeboard closer to estimates published from the focussed study of arc volumes [Reymer and Schubert, 1984]. The theoretical flux of continental material through the magmatic arc will also be reduced, more in keeping with the geochemical signature of arc volcanic output [Woodhead and Fraser, 1985; Ewart and Hawkesworth, 1987; Vroon et al., 1993]. This thesis concludes with the proposition that the cyclical forearc dynamic and the rates of crustal underplating presented here, solve the discrepancy between the inputs and outputs at global subduction margins within analytical uncertainty. 


\section{6 - Future Research}

The research presented within this thesis is large in scope and lays the foundations for a number of studies to branch off from this work. Several potential studies are presented below but many more exist in this complex setting and the author is happy to discuss future research with interested parties.

- Analyses of the physical properties of the plate interface

For shots originating from the central Raukumara Basin and within the East Cape Ridge region, a west dipping phase is commonly observed and modelled as a reflection from the plate interface. Analyses of the waveforms of these data may be used to study the physical properties of the plate interface which have important implications for hazard assessment.

- Characterisation of the Raukumara gravity anomaly

The geophysical expression of Raukumara Basin is dominated by a -150 mgal free-air gravity anomaly. The geometry of the anomaly is triangular in shape, is approximately centred in the south-western corner of the Raukumara Plain adjacent to the rising East Cape Ridge and Raukumara Peninsula, and is located west of the intersection between the subducting slab and the forearc Moho. These characteristics are broadly similar to those observed within the Wanganui basin which is also characterised by a -150 mgal gravity anomaly.

Preliminary gravity models constructed throughout the course of this thesis for the Raukumara anomaly required some component of downward pull from within the mantle wedge, in addition to flexural effects associated with the uplift of the bordering regions. Again, these observations are similar to those from the Wanganui Basin [Stern et al., 1992] and a process focussed investigation of the Raukumara, Wanganui, and potentially Hawke Bay gravity anomalies may make a significant contribution toward understanding the degree of coupling between the subducting slab, mantle wedge and forearc crust along the HikurangiKermadec subduction margin. These studies may also have implications for 
hazard assessment beneath the North Island given the recently proposed links between large forearc gravity lows and the source regions for large subduction thrust earthquakes [Song \& Simons, 2003; Wells et al., 2003].

- Relocation of Earthquake hypocenters

FMTOMO has the capability to invert for earthquake hypocenters. It would be a simple yet beneficial exercise to relocate hypocenters beneath the Northern Raukumara Peninsula, Raukumara Plain and trench slope in light of the velocity model presented in this thesis.

- Differential uplift of the northern Raukumara Peninsula

A short survey in which the marine terraces mapped by Wilson et al., [2007] are revisited, may allow calculation of rates of contemporary differential uplift to be compared across the Raukumara Peninsula.

- Tectonics of the Raukumara forearc block.

From stratigraphic observations and the structural deformation observed onshore, the northern Raukumara Peninsula and Raukumara Plain is inferred to be as a rigid forearc block ( $>150 \mathrm{~km}$ in length). Onshore paleomagnetic declinations indicate that the Raukumara Peninsula (and hence this forearc block) have not experienced Neogene vertical axis clockwise rotations relative to the Australian plate [Mumme et al., 1989; Rowan et al., 2005; Rowan \& Roberts, 2008]. Correlations between the Northland and East Coast Allochthons suggest Raukumara Basin was originally positioned adjacent to Northland prior to $\sim 25$ Ma [e.g. Rait et al., 1991; King and Thrasher, 1996]. Passive translation of the Raukumara forearc block away from Northland, in the absence of any rotation, require kinematic separation of the Raukumara block from the East Coast further south (which has undergone large vertical axis rotations in Neogene time, [Nicol et al., 2007]). The Vening Meinesz Fracture Zone (VMFZ) may provide a viable means of such kinematic separation and may propagate through the Harve trough 
and northern Raukumara Peninsula in a location approximately correlated with the distinct change in the style of faulting observed onshore (Figure $4.11 \mathrm{a}-\mathrm{b}$ ).

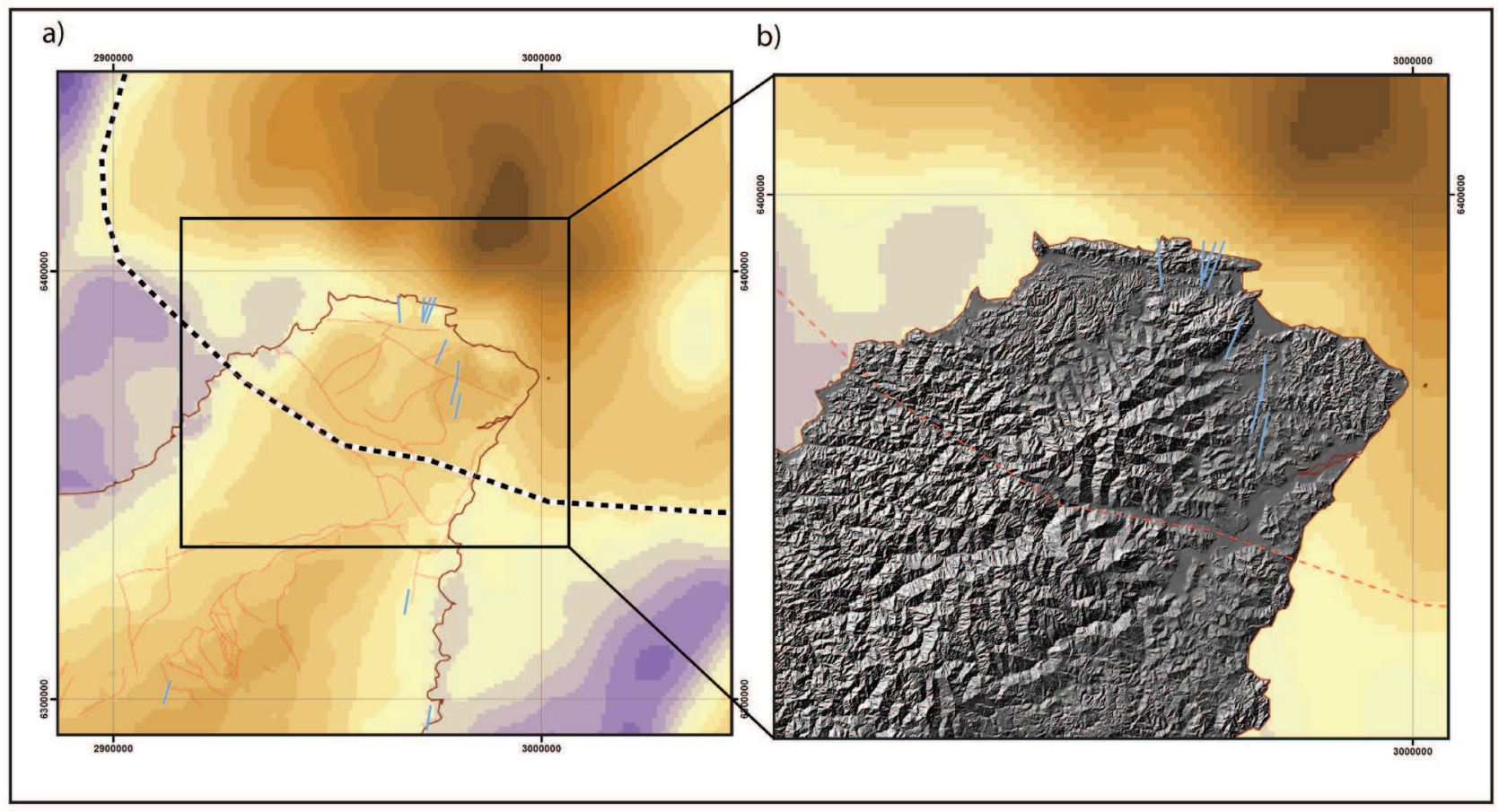

Figure 4.11 a) Free-air and bouguer gravity map and b) digital elevation model for the northern Raukumara Peninsula illustrating a possible position for the Vening Meinesz Fracture Zone displayed as dashed lines on both plots. In figure a, onshore faults are displayed in orange with the coastline plotted in red. Paleomagnetic declinations in are displayed in blue.

Building on the work of Herzer et al., [2009] who map the VMFZ adjacent to, and northeast of Northland, an interesting study may intergrate bathymetric, gravity and magnetic data to investigate the feasibility of using the VMFZ as a kinematic boundary between the northern Raukumara Peninsula and the East Coast of the North Island. 


\section{REFERENCES}

Baldock, G., 2004. High resolution crustal and upper mantle structure adjacent to a continental transform, South Island, New Zealand. Unpublished MSc thesis, Victoria University of Wellington.

Ballance, P.F., 1976. Evolution of the upper Cenozoic magmatic arc and plate boundary in northern New Zealand. Earth and planetary science letters, $28,356-370$.

Ballance, P.F. \& Spörli, K.B., 1979. Northland allochthon. Journal of the Royal Society of New Zealand, 9(2), 259-275.

Bannister, S., Bryan, C.J. \& Bibby, H.M., 2004. Shear wave velocity variation across the Taupo Volcanic Zone, New Zealand, from receiver function inversion. Geophysical Journal International, 159(1), 291-310.

Barker, D.H. et al., 2009. Geometry of the Hikurangi subduction thrust and upper plate, North Island, New Zealand. Geochemistry Geophysics Geosystems, 10(2), Q02007.

Beavan, J. et al., 2002. Motion and rigidity of the Pacific plate and implications for plate boundary deformation. J. geophys. Res, 107, 2261.

Black, P., Picard, C. \& Cluzel, D., 2002. Geology and Geochemistry of the Matakaoa Ophiolite, New Zealand: a Cretaceous Obducted Arc-Back Arc system: Comparison with the Tangihua Ophiolite. In 2002 Western Pacific Geophysics Meeting.

Brink, U.S. et al., 1993. Geophysical investigations of the tectonic boundary between East and West Antarctica. Science, 261(5117), 45-50.

Brisbourne, S. \& Stuart, G., 1998. Shear-wave velocity structure beneath North Island, New Zealand, from Rayleigh-wave interstation phase velocities. Journal of the Royal Society of New Zealand, 19, 93-106.

Brook, F.J., Isaac, M.J. \& Hayward, B.W., 1988. Geology of autochthonous and allochthonous strata in the Omahuta area, northern New Zealand. New Zealand Geological Survey Record, 32, 40.

Bull, S., Cartwright, J. \& Huuse, M., 2008. A subsurface evacuation model for submarine slope failure. Basin Research, 21(4), 433-443.

Cande, S.C. \& Stock, J.M., 2004. Pacific-Antarctic-Australia motion and the formation of the Macquarie Plate. Geophysical Journal International, 157(1), 399-414.

Chadwick, M., 1997. The 1991 Hikurangi Margin seismic refraction experiment. PhD thesis, Victoria University of Wellington, New Zealand, 1-234. 
Clift, P. \& Vannucchi, P., 2004. Controls on tectonic accretion versus erosion in subduction zones: Implications for the origin and recycling of the continental crust. Reviews of Geophysics, 42(2).

Clift, P.D. et al., 1998. Tectonic controls on sedimentation and diagenesis in the Tonga Trench and forearc, southwest Pacific. Bulletin of the Geological Society of America, 110(4), 483-496.

Cloos, M., 1993. Lithospheric buoyancy and collisional orogenesis; subduction of oceanic plateaus, continental margins, island arcs, spreading ridges, and seamounts. Bulletin of the Geological Society of America, 105(6), $715-737$.

Collot, J.Y. \& Davy, B., 1998. Forearc structures and tectonic regimes at the oblique subduction zone between the Hikurangi Plateau and the southern Kermadec margin. Journal of Geophysical Research-Solid Earth, 103, 623-650.

Collot, J.Y. et al., 1996. From oblique subduction to intra-continental transpression: structures of the southern Kermadec-Hikurangi margin from multibeam bathymetry, side-scan sonar and seismic reflection. Marine Geophysical Researches, 18(2), 357-381.

Davey, F.J., Henrys, S. \& Lodolo, E., 1997. A seismic crustal section across the East Cape convergent margin, New Zealand. Tectonophysics, 269(3-4), 199-215.

Davies, G.F. \& Richards, M.A., 1992. Mantle convection. The Journal of Geology, 151-206.

Davy, B., 1992. The influence of subducting plate buoyancy on subduction of the Hikurangi-Chatham Plateau beneath the North Island, New Zealand. Advances in the Geology and Geophysics of the Continental Margin, American Assn of Pet. Geol, 75-91.

Davy, B. \& Collot, J.Y., 2000. The Rapuhia Scarp (northern Hikurangi Plateau) - its nature and subduction effects on the Kermadec Trench. Tectonophysics, 328(3-4), 269-295.

Davy, B., Hoernle, K. \& Werner, R., 2008. Hikurangi Plateau: Crustal structure, rifted formation, and Gondwana subduction history. Geochemistry Geophysics Geosystems, 9(7), Q07004.

Davy, B. \& Wood, R., 1994. Gravity and magnetic modelling of the Hikurangi Plateau. Marine geology, 118(1-2), 139-151.

DeMets, C. et al., 1994. Effect of recent revisions to the geomagnetic reversal time scale on stimates of current plate motions. Geophysical Research Letters, 21, 2191-2194. 
Dickinson, W.R. \& Seely, D.R., 1979. Structure and stratigraphy of forearc regions. AAPG Bulletin, 63(1), 2-31.

Dowling, J.J., 1968. The east coast onshore-offshore experiment, II. Seismic refraction measurements on the Continental Shelf between Cape Hatteras and Cape Fear. Bulletin of the Seismological Society of America, 58(3), 821-834.

Eberhart-Phillips, D. \& Reyners, M., 1999. Plate interface properties in the northeast Hikurangi subduction zone, New Zealand, from converted seismic waves. Geophysical Research Letters, 26(16).

Eberhart-Phillips, D. \& Reyners, M., 2009. Three-dimensional distribution of seismic anisotropy in the Hikurangi subduction zone beneath the central North Island, New Zealand. Journal of Geophysical Research-Solid Earth, 114(B6), B06301.

Ewart, A. \& Hawkesworth, C.J., 1987. The Pleistocene-Recent Tonga-Kermadec arc lavas: interpretation of new isotopic and rare earth data in terms of a depleted mantle source model. Journal of Petrology, 28(3), 495-530.

Field, B.D. et al., 2004. Play concepts for a complex margin: East Coast North Island, New Zealand. In 2004 New Zealand Petroleum Conference Proceedings. pp. 34-1.

Field, B.D. et al., 1997. Cretaceous-Cenozoic geology and petroleum systems of the East Coast region, New Zealand. Institute of Geological \& Nuclear Sciences Monograph, 19(301), 7.

Forsyth, D. \& Uyedaf, S., 1975. On the Relative Importance of the Driving Forces of Plate Motion. Geophysical Journal of the Royal Astronomical Society, 43(1), 163-200.

Frey-Martınez, J., Cartwright, J. \& James, D., 2006. Frontally confined versus frontally emergent submarine landslides: a 3D seismic characterisation. Marine and Petroleum Geology, 23(5), 585-604.

Fugro Seismic Imaging, 2007. Raukumara Basin 2D Seismic Survey - RAU07, New Zealand. Unpublished Openfile Petroleum Report, Minustry of Economic Development, Crown Minerals, Wellington, 1-37.

Galea, P., 1992. Observations of very high P-velocities in the subducted slab, New Zealand, and their relation with the slab geometry. Geophysical Journal International, 110(2), 238-250.

Gillies, P.N. \& Davey, F.J., 1986. Seismic reflection and refraction studies of the Raukumara forearc basin, New Zealand. New Zealand Journal of Geology and Geophysics, 29(4), 391-403. 
Gillies, P., 1984. A marine geophysical study of the junction of the Kermadec and Hikurangi subduction systems. Unoublished PhD thesis, loged in the library, University of Auckland.

Gladczenko, T.P., Coffin, M.F. \& Eldholm, O., 1997. Crustal structure of the Ontong Java Plateau: Modeling of new gravity and existing seismic data. Journal of Geophysical Research-Solid Earth, 102(B10).

Gledhill, K. \& Gubbins, D., 1996. SKS splitting and the seismic anisotropy of the mantle beneath the Hikurangi subduction zone, New Zealand. Physics of the Earth and Planetary Interiors, 95(3), 227-236.

Greve, S.M., Savage, M.K. \& Hofmann, S.D., 2008. Strong variations in seismic anisotropy across the Hikurangi subduction zone, North Island, New Zealand. Tectonophysics, 462(1-4), 7-21.

Hacker, B.R. et al., 2003. Subduction factory 2. Are intermediate-depth earthquakes in subducting slabs linked to metamorphic dehydration reactions. J. geophys. Res, 108(B1), 2030.

Haines, J., 1979. Seismic wave velocities in the uppermost mantle beneath New Zealand. New Zealand Journal of Geology \& Geophysics, 22(2), 245257.

Hamilton, R.M., 1969. Seismological studies of the Gisborne earthquake sequence, 1966, New Zealand Department of Scientific and Industrial Research. Bulletin, 194.

Hayward, B.W. et al., 2001. K-Ar ages of early Miocene arc-type volcanoes in northern New Zealand. New Zealand Journal of Geology and Geophysics, 44(2), 285-312.

Henrys, S. et al., 2006. Kinking of the subducting slab by escalator normal faulting beneath the North Island of New Zealand. Geology, 34(9), 777780 .

Herzer, R.H., 1995. Seismic stratigraphy of a buried volcanic arc, Northland, New Zealand and implications for Neogene subduction. Marine and petroleum geology, 12(5), 511-531.

Hobro, J.W., Singh, S.C. \& Minshull, T.A., 2003. Three-dimensional tomographic inversion of combined reflection and refraction seismic traveltime data. Geophysical Journal International, 152(1), 79-93.

Horspool, N.A., Savage, M.K. \& Bannister, S., 2006. Implications for intraplate volcanism and back-arc deformation in northwestern New Zealand, from joint inversion of receiver functions and surface waves. Geophysical Journal International, 166(3), 1466-1483. 
von Huene, R. \& Scholl, D.W., 1991. Observations at convergent margins concerning sediment subduction, subduction erosion, and the growth of continental crust. Reviews of Geophysics, 29(3).

Isaac, M.J., 1996. Geology of the Kaitaia area, in Institute of Geological and Neclear Sciences 1:250 000 geological map. Institute of Geological \& Nuclear Sciences .

Isaac, M.J., Brook, F.J. et al., 1994. Emplacement of the Northland Allochthon. Institute of Geological \& Nuclear Sciences Science Report 92, 24, 7-11.

Isaac, M.J., Herzer, R.H. et al., 1994a. Cretaceous and Cenozoic geology of Northland. New Zealand: Lower Hutt, Institute of Geological and Nuclear Sciences, Institute of Geological and Nuclear Sciences Limited, monograph, 8, 203.

Isaac, M.J. et al., 1994b. Cretaceous and Cenozoic sedimentary basins of Northland, New Zealand. Institute of Geological \& Nuclear Sciences Monograph, 8, 203.

Jacobsen, S.B., 1988. Isotopic constraints on crustal growth and recycling. Earth and planetary science letters, 90(3), 315-329.

Katz, H.R., 1974. Margins of the southwest Pacific. The geology of continental margins: New York, Springer-Verlag, 549-565.

Kayal, J. \& Smith, E., 1984. Upper mantle P-wave velocities in the southeast North Island, New Zealand. Tectonophysics, 104, 115-125.

Kenny, J.A., 1984. Stratigraphy, sedimentology and structure of the Ihungia decollement, Raukumara Peninsula, North Island, New Zealand. New Zealand Journal of Geology and Geophysics, 27(1), 1-19.

King, P. \& Thrasher, G.P., 1996. Cretaceous-Cenozoic petroleum systems of the Taranaki Basin, Institute of Geological and Nuclear Sciences, Wellington.

Knopoff, L. \& Gangi, A.F., 1959. Seismic reciprocity. Geophysics, 24, 681.

de Kool, M., Rawlinson, N. \& Sambridge, M., 2006. A practical grid-based method for tracking multiple refraction and reflection phases in threedimensional heterogeneous media. Geophysical Journal International, 167(1), 253-270.

Lafond, C.F. \& Levander, A., 1995. Migration of wide-aperture onshore-offshore seismic data, central California: Seismic images of late stage subduction. Journal of Geophysical Research-Solid Earth, 100(B11). 
Lamarche, G., Barnes, P.M. \& Bull, J.M., 2006. Faulting and extension rate over the last 20,000 years in the offshore Whakatane Graben, New Zealand continental shelf. Tectonics, 25(4).

Lamarche, G., Joanne, C. \& Collot, J.Y., 2008. Successive, large mass-transport deposits in the south Kermadec fore-arc basin, New Zealand: The Matakaoa Submarine Instability Complex. Geochemistry Geophysics Geosystems, 9(4), Q04001.

Lamb, S.H., 1988. Tectonic rotations about vertical axes during the last $4 \mathrm{Ma}$ in part of the New Zealand plate-boundary zone. Journal of structural geology, 10(8), 875-893.

Litchfield, N. et al., 2007. Insights into subduction-related uplift along the Hikurangi Margin, New Zealand, using numerical modeling. Journal of Geophysical Research-Earth Surface, 112(F2), F02021.

Lueschen, E. et al., (submitted manuscript). Structure, evolution and tectonic activity of the eastern Sunda forearc, Indonesia, from marine seismic investigations, Tectonophyics,

Mazengarb, C. \& Speden, I., 2000. Geology of the Raukumara area, in Institute of Geological and Neclear Sciences 1:250 000 geological map. Institute of Geological \& Nuclear Sciences , 6, 1-60.

Moore, P.R., 1988. Stratigraphy, composition and environment of deposition of the Whangai Formation and associated Late Cretaceous-Paleocene rocks, eastern North Island, New Zealand. New Zealand Geological Survey Bulletin, 100, 1-82.

Mumme, T.C., Lamb, S.H. \& Walcott, R.I., 1989. The Raukumara paleomagnetic domain: constraints on the tectonic rotation of the East Coast, North Island, New Zealand, from paleomagnetic data. New Zealand Journal of Geology and Geophysics, 32(3), 317-326.

Nicol, A. et al., 2007. Tectonic evolution of the active Hikurangi subduction margin, New Zealand, since the Oligocene. Tectonics, 26(4).

Rait, G., Chanier, F. \& Waters, D.W., 1991. Landward-abd seaward-directed thrusting accompanying the onset of subduction beneath New Zealand. Geology, 19(3), 230-233.

Rait, G.J., 2000. Thrust transport directions in the Northland allochthon, New Zealand. New Zealand Journal of Geology and Geophysics, 43(2), 271288.

Rait, G.J., 1993. Early Miocene Thrust Tectonics on Raukumara Peninsula, Northeastern New Zealand, PhD thesis, Victoria University of Wellington, New Zealand, 1-241. 
Rawlinson, N. \& Sambridge, M., 2004. Multiple reflection and transmission phases in complex layered media using a multistage fast marching method. Geophysics, 69(5), 1338-1350.

Rawlinson, N. \& Sambridge, M., 2005. The fast marching method: an effective tool for tomographic imaging and tracking multiple phases in complex layered media. Exploration Geophysics, 36(1), 341-350.

Rawlinson, N. \& Sambridge, M., 2004. Wave front evolution in strongly heterogeneous layered media using the fast marching method. Geophysical Journal International, 156(3), 631-647.

Reyners, M., Eberhart-Phillips, D. \& Stuart, G., 1999. A three-dimensional image of shallow subduction: crustal structure of the Raukumara Peninsula, New Zealand. Geophys. J. Int., 137(3), 873-890.

Reyners, M. et al., 2006. Imaging subduction from the trench to $300 \mathrm{~km}$ depth beneath the central North Island, New Zealand, with $\mathrm{Vp}$ and $\mathrm{Vp} / \mathrm{Vs}$. Geophysical Journal International, 165(2), 565-583.

Robinson, R., 1986. Seismicity, structure and tectonics of the Wellington region, New Zealand. Geophysical Journal of the Royal Astronomical Society, 87(2), 379-409.

Rowan, C.J. \& Roberts, A.P., 2008. Widespread remagnetizations and a new view of Neogene tectonic rotations within the Australia-Pacific plate boundary zone. New Zealand: Journal of Geophysical Research, 113.

Rowan, C.J., Roberts, A.P. \& Rait, G.J., 2005. Relocation of the tectonic boundary between the Raukumara and Wairoa Domains (East Coast, North Island, New Zealand): implications for the rotation history of the Hikurangi margin. New Zealand Journal of Geology \& Geophysics, 48, 185-196.

Scherwath, M. et al., (submitted manuscript). Forearc deformation at the nothern Hikurangi Margin, New Zealand. Journal of Geophysical Research.

Scherwath, M. et al., 2003. Lithospheric structure across oblique continental collision in New Zealand from wide-angle P wave modeling. J. geophys. Res, 108(12), 2566.

Schubert, G. \& Reymer, A.P.S., 1985. Continental volume and freeboard through geological time.

Sethian, J.A. \& Popovici, A.M., 1999. Three dimensional traveltimes computation using the fast marching method. Geophysics, 64(2), 516523.

Sethian, J.A., 1996. A fast marching level set method for monotonically advancing fronts, National Acad Sciences. 
Smith, E.G., Stern, T. \& Reyners, M., 1989. Subduction and back-arc activity at the Hikurangi convergent margin, New Zealand. Pure and Applied Geophysics, 129(1), 203-231.

Spence, G.D., Clowes, R.M. \& Ellis, R.M., 1985. Seismic structure across the active subduction zone of western Canada. J. geophys. Res, 90, 67546772 .

Stern, R.J., 2002. Subduction zones. Rev. Geophys, 40(4), 1012.

Stern, T. et al., 2001. Low seismic-wave speeds and enhanced fluid pressure beneath the Southern Alps of New Zealand. Geology, 29(8), 679-682.

Stoneley, R., 1968. A lower Tertiary decollement on the east coast, North Island, New Zealand. New Zealand journal of geology and geophysics, 11, 128156.

Sutherland et al., 2009. Reactivation of tectonics, crustal underplating and uplift after 60 Myr of passive subsidence, Raukumara Basin, HikurangiKermadec forearc, New Zealand: implications for global growth and recycling of continents. Tectonics, Vol 28, TC5017, doi:10.1029/2008TC002356.

Sutherland, R. et al., 2007. Do great earthquakes occur on the Alpine fault in central South Island, New Zealand. A Continental Plate Boundary: Tectonics at South Island, New Zealand. Washington DC: American Geophysical Union. Geophysical monograph, 235-251.

Ten Brink, U. \& Stern, T., 1992. Rift flank uplifts and hinterland basins: Comparison of the Transantarctic Mountains with the Great Escarpment of southern Africa. Journal of Geophysical Research-Solid Earth, 97(B1).

Thornley, S., 1996. Neogene Tectonics of Raukumara Peninsula, Northern Hikurangi Margin, New Zealand. Unpublished PhD thesis, Victoria University of Wellington.

Tréhu, A.M. et al., 1995. A seismic reflection profile across the Cascadia subduction zone offshore central Oregon: New constraints on methane distribution and crustal structure. Journal of Geophysical Research-Solid Earth, 100(B8).

Uruski, C. et al., 2008. The discovery of a new sedimentary basin: offshore Raukumara, East Coast, North Island. APPEA Journal, 47.

Vroon, P.Z. et al., 1993. Sr-Nd-Pb isotope systematics of the Banda Arc, Indonesia: Combined subduction and assimilation of continental material. Journal of Geophysical Research (ISSN 0148-0227), 98(B12). 
Walcott, R.I., 1987. Geodetic strain and the deformational history of the North Island of New Zealand during the late Cainozoic. Philosophical Transactions for the Royal Society of London. Series A, Mathematical and Physical Sciences, 163-181.

Walcott, R.I., 1998. Modes of oblique compression: Late Cenozoic tectonics of the South Island of New Zealand. Reviews of Geophysics, 36(1), 1-26.

Walcott, R.I., 1984. The kinematics of the plate boundary zone through New Zealand: a comparison of short-and long-term deformations. Geophysical Journal of the Royal Astronomical Society, 79(2), 613-633.

Wallace, L.M. et al., 2004. Subduction zone coupling and tectonic block rotations in the North Island, New Zealand. Journal of Geophysical Research-Solid Earth, 109(B12), B12406.

Walters, R. et al., 2006. Locally generated tsunami along the Kaikoura coastal margin: Part 2. Submarine landslides. New Zealand Journal of Marine and Freshwater Research, 40(1), 17.

Ward, S.N. \& Day, S., 2002. Suboceanic landslides, in 2002 yearbook of science and technology, New York, McGraw-Hill.

Wilson, K. et al., 2007. Distribution, age, and uplift patterns of Pleistocene marine terraces of the northern Raukumara Peninsula, North Island, New Zealand. New Zealand Journal of Geology \& Geophysics, 50, 181-191.

Woodhead, J.D. \& Fraser, D.G., 1985. Pb, $\mathrm{Sr}$ and $10 \mathrm{Be}$ isotopic studies of volcanic rocks from the Northern Mariana Islands. Implications for magma genesis and crustal recycling in the Western Pacific. Geochim. Cosmochim. Acta, 49(9), 1925-1930.

Zelt, C.A. \& Smith, R.B., 1992. Seismic traveltime inversion for 2-D crustal velocity structure. Geophysical Journal International, 108(1), 16-34. 


\title{
3-D Velocity structure of the northern Hikurangi margin: implications for crustal growth
}

\author{
Daniel Graham Bassett
}

VOLUME TWO - APPENDICES

A thesis submitted to Victoria University of Wellington in fulfilment of the requirement for the degree

Master of Science - Geology/Geophysics

August 2009

Institute of Geophysics

School of Geography, Environment and Earth Science

Victoria University of Wellington 


\title{
VOLUME TWO - TABLE OF CONTENTS
}

\author{
APPENDIX ONE - ACQUISITION, PROCESSING AND \\ INTERPRETATION OF ONSHORE-OFFSHORE SEISMIC DATA
}

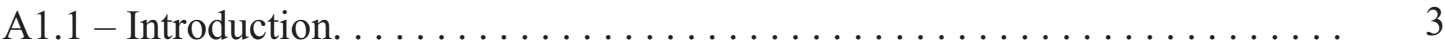

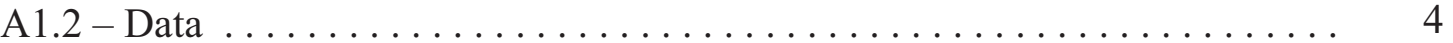

A1.3 - Data Processing

A1.3.1 - Data extraction and Conversion

A1.3.1.1 - VUW Data ...................... 6

A1.3.1.2-GNS Data ..................... 6

A1.3.2 -Compilation of navigation and shot time data

A1.3.2.1 - Shot times. . . . . . . . . . . . . . . . . . 7

A1.3.2.2 - Shot positions .................... 9

A1.3.3 - Data preparation ........................ 12

A1.3.3.1 - VUW Data ..................... 12

A1.3.3.2 - GNS Data ........................ 13

A1.3.4 - Cutting Receiver Gathers. . . . . . . . . . . . . . . . . . . . . . 14

A1.3.5 - Processing . . . . . . . . . . . . . . . . . . . . . 16

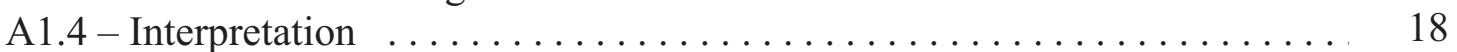

A1.5 - Results

A1.5.1 - Data and travel times . . . . . . . . . . . . . . . . . . . 19

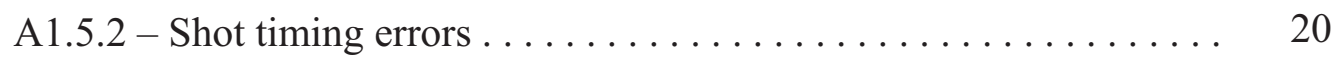

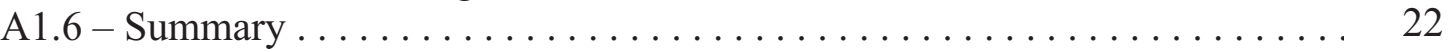

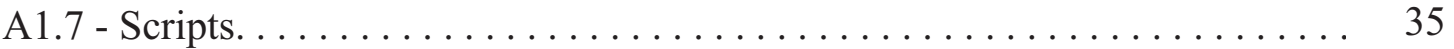

APPENDIX TWO - 3-D FORWARD MODELLING

A2.1 - Introduction. . . . . . . . . . . . . . . . . . . . . . . . . . . . . . . . . 87

$\mathrm{A} 2.2-$ FMTOMO $\ldots \ldots \ldots \ldots \ldots \ldots \ldots \ldots \ldots \ldots \ldots \ldots \ldots \ldots \ldots \ldots \ldots \ldots$

A2.2.1 - Fast Marching Method ..................... 88

A2.2.2 - grid $3 d g$ grid generation . . . . . . . . . . . . . . . . . 89

A2.2.2.1 - Interface grids $\ldots \ldots \ldots \ldots \ldots \ldots \ldots \ldots \ldots \ldots$

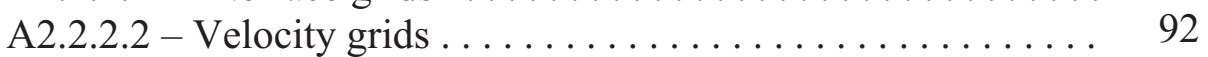

A2.3-Complex grid generation $\ldots \ldots \ldots \ldots \ldots \ldots \ldots \ldots \ldots \ldots \ldots$

A2.3.1 - Grid Space .......................... 93

A2.3.2 - Interface Grids . . . . . . . . . . . . . . . . . . . . 94

A2.3.3 - Velocity Grids ... . . . . . . . . . . . . . . . . . 95

A2.4- Interpretation of results $\ldots \ldots \ldots \ldots \ldots \ldots \ldots \ldots \ldots \ldots \ldots \ldots \ldots$

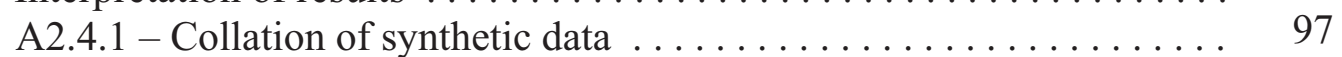

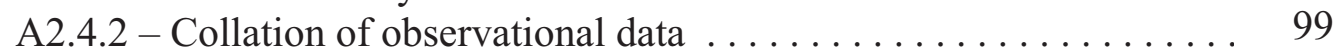

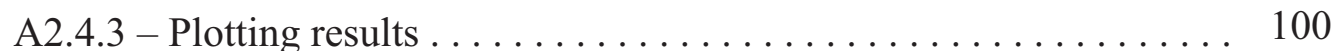

A2.4.4 - Visualising raypaths _... . . . . . . . . . . . . . . . 103

A2.5 - Model resolution . . . . . . . . . . . . . . . . . . . . . . . . . . . 104

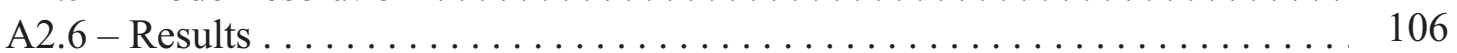

A2.7 - Summary . . . . . . . . . . . . . . . . . . . . . . . . . 108

A2.8 - Scripts. . . . . . . . . . . . . . . . . . . . . . . . . . . . . . 109 
APPENDIX THREE - TOMOGRAPHC INVERSION

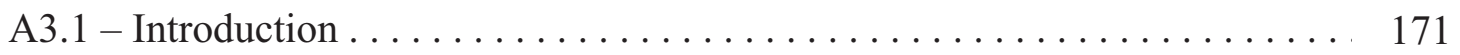

A3.2 - Unconstrained Inversion . . . . . . . . . . . . . . . . . 173

A3.3 - Constrained Inversion . . . . . . . . . . . . . . . . . . . . . 177

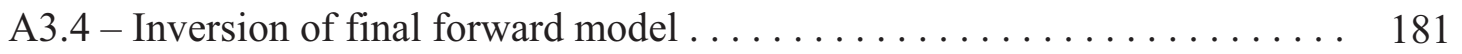

APPENDIX FOUR - SUPPLEMENTARY FIGURES

A4.1 - Forward model results . . . . . . . . . . . . . . . . . . . . . . . . . . . . . 187

A4.2 - Model ray coverage plots

A4.2.1-Cross-sections . . . . . . . . . . . . . . . . . . . . . . . . . . . . . . . . 197

A4.2.2 - Depth-slices . . . . . . . . . . . . . . . . . . . . . 199

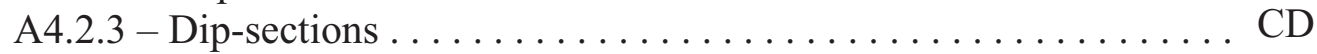

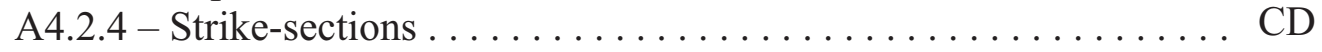




\section{APPENDIX ONE - ACQUISITION, PROCESSING AND INTERPRETATION OF ONSHORE-OFFSHORE SEISMIC DATA}

\section{TEXT}

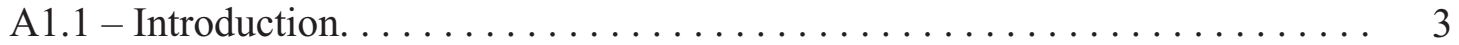

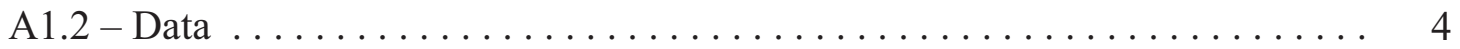

A1.3 - Data Processing

A1.3.1 - Data extraction and Conversion

A1.3.1.1 - VUW Data ..................... 6

A1.3.1.2 - GNS Data ..................... 6

A1.3.2 -Compilation of navigation and shot time data

A1.3.2.1 - Shot times. . . . . . . . . . . . . . . . 7

A1.3.2.2 - Shot positions ................... 9

A1.3.3 - Data preparation ....................... 12

A1.3.3.1 - VUW Data . . . . . . . . . . . . . . . . . . . 12

A1.3.3.2 - GNS Data ...................... 13

A1.3.4 - Cutting Receiver Gathers. . . . . . . . . . . . . . . . . . . 14

A1.3.5 - Processing . . . . . . . . . . . . . . . . . . . . 16

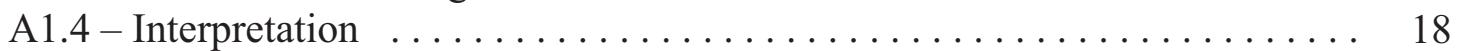

A1.5 - Results

A1.5.1 - Data and travel-times ..................... 19

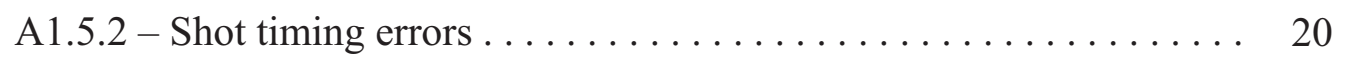

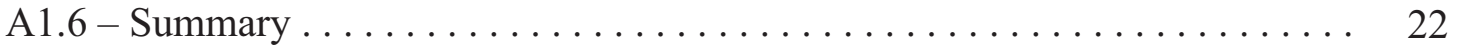

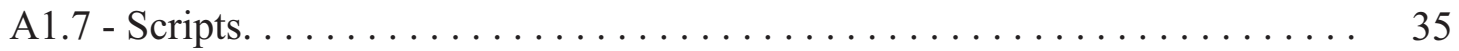

\section{SCRIPTS}

Scripts used for the conversion of raw data into Passcal SEG-Y

A1.1 - rt130 processing . . . . . . . . . . . . . . . . . . . 37

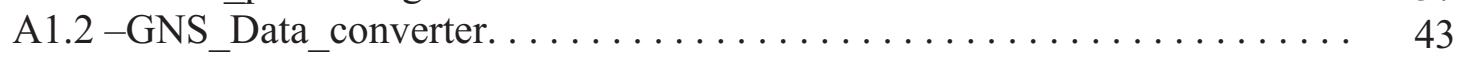

Scripts used in the preparation of data and construction of segyfile lists

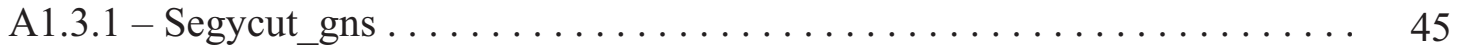

A1.3.2 - create_allsegyfilelists_gns ..................... 57

A1.4.1-merge_segy_dan ............................. 59

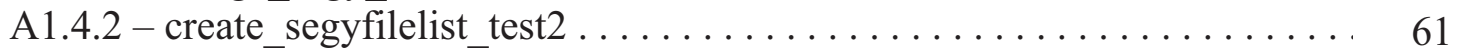

Scripts used to create of segygather input files

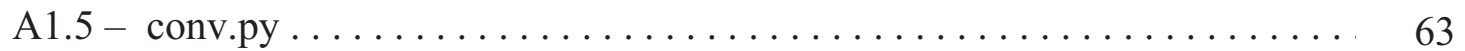

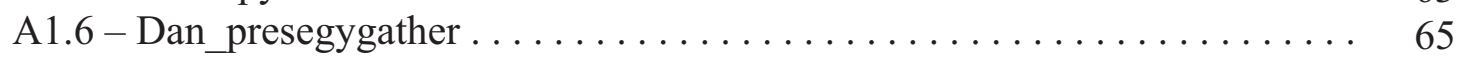

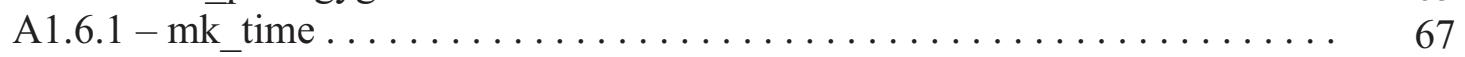

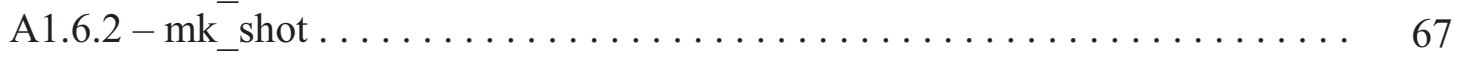

Scripts used to automate the cutting of receiver gathers

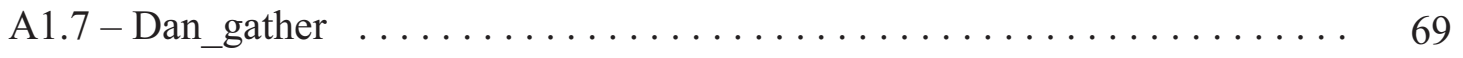

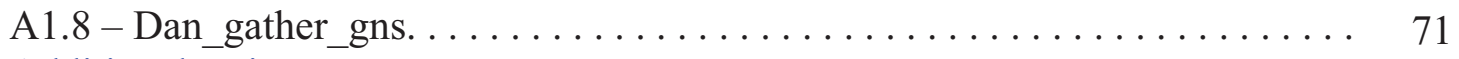

Additional scripts $\quad \ldots \ldots \ldots \ldots \ldots \ldots . \ldots \ldots \ldots$

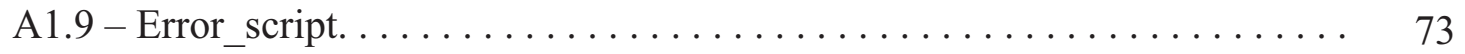

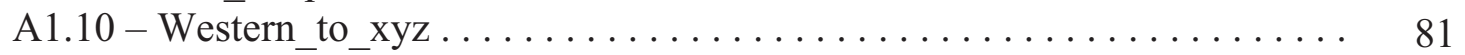




\section{A1.1 - Introduction}

This appendix details the process by which raw onshore-offshore wide-angle seismic reflection and refraction data acquired during the RAU07 seismic reflection survey are processed and reduced to a travel-time dataset. These data are most effectively processed and interpreted as receiver gathers, whereby all airgun shots associated with an offshore reflection profile are displayed for a single common receiver.

Data are compiled, reduced and cut into receiver gathers using Passcal utility codes and are processed and interpreted using the Globe Claritas seismic processing package. In total, 81 receiver gathers are generated, of which first arrivals are identified on 69 with 174 discrete phase segments interpreted and $\sim 275,000$ travel-time picks made.

These travel-times are used to constrain a 3-D crustal velocity model encompassing $\mathrm{a} \sim 32,000 \mathrm{~km}^{2}$ region of the northern Hikurangi subduction margin (Figure A1.1). The modelling methodology developed in this thesis is presented in Appendix Two, with the results and implications of this model presented within Chapters Three and Four respectively.

All scripts presented at the back of this appendix and several files detailing survey parameters are also provided on the attached CD. Passcal programs and instruction manuals used throughout data processing can be obtained from www.passcal.nmt.edu/software/software.html. 


\section{A1.2 - Data}

For the duration of the RAU07 seismic reflection survey, GNS Science and Victoria University deployed nine three-component short-period seismometers around the northern Raukumara Peninsula, North Island, New Zealand (Table A1.1, Figure A1.1). These seismometers recorded the onshore arrival of seismic energy emanating from airgun shots associated with the offshore RAU07 reflection survey and through this deployment, an onshore-offshore wide-angle seismic reflection and refraction dataset has been acquired.

\begin{tabular}{|l|l|l|l|l|l|l|l|c|}
\hline & & WGS 84 & & NZGD & & NZMG & & \\
\hline VUW & Instrument & Latitude & Longitude & Latitude & Longitude & Easting & Northing & Elevation \\
\hline Rewetu & & -37.68242683 & 178.13189496 & -37.684206 & 178.13168 & 2962643 & 6378215 & $540 \mathrm{~m}$ \\
\hline Waihau & & -37.62422023 & 177.90479139 & -37.626001 & 177.90458 & 2942989 & 6385777 & $37 \mathrm{~m}$ \\
\hline Pakira & & -37.73725510 & 178.07505049 & -37.739034 & 178.07483 & 2957295 & 6372421 & $420 \mathrm{~m}$ \\
\hline GNS & & & & & & & & \\
\hline RAUK01 & 0584 & -37.55872451 & 178.02948299 & -37.560507 & 178.02927 & 2954385 & 6392432 & $19 \mathrm{~m}$ \\
\hline RAUK02 & 0576 & -37.55652584 & 178.17649913 & -37.558308 & 178.17628 & 2967370 & 6391944 & $285 \mathrm{~m}$ \\
\hline RAUK03 & 0576 & -37.63103680 & 178.31340546 & -37.632817 & 178.31318 & 2978964 & 6382987 & $35 \mathrm{~m}$ \\
\hline RAUK04 & 0602 & -37.68804014 & 178.52922117 & -37.689819 & 178.529 & 2997598 & 6375532 & $29 \mathrm{~m}$ \\
\hline WAIK & 0599 & -37.59965990 & 178.16870199 & -37.601441 & 178.16848 & 2966409 & 6387203 & $242 \mathrm{~m}$ \\
\hline MANU & 0610 & -37.70765887 & 178.26462807 & -37.709438 & 178.26441 & 2974171 & 6374747 & $331 \mathrm{~m}$ \\
\hline
\end{tabular}

Table A1.1-Locations of short period seismometers deployed by GNS Science and VUW for the duration of the RAU07 seismic reflection survey.

RAU07 consisted of nine high-fold seismic reflection lines totalling $1128 \mathrm{kms}$ recorded by CGG Veritas onboard CGG Duke in July 2007. Of the nine lines acquired, lines 1-7 were dip profiles with the remaining two profiles, RAU07-09 and RAU07-10, approximately parallel to the strike of the subducting slab (Figure A1.1). The seismic source was a $5280 \mathrm{cu}$.in airgun array charged to 2000 psi. Shot intervals were $37.5 \mathrm{~m}$ with the exception of RAU07-05, which had a $50 \mathrm{~m}$ shot spacing. In total, RAU07 consisted of $\sim 30,000$ shots, each of which was recorded by nine onshore seismometers resulting in the acquisition of traveltimes for $\sim 270,000$ unique onshore-offshore raypaths. 


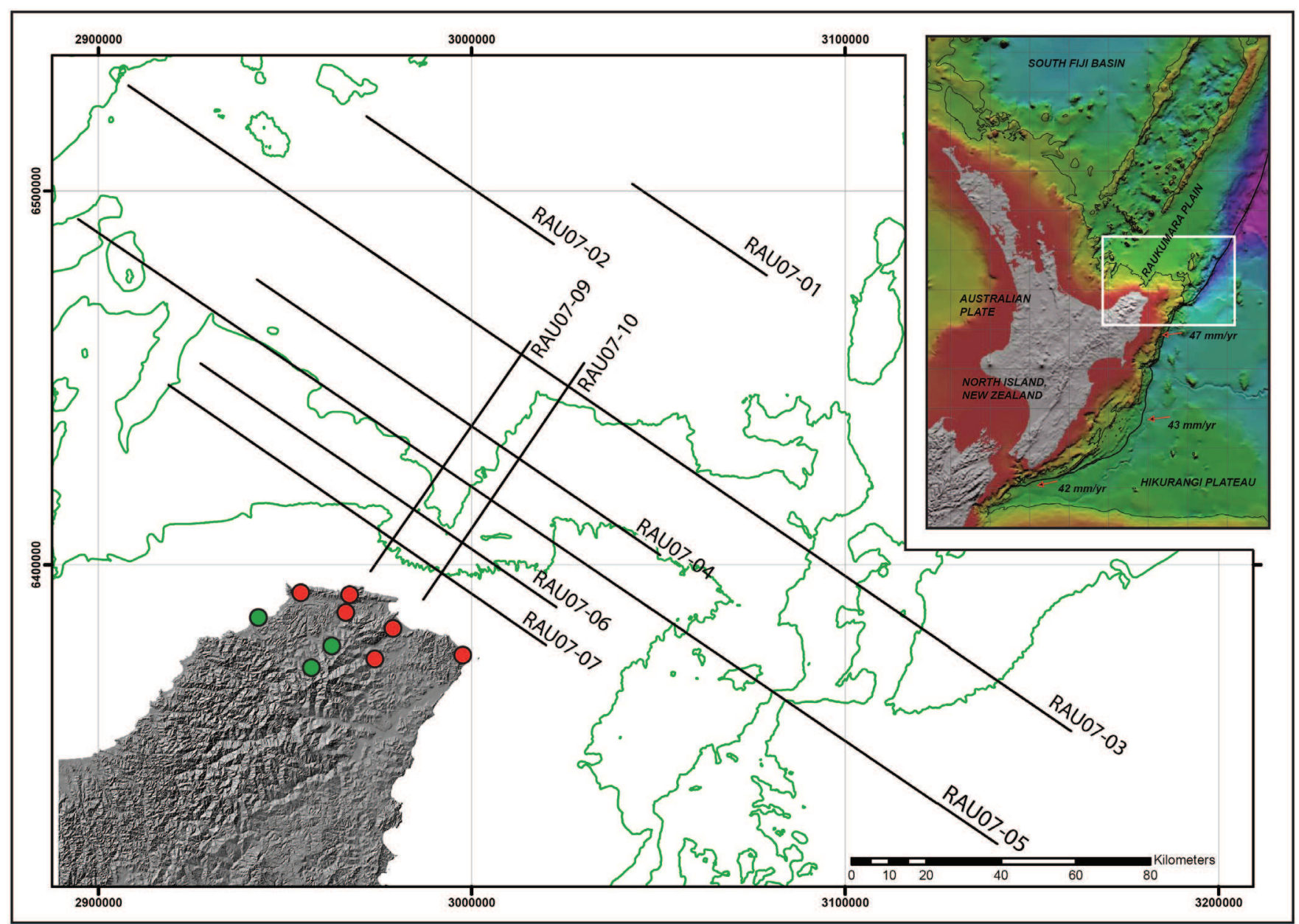

Figure A1.1 - Map illustrating the geometry of onshore-offshore seismic data. Black lines denote RAU07 seismic reflection profiles. Shot from these profiles were recorded onshore by nine short-period seismometers deployed by Victoria University (Green Dots) and GNS Science (Red Dots). Green lines denote bathymetric contours at $1000 \mathrm{~m}$ intervals. Insert displays the location of the study region in relation to the regional tectonic setting of New Zealand's North Island (Nicol et al., 2007). 


\section{A1.3 - Data Processing}

\section{A1.3.1 - Data extraction and Conversion}

\section{A1.3.1.1 - VUW Data}

Data from stations deployed by VUW were recorded in Reftek format by MARKS L-4C3D three-component short-period seismometers. The Passcal ref2segy command was used to convert these data into Passcal SEG-Y. This command is entered at the command line and provided no output filename is specified, a SEG-Y output file of the same name will be created with the .segy suffix and written to the same directory as the raw data.

The script rt130 processing was used to automate this process (Script A1.1). This script was developed by Sandra Bourguignon (VUW, now GNS Science) and can perform a variety of tasks associated with the extraction and manipulation of data from raw Reftek files. To work successfully, the directory structure containing raw data and several files used to specify parameters must be identical to those detailed within the first few lines of the script. As this script was only used to convert raw Reftek data into SEG-Y format, only the cvt2segy function of the script was executed.

\section{A1.3.1.2 - GNS Data}

Data from Lennartz LE-3D short period seismometers deployed by GNS Science were recorded in miniSEED format. Data was converted from miniSEED format into Passcal SEG-Y using the Passcal mseed2segy command (version 2002.058).

The script GNS_Data_converter (Script A1.2) was created to automate this task.

Throughout conversion of both VUW and GNS data into Passcal SEG-Y format, the Passcal pql command was utilised to carry out periodic visual inspections of data for quality control purposes. 


\section{A1.3.2 - Compilation of navigation and shot time data}

Navigation data and shot times specifying the geometry and timing of the RAU07 survey were supplied by Callum Kennedy (MED - Crown Minerals).

\section{A1.3.2.1- Shot times}

RAU07 reflection data was acquired as a series of 17 discrete blocks and shot times for each block were provided in a separate sequence file. For shorter RAU07 profiles, data was recorded continuously with the profile shot times specified within a single sequence file. Longer profiles (e.g. RAU07-05 and RAU07-03, Figure A1.1) were acquired in several segments and it was necessary to combine multiple sequence files to completely specify the shot times along the profile (Table A1.2).

\begin{tabular}{|ll|}
\hline Line & Comprised of Sequence files \\
\hline 01 & SR7-01-22 \\
\hline 02 & SR7-02-19 \\
\hline 03 & SR7-03-01, SR7-03A02, SR7-03-C04 \\
\hline 04 & SR7-04-01 \\
\hline 05 & SR7-05A06, SR7-05C08, SR7-05E10, SR7-05F11, SR7-05G12 \\
\hline 06 & SR7-06-13, SR7-06A14 \\
\hline 07 & SR7-07-15, SR7-07B18 \\
\hline 09 & SR7-09-20 \\
\hline 10 & SR7-10-21 \\
\hline
\end{tabular}

Table A1.2- Sequence files combined to create complete shot-time files for each line within the RAU07 survey. 
These sequence files were slightly faulty as periodically a shot would have no corresponding trigger time, listing 1 Jan 1970 in its place (See example below from seq001 - Table A1.3).

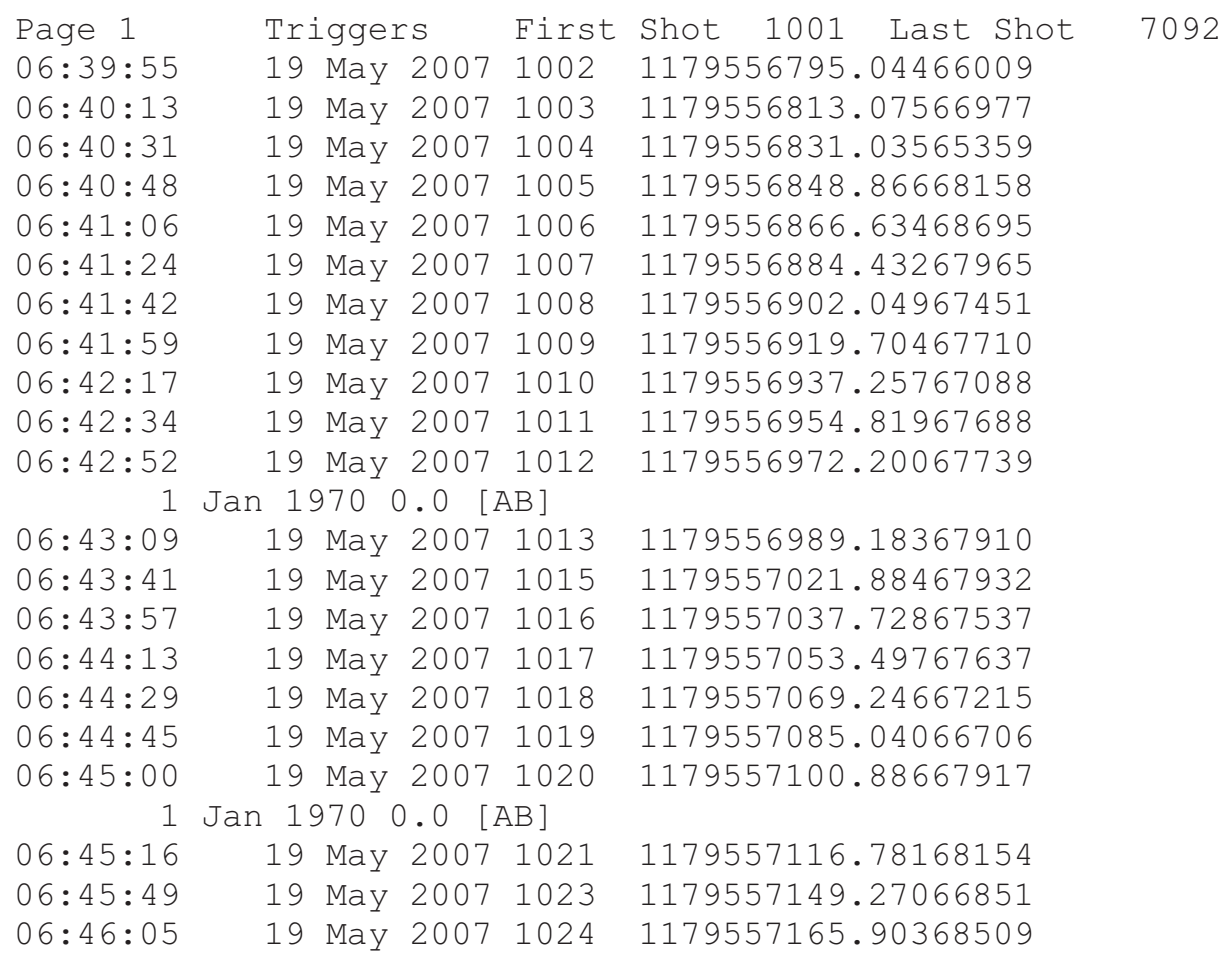

Table A1.3- Extract from sequence file 1 displaying erroneous lines within start time files.

In the above example (Table A1.3), erroneous lines appear between shots 1012 1013 and shots 1020 - 1021 respectively, lines which should appear in sequence. The two lines directly underlying the erroneous line are also not in sequence, with the shot number incrementing by 2 in between these lines. In order to match the shot times files with the navigation file (which was without erroneous lines) it was necessary to manually replace each erroneous line with the line directly underlying it, such that (in the above example) 1012 and 1013 are in sequence followed by a gap (vacated by 1013) which is where 1014 should lie if present. 
This was an extremely time consuming process and several numerical checks were performed to ensure shot time data and erroneous lines were in their correct positions. No attempt was made to recover the shot times of erroneous lines. This was considered unnecessary given the shot spacing $(37.5-50 \mathrm{~m})$ and the data redundancy inherent with such finely spaced offshore acquisition parameters.

\section{A1.3.2.2 - Shot positions}

Precise locations of airgun shots were provided in a text file (RAU07wgs84.txt on Appendix CD). These were extracted and formatted using several awk commands and were segmented into complete line files and shot sequence files.

Throughout the RAU07 survey, the airgun was offset $132.5 \mathrm{~m}$ from the ships GPS receiver. It appears as though this offset had not been corrected for within the supplied navigation files (C.Kennedy, pers comm. 2008).

To correct for this offset, it was necessary to take into consideration both the orientation of the line and the direction the ship was travelling in (Figure A1.2). Simple trigonometry and coordinate conversion allowed calculation of the GPS-Source offset in terms of Eastings and Nothings (NZMG) which were used to correct for the true position of the source. 


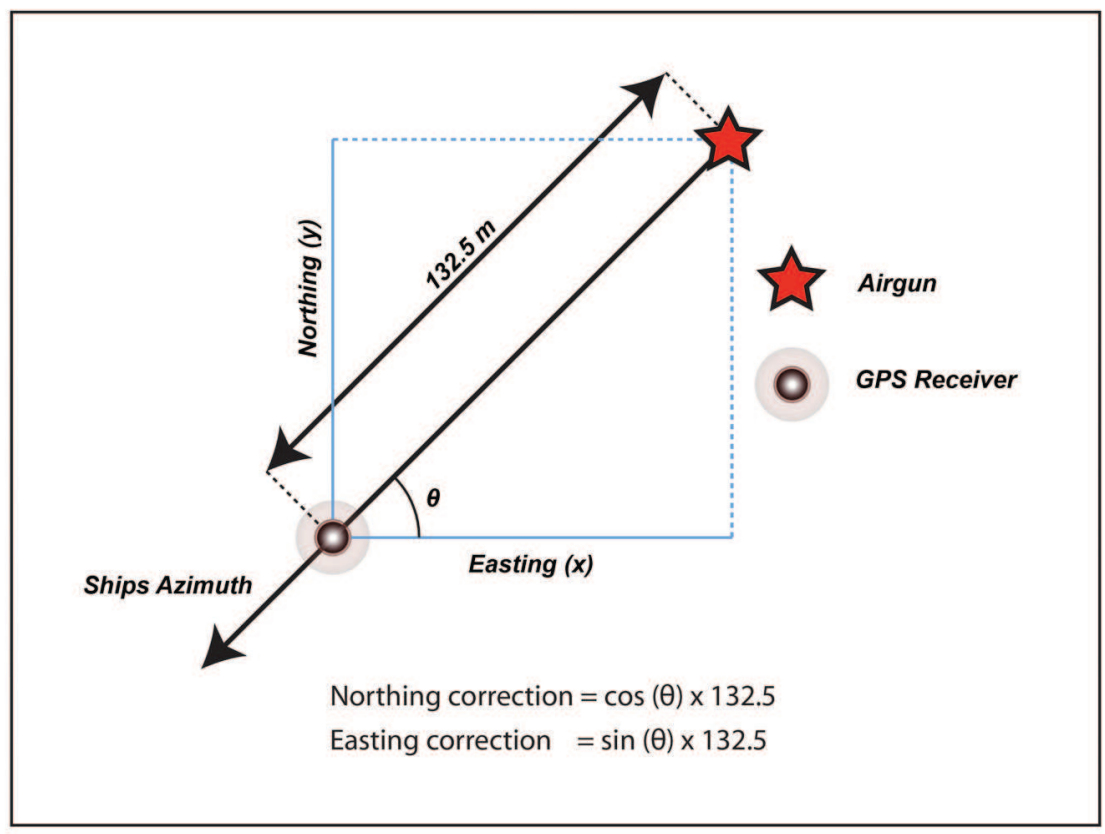

Figure A1.2 - Schematic diagram illustrating the offset between the GPS receiver and the source (airguns) and the partitioning of this offset into Easting (x) and Nothing (y) components based on ship azimuth.

For each line segment, the offset between the source and the GPS receiver was initially calculated in meters, subdivided into E-W and N-S components and applied to GPS receiver positions converted into the New Zealand Map Grid (NZMG) coordinate system. Coordinate conversions were calculated using the functions (listed below) within converterxp.xls available from GNS Science.

- Position of GPS receiver converted from WGS 84 to NZGD

○ WGS_NZGDLT and WGS_NZGDLN

- Position of GPS receiver converted from NZGD to NZMG

- GEODNZE and GEODNZN

- True position of source calculated by either addition or subtraction of E$\mathrm{W}$ and N-S offset components from the NZMG position of the GPS receiver

- Note, although the offset in each direction $(\mathrm{N}-\mathrm{S}, \mathrm{E}-\mathrm{W})$ is approximately constant along a specific profile, whether the offset is added to, or subtracted from the coordinates of the GPS receiver will depend on the direction the ship is sailing in. 
- NZMG position of source converted back to NZGD

- NZLAT and NZLONG

- $\quad$ NZGD position of source converted back to WGS 84

○ NZGD_WGSLT and NZGD_WGSLN

Having calculated the true position of the source for each shot point, navigation and timing data were combined into several text files containing all available information for each shot sequence and also complete RAU07 profiles.

A python script (conv.py - Script A1.5) was created to take each .txt file and manipulate it into the necessary format (*.nav) as required by the script Dan_pre_segygather (Script A1.6), initially developed by Suzannah Toulmin (then GNS Science, now Heriot Watt University, Edinburgh). This script generates the shot and start time files required to cut receiver gathers using segygather (Section 3.4).

The required format of *.nav files is displayed below.

\begin{tabular}{|c|c|c|}
\hline & & \\
\hline & $S R 7-01-22$ & 99323 \\
\hline 0614020925 & $S R 7-01-22$ & $1004-36.726333179 .36$ \\
\hline 70614020940.44368 & $S R 7-01-22$ & $1005-36.726164179 .3672892655 .3-36.726724179 .368598$ \\
\hline 070614020955.61468 & $S R 7-01-22$ & $1006-36.725994179 .3669252654 .5-36.726555179 .368234$ \\
\hline 70614021010.78268 & $S R 7-01-22$ & $1007-36.725828179 .3665582654 .0-36.726388179 .367867$ \\
\hline 70614021025.91469 & SR7-01-22 & $1008-36.725658179 .3661972654 .3-36.726218179 .367506$ \\
\hline 20070614021041.7667 & $S R 7-01-22$ & $1009-36.725489179 .3658362654 .0-36.726049179 .367145$ \\
\hline 20070614021056.38867 & $S R 7-01-22$ & $1010-36.725317179 .3654722653 .0-36.725877179 .366781$ \\
\hline 0070614021111.69268 & $S R 7-01-22$ & $1011-36.725147179 .3651112652 .2-36.725707179 .366420$ \\
\hline 1070014021127.0708 & $S R 7-01-22$ & $1012-36.724981179 .3647442651 .2-36.725541179 .366053$ \\
\hline
\end{tabular}

The column order is a follows

Year - Month - Day - Hour - Minute - Second - Line segment - Shot Number - Master Lat -

Master Long - Water Depth - Source Lat - Source Long

The script dan_pre_segygather (Script A1.6) reads *.nav files before calling two supplementary scripts ( $m k \_$time - A1.6.1 and $\left.m k \_s h o t-A 1.6 .2\right)$ containing awk commands which are used to segment *.nav files into the start time and shot files required by segygather (Section 4.4). 


\section{A1.3.3- Data preparation}

Onshore-offshore data are best displayed as receiver gathers, in which all traces originating from a specific offshore profile are plotted in sequence as recorded by a common receiver.

Receiver gathers are cut from continuously recorded data using Passcal segygather. This utility code extracts seismogram slices of a given length from a continuous record based on specified trace start times (shot times) and record lengths. Before extracting a trace, segygather scans all provided SEG-Y data in search of the specified start time. It is thus important to remove all redundant data as large files can slow segygather considerably, and may exceed the memory capacity of the computer causing segygather to fail.

Redundant data are extracted by cutting continuous records such that only periods coincident with offshore data acquisition are retained. As data were recorded onshore, it was segmented into smaller files containing either one week (GNS Stations) or 20 minutes (VUW Stations) of data. As a result of this segmentation, several RAU07 segments were acquired over a time period spanning multiple blocks of data and for these profiles, it was necessary to merge adjacent data files together (segymerge) before cutting the redundant data off each end.

Data reduction was automated via the construction of the scripts Segycut_gns (Script A1.3.1) applied to GNS data and merge_segy_dan (Script A1.4.1) applied to VUW data.

\section{A1.3.3.1- GNS Data}

GNS Data were reduced using the Passcal commands segymerge and segycut. Each shot segment represents a period of continuous data acquisition and all redundant data is removed by creating a separate SEG-Y file for each shot segment. 
As mentioned above, where an individual shot segment was acquired over two blocks of data, segymerge was used to merge these adjacent data files together. A start time and record length for the merged file was specified to ensure only data containing shots was extracted. Data from RAU07 profiles acquired in several shot segments are merged into a complete common receiver gather by merging and reordering sequences shot time files used within segygather (Section A1.3.4).

It should be noted that the files merged to create continuous data records for each shot sequence will be different for each station. This is due to the deployment of stations at different times which consequently results in a non-uniform partitioning of data into smaller files. This requires the construction of scripts which although simple, are long to automate this step (Segycut_gns - Script A1.3.1).

\section{A1.3.3.2 - VUW Data}

VUW data was recorded in 20 minute blocks and saved within day folders. The script merge_segy_dan (Script A1.4.1) merges each of these day folders into a single SEG-Y file, for each station, day and channel combination. Further reduction of VUW data into profile segments (using segycut) was unnecessary as day files were sufficiently small for use directly within segygather. All day files during which offshore shooting took place are therefore listed within the SEG-Y list required by segygather. 


\section{A1.3.4 - Cutting Receiver Gathers}

Irrespective of direction, reciprocal rays must by definition (Knopoff \& Gangi 1959) have identical travel-times as they sample the same velocity structure. The raypath is reversible which makes the position of the receiver and shot points interchangeable (Figure A1.3). Receiver gathers are therefore equivalent to shot gathers and will be identical to the shot gather generated if the source were positioned at the station, and the receivers positioned at the true shot points.

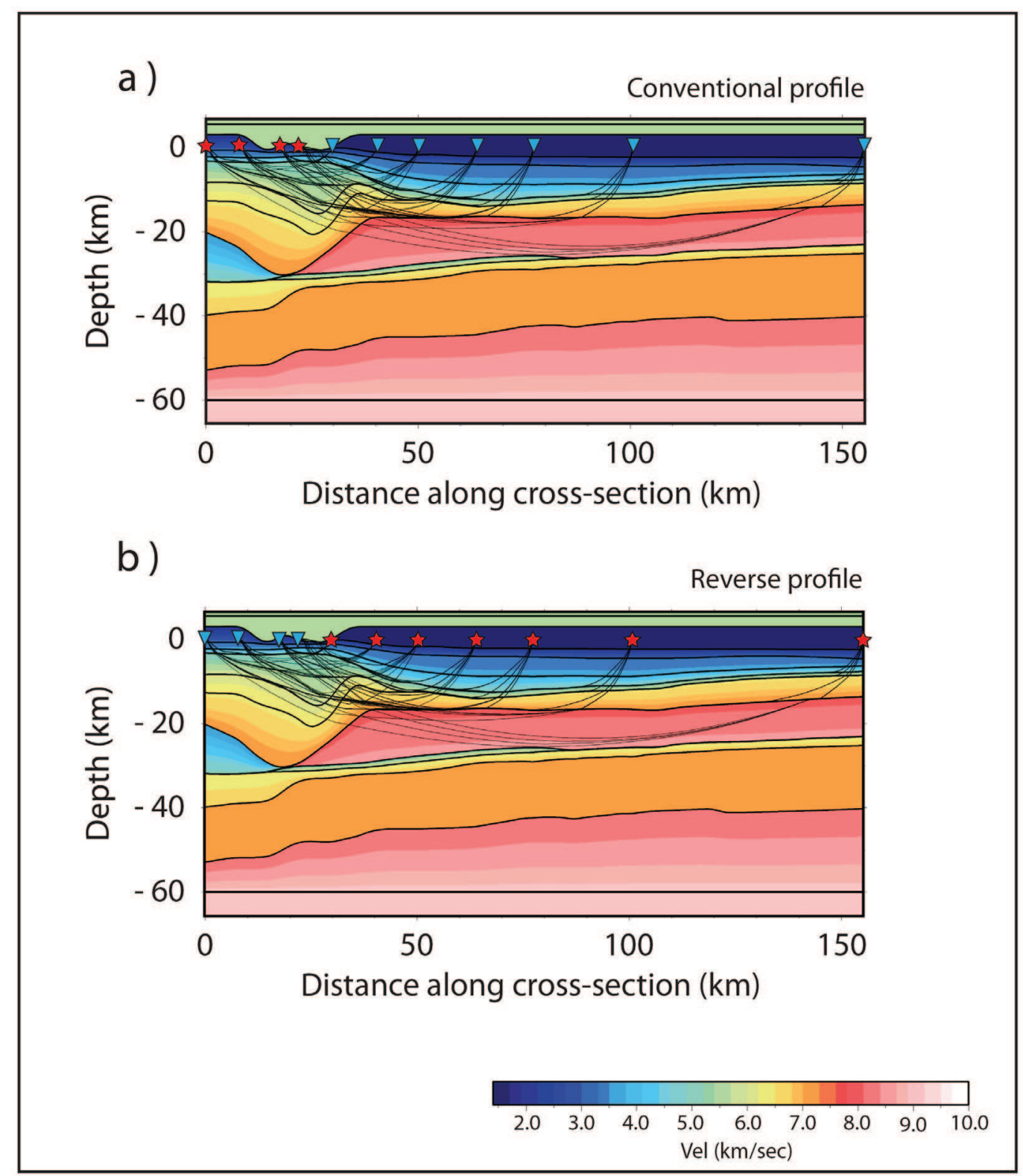

Figure A1.3 - Illustration of reciprocal raypaths. The two models presented above are identical except for the reversal between sources (red stars) and receivers (blue triangles). Note the identical raypaths generated by each model. 
Receiver gathers were considered the most efficient means of analysing the onshore-offshore data and were cut from continuous SEG-Y files using the Passcal command segygather.

This program requires the provision of at least two files and the specification of the several parameters. The start time file contains the start time (shot time) of each trace in the receiver gather. The segylist contains the full path name of SEG-Y files containing the data from which the gather will be cut. These lists are created using the scripts create_allsegyfilelists_gns (Script A1.3.2) and create_segyfile_test_2 (Script A1.4.2). If desired, Shot files can be constructed for use in place of start time files and in addition to shot times, Shot Files contain source locations and water depths.

Both Start time files and Shot files were constructed using the script Dan presegygather (Script A1.6) with Shot files used in place of a start time file for these receiver gathers. Shot Files were preferred as reordering of shot numbers on the basis of geographic location was required.

RAU07 profiles acquired in several segments were merged into a single receiver gather by combining segment Shot time files into a single document. As adjacent segments spatially overlap, it was necessary to reorder shot time files from EastWest and/or North-South requiring the source locations. This was necessary to remove travel-time discrepancies between adjacent traces, which although chronologically in sequence, are spatially distinct resulting in large variations in offset and/or raypath between traces. For profiles acquired as several overlapping segments, reordering results in a smoother more coherent receiver gather which is easier to interpret.

Finally, the user is also required to specify a record length for each trace (in seconds) and the desired name of the output file. The trace length for these gathers was set to 60 seconds to ensure all recognisable events were within the time window. 
The scripts Dan_gather (Script A1.7) and Dan_gather_gns (Script A1.8) were created to automate this process.

\begin{abstract}
A1.3.5 - Processing
Receiver gathers were processed and interpreted using the Globe Claritas seismic processing software. Most data was of sufficient quality to be interpreted in the absence of any significant processing. Where required, processing was minor and adjusting the aspect ratio of the visual display of data proved equally as useful as processing functions within Claritas.

\section{- Frequency filtering}

Receiver gathers were filtered using a low frequency band pass filter. Frequency bands were determined and applied independently to data from each station. Filter values were determined via a fixed and anchor method where each filter value is determined separately while holding all others fixed.
\end{abstract}

Applied frequency filters ranged from [2 $\left.4 \begin{array}{lll}2 & 8 & 9\end{array}\right]$ - [ [ $\left.\begin{array}{llll}4 & 7 & 10 & 12\end{array}\right]$ with most gathers processed with a [2 $\left.\begin{array}{llll}4 & 8 & 12\end{array}\right]$ band pass filter.

$-A G C$

An Automatic Gain Correction (AGC) was applied to data from all stations to normalise amplitudes across traces. The optimal AGC window was determined for each station and varied between $6000 \mathrm{~ms}$ and 10,000 ms.

\title{
- Trace Sum
}

All lines with the exception of RAU07-05 $(50 \mathrm{~m})$ had a shot spacing of $37.5 \mathrm{~m}$. Adjacent traces will display near identical shot times which offers the use of trace summing to boost the signal across profiles displaying lower quality data. Trace summing essentially sums adjacent traces together and can aid in the interpretation of noisy data through an increase in the signal to noise ratio. This function was only applied periodically to data from Waihau and MANU and to far offset $(>100 \mathrm{~km})$ data. The optimal number of traces to sum was 3 . 


\section{- Runmix}

Runmix was often preferred to trace summing. This function completes an identical task to tracesum however operates with a moving window rather than within discrete blocks. As a result, there is no reduction in the number of traces and coherency advantages associated with closely spaced shots are preserved. Weights can be applied to specific sum positions so that traces two spaces either side of centre have a lesser influence on the resulting seismogram than traces immediately adjacent to the trace being calculated. This function was only applied periodically to data from Waihau and MANU and to far offset $(>100 \mathrm{~km})$ data with particularly low amplitude first arrivals. Where applied, the optimal number of traces was 3 with weightings of $0.5-1-0.5$.

\section{- Data display}

The ability to easily manipulate the visual display of data was without doubt the most useful tool throughout the interpretation process. Data were interpreted using both Variable Density (VD) and standard Wiggle displays plotted in total and reduced travel-time. VD display was useful in identifying coherency within noisy data and was particularly effective when combined with a high trace density. The flatten function was useful discriminating first arrivals from other phases and identifying traces with timing errors when used in conjunction with a VD display. 


\section{A1.4 - Interpretation}

Receiver gathers were interpreted using the Globe Claritas Seismic Viewer (SV).

Initial interpretations were focused on the identification of first arrivals and although additional phases were identified, these were not picked.

After initial forward velocity models were constructed, it was necessary to revaluate some arrivals which were particularly hard to replicate and obviously erroneous when considered in light of travel-times into adjacent stations. Although the vast majority ( $>95 \%$ ) of picks remained unchanged, some picks were remade where earlier interpretations were in error, or deleted where the signal to noise ratio was considered too low to interpret arrivals with any useful degree of confidence. During this process, for stations displaying strong data, phase interpretations were made with up to 6 discrete phases interpreted on some gathers. Minimal attempt was made to identify the origin of picked phases as apparent velocities are compromised by variations in ray azimuth - profile obliquity (Figure 3.2a-d).

Pick files generated within Claritas SV are only able to allocate one interpreted travel-time to each trace. Phase interpretations were thus made independently and saved as separate *.pic files.

Visual estimates of error were recorded in a spreadsheet and incorporated into the script Error Script (Script A1.9) which allocates interpreted errors to the relevant ranges in shotnumber.

Finally, to ensure consistency in interpretations at points of intersection between RAU07 profiles, an intersection spreadsheet was created. The nearest shot numbers to points of intersection were calculated with the first arrival travel-time recorded for each of these traces. As these shot points are in close proximity, their raypaths will be almost identical allowing significant differences in traveltime between these traces to be used to signify erroneous interpretations on one or both of the intersecting gathers. 


\section{A1.5 - Results}

\section{A1.5.1- Data and travel-times}

Through the methodology discussed above, 81 receiver gathers have been constructed. These gathers document the arrival of seismic energy for each RAU07 profile into each onshore seismometer (Figure A1.1). Of the 81 gathers constructed, arrivals were interpreted on 69. In total, 174 discrete phase segments were interpreted with $\sim 275,000$ travel-time picks made (Table A1.4). The degree of confidence in interpreted arrivals ranges between $70 \mathrm{~ms}$ and 1 second, however, most interpreted arrivals have associated errors below $200 \mathrm{~ms}$.

\begin{tabular}{|l|r|r|r|r|}
\hline Station & Station number & Lines interpreted & $\begin{array}{l}\text { Discrete phase } \\
\text { segments interpreted }\end{array}$ & Picks made \\
\hline VuW & & 8 & 26 & 33,822 \\
\hline Rewetu & & 6 & 6 & 17,192 \\
\hline Waihau & & 9 & 35 & 44,672 \\
\hline Pakira & & & & 16 \\
\hline GNS & 584 & 9 & 24 & 29,027 \\
\hline RAUK01 & 576 & 9 & 1 & 40,470 \\
\hline RAUK02 & 476 & 1 & 24 & 1,926 \\
\hline RAUK03 & 602 & 9 & 29 & 41,664 \\
\hline RAUK04 & 599 & 9 & 13 & 44,281 \\
\hline WAIK & 610 & 9 & 174 & 21,374 \\
\hline MANU & & & $\mathbf{1 4}$ & $\mathbf{2 7 4 , 4 2 8}$ \\
\hline
\end{tabular}

Table A1.4 - Table summarizing travel-time interpretations made from onshore-offshore receiver gathers.

Below, Figures A1.6-14 present processed receiver-gathers and interpreted arrivals for each RAU07 profile as recorded at Pakira. In each figure, the top panel illustrates the processed data, with the lower panel displaying the same data with interpreted arrivals projected on top. The data is reduced to $6.0 \mathrm{~km} / \mathrm{sec}$ with lines 1-7 orientated NW-SE and lines 9 and 10 orientated NE-SW and SWNE respectively. Traces are plotted with equal spacing however offset markers are also displayed. The marker spacing is a useful indicator of varying obliquity between the profile orientation and the source-receiver azimuth. The insert in the 
bottom right of each figure displays the station position (Yellow star) and the geometry of the profile from which shots were fired (Red profile).

\section{A1.5.2 - Shot timing errors}

Given the small shot spacing of the RAU07 survey $(\leq 50 \mathrm{~m})$, it is reasonable to expect similar travel-times between adjacent traces. This was generally the case however, periodically a trace would exhibit a first arrival travel-time considerably different to adjacent traces. As energy from a particular shot will travel an almost identical path to that from a neighbouring shot, these travel-time jumps were interpreted as inaccurate shot times for some traces. This interpretation was confirmed by the observation of an identical travel-time offset for consistent shot numbers from data across all stations.

It would be straight forward to correct for these erroneous start times by creating a time base correction file for each RAU07 profile. This file could be constructed via the interpretation of two pick files; the first of which ignores erroneous travel-times allocating picks to misfit traces as determined by the local traveltime gradient observed across proximal traces. The second pick file interprets all first arrivals honourably and allocates a pick which is offset from the local traveltime gradient to traces with hypothesised timing errors (Figure A1.4a). By subtracting pick file one from pick file two, the timing error is calculated which can be applied to the start times file thus correcting the time base on all gathers constructed form shots along the profile in question (Figure A1.4b). As only one correction file is required for each profile, it should be constructed using the highest quality data. 


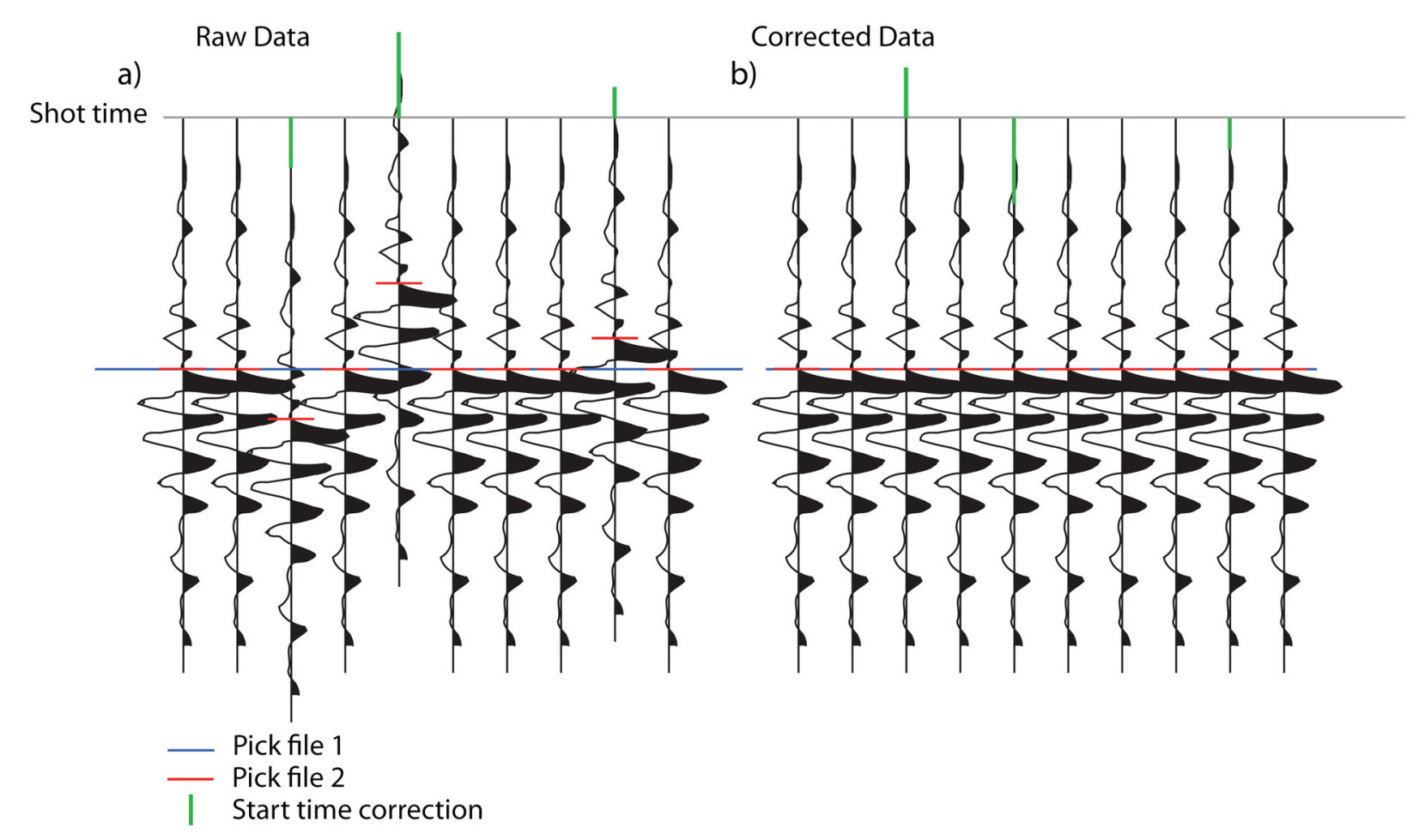

Figure A1.4 - Cartoon illustrating the travel-time correction discussed above. This method of correcting the time base involves creating two pick files. a) The first (blue) is based on coherency between adjacent traces and the second (red) picks all first arrivals irrespective of traveltimes exhibited by neighbouring traces. b) Pick file 2 is then subtracted from pick file 1 to calculate a time difference which is used to adjust the start time of the trace thus bringing all arrivals into alignment.

Although straight forward, the correction described above was not performed. This was considered unnecessary given the small proportion of shots which exhibited timing errors and the uncertainty introduced while identifying and picking misfit traces. No correlation was observed between traces adjacent to erroneous shot times in sequence files and traces exhibiting hypothesised timing errors on receiver gathers. 


\section{ONSHORE-OFFSHORE PROCESSING}

\section{1 - Data Extraction}

VUW - rt130_processing

24 Hour continious SEG-Y files

GNS - GNS_Data_converter

Week long continious SEG-Y files

\section{3 - Removal of redundant data}

GNS - GNS_Data_converter

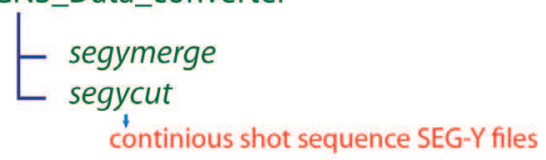

\section{4 - Cut Receiver Gathers}

Prepare segylists

VUW - create_segyfile_test_2

$$
\text { VUW_segylist }
$$

GNS - create_allsegyfilelists_gns

$$
\text { GNS_segylist }
$$

Cut Gathers

VUW - Dan_gather

L segygather

27 Raw receiver gathers

GNS - Dan_gather_gns

L segygather

54 Raw receiver gathers

\section{2 - Compilation of survey parameters}

- Shot times - erroneous lines removed

Shot positions - true source position determined

Shot times and shot positions combined and reformatted

$$
\text { conv.py }
$$$$
\text { *******nav }
$$

Start time and Shot time files created

dan_pre_segygather

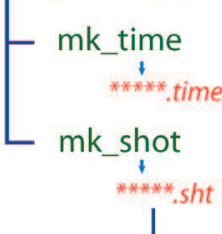

$$
\begin{aligned}
& { }_{* * * * *}^{t} \text {.time } \\
& \text { shot } \\
& \text { ******.sht }
\end{aligned}
$$

\section{5 - Processing}

\section{$\rightarrow$ Globe Claritas - GNS Science}

Frequency filtering BP - [2 $\left.\begin{array}{llll}2 & 8 & 12\end{array}\right]$

AGC - [6 - $10 \mathrm{sec}]$

Trace Sum (3)

Runmix (3, $[0.5,1,0.5])$

81 Receiver gathers

\section{6 - Interpretation of travel times}

Gather Picking - Claritas SV

275,000 travel times

\section{Estimation of Error}

L Error_Script

Figure A1.5 - Flow chat summarising the process by which raw onshore-offshore wide angle seismic reflection and refraction data are reduced, processed and interpreted to create a first/phase arrival time dataset. Black text describes processing steps, Green text illustrates the scripts used and Red text gives output files. Lighter blue lines used purely to aid in the distinction of crossing file paths. 
Figures A1.6-14 - Processed receiver-gathers and interpreted arrivals displaying data as recorded at Pakira with shot positions along: 6) RAU07-10; 7) RAU0709; 8) RAU07-07; 9) RAU07-06; 10) RAU07-05; 11) RAU07-04; 12) RAU0703; 13) RAU07-02 and 14) RAU07-01. In each figure, the top panel illustrates the processed data, with the lower panel displaying the same data with interpreted arrivals projected on top. The data is reduced to $6.0 \mathrm{~km} / \mathrm{sec}$ and traces are plotted with equal spacing. Offset markers are displayed and provide a useful indicator of varying obliquity between the profile orientation and the sourcereceiver azimuth along the profile. The insert in the bottom right of each figure displays the station position (Yellow star) and the geometry of the profile from which shots were fired (Red profile). 

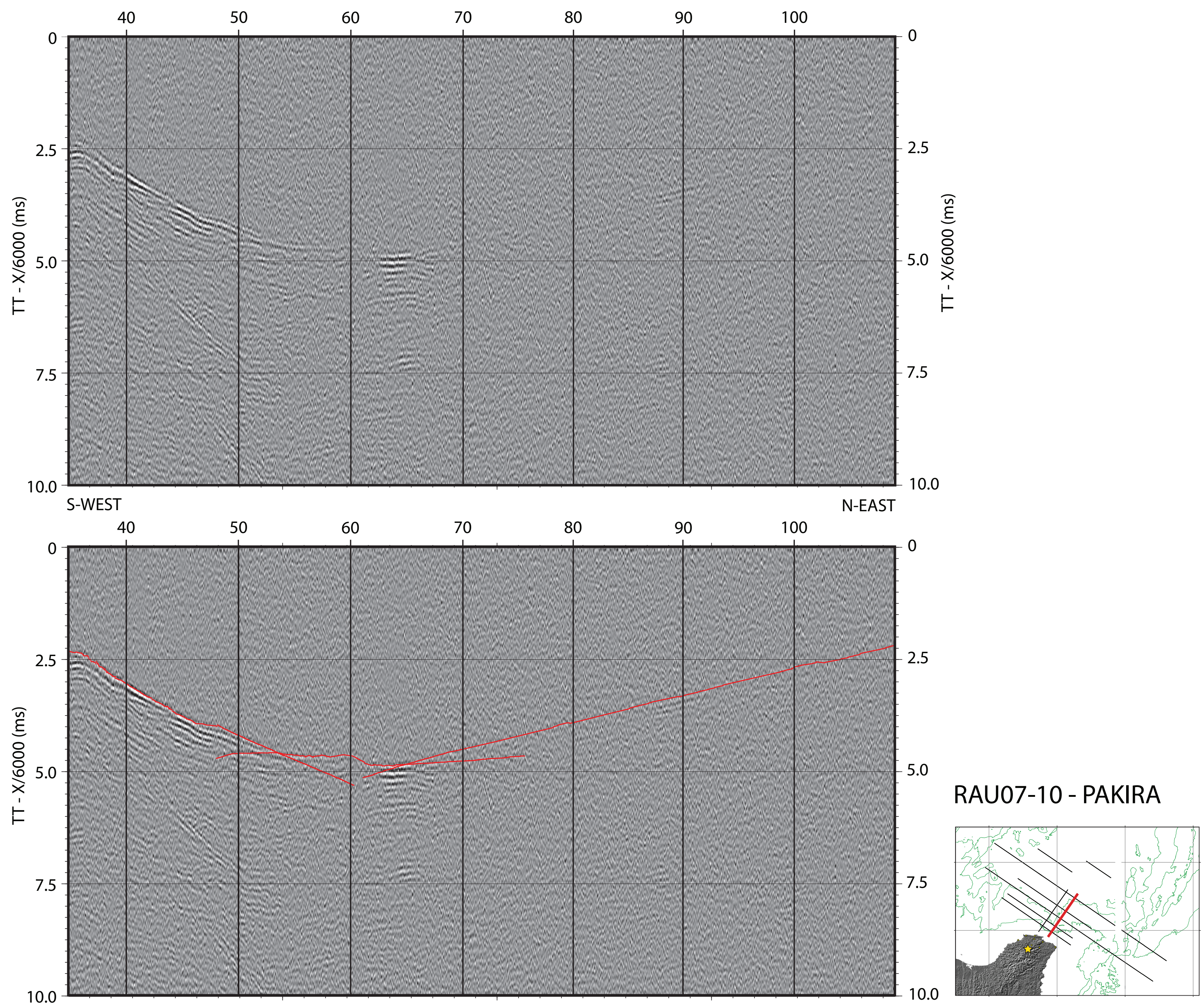

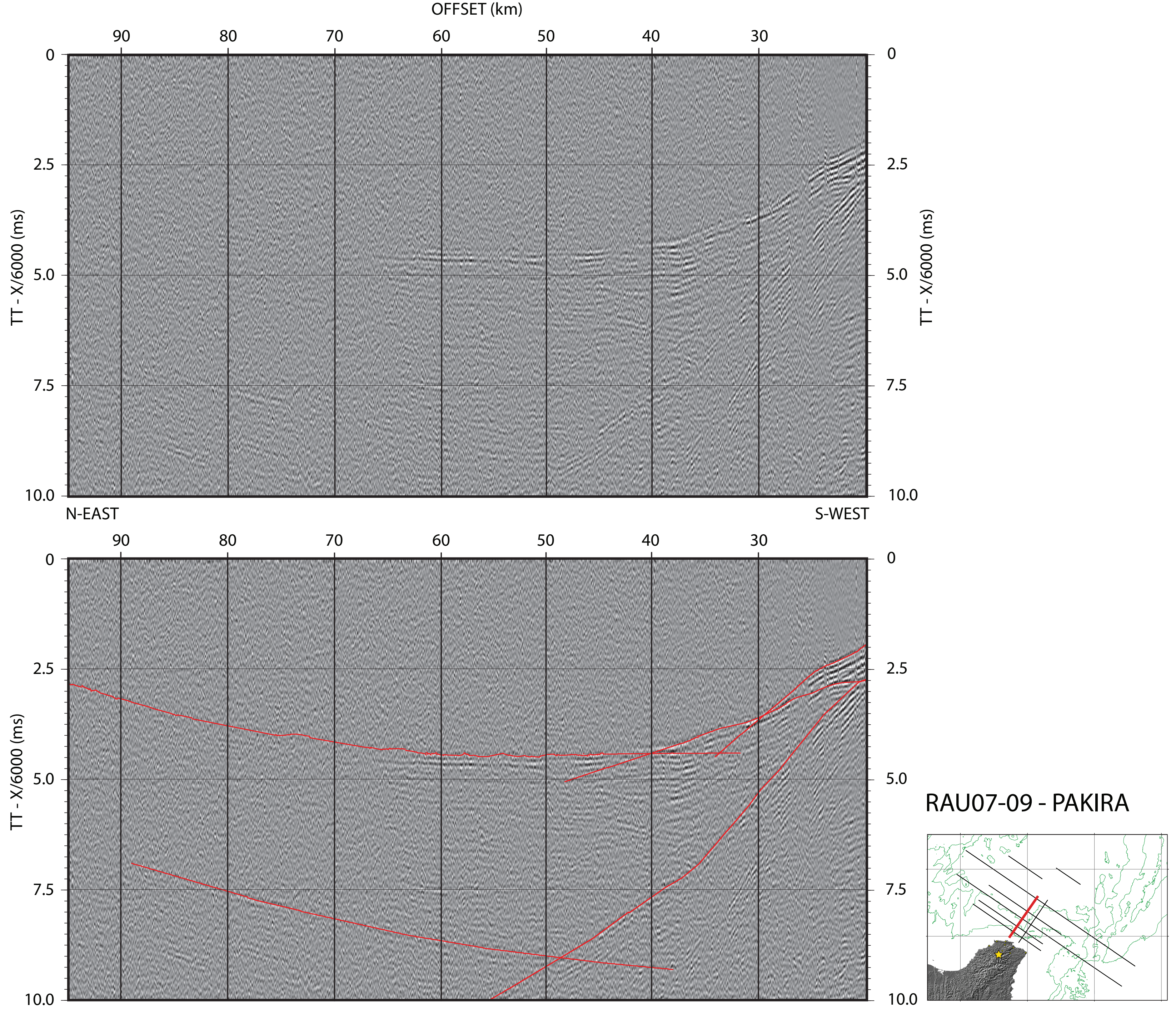


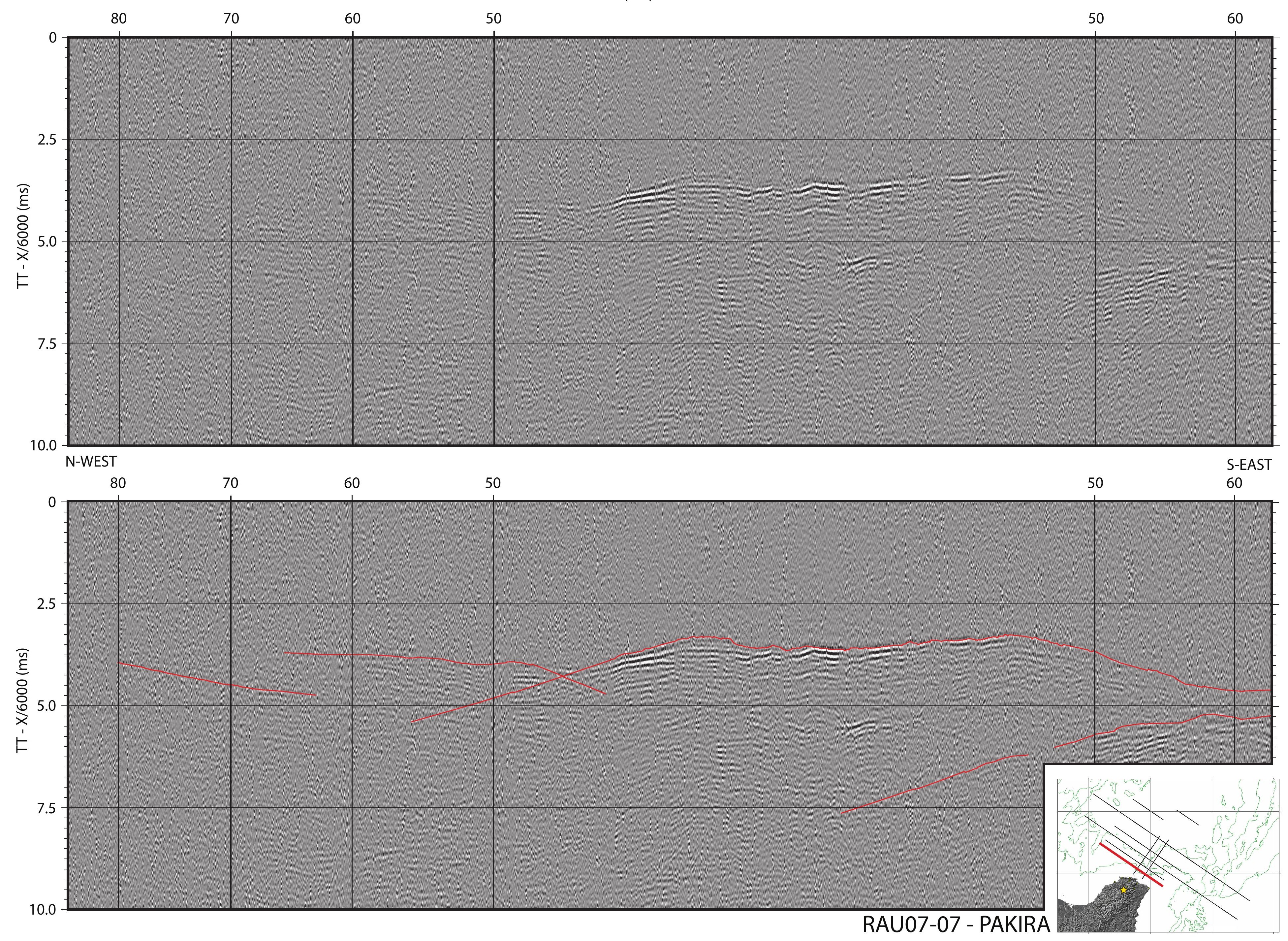



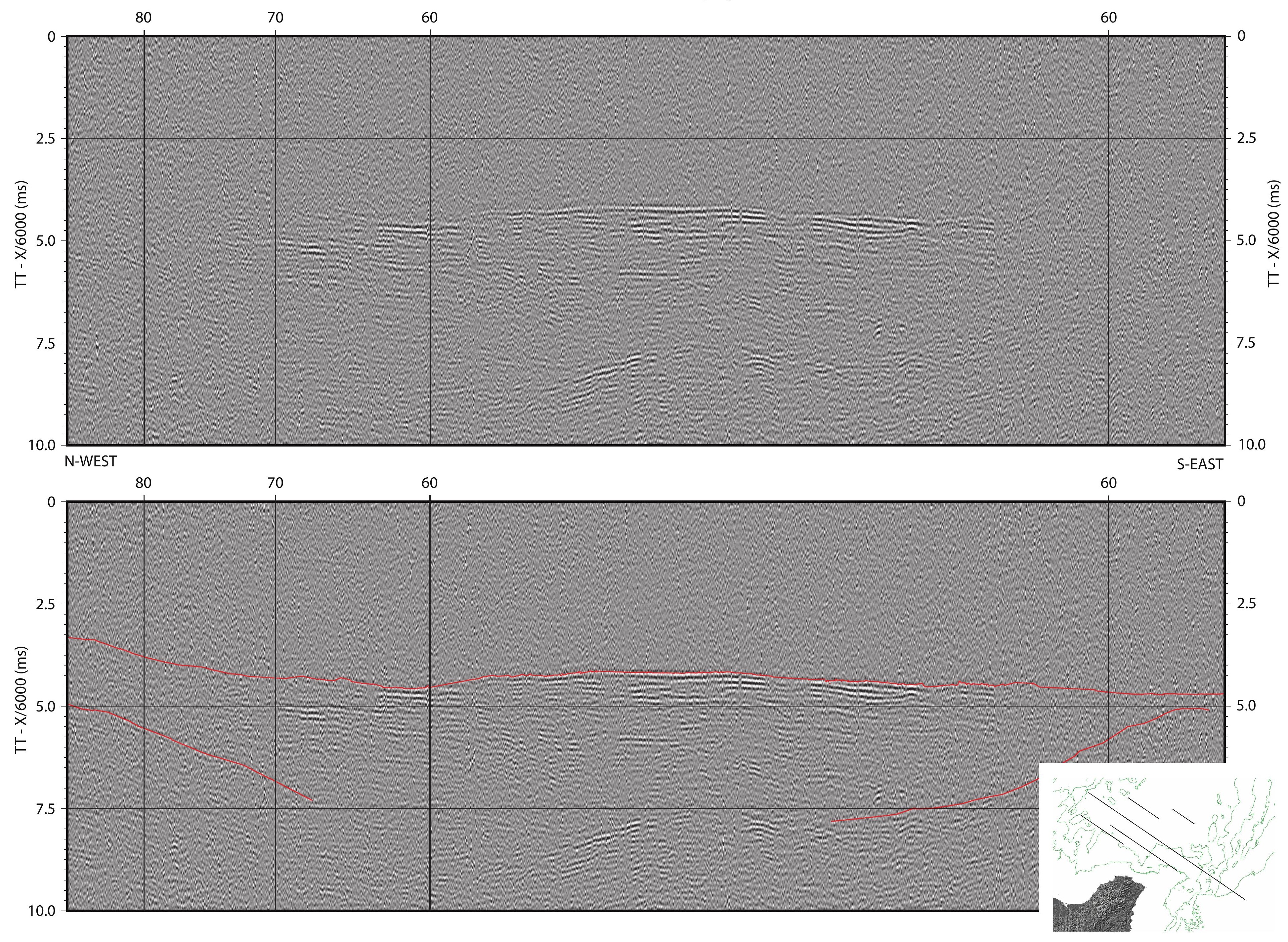


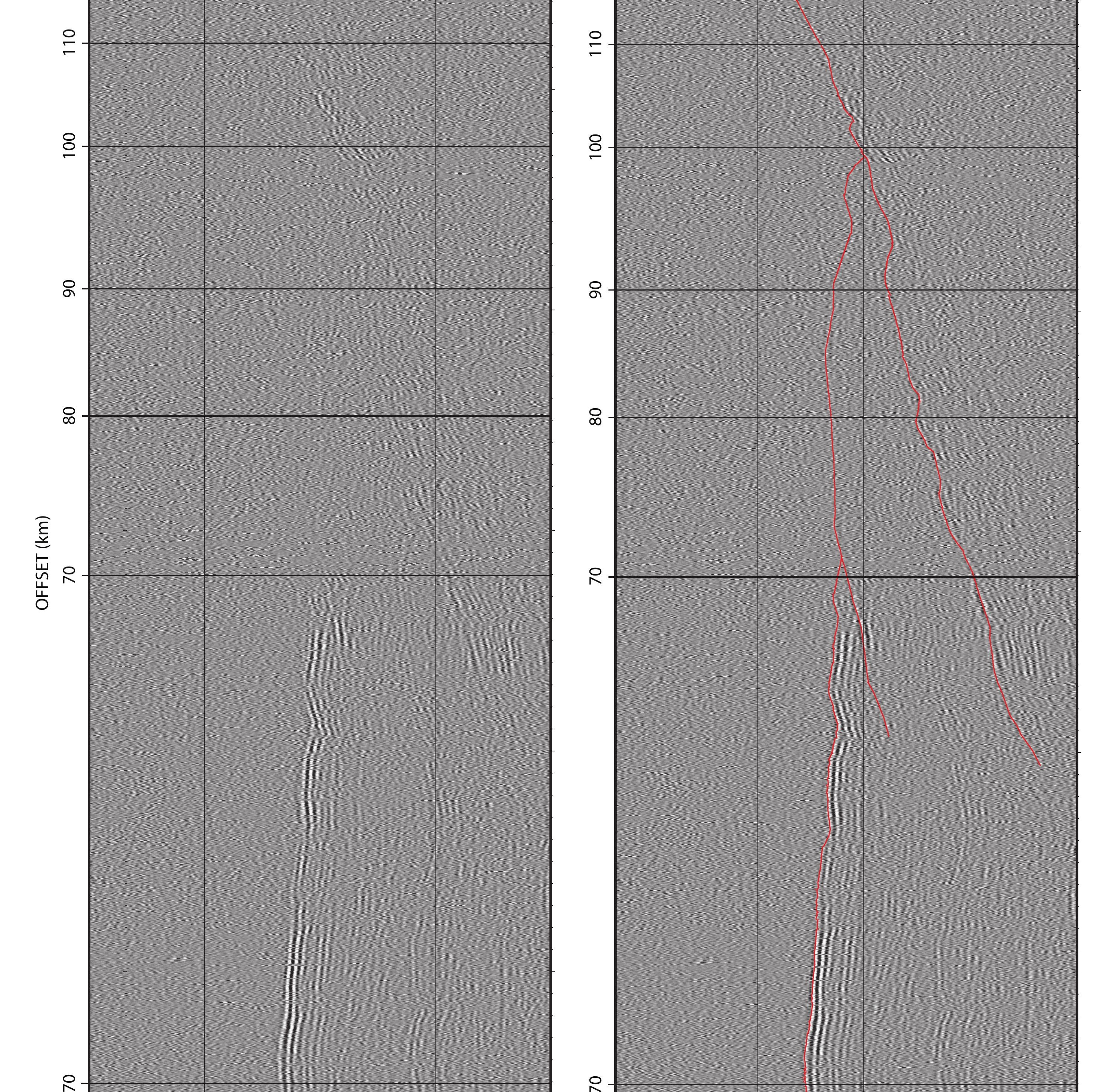





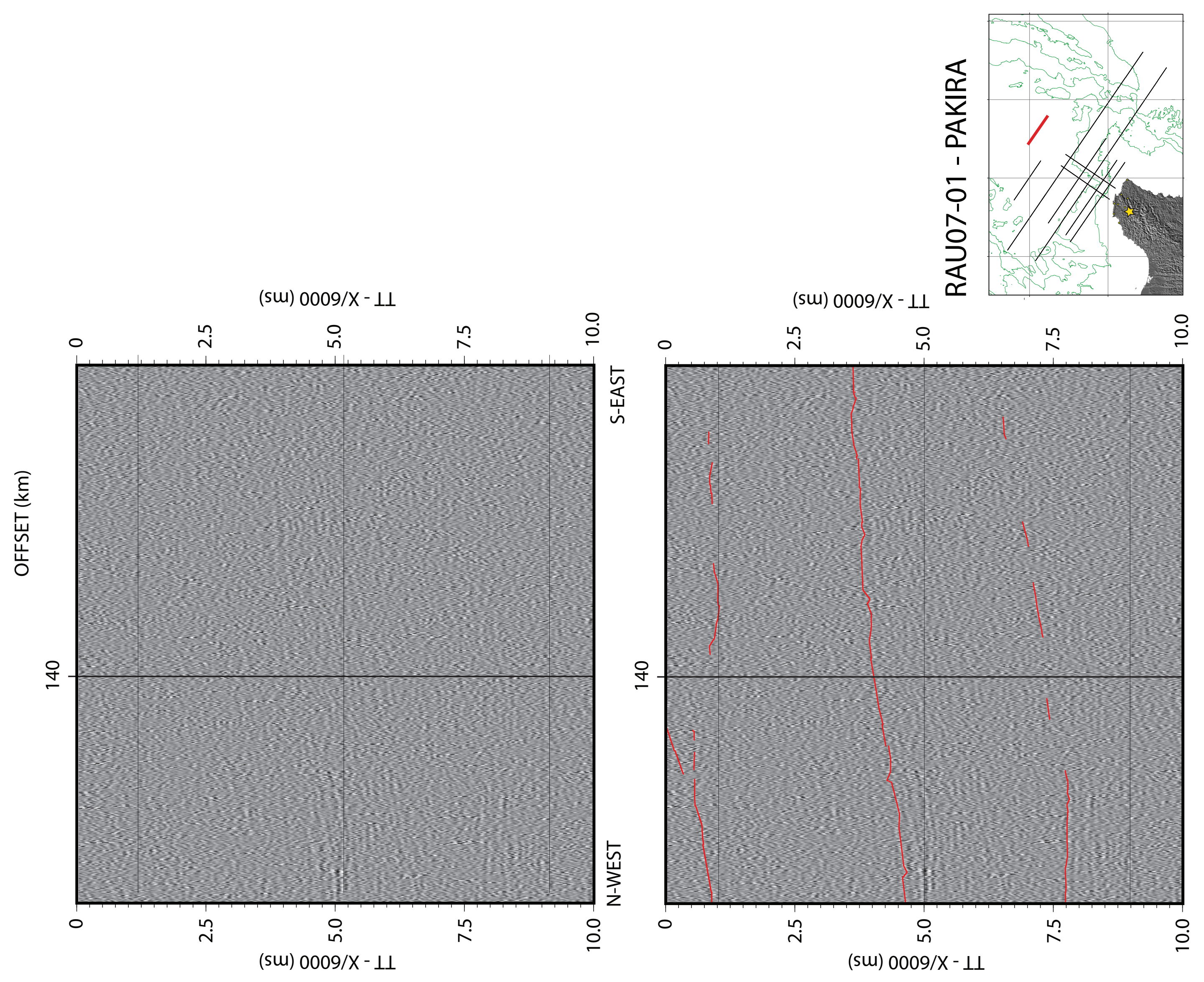




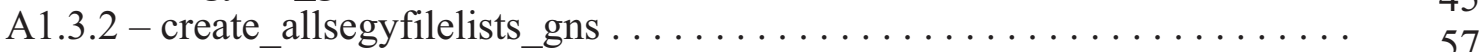

A1.4.1-merge_segy_dan. ............................... 59

A1.4.2 - create_segyfilelist_test2. .

Scripts used to create of segygather input files

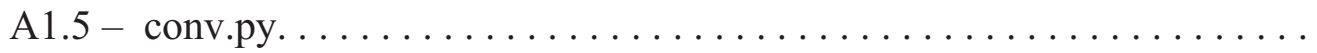

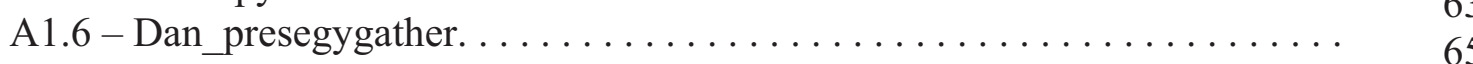

A1.6.1 - mk time. . . . . . . . . . . . . . . . . . . . . . . . . . 65

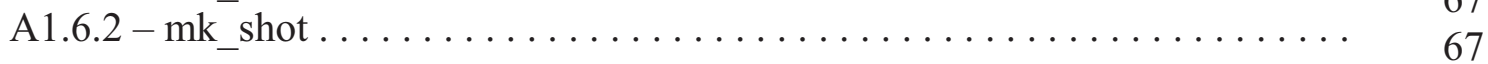

Scripts used to automate the cutting of receiver gathers

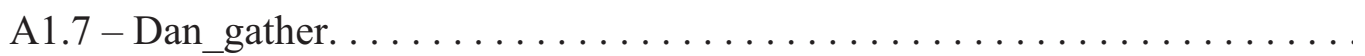

A1.8-Dan gather gns.

Additional scripts

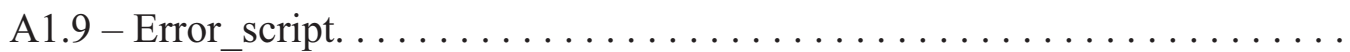

A1.10 - Western_to_xyz. 
\# cvt2ref: converts from rt130 to reftek format

\# cvt2segy: converts from reftek to segy format

\# clock : timing correction if necessary

\# location :extracts the Das coordinates

\# extract : extracts liste of earthquakes in eqcut.evt file for liste of das

\#

\# VERY IMPORTANT:

\# Parameters you should modify : spl_rate (samples per sec)

\# rec_len (seconds)

\# ALL YOU NEED IS :

\# - a directory "RT130_data" which includes your raw data

- a directory "Stations" including; --> a file called "ref2segy.das" (acquisition qrmation)

\# $\quad$--> a file called "exp_name.das" (das\#, station name, exp_name

\# geophone)

\# - - a directory "Events" including:

--> a file called "eqcut.tele" or "eqcut.local"

(earthquake windows)

Sandra 15/03/2005

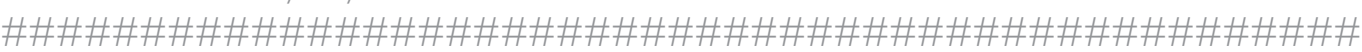

set $\operatorname{argc}=\$ \# \operatorname{argv}$

echo $\$ \operatorname{argc} \$ 1 \$ 2 \$ 3 \$ 4$

\# if ( $\$$ argc ! $=4$ ) goto USAGE

set $\exp =\$ 1$

\# tele or local

set eqs_type $=\$ 2$

set das_list=`echo $\$ 3 \mid$ awk 'BEGIN $\{F S="$ ", $\}$ for

$(\mathrm{i}=1 ; \mathrm{i}<=\mathrm{NF} ; \mathrm{i}++) \mathrm{if}(\mathrm{i}==\mathrm{NF})\{\operatorname{printf}(" \% \mathrm{~s} ", \$(\mathrm{i}))\}$ else $\{\operatorname{printf}(" \% \mathrm{~s} ", \$(\mathrm{i}))\}\}^{\prime}$.

echo \$das_list

set process $=\$ 4$ 
set stn_info $=$ "\$\{DIRin $\} /$ nav_files $/$ das_info/das.list"

1s $\$ \mathrm{rt} 130$

1s $\$$ segy

echo

1s \$stn_info

\# exit

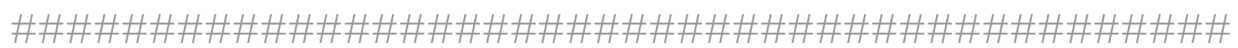

\# parameters for timing corrections

set $\log =" \$\{$ data $\} /$ Log_files"

set err = "\$\{data $\} /$ Err_files"

set rating $=" \$\{$ data $\} / \mathrm{PCF}$ _files"

set blackout $=" \$\{$ data $\} /$ PCF_files $/$ blackout"

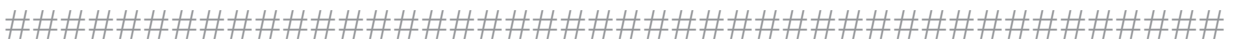

\# parameters for eqcut

set spl_rate $=$ "100"

set rec_len $=$ "600" \# 10 min length records of reftek data

set tolerance $=" 40 " \quad \# \mathrm{~ms}$

if ( \$eqs_type $==$ "tele" ) then

set len $=" 3000 " \quad$ \# secs $->50$ min

set out_dir = "\$\{data $\} /$ Teleseisms"

else if ( \$eqs_type $==$ "local" ) then

set len $=" 500 " \quad$ \# secs --> 8 min

set out_dir $=" \$\{$ data $\} /$ Local"

endif

set eqcut_evt $=" \$\{$ data $\} /$ Events $/ \$\{\exp \} . \$\{$ eqs_type $\} "$

set eqcut_das $=" \$\{$ data $\} /$ Stations $/$ eqcut.das"

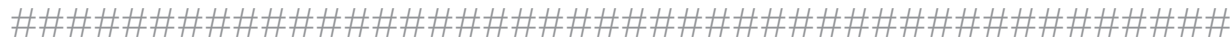

if $($ process $==$ "create" $)$ goto CREATE

if ( $\$$ process $==$ "cvt2ref" ) goto CVT2REF

if ( $\$$ process $==$ "cvt2segy" ) goto CVT2SEGY 


\section{goto CVT2REF}

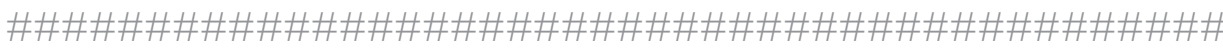

\# rt130 format --> reftek format

\# output: one big reftek file/das\#

\section{CVT2REF:}

cd \$ref

rt130cut -r \$rt130 -d \$3

cd ..

\section{goto CVT2SEGY}

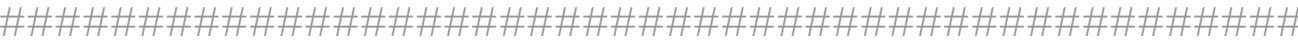

\# reftek format --> segy format

\# output: Rjjj.01/yy.ddd.hh.mm.ss.iiii.c

\# ! if the data packet starts before the start

\# time specified in the Time-range file,

\# this data packet won't be converted

\# Either specify a start time anticipating as

\# much as the length of one data packet

\# or merge and cut afterwards

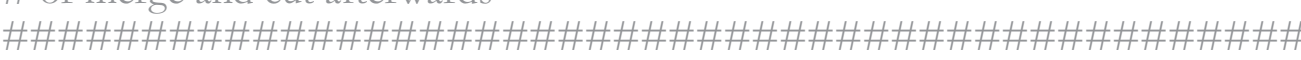

\section{CVT2SEGY:}

cd \$segy

foreach das (\$das_list)

head -1 \$stn_info $>$ \$das.info 
\# $\operatorname{mv} \$\{$ das $\} \cdot \operatorname{pos} \$\{$ data $\} /$ Stations/

\# $\operatorname{mv} \$\{$ das $\}$. loc $\$\{$ data $\} /$ Stations $/$

end

cd ..

goto CLOCK

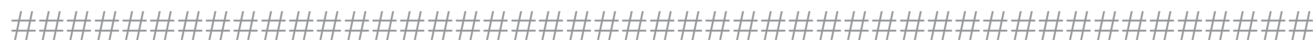

\# operates time corrections

\# looks first in the logfile and then the ratingfile

\# for time correction

\# $\quad$ t_corr $=0$ then yes

\# $\quad$ t_corr $=-1$ then no

\section{CLOCK:}

echo "Running Clock corrections"

cd $\$ \log$

foreach das (\$das_list)

set $t$ corr $=$ "no"

set nt_corr $=$ 'grep jump A1 $\$\{$ das $\} \cdot \log \mid$ wc -1 '

echo \$nt_corr

if ( \$nt_corr != "0" ) then

echo "refrate -m A1 $\$\{$ das $\} . \log >\$\{$ rating $\} / \$\{$ das $\}$ rating"

refrate -m A1 $\$\{$ das $\} \cdot \log >\$\{$ rating $\} / \$\{$ das $\} \_$rating

echo "refrate -m A1 $\$\{$ das $\} . \log >\$\{$ rating $\} / \$\{$ das $\}$ rating"

set t_corr = 'awk ' $\{$ if $(\mathrm{NR}>1)\{$ if $(\$ 3 !=0|| \$ 4 !=0)\{$ print "yes" $\}$ else $\{$ print $"$ no" $\}\}\}^{\prime}<\$\{$ rating $\} / \$\{$ das $\}$ rating

endif

if $($ \$t_corr $==$ "yes") then

set t_opt $=$ "-c $\$\{$ rating $\} / \$\{$ das $\}$ _rating"

else

set t_opt $=" 1 "$ 
\# \# creates the eqcut.das file

\# \# input is das\# geophone stnnm profile lat lon elv channel

\# echo "\#das geophone site profile lat lon elv chan" > \$eqcut_das

\#

\# foreach das (\$das list)

\#

\# $\quad$ set $\operatorname{stn}={ }^{\prime}$ gawk $-\mathrm{v}$ das $=\$$ das ' $\{\text { if }(\$ 1==\text { das }) \text { print } \$ 2\}^{\prime}<$

$\$\{$ data $\} /$ Stations $/ \$\{\exp \}$.das

\#

\# $\quad$ set geoph $={ }^{\prime}$ gawk $-\mathrm{v}$ das $=\$$ das ' $\{\text { if }(\$ 1==\text { das }) \text { print } \$ 4\}^{\prime}<$

$\$\{$ data $\} /$ Stations $/ \$\{\exp \}$.das

\#

\# $\quad$ echo \$das \$stn \$geoph \$exp

\# gawk $-\mathrm{v}$ das $=\$$ das $-\mathrm{v}$ site $=\$$ stn $-\mathrm{v}$ prof $=\$\{\exp \}-\mathrm{v}$ geoph $=\$$ geoph $\{\backslash$

\# printf("\%4s \%3d \%3s \% \% \% $\%$. $\% 10.5 f \% 5 d$

$1,2,3 \backslash \mathrm{n}$ ",das,geoph,site,prof,\$1,\$2,\$3)

$\# \quad\}^{\prime}<\$\{$ data $\} /$ Stations $/ \$\{$ das $\}$. pos $>>$ \$eqcut_das

\#

\# end

\# echo "extracts earthquakes"

\#

\# \# / ref_bin/eqcut/eqcut.py \

\# nice -20 /usr/local/packages/passcal/2005.059/bin/eqcut \

\# -d $\$\{$ eqcut_das $\}$.

\# $\quad$-e $\$\{$ eqcut_evt $\} \backslash$

\# - $\quad$ - \$len

\# -r \$rec_len \

\# $\quad$-s \$spl_rate

\# -D \$segy

\# $\quad$-o \$out_dir \

\# -t \$tolerance $\backslash$

\# $\quad$-c $\$\{$ rating $\} / \$\{$ das $\}$ _rating

\# alternative to eqcut use runmerge but has to change settings before 
echo " clock : timing correction if necessary"

echo" location :extracts the Das coordinates"

echo " extract : extracts liste of earthquakes in eqcut.evt file for liste of das" 
\# name and location as the input miniSEED file but will end with the segy suffix.

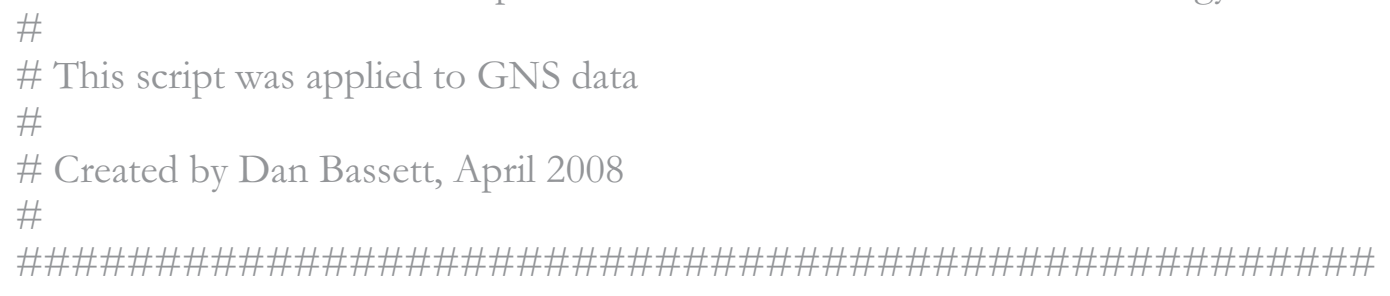

\section{for station in \$stations; do}

1s \$input_rootdir/\$station/A1.seed | stationfiles $=\$(1 \mathrm{~s}$ \$input_rootdir/\$station/A1.seed )

echo $\$$ stationfiles $\mid$ perl -pe 's $\backslash s+/ \mathrm{n} / \mathrm{g}$ '

for stationfile in \$stationfiles; do

\$input_rootdir/mseed2segy \$stationfile echo Data Conversion Complete

Output_directory="\$output_rootdir/\$station/data/raw_segy" mv \$input_rootdir/\$station/A1.segy \$Output_directory

echo Data Relocation Complete

\section{done}

done 
\# with lines comprised of multiple segments merged within segygather

\# Creation of these segment segy files significantly reduces data redundancy and

\# speeds up the segygather function.

\#

\# This script was applied to GNS data.

\#

\# Created by Dan Bassett, May 2008

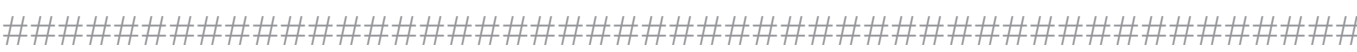

echo Starting segycut 'date` >> prep_gather.log

lines="Line1 Line2 Line3a Line3b Line4 Line5a Line5b Line5c Line5d Line6 Line7 Line9 Line10"

stations="taurus_0487 taurus_0576 taurus_0584 taurus_0599 taurus_0602 taurus_0610"

\section{\#\#\#\#START TIMES\#\#\#\#}

Line1_start="07:165:02:08:50.00"

Line2_start="07:163:12:43:10.00"

Line3a_start="07:139:06:39:50.00"

Line3b_start="07:144:19:42:00.00"

Line4_start="07:160:12:18:20.00"

Line5a_start="07:145:14:16:50.00"

Line5b_start="07:150:13:31:30.00"

Line5c_start="07:151:13:43:10.00"

Line5d_start="07:152:00:47:30.00"

Line6_start="07:154:20:58:20.00"

Line7a_start="07:155:16:19:30.00"

Line7b_start="07:162:17:11:40.00"

Line9_start="07:163:22:55:50.00"

Line10_start="07:164:10:02:00.00" 
Line9_length="30729"

Line10_length="31485"

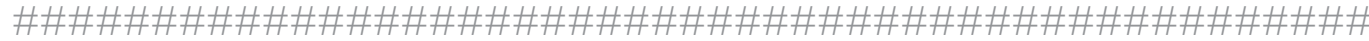

\section{echo STATION taurus_0487}

\section{\#\#\#\#SEGY FILES\#\#\#\#}

may_16="/scratch/dbassett/RAU07/segydata/taurus_0487/data/STN01_taurus_ 0487_20070516_002010.seed.segy"

may_30=" /scratch/dbassett/RAU07/segydata/taurus_0487/data/STN01_taurus_ 0487_20070530_002010.seed.segy"

june_13="/scratch/dbassett/RAU07/segydata/taurus_0487/data/STN01_taurus_ 0487_20070613_002010.seed.segy"

\section{echo STARTING SEGYCUT}

\section{echo LINE 1}

/opt/local/passcal/bin/segycut \$june_13 -s \$\{Line1_start $-1 \$\{$ Line1_length $\}>$ /scratch/dbassett/RAU07/segydata/taurus_0487/data/line_segy/0487_Line1.s egy

\section{echo LINE 2}

/opt/local/passcal/bin/segycut \$may_30 -s \$ LLine2_start $\}$-1 \$ \{Line2_length $\}>$ /scratch/dbassett/RAU07/segydata/taurus_0487/data/line_segy/0487_Line2.s egy

\section{echo LINE 3 a}

/opt/local/passcal/bin/segycut \$may_16 -s \$ \{Line3a_start $\}-1$ \$ Line3a_length $\}>$ /scratch/dbassett/RAU07/segydata/taurus_0487/data/line_segy/0487_Line3a. segy

\section{echo LINE 3b}

/opt/local/passcal/bin/segycut \$may_16 -s \$\{Line3b_start $\}$-1 \$\{Line3b_length $\}>$ /scratch/dbassett/RAU07/segydata/taurus_0487/data/line_segy/0487_Line3b segy 
/scratch/dbassett/RAU07/segydata/taurus_0487/data/line_segy/0487_Line5b .segy

echo LINE $5 \mathrm{c}$

/opt/local/passcal/bin/segycut \$may_30 -s $\$\{$ Line5c_start $\}-1 \$\{$ Line5c_length $\}>$ /scratch/dbassett/RAU07/segydata/taurus_0487/data/line_segy/0487_Line5c .segy

\section{echo LINE 5d}

/opt/local/passcal/bin/segycut \$may_30 -s \$\{Line5d_start $\}$-1 \$\{Line5d_length $\}>$ /scratch/dbassett/RAU07/segydata/taurus_0487/data/line_segy/0487_Line5d .segy

\section{echo LINE 6}

/opt/local/passcal/bin/segycut \$may_30 -s \$\{Line6_start $\}$-1 \$\{Line6_length $\}>$ /scratch/dbassett/RAU07/segydata/taurus_0487/data/line_segy/0487_Line6.s egy

echo LINE $7 \mathrm{a}$

/opt/local/passcal/bin/segycut \$may_30 -s \$\{Line7a_start $\}$-1 \$\{Line7a_length $\}>$ /scratch/dbassett/RAU07/segydata/taurus_0487/data/line_segy/0487_Line7a. segy

echo LINE 7b

/opt/local/passcal/bin/segycut \$may_30 -s \$\{Line7b_start $\}$-1 \$\{Line7b_length $\}>$ /scratch/dbassett/RAU07/segydata/taurus_0487/data/line_segy/0487_Line7b .segy

\section{echo LINE 9}

/opt/local/passcal/bin/segycut \$may_30 -s \$\{Line9_start $\}$-1 \$\{Line9_length $\}>$ /scratch/dbassett/RAU07/segydata/taurus_0487/data/line_segy/0487_Line9.s egy

\section{echo LINE 10}

/opt/local/passcal/bin/segycut \$june_13 -s \$\{Line10_start $\}$-1 \$\{Line10_length $\}>$ /scratch/dbassett/RAU07/segydata/taurus_0487/data/line_segy/0487_Line10 .segy

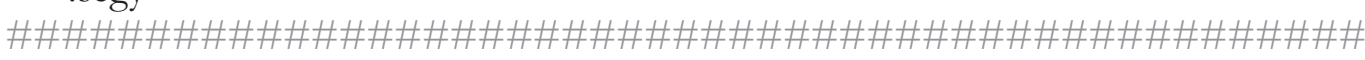




\section{echo LINE 1}

/opt/local/passcal/bin/segycut \$june_05 -s \$\{Line1_start $\}$-1 \$\{Line1_length $\}>$ /scratch/dbassett/RAU07/segydata/taurus_0576/data/line_segy/0576_Line1.s egy

\section{echo LINE 2}

/opt/local/passcal/bin/segycut \$june_05 -s \$\{Line2_start $\}$-1 \$\{Line2_length $\}>$ /scratch/dbassett/RAU07/segydata/taurus_0576/data/line_segy/0576_Line2.s egy

\section{echo LINE 3 a}

/opt/local/passcal/bin/segycut \$may_08 -s \$\{Line3a_start $\}$-1 \$\{Line3a_length $\}>$ /scratch/dbassett/RAU07/segydata/taurus_0576/data/line_segy/0576_Line3a. segy

echo LINE 3b

/opt/local/passcal/bin/segycut \$may_22 -s \$\{Line3b_start $\}$-1 \$\{Line3b_length $\}>$ /scratch/dbassett/RAU07/segydata/taurus_0576/data/line_segy/0576_Line3b segy

echo LINE 4

/opt/local/passcal/bin/segycut \$june_05 -s \$\{Line4_start $\}$-1 \$\{Line4_length $\}>$ /scratch/dbassett/RAU07/segydata/taurus_0576/data/line_segy/0576_Line4.s egy

\section{echo LINE 5 a}

/opt/local/passcal/bin/segycut \$may_22 -s \$\{Line5a_start $\}$-1 \$\{Line5a_length $\}>$ /scratch/dbassett/RAU07/segydata/taurus_0576/data/line_segy/0576_Line5a. segy

echo LINE $5 b$

/opt/local/passcal/bin/segycut \$may_22 -s \$\{Line5b_start $\}$-1 \$\{Line5b_length $\}>$ /scratch/dbassett/RAU07/segydata/taurus_0576/data/line_segy/0576_Line5b segy 
echo LINE $7 \mathrm{a}$

/opt/local/passcal/bin/segycut \$may_22 -s \$\{Line7a_start $\}$-1 \$\{Line7a_length $\}>$ /scratch/dbassett/RAU07/segydata/taurus_0576/data/line_segy/0576_Line7a. segy

\section{echo LINE $7 \mathrm{~b}$}

/opt/local/passcal/bin/segycut \$june_05 -s \$\{Line7b_start $\}$-1 \$\{Line7b_length $\}>$ /scratch/dbassett/RAU07/segydata/taurus_0576/data/line_segy/0576_Line7b .segy

\section{echo LINE 9}

/opt/local/passcal/bin/segycut \$june_05 -s \$\{Line9_start $\}$-1 \$\{Line9_length\} > /scratch/dbassett/RAU07/segydata/taurus_0576/data/line_segy/0576_Line9.s egy

echo LINE 10

/opt/local/passcal/bin/segycut \$june_05 -s \$\{Line10_start $\}$-1 \$\{Line10_length $\}>$ /scratch/dbassett/RAU07/segydata/taurus_0576/data/line_segy/0576_Line10 .segy

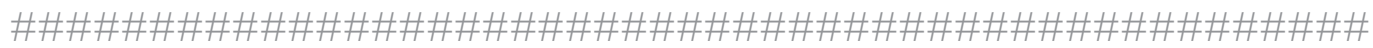

\section{echo STATION taurus 0584}

\section{\#\#\#\#SEGY FILES\#\#\#\#}

may_14="/scratch/dbassett/RAU07/segydata/taurus_0584/data/STN01_taurus_ 0584_20070514_231215.seed.segy"

may_28="/scratch/dbassett/RAU07/segydata/taurus_0584/data/STN01_taurus_ 0584_20070528_231215.seed.segy"

june_11="/scratch/dbassett/RAU07/segydata/taurus_0584/data/STN01_taurus_ 0584_20070611_231215.seed.segy"

echo STARTING SEGYCUT 
echo LINE 3b

/opt/local/passcal/bin/segycut \$may_14 -s \$\{Line3b_start $\}$-1 \$\{Line3b_length $\}>$ /scratch/dbassett/RAU07/segydata/taurus_0584/data/line_segy/0584_Line3b .segy

\section{echo LINE 4}

/opt/local/passcal/bin/segycut \$may_28 -s \$\{Line4_start $\}$-1 \$\{Line4_length $\}>$ /scratch/dbassett/RAU07/segydata/taurus_0584/data/line_segy/0584_Line4.s egy

\section{echo LINE 5 a}

/opt/local/passcal/bin/segycut \$may_14 -s \$\{Line5a_start $\}$-1 \$\{Line5a_length $\}>$ /scratch/dbassett/RAU07/segydata/taurus_0584/data/line_segy/0584_Line5a. segy

echo LINE $5 b$

/opt/local/passcal/bin/segycut \$may_28 -s \$\{Line5b_start $\}$-1 \$ $\{$ Line5b_length $\}>$ /scratch/dbassett/RAU07/segydata/taurus_0584/data/line_segy/0584_Line5b .segy

echo LINE $5 \mathrm{c}$

/opt/local/passcal/bin/segycut \$may_28 -s \$\{Line5c_start $\}$-1 \$\{Line5c_length $\}>$ /scratch/dbassett/RAU07/segydata/taurus_0584/data/line_segy/0584_Line5c .segy

\section{echo LINE 5d}

/opt/local/passcal/bin/segycut \$may_28 -s \$\{Line5d_start $\}$-1 \$\{Line5d_length $\}>$ /scratch/dbassett/RAU07/segydata/taurus_0584/data/line_segy/0584_Line5d segy

\section{echo LINE 6}

/opt/local/passcal/bin/segycut \$may_28 -s \$\{Line6_start $\}$-1 \$\{Line6_length $\}>$ /scratch/dbassett/RAU07/segydata/taurus_0584/data/line_segy/0584_Line6.s egy 
/scratch/dbassett/RAU07/segydata/taurus_0584/data/line_segy/0584_Line9.s egy

echo LINE 10

/opt/local/passcal/bin/segycut \$june_11 -s \$\{Line10_start $\}$-1 \$\{Line10_length $\}>$ /scratch/dbassett/RAU07/segydata/taurus_0584/data/line_segy/0584_Line10 .segy

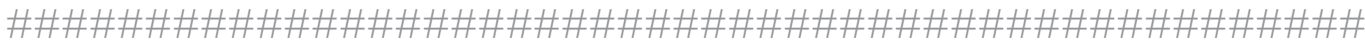

echo STATION taurus_0599

\#\#\#\#SEGY FILES\#\#\#\#

may15="/scratch/dbassett/RAU07/segydata/taurus_0599/data/STN01_apollo_0 599_20070515_043745.seed.segy"

may22="/scratch/dbassett/RAU07/segydata/taurus_0599/data/STN01_apollo_0 599_20070522_043745.seed.segy"

may29="/scratch/dbassett/RAU07/segydata/taurus_0599/data/STN01_apollo_0 599_20070529_043745.seed.segy"

june05="/scratch/dbassett/RAU07/segydata/taurus_0599/data/STN01_apollo_0 599_20070605_043745.seed.segy"

june12="/scratch/dbassett/RAU07/segydata/taurus_0599/data/STN01_apollo_0 599_20070612_043745.seed.segy"

\section{echo STARTING SEGYCUT}

\section{echo LINE 1}

/opt/local/passcal/bin/segycut \$june12 -s \$\{Line1_start $\}$-1 \$\{Line1_length $\}>$ /scratch/dbassett/RAU07/segydata/taurus_0599/data/line_segy/0599_Line1.s egy

echo LINE 2

/opt/local/passcal/bin/segymerge \$june05 \$june12 -c -s \$\{Line2_start $\}$-1

$\$\{$ Line2_length $\}>$

/scratch/dbassett/RAU07/segydata/taurus_0599/data/line_segy/0599_Line2.s egy 
echo LINE $5 \mathrm{a}$

/opt/local/passcal/bin/segycut \$may22 -s \$\{Line5a_start $\}$-1 \$\{Line5a_length $\}>$

/scratch/dbassett/RAU07/segydata/taurus_0599/data/line_segy/0599_Line5a. segy

echo LINE $5 b$

/opt/local/passcal/bin/segycut \$may29 -s \$\{Line5b_start $\}$-1 \$\{Line5b_length $\}>$ /scratch/dbassett/RAU07/segydata/taurus_0599/data/line_segy/0599_Line5b .segy

echo LINE $5 c$

/opt/local/passcal/bin/segycut \$may29 -s \$\{Line5c_start $\}$-1 \$\{Line5c_length $\}>$ /scratch/dbassett/RAU07/segydata/taurus_0599/data/line_segy/0599_Line5c segy

echo LINE $5 \mathrm{~d}$

/opt/local/passcal/bin/segycut \$may29 -s \$\{Line5d_start $\}$-1 \$ \{Line5d_length $\}>$ /scratch/dbassett/RAU07/segydata/taurus_0599/data/line_segy/0599_Line5d .segy

echo LINE 6

/opt/local/passcal/bin/segycut \$may29 -s \$\{Line6_start\} -1 \$\{Line6_length\} > /scratch/dbassett/RAU07/segydata/taurus_0599/data/line_segy/0599_Line6.s egy

\section{echo LINE 7a}

/opt/local/passcal/bin/segycut \$may29 -s \$\{Line7a_start $\}$-1 \$ \{Line7a_length $\}>$ /scratch/dbassett/RAU07/segydata/taurus_0599/data/line_segy/0599_Line7a. segy

echo LINE $7 \mathrm{~b}$

/opt/local/passcal/bin/segymerge \$june05 \$june12 -c -s \$\{Line7b_start $\}$-1 $\$\left\{\right.$ Line $7 b \_l$ length $\}>$

/scratch/dbassett/RAU07/segydata/taurus_0599/data/line_segy/0599_Line7b .segy 
may_10="/scratch/dbassett/RAU07/segydata/taurus_0602/data/STN01_taurus_ 0602_20070510_001430.seed.segy"

may_24="/scratch/dbassett/RAU07/segydata/taurus_0602/data/STN01_taurus_ 0602_20070524_001430.seed.segy"

june_07="/scratch/dbassett/RAU07/segydata/taurus_0602/data/STN01_taurus_ 0602_20070607_001430.seed.segy"

\section{echo STARTING SEGYCUT}

\section{echo LINE 1}

/opt/local/passcal/bin/segycut \$june_07 -s \$\{Line1_start $\}$-1 \$\{Line1_length $\}>$ /scratch/dbassett/RAU07/segydata/taurus_0602/data/line_segy/0602_Line1.s egy

\section{echo LINE 2}

/opt/local/passcal/bin/segycut \$june_07 -s \$\{Line2_start $\}$-1 \$\{Line2_length $\}>$ /scratch/dbassett/RAU07/segydata/taurus_0602/data/line_segy/0602_Line2.s egy

\section{echo LINE 3a}

/opt/local/passcal/bin/segycut \$may_10 -s \$\{Line3a_start $\}-1 \$\{$ Line3a_length $\}>$ /scratch/dbassett/RAU07/segydata/taurus_0602/data/line_segy/0602_Line3a. segy

\section{echo LINE $3 \mathrm{~b}$}

/opt/local/passcal/bin/segymerge \$may_10 \$may_24 -c -s \$\{Line3b_start $\}$-1 $\$\{$ Line3b_length $\}>$

/scratch/dbassett/RAU07/segydata/taurus_0602/data/line_segy/0602_Line3b segy

\section{echo LINE 4}

/opt/local/passcal/bin/segycut \$june_07 -s \$\{Line4_start $\}$-1 \$\{Line4_length $\}>$ /scratch/dbassett/RAU07/segydata/taurus_0602/data/line_segy/0602_Line4.s egy 
echo LINE $5 \mathrm{~d}$

/opt/local/passcal/bin/segycut \$may_24 -s \$\{Line5d_start $\}$-1 \$\{Line5d_length $\}>$ /scratch/dbassett/RAU07/segydata/taurus_0602/data/line_segy/0602_Line5d segy

\section{echo LINE 6}

/opt/local/passcal/bin/segycut \$may_24 -s \$\{Line6_start $\}$-1 \$\{Line6_length $\}>$ /scratch/dbassett/RAU07/segydata/taurus_0602/data/line_segy/0602_Line6.s egy

\section{echo LINE 7a}

/opt/local/passcal/bin/segycut \$may_24 -s \$\{Line7a_start $\}$-1 \$\{Line7a_length $\}>$ /scratch/dbassett/RAU07/segydata/taurus_0602/data/line_segy/0602_Line7a. segy

\section{echo LINE 7b}

/opt/local/passcal/bin/segycut \$june_07 -s \$\{Line7b_start $\}$-1 \$\{Line7b_length $\}>$ /scratch/dbassett/RAU07/segydata/taurus_0602/data/line_segy/0602_Line7b .segy

\section{echo LINE 9}

/opt/local/passcal/bin/segycut \$june_07 -s \$\{Line9_start $\}$-1 \$\{Line9_length $\}>$ /scratch/dbassett/RAU07/segydata/taurus_0602/data/line_segy/0602_Line9.s egy

\section{echo LINE 10}

/opt/local/passcal/bin/segycut \$june_07 -s \$\{Line10_start $\}$-1 \$\{Line10_length \} > /scratch/dbassett/RAU07/segydata/taurus_0602/data/line_segy/0602_Line10 segy

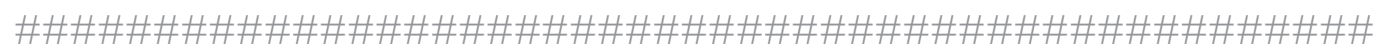

echo station 0610 
echo LINE 1

/opt/local/passcal/bin/segycut \$june13 -s \$\{Line1_start $\}$-1 \$ \{Line1_length $\}>$

/scratch/dbassett/RAU07/segydata/taurus_0610/data/line_segy/0610_Line1.s egy

\section{echo LINE 2}

/opt/local/passcal/bin/segycut \$june06 -s \$\{Line2_start $\}-1 \$\{$ Line2_length $\}>$ /scratch/dbassett/RAU07/segydata/taurus_0610/data/line_segy/0610_Line2.s egy

echo LINE 3 a

/opt/local/passcal/bin/segycut \$may16 -s \$\{Line3a_start $\}-1 \$\{$ Line3a_length $\}>$ /scratch/dbassett/RAU07/segydata/taurus_0610/data/line_segy/0610_Line3a. segy

echo LINE 3b

/opt/local/passcal/bin/segycut \$may23 -s \$\{Line3b_start $\}$-1 \$\{Line3b_length $\}>$ /scratch/dbassett/RAU07/segydata/taurus_0610/data/line_segy/0610_Line3b .segy

\section{echo LINE 4}

/opt/local/passcal/bin/segycut \$june06 -s \$\{Line4_start $\}$-1 \$ \{Line4_length\} > /scratch/dbassett/RAU07/segydata/taurus_0610/data/line_segy/0610_Line4.s egy

\section{echo LINE $5 a$}

/opt/local/passcal/bin/segycut \$may23 -s \$\{Line5a_start $\}$-1 \$\{Line5a_length $\}>$ /scratch/dbassett/RAU07/segydata/taurus_0610/data/line_segy/0610_Line5a. segy

\section{echo LINE $5 b$}

/opt/local/passcal/bin/segymerge \$may23 \$may30 -c -s \$ \{Line5b_start $\}$-1 $\$\{$ Line5b_length $\}>$ /scratch/dbassett/RAU07/segydata/taurus_0610/data/line_segy/0610_Line5b .segy 
echo LINE 7a

/opt/local/passcal/bin/segycut \$may30 -s \$\{Line7a_start $\}$-1 \$\{Line7a_length $\}>$ /scratch/dbassett/RAU07/segydata/taurus_0610/data/line_segy/0610_Line7a. segy

echo LINE $7 b$

/opt/local/passcal/bin/segycut \$june06 -s \$\{Line7b_start $\}$-1 \$\{Line7b_length $\}>$ /scratch/dbassett/RAU07/segydata/taurus_0610/data/line_segy/0610_Line7b .segy

\section{echo LINE 9-PART 1}

/opt/local/passcal/bin/segycut \$june06 -s \$\{Line9_start $\}$-1 \$\{Line9_length $\}>$ /scratch/dbassett/RAU07/segydata/taurus_0610/data/line_segy/0610_Line9_ Part1.segy

echo LINE 9-PART 2

/opt/local/passcal/bin/segycut \$june13 -s 07:164:00:04:08.00 -1 30000 > /scratch/dbassett/RAU07/segydata/taurus_0610/data/line_segy/0610_Line9_ Part2.segy

echo LINE 10

/opt/local/passcal/bin/segycut \$june13 -s \$\{Line10_start $\}$-1 \$\{Line10_length $\}>$ /scratch/dbassett/RAU07/segydata/taurus_0610/data/line_segy/0610_Line10 .segy

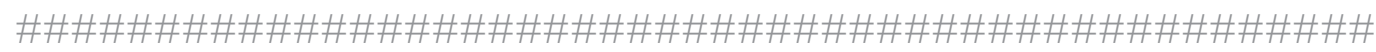
echo ALL DONE 


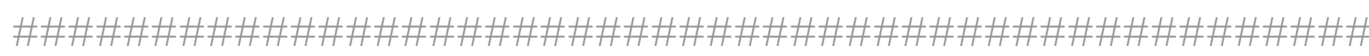

segy_rootdir="/scratch/dbassett/RAU07/segydata"

segylist $=\$(1$ s $\$$ segy_rootdir/taurus_0487/data/line_segy $/$ )

echo $\$$ segylist | grep $0487 \mid$ perl -p -e 's $\backslash$ s $+\wedge \mathrm{n} / \mathrm{g}^{\prime}>$

/scratch/dbassett/RAU07/segydata/taurus_0487/support_files/taurus_0487.list

echo LIST CREATED taurus_0487

segylist $=\$(1$ s $\$$ segy_rootdir/taurus_0576/data/line_segy/)

echo $\$$ segylist $\mid$ grep $0576 \mid$ perl $-\mathrm{p}-\mathrm{e}$ 's $\bigwedge \mathrm{s}+/ \mathrm{n} / \mathrm{g}$ ' >

/scratch/dbassett/RAU07/segydata/taurus_0576/support_files/taurus_0576.list

echo LIST CREATED taurus_0576

segylist $=\$(1$ s $\$$ segy_rootdir/taurus_0584/data/line_segy $/)$

echo $\$$ segylist | grep $0584 \mid$ perl -p -e 's/ $\backslash \mathrm{s}+/ \mathrm{n} / \mathrm{g}$ ' >

/scratch/dbassett/RAU07/segydata/taurus_0584/support_files/taurus_0584.list echo LIST CREATED taurus_0584

segylist $=\$$ (1s \$segy_rootdir/taurus_0599/data/line_segy/)

echo $\$$ segylist | grep $0599 \mid$ perl -p -e 's/ $\backslash \mathrm{s}+/ \mathrm{n} / \mathrm{g}$ ' >

/scratch/dbassett/RAU07/segydata/taurus_0599/support_files/taurus_0599.list echo LIST CREATED taurus_0599

segylist=\$(1s \$segy_rootdir/taurus_0602/data/line_segy/)

echo $\$$ segylist | grep $0602 \mid$ perl $-\mathrm{p}-\mathrm{e}$ 's $\bigwedge \mathrm{s}+/ \mathrm{n} / \mathrm{g}$ ' >

/scratch/dbassett/RAU07/segydata/taurus_0602/support_files/taurus_0602.list echo LIST CREATED taurus_0602

segylist $=\$(1$ s $\$$ segy_rootdir/taurus_0610/data/line_segy/)

echo \$segylist | grep $0610 \mid$ perl -p -e 's/ $\backslash \mathrm{s}+/ \mathrm{n} / \mathrm{g}$ ' >

/scratch/dbassett/RAU07/segydata/taurus_0610/support_files/taurus_0610.list

echo LIST CREATED taurus_0610 
yy="\$1"
jday="\$2"
hr="\$3"
min="\$4"
ss="\$5"
tol="100"
spl="100"
reclength=" $3600 "$
echo $" 20 \$\{y y\}: \$\{$ jay $\}: \$\{\mathrm{hr}\}: \$\{\min \}: 00 "$

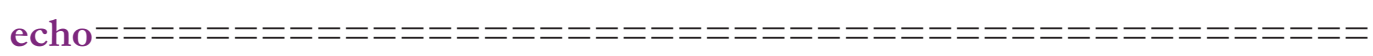

segy_rootdir="/Volumes/data/bassetda/reftek_data"

echo SEGY ROOT DIRECTORY SET AS /Volumes/data/bassetda/reftek_data

for station in \$stations; do

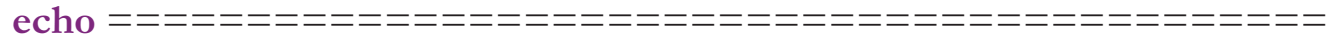
echo Processing Station \$station

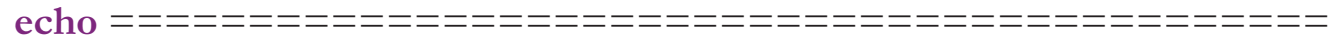
echo Started $\$($ date $)$

for channel in \$channels; do

echo "Working on channel \$channel"

segydir=\$segy_rootdir/\$station

for dayfolder in \$dayfolders; do

segylist $=\$$ (1s \$segy_rootdir $/ \$$ station $/$ SEGY_data/\$dayfolder $/ *$. channel) 
done

done

done 
\# Created by Dan Bassett, April 2008

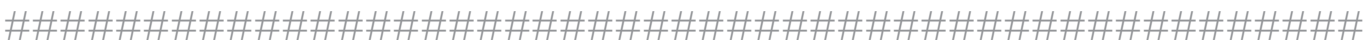

stations $=$ "rewetu waihau pakira"

channel="1 2 3"

dayfolders="R139.01 R140.01 R145.01 R146.01 R150.01 R151.01 R152.01 R153.01

R154.01 R155.01 R160.01 R161.01 R162.01 R163.01 R164.01 R165.01"

segy_rootdir="/data/bassetda/data"

for station in $\$$ stations do

for channel in \$channels do

for day in $\$$ dayfolders do

echo DAY \$station \$channel \$day

segylist=\$(1s \$segy_rootdir/\$station/SEGY_data/\$day/A1.\$channel)

echo \$segylist | grep 915E.1 | perl -p -e 's $\bigwedge s+/ n / g '>$

/data/bassetda/data/rewetu/support_files/\$station.\$day.\$channel.list

echo LIST CREATED \$station \$day \$channel

done

done

done 
Created by Dan Bassett and Chris Le Blanc, Mav 2008

\#

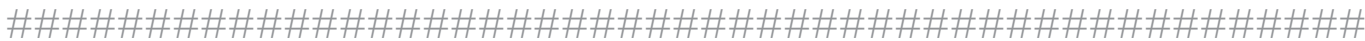

\# hackin!

import sys

if len(sys.argv) $<2$ :

print "Error, must supply an input filename"

sys.exit(1)

inputFile $=$ sys.argv $[1$

inputFileObj $=$ open(inputFile, 'r')

for line in inputFileObj.readlines $($ :

fields $=$ line.split 0

if len(fields) $==0$ :

continue

print $(" \% 04 \mathrm{~d} \% 02 \mathrm{~d} \% 02 \mathrm{~d} \% 02 \mathrm{~d} \% 02 \mathrm{~d} \% 02 \mathrm{~d} . \% \mathrm{~s} \quad \%$ s $\% 04 \mathrm{~d} \% 09.6 \mathrm{f} \% 010.6 \mathrm{f}$ $\% 06.1$ f \%010.6f \%010.6f" \%

(int(fields[0]), int(fields[1]), int(fields[2]),

int(fields [3]), int(fields [4]), int(fields [5]), fields [6].ljust(6),

fields[7], int(fields [8]),float(fields[9]),float(fields[10]), float(fields[11]), float(fields[12]),float(fields[13]))) 
\# This script was modified from pre_segygather_2.csh developed by Suzannah

\# Toulmin

\#

\# Created by Dan Bassett and Chris Le Blanc, May 2008

\#

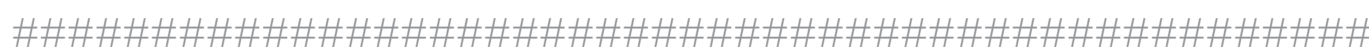

mv \$3.ahl \$3.ahl

mv \$3.time \$3.time

mv \$3.sht \$3.sht

set ST_LAT $=\$ 1$

set ST_LON $=\$ 2$

echo \$ST_LAT

echo \$ST_LON

set data = `echo

/sp/scratch/tmp1/RAU07/navigation_data/Nav_Input_Data/Txt/\$3.txt

echo $\$$ data

set nlines = 'wc $-1 \$$ data $\mid$ awk' $\{$ print $\$ 1\}$ '

set nline $={ }^{\prime e c h o ~} 1{ }^{`}$

set STLAT $=$ echo $\$ S T \_L A T \mid$ awk ' $\{\$ 1=\$ 1 \mathrm{~A} 13600$; printf("\%7s", \$1)\}"

set STLON = echo $\$ S T \_L O N \mid$ awk ' $\{1=\$ 1 \mathrm{~A} 13600$; printf $(" \% 6 \mathrm{~s} ", \$ 1)\}$ "

echo "ADDHDR" > \$3.ahl

echo "Primary key : SHOTID" >> \$3.ahl

echo "Secondary key : CHANNEL" >> \$3.ahl 
rm tmp2

rm tmp3

daz - k \$lat \$lon \$ST_LAT \$ST_LON > tmp2

set dist $=`^{\prime a w k}$ ' $\{$ print $\$ 0\}$ ' tmp2

set LAT = 'echo \$line1 $\mid$ awk ' $\{12=\$ 12 \mathrm{~A} 13600$; printf ("\%10.0f",\$12)\}"

set LON = 'echo $\$$ line1 $\mid$ awk ' $\{13=\$ 13 \mathrm{~A} 13600$; printf ("\%10.0f",\$13)\}"

set WDEPTH = 'echo $\$$ line1 $\mid$ awk ' $\left\{11=\$ 11 \mathrm{~A} 110\right.$; printf $\left.\left(" \% \mathrm{~s}^{\prime \prime}, \$ 11\right)\right\} "$

set MSEC = 'echo \$line1 $\mid$ awk ' $\left\{\mathrm{msec}=\operatorname{substr}(\$ 6,4,0)\right.$; $\left.\operatorname{printf}\left(" \% \mathrm{~s}^{\prime}, \mathrm{msec}\right)\right\}$ '"

set DIST = `echo $\$$ dist $\mid$ awk ' $\{\$ 1=\$ 1 \mathrm{~A} 11000$; print $\$ 0\}$ '

echo \$shotid 1 \$STLAT \$STLON \$WDEPTH \$DIST \$MSEC > tmp3

cat tmp3 | awk' $\{$ if $(\$ 1<1000) \$ 1="$ " $\$ 1$; else $\$ 1=\$ 1$; if $(\$ 6<100000) \$ 6=\$ 6 "$

"; else $\$ 6=\$ 6$; printf(" \%s \%s \%s \%s \%s \%s \%s \n", \$1, \$2, \$3, \$4, \$6, \$7, \$5)\}'

>> \$3.ahl

(a) nline ++

end

echo "shot time" > \$3.time

awk -f /sp/scratch/tmp1/RAU07/scripts/mk_time.awk \$data >> \$3.time

echo \$3.time written to file

echo "shot time lon lat elevation depth wdepth" $>\$ 3$.sht

awk -f /sp/scratch/tmp1/RAU07/scripts/mk_sht.awk \$data >> \$3.sht

echo $\$ 3$. sht written to file 
10.6.2-mk_shot

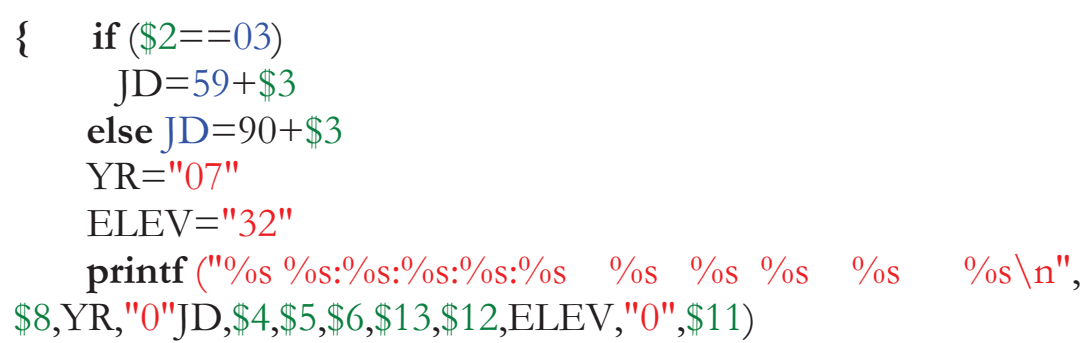

\# Note - Elevation needs to be changed for each station. 
\# be sourced at www.passcal.nmt.edu/software/intro_passcal.html

\# For VUW data, receiver gathers were cut without provision of a start time file.

\# Shot times were extracted from the shot file.

\# Created by Dan Bassett, April 2008

\#

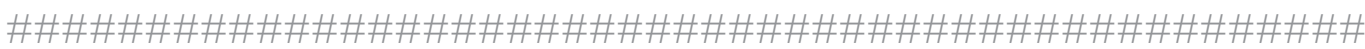

echo Starting run_gather `date` >> prep_gather.log

Lines="Line1_stf Line2_stf Line3_stf Line4_stf Line5_stf Line6_stf Line7_stf

Line9_stf Line10_stf"

stations="Rewetu Pakira Waihau"

channels="1 2 3"

trlength $=60.0$

segy_rootdir="/Users/home/bassetda/EC_SEISMIC"

shott_rootdir="/Users/home/bassetda/EC_SEISMIC/Shot_time_files/Txt"

gather_rootdir="/Users/home/bassetda/EC_SEISMIC"

for line in \$lines; do

echo $=$ ニニニニニニニニニニニニニニニニニニニニニニニニニニニニニニニニニニニニニニニニニ

echo Processing Line \$line

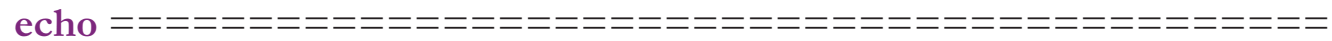

echo Started \$(date)

shot_time_file $=\$$ shott_rootdir $/ \$$ lines.sht

for stn in \$stations; do

echo "A1A1 Working on station \$station"

segydir=\$segy_rootdir/\$station

for channel in \$channels; do

output_gather $=\$$ gather_rootdir $/ \$$ stn $/$ receiver_gathers $/ \$\{\operatorname{stn}\} . \$\{$ line $\} . \$\{$ channel $\} . s$

gy 
\# Here segygather reads the relevant input files and creates a common receiver gather

segygather -s \$shot_time_file -p -n \$trlength -o \$output_gather \$segyinput

\section{done}

done

done 
\# be sourced at www.passcal.nmt.edu/software/intro_passcal.html

\# Created by Dan Bassett, April 2008

\#

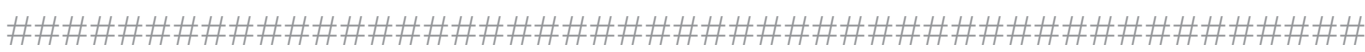

echo Starting run_gather `date` >> prep_gather.log

lines="Line1 Line2 Line3a Line3b Line3all Line4 Line5a Line5b Line5c Line5d Line5all Line6 Line7a Line7b Line7all"

stations="taurus_0602 taurus_0610 taurus_0487 taurus_0576 taurus_0584

taurus_0599"

channels="1 $23 "$

trlength="60.0"

data_rootdir="/scratch/dbassett/RAU07/segydata"

nav_rootdir="/scratch/dbassett/RAU07/Nav_files/Renumbered_nav"

for line in $\$$ lines; do

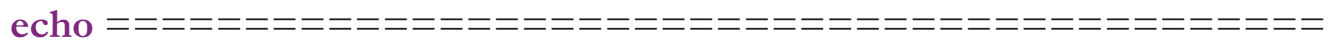

echo Processing Line \$line

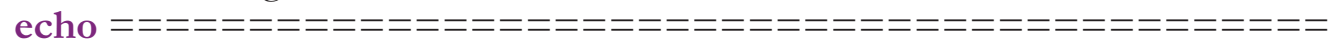

echo Started $\$($ date $)$

for station in \$stations; do

echo "A1A1 Working on station \$station"

for channel in \$channels; do

output_gather $=\$$ data_rootdir $/ \$$ station $/$ receiver_gathers $/ \$\{$ station $\} . \$\{$ line $\} . \$\{$ channel $\}$ .sgy

segylist=\$data_rootdir $/ \$\{$ station $\} /$ support_files $/ \$\{$ station $\}$.list

echo " Processing Channel \$channel"

echo " output to \$data_rootdir/\$station/receiver_gathers" 
\# Here segygather reads the relevant input files and creates a common receiver

\# gather

/opt/local/passcal/bin/segygather -1

\$nav_rootdir/start_time_files/Txt/\$ $\{$ line $\} \_n a v . s h t-s$

\$nav_rootdir/shot_files/\$ $\{$ line $\}$ shot.txt - $\mathrm{p}-\mathrm{n}$ \$trlength -o \$output_gather -i

/scratch/dbassett/RAU07/segydata/\$\{station\}/support_files/\$\{station\}.list

\# Script below should be used if a start time file is not present. If this is the case the \#start times are extracted from the shot file.

\# /opt/local/passcal/bin/segygather -1 \$nav_rootdir/shot_files/\$ $\{$ line $\}$ _shot.txt -p -n \$trlength -o \$output_gather-i

/scratch/dbassett/RAU07/segydata/\$\{station\}/support_files/\$\{station\}.list

done

done

done 
\# Errors were estimated from the ease at which first arrivals could be identified

\# Created by Dan Bassett and Adrian Benson, September 2008

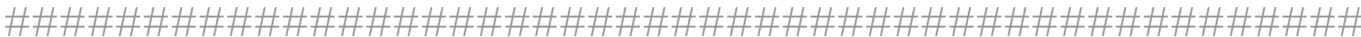

if not len (sys.argv) $==4$ :

sys.exit("Syntax : ./error_file station_name input_file output_file")

station $=$ int (sys.argv[1])

inputfile $=$ sys.argv $[2]$

outputfile $=$ sys.argv $[3$

\#README

\#\#\#\#\# if trying to do pakira - enter 123 as systems arg 1

\#\#\#\#\# if trying to do rewetu - enter 456 as systems arg 1

\#\#\#\#\# if trying to do rewetu - enter 789 as systems arg 1

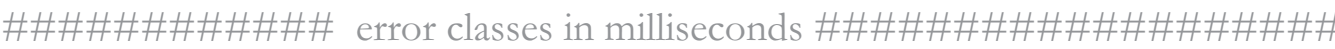

\section{minimal $=0.020$}

minimalsmall $=0.040$

small $=0.050$

smallmedium $=0.075$

medium $=0.100$

mediumlarge $=0.150$

large $=0.200$

fin $=$ open(inputfile, $\left.{ }^{\prime} r^{\prime}\right)$

fout $=$ open $\left(\right.$ outputfile, $\left.{ }^{\prime} w^{\prime}\right)$

hdrline $=$ fin.readline 0

for 1 in fin:

$$
\begin{aligned}
& \text { la }=[\text { float }(\mathrm{x}) \text { for } \mathrm{x} \text { in l.strip }(\text {.split })] \\
& \text { shots }=\mathrm{la}[0] \\
& \text { line }=\operatorname{int}(\text { round }(\text { shots } / 1000000))
\end{aligned}
$$


elif line $==6$ :

if shots $>6001101$ and shots $<6003874$ : error $=$ minimal

elif shots $>6003874$ and shots $<6003963$ : error $=$ small

else :

error $=$ smallmedium

elif line $==5$ :

if shots $>5001001$ and shots $<5004381$ : error $=$ small

elif shots $>5004381$ : error $=$ medium

elif line $==4$ :

if shots $>4001742$ and shots $<4003137$ : error $=$ minimal

else: error $=$ small

elif line $==3$ :

if shots $>3004455$ and shots $<3006726:$ error $=$ minimal

elif shots $>3001001$ and shots $<3004455$ : error $=$ medium

else : error $=$ small

elif line $==2$ :

error $=$ small

elif line $==1$

if shots $<1001578$ or shots $>1002089$ : error $=$ medium

else: error $=$ small

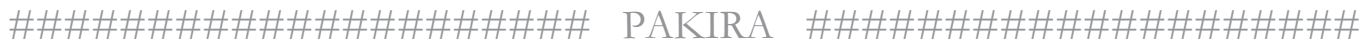

elif station $==123$ :

if line $==10$ :

if shots $<10004000:$ error $=$ minimal

elif line $==9$ :

if shots $<9003000$ : error $=$ minimal

elif line $==7$ :

if shots $>7002311$ and shots $<7004157$ : error $=$ minimal

elif shots $<7002311$ : error $=$ small

elif shots $>7004157$ : error $=$ small

elif line $==6$ :

if shots $>6001351$ and shots $<6003482$ : error=minimal

elif shots $<6001351$ : error $=$ small

elif shots $>6003482$ : error $=$ smallmedium

elif line $==5$ :

if shots $>5002041$ and shots $<5004023:$ error $=$ minimal 
elif line $==1$ :

if shots $<1003000$ : error $=$ minimal

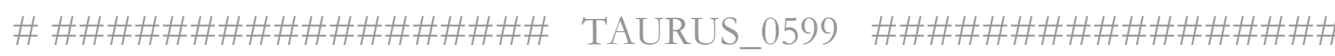

if station $==599$ :

if line $==10$

if shots $<10001944$ : error $=$ minimal

elif shots $>10001944$ and shots $<10002313$ : error $=$ small

elif shots $>10002313$ : error $=$ minimal

elif line $==9$ :

if shots $>9001001$ and shots $<9001288:$ error $=$ small

if shots $>9001288:$ error $=$ minimal

elif line $==7$ :

if shots $>7001001$ and shots $<7001393:$ error $=$ medium

elif shots $>7001393$ : error $=$ minimal

elif line $==6$ :

if shots $>6003528$ and shots $<6003963:$ error $=$ medium

elif shots $<6003528$ : error $=$ minimalsmall

elif shots $>6003863$ : error $=$ minimalsmall

elif line $==5$ :

if shots $>5001001$ and shots $<5004444$ : error $=$ minimalsmall

elif shots $>5004444$ and shots $<5005508$ : error $=$ medium

elif shots $<5005508$ and shots $>5006828$ : error $=$ small

elif line $==4$ :

if shots $>4001001$ and shots $<4002889$ : error $=$ minimal

elif shots $>4002889$ and shots $<4003407$ : error $=$ small

elif shots $<4004052$ : error $=$ minimal

elif line $==3$ :

if shots $>3002767$ and shots $<3003769:$ error $=$ small

elif shots $>3004670$ and shots $<3008913$ : error $=$ small

elif shots $>3003769$ and shots $<3004670$ : error $=$ medium

elif shots $<3002767:$ error $=$ medium

elif line $==2$ :

if shots $>2001000$ and shots $<2003000:$ error $=$ small

elif line $==1$ :

if shots $>1001578$ and shots $<1002089$ : error $=$ small 
if shots $<7001863$ : error $=$ small

elif shots $>7001863$ and shots $<7002929$ : error=smallmedium

elif shots $>7002929$ : error $=$ medium

elif line $==6$ :

if $6001909<$ shots $<6003130$ : error $=$ small

elif shots $<6001909$ : error $=$ smallmedium

elif shots $>6003130:$ error $=$ smallmedium

elif line $==5$ :

if shots $<5001779$ : error=smallmedium

elif shots $>5001779$ and shots $<5004400$ : error $=$ small

elif shots $>5004400:$ error $=$ medium

elif line $==4$

if shots $>4002039$ and shots $<4003373$ : error $=$ small

elif shots $>4002039$ : error $=$ medium

elif shots $<4003373$ : error $=$ medium

elif line $==3$ :

if shots $>3005166$ and shots $<3006485:$ error $=$ small

elif shots $<3005166$ : error $=$ mediumlarge

elif shots $<3006485$ : error $=$ mediumlarge

elif line $==2$ :

if shots $>2002143$ and shots $<2002512$ : error=small

elif shots $<2002143$ : error $=$ medium

elif shots $>2002512$ : error $=$ medium

elif line $==1$ :

if shots $>1001624$ and shots $<1001895:$ error $=$ small

elif shots $<1001624$ : error $=$ medium

elif shots $>1001895$ : error $=$ medium

if station $==602$ :

if line $==10$ :

if shots $>10001643$ and shots $<10001738:$ error $=$ small

elif shots $>10002234$ and shots $<10002342$ : error $=$ small

elif shots $>10002737$ : error $=$ small

else : error $=$ minimal 
elif line $==4$ :

if shots $>4001887$ and shots $<4003325$ : error $=$ minimal

elif shots $>4003325$ : error $=$ smallmedium

elif shots $<4001887$ : error $=$ smallmedium

elif line $==3$ :

if shots $>3004077$ and shots $<3006473$ : error $=$ small

elif shots $<3004077$ : error $=$ mediumlarge

elif shots $>3006473$ : error $=$ mediumlarge

elif line $==2$ :

if shots $>2001150$ and shots $<2001565$ : error $=$ minimal

elif shots $<2001150$ : error $=$ small

elif shots $>2001565$ : error $=$ small

elif line $==1$ :

if shots $>1001000$ : error $=$ mediumlarge

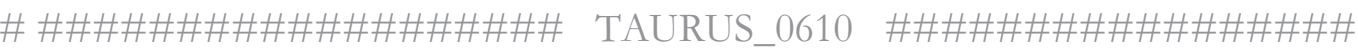

if station $==610$ :

if line $==10$

if shots $>10001001$ and shots $<10002335$ : error $=$ small

else : error $=$ smallmedium

elif line $==9$ :

if shots $>9001662$ and shots $<9003000$ : error $=$ small

else : error $=$ medium

elif line $==7:$ error $=$ minimalsmall

elif line $==6$ :

if shots $>6001927$ and shots $<6003398$ : error $=$ minimal

elif shots $<6001927$ : error $=$ small

elif shots $>6003398:$ error $=$ small

elif line $==5$ :

if shots $>5002817$ and shots $<5004255$ : error $=$ minimalsmall

elif shots $>5001001<$ shots $<5002817$ : error $=$ small

elif shots $>5004255$ : error $=$ smallmedium

elif line $==4$ : error $=$ large

elif line $==3$ :

if shots $>3001001$ and shots $<3002637$ : error $=$ smallmedium

elif shots $>3005560$ and shots $<3008913$ : error $=$ smallmedium 
elif line $==7$ :

if shots $>7001000$ and shots $<7003745:$ error $=$ small

else : error $=$ medium

elif line $==6$ :

if shots $>6001328$ and shots $<6003453:$ error $=$ minimal

else : error $=$ small

elif line $==5$ :

if shots $>5001000$ and shots $<5004000$ : error $=$ small

else : error $=$ mediumlarge

elif line $==4$ :

if shots $>4001000$ and shots $<4003600$ : error $=$ small

else : error $=$ smallmedium

elif line $==3$ :

if shots $>3002027$ and shots $<3003527:$ error $=$ small

if shots $>3001000$ and shots $<3002027:$ error $=$ smallmedium

else : error $=$ mediumlarge

elif line $==2:$ error $=$ medium

elif line $==1:$ error $=$ medium

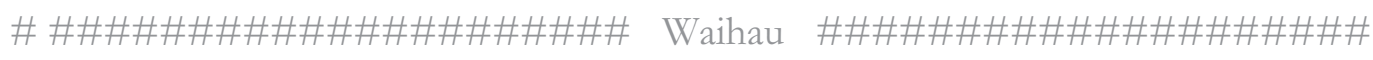

if station $==789$ :

if line $==10$ : error $=$ large

elif line $==9$ :

if shots $<9002008$ : error $=$ smallmedium

else : error=large

elif line $==7$ :

if $7002315<$ shots $>7003062:$ error $=$ small

else : error $=$ smallmedium

elif line $==6$ :

if $6001409<$ shots $<6003363:$ error $=$ smallmedium

else : error $=$ medium

elif line $==5$ :

if $5002772<$ shots $<5003881$ : error $=$ medium

else : error $=$ mediumlarge

elif line $==4$ : error=large 
\# Created by Chris Le Blanc and Dan Bassett, September 2008

\#

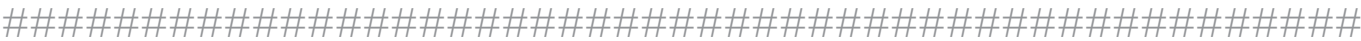

import sys

\section{if len(sys.argv) $<=1$ : \\ print "Error, please supply an input file" \\ sys.exit (}

file $=$ sys.argv $[1]$

spnt_x $=$ None

spnt_y = None

\# holding values for shots with bad velocity values (zero)

bad_spntf_x = None

readFile $=$ open(file, ' $r$ ')

for line in readFile.readlines () :

fields $=$ line.split

if fields $[0]==$ "LINE":

inline $=$ fields $[1]$

elif fields $[0]==$ "SPNT".

spnt_x = float(fields[2])

spnt_y = float(fields[3])

if fields $[0]==$ "VELF":

try:

$\mathrm{t} 1=\operatorname{int}($ fields $[1])$

$\mathrm{t} 1 \mathrm{~s}=(" 0 \% 5 \mathrm{~d} " \% \mathrm{t} 1)$

except:

$\mathrm{t} 1 \mathrm{~s}=" \prime \prime$ 
v2 = int(fields[4])

$\mathrm{v} 2 \mathrm{~s}=(" 0 \% 5 \mathrm{~d} " \% \mathrm{v} 2)$

except:

$\mathrm{v} 2 \mathrm{~s}=" "$

try:

t3 = int(fields [5])

$\mathrm{t} 3 \mathrm{~s}=(" \% 5 \mathrm{~d} " \% \mathrm{t} 3)$

except:

t3s = "'"

try:

v3 = int(fields [6])

$\mathrm{v} 3 \mathrm{~s}=(" \% 5 \mathrm{~d}$ " \% v3)

except:

$\mathrm{v} 3 \mathrm{~s}=" 1$

try:

t4 $=$ int(fields[7])

$\mathrm{t} 4 \mathrm{~s}=(" 05 \mathrm{~d} " 0 \mathrm{t} 4)$

except:

$\mathrm{t} 4 \mathrm{~s}=$ ""

try:

$\mathrm{v} 4=\operatorname{int}($ fields [8])

$\mathrm{v} 4 \mathrm{~s}=(" \% 5 \mathrm{~d}$ " \% v4)

except:

$\mathrm{v} 4 \mathrm{~s}=" "$

try:

t5 = int(fields [9])

$\mathrm{t} 5 \mathrm{~s}=(10 \% 5 \mathrm{~d} " \%$ t5 $)$

except:

t5s $=" " \prime$

try:

v5 $=$ int(fields[10])

$\mathrm{v} 5 \mathrm{~s}=(" \% 5 \mathrm{~d}$ " \% v 5$)$ 
print_str = "'"

if $\mathrm{v} 1 \mathrm{~s}$ :

print_str $+=(" \% 12.3 \mathrm{f} \% 12.3 \mathrm{f} \% \mathrm{~s} \% \mathrm{~s} \backslash \mathrm{n} " \%$ (spnt_x, spnt_y, t1s, v1s)

if $\mathrm{v} 2 \mathrm{~s}$ :

print_str $+=(" \% 12.3 \mathrm{f} \% 12.3 \mathrm{f} \% \mathrm{~s} \% \mathrm{~s} \backslash \mathrm{n} " \%$ (spnt_x, spnt_y, t2s, v2s)

if $v 3 s$ :

print_str $+=(" \% 12.3 \mathrm{f} \% 12.3 \mathrm{f} \% \mathrm{~s} \% \mathrm{~s} \backslash \mathrm{n} " \%$ (spnt_x, spnt_y, t3s, v3s)

if $\mathrm{v} 4 \mathrm{~s}$ :

print_str $+=(" \% 12.3 \mathrm{f} \% 12.3 \mathrm{f} \% \mathrm{~s} \% \mathrm{~s} \backslash \mathrm{n} " \%$ (spnt_x, spnt_y, t4s, v4s)

if $\mathrm{v} 5 \mathrm{~s}$ :

print_str $+=(" \% 12.3 \mathrm{f} \% 12.3 \mathrm{f} \% \mathrm{~s} \% \mathrm{~s} \backslash \mathrm{n} " \%$ (spnt_x, spnt_y, t5s, v5s)

\# use sys.stdout instead of print, no newlines

sys.stdout.write(print_str) 


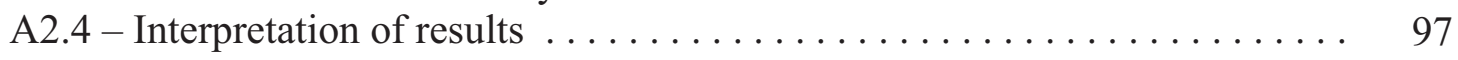

A2.4.1 - Collation of synthetic data . . . . . . . . . . . . . . 97

A2.4.2 - Collation of observational data ................ 99

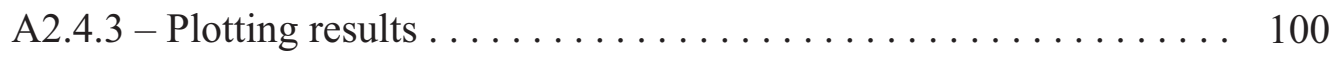

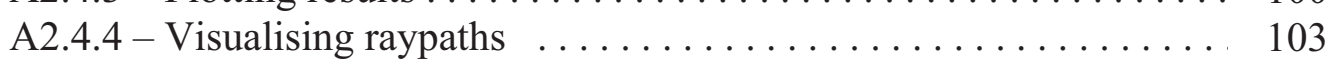

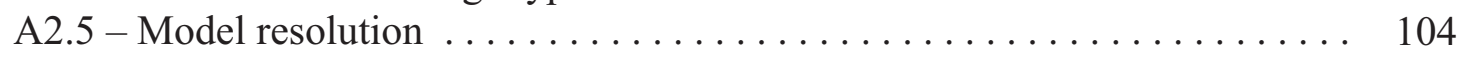

A2.6-Results . . . . . . . . . . . . . . . . . . . . . . . . . . . 106

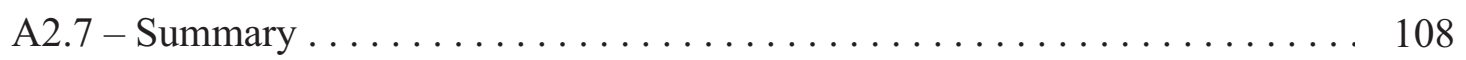

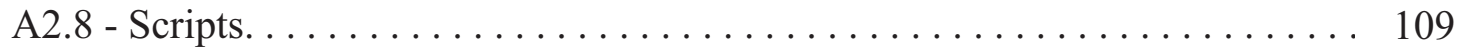

\section{SCRIPTS}

Conversion of exported interface grids

A2.1.1 - Coordinate conversion.int

A2.1.2 - Coordinate_conversion.vel ......................... 113

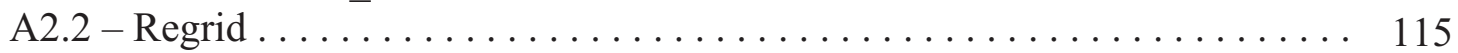

Construction of $3 \mathrm{D}$ velocity grids

A2.3 - Velocitygrid.py ............................. 119

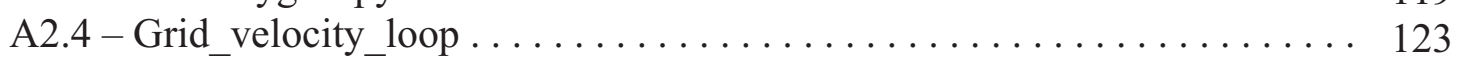

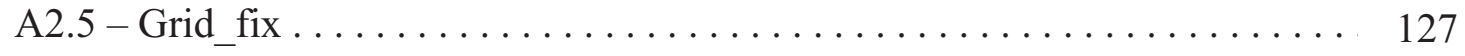

Merging of observed and synthetic traveltime files

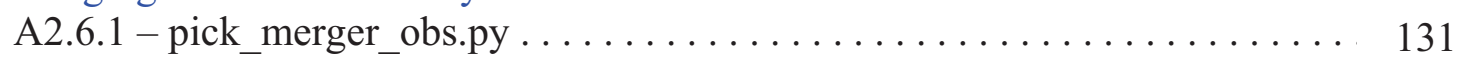

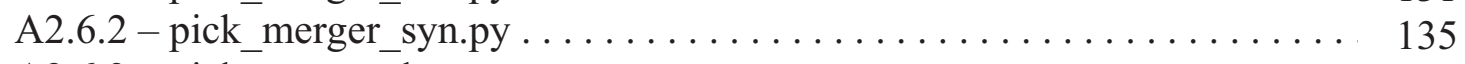

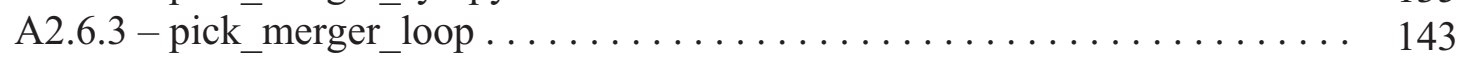

Plotting of observed vs synthetic traveltimes

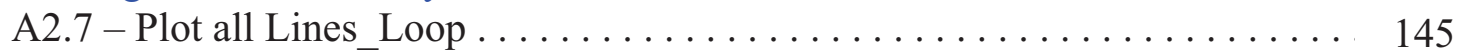

Visualisation of raypaths

A2.8 - Create_X_sections . . . . . . . . . . . . . . . . . . . 153

Model resolution

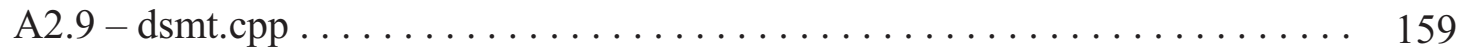

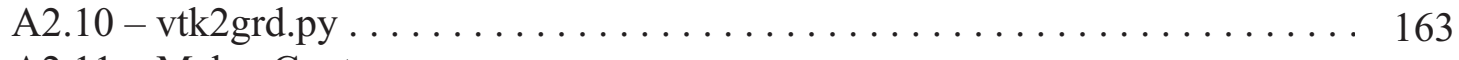

A2.11-Make_Contour............................. 165 
analysis of ray coverage through the model region.

Although onshore-offshore data are interpreted as receiver gathers, seismic reciprocity [Knopoff and Gangi, 1959] allows these data to be modelled as shot gathers. This reversal is achieved by modelling offshore airgun shots as receivers, and onshore seismograph stations as source locations. Terminology can become confusing and for clarity, in this appendix, the terms Shot and Receiver are used to refer to offshore airgun shots (modelled as receivers) and Station and Source are used to refer to onshore seismometers which act as source locations during modelling.

The results and implications of velocity forward models generated through the methodology discussed below are presented in Chapters Three and Four of the main volume respectively. All scripts presented within this appendix are also supplied on the attached CD. 
The data acquired in this study are spatially incomplete with unidirectional shooting and the absence of reversed profiles. The inverse problem is underdetermined and to overcome deficiencies in experimental design, these data are analysed using a forward model. Synthetic travel-times through forward models are calculated using the grid3dg and $f m 3 d$ applications (FMTOMO), with the comparison of synthetic and observational data facilitated by code developed in this thesis.

\section{A2.2.1- Fast Marching Method}

Forward modelling within $f m 3 d$ uses the multi-stage fast marching method (FMM) for travel-time prediction. FMM is a grid based numerical scheme for tracking the evolution of advancing interfaces (e.g. seismic wavefronts) via finite-difference solution of the eikonal equation [Sethian, 1996; Sethian and Popovici, 1999; Rawlinson and Sambridge, 2004]. The advantage of FMM is that it combines unconditional stability with rapid computation. When applied independently, however, FMM is only capable of finding the first arriving phase in continious media; a problem encountered by most other grid based techniques [Rawlinson and Sambridge, 2004]

Multistage FMM resolves this problem through the iterative application of FMM, in which each layer the wavefront enters is treated as a separate computational domain. The evolving wave front is propagated through a layer using FMM until all points of a bounding interface are intersected [Rawlinson and Sambridge, 
around the source area. The curvature of the wavefront is highest near to the shot point and grid refinement in this region increases the accuracy at which the evolving wavefront is tracked away from the source. The importance of local grid refinement is demonstrated by Rawlinson and Sambridge [2004b] who calculate that provided the velocity model is not too complex, miscalculation of arrival times is dominated by errors introduced very close to the source, particularly where the radius of curvature is not much larger than the spacing of grid nodes [De Kool et al, 2006].

Further discussion of the FMM and the grid based eikonal solver used within fm3d are given in Rawlinson [2007] Rawlinson and Sambridge [2004], De Kool, Rawlinson and Sambridge [2006], Rawlinson, De Kool and Sambridge [2006]. The FMTOMO code and accompanying manuscripts can be freely downloaded from http://rses.anu.edu.au/ nnick/

\section{A2.2.2- grid3dg grid generation}

FMTOMO represents the model region through the specification of regular and irregular grids of nodes to which tricubic, and bicubic interpolations are performed to define continuums (Figure A2.1).

The first grid to be defined is the propagation grid (Figure A2.1). This is a 3-D grid defined in spherical coordinates (radius, latitude and longitude) and must 
depth and although they cannot intersect, are able to pinch together if required (Figure A2.1).

Through the specification of interfaces, the propagation grid is divided into a number of layers. Multistage FMM tracks evolving wave fronts by reinitialised FMM at each interface the wave front intersects. This approach requires the presence of propagation grid nodes on each interface in the model region from which to reinitialise FMM into incident or adjacent layers. These nodes are called intersection nodes and each layer within the model is defined as the set of regular propagation grid nodes which lie between the two meshes of regular (propagation) and irregular (intersection) nodes which define the geometries of adjacent interfaces.

The velocity field within each layer is defined through the specification of velocities to a regular 3-D grid of nodes. These grids must cover the entire model region, including cushion nodes, with a separate grid defined for each layer in the model (Figure A2.1). From these grids, a tricubic B-spline interpolation is performed to compute the continuous 3 -D velocity field. It is necessary that the velocity grids for each region allocate velocities to all nodes, including those currently outside the layers extent (e.g. below the basal interface). During tomographic inversion, interfaces may vertically expand or contract thus encompassing previously redundant nodes within the velocity grid.

It is important to note that the velocity grid within each layer is defined independently of all other layers and that both velocity and interface grids are 


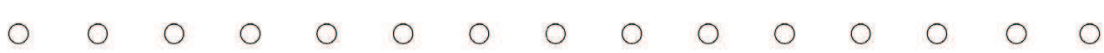

- Interface node $\square$ Boundary interface node Velocity node $\bigcirc$ Boundary velocity node

Figure A2.1 - Schematic diagram (from Rawlinson [2007]) illustrating the model parameterization in cross-section required by FMTOMO (see text). The propagation grid and model region is represented by the black box, the area within which is occupied by a regular grid of nodes (not shown). As velocity continuums and interface surfaces are defined by cubic Bsplines, there is no requirement that, for example, interface surfaces intersect all interface nodes. Note the presence of cushion nodes on both interface and velocity grids. Also note that no boundary nodes are present above the propagation grid. The reason for this is discussed in section A2.2.2.2.

The interface, velocity and propagation grids which define the 3-D model region can be compiled with grid3dg. This utility can either construct simple 3-D grids from a minimal number of parameters, or compile more complicated grids imported from other programs into the format required by $f m 3 d$. The capabilities for constructing velocity models within grid $3 d g$ are simple and not well suited to complex forward modelling.

\section{A2.2.2.1 - Interface grids}

Interfaces generated within grid $3 d g$ are planar, defined only by their depths at the northeast, northwest and southwest limits of the model region. Interfaces of this nature are clearly insufficient for forward modelling and in this thesis; a 
entire model region. As the first velocity is assigned to the top of the model region, no cushion nodes are required above the propagation grid (Figure A2.1).

The primary result of this method of grid derivation is that velocity contours are horizontal which makes forward modelling particularly difficult where dipping structures (e.g. subducting slabs) are present (Figure A2.2).

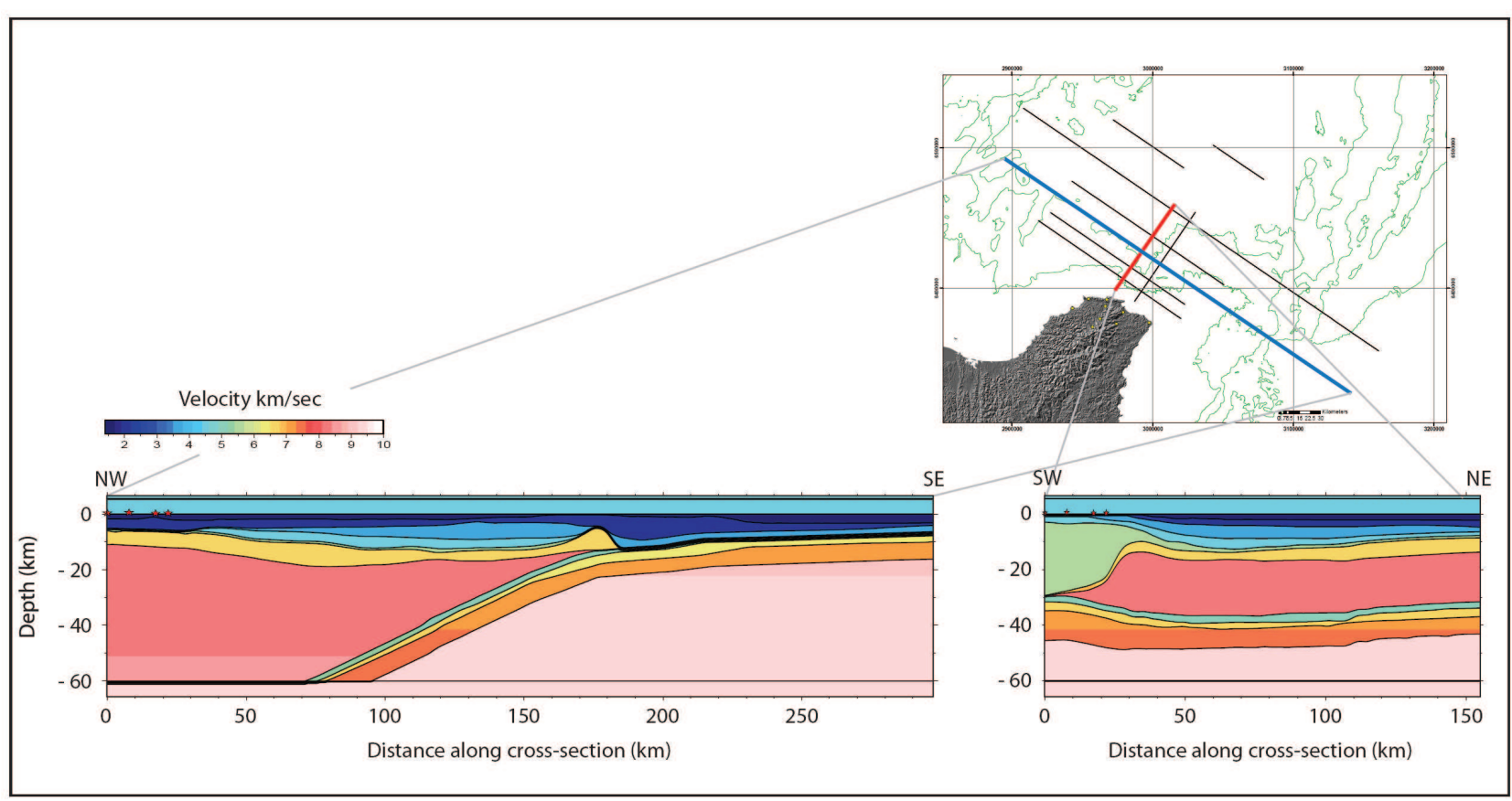

Figure A2.2 - Cross-sections along lines RAU07-05 (blue) and RAU07-09 (red) illustrating the velocity structure of grids generated by grid $3 d g$. Note that all velocity contours are horizontal irrespective of layer geometry. Interfaces depicted above are imported from Seisware (Section A2.3.2) and not generated by grid3dg. 
seismic reflection data (Seisware). Grids of interface positions are exported from Seisware and used by a sequence of scripts to create 3-D interface and velocity grids in a format compatible with grid $3 d g$.

\section{A2.3.1 - Grid Space}

The primary advantage of this modelling methodology is the ability to manually manipulate interface positions. Software developed for the interpretation of seismic reflection data is well suited to this task and for this study, a grid space is constructed within Seisware (version 6.5).

This grid is predominantly comprised of a mesh of hypothetical seismic lines throughout the model region extending to $60 \mathrm{~km}$ depth (Figure A2.3). Where available, depth converted seismic reflection profiles should be incorporated to provide structural constraints and in this study, depth-converted RAU07 data [Fugro Seismic Imaging, 2008] are included. Shots from this survey are the source of onshore-offshore wide-angle data and thus the MCS reflection profiles place important constraints on the basin and crustal structure directly beneath the shotpoints.

While the forward model presented in this thesis was constructed using Seisware, most seismic reflection software packages should be equally well suited to this task. The only requirement is that tools are present which can be used to grid and export interface positions in a xyz format. 


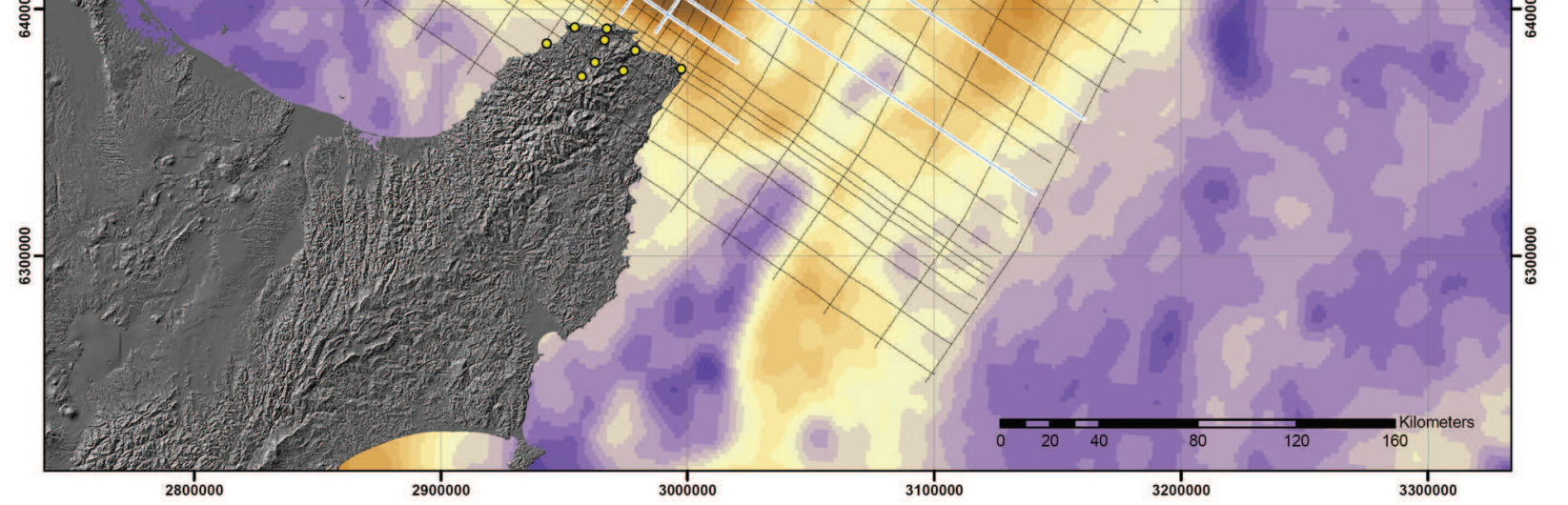

Figure A2.3 - Grid of hypothetical profiles used for the manipulation of interfaces during forward modelling. Black lines denote hypothetical seismic lines extending to $60 \mathrm{~km}$ depth. White lines display depth converted RAU07 seismic reflection profiles. Yellow dots represen onshore seismometers. Background colour illustrates free air gravity anomaly at $10 \mathrm{mgal}$ intervals with the darkest brown reflecting a -150 mgal anomaly.

\section{A2.3.2 - Interface Grids}

Interface grids are constructed by manually defining interface positions along profiles crossing the model region. These interpretations are gridded and exported (in xyz format) using tools within Seisware.

The script Regrid (Script A2.2) smoothes and resamples exported grids using user specified cell sizes in GMT and converts interface grids into a format compatible with grid $3 d g$. 
interfaces of a given layer intersect each profile. Nodes positioned immediately outside the layer vertical extent are selected, and a linear velocity gradient is calculated and applied down each 1-D model, such that the velocities at the top and bottom of a layer is consistent with user specified values. $f m 3 d$ requires that velocities for all nodes within the model region are defined and all nodes offset more than one position from the layer are assigned the velocity of the node either immediately above or below the layers upper and lower surfaces.

The subtle differences between these scripts concern their handling of layer pinchouts. Using the simple 1-D approach detailed above, where the upper and lower interfaces of a layer pinch together this would give rise to unfeasibly high velocity gradients which cause $f m 3 d$ to fail. It is thus necessary to place a limitation on the maximum velocity gradient that can occur within a given layer. In each script the user specifies a value which dictates the minimum thickness over which the full range of layer velocities will be observed. Herein lies the fundamental difference between these scripts. Where layer interfaces are closer than the threshold value, Velocitygrid_forward.py (Script A2.3.1) applies a hanging velocity gradient down from the top interface, distributing velocities over the vertical distance specified by the threshold value. Velocitygrid_reverse.py (Script A2.3.2) does the exact opposite and applies a constant velocity gradient, the height of which is also set by the threshold value, from the basal interface up.

Although these modifications to a simple 1-D approach will not affect the majority layers in the model region, they make layer pinchout possible and offer 
unreasonably high or low $(1.4 \mathrm{~km} / \mathrm{sec}<\mathrm{vel}<10.0 \mathrm{~km} / \mathrm{sec})$. 
The scripts pick_merger_syn (Script A2.6.1), pick_merger_obs (Script A2.6.2) and Plot_all_lines_loop (Script A2.6.3) were constructed to analyse the results of forward models.

The merging of observed and calculated travel-time files is carried out through the use of the scripts pick_merger_syn and pick_merger_obs. These scripts have been constructed to manipulate the input files required by grid $3 d g$ and the output files from $f m 3 d$ and Claritas $S V$ making them easy to use with a minimal amount of data reformatting.

\section{A2.4.1 - Collation of synthetic data}

pick_merger_syn is used for the collation of synthetic arrival times generated by fm $3 d$ into a single file containing all the necessary data required to match up synthetic travel-times with observations (using shotnumber), and plot the results using GMT. This script reads in five files. These are arrivals.dat, which contains all the synthetic arrivals from $f m 3 d$; sources.in, which contains all source locations; receivers.in, which contains all receiver locations; Receiver_locations, which contains the shot numbers and locations of all receivers; and finally Source_Locations, which contains the names and positions of all onshore stations. The first three files are input at the command line as system arguments, with Source_locations and Receiver_locations sourced within the script. 
which is used to replace the $f m 3 d$ shot number with the Claritas shot number which is saved as the primary key on observed pick files. Shot numbers are thus reallocated on the basis of geographic locations; this being the most accurate method of renumbering given the unique location of each shot point.

The second column in arrivals.dat relates to station number. As for the shot numbers detailed above, this number relates to the position of the shot within the sources.in file and not the actual name of the station. Here the same procedure for renaming stations is followed, matching up source positions from sources.in with station positions from Source_Locations using a "crazy key" identifier comprised of geographic locations. Source numbers are replaced with the actual station name (e.g. 1 is replaced by Pakira, 2 is replaced by 0576).

The script now has all the data required to create indexes of all the information relating to a specific arrival. This information includes the locations of source and receiver, shot number (Claritas), station name, line number and phase number. The output file only lists the line number, shot number, station name, phase number, calculated arrival time and offset for each synthetic arrival. Source and receiver locations are not required as arrivals are plotted against shotnumber. 
This script requires only one systems argument although the Source_locations and Receiver_locations files are sourced within the script. The picklist, which contains the names of all pick files for a specific station is given at the command line (systems argument one). The first line of this file gives the relative path to the folder in which the $S V^{*}$.pic files are located, followed by a list of the pick files within this directory which are to be merged. Pick files for each station are named in a specific format which includes the station name, line number and phase number (e.g. Pakira_Line10_1.pic, 0576_Line5_3.pic). This naming format is very important as the script reads and extracts information contained within the file name and uses this information while incorporating data from other sources.

Source positions for each pick are determined by matching the station name contained within the name of the pickfile, with the station names and locations contained within Source_Locations. Shot positions are determined in a similar manner, matching the shot numbers within pick files, to the shot numbers contained within Receiver_locations. Phase information extracted from the pick file name is not used and in Figure A2.4, all observed traveltimes are plotted in black.

The output file for pick_merger_obs is identical in format to that created by pick_merger_syn although only contains observed travel-times for the station relating to the picklist which is an input to the program. 
Plot_all_lines_loop (Script A2.7) is executed. This script creates a single A3 plot of observed versus calculated travel-times displaying each line within the RAU07 survey for a particular station (Figure A2.4). This script reads the output files from pick_merger_syn and pick_merger_obs before using GMT to create the plot. Data is plotted against shot number rather than offset due to the geometry of onshore-offshore data analysed in this study with offsets lowest in the middle of dip parallel profiles. Results can be plotted in total travel-time or with a particular reduction velocity applied.

Figure A2.4 (Overleaf) - Output file created by Plot_all_lines_loop. This example is for station Rewetu and displays observed (black) and synthetic traveltimes (coloured) for a number of phases through the forward model. Plotted behind each observed arrivals is a white line displaying the estimated error associated with each arrival. Each block of data represents a separate RAU07 profile with the first digit of the shotnumber representing the line number. The vertical scale is total travel-time with no reduction velocity applied. 
of cross-sections through the model region using the gmtslice and plotgc tools within FMTOMO. This script iterates through grid $3 d g, f m 3 d$, gmtslice and plotgc changing both the source and receiver positions, and the orientation of the great circle slice, such that only rays travelling entirely along the azimuth of the crosssection are included. In constructing this script, ArcGIS was used to extract the locations of shots and stations lying along each profile which were included in the unique receivers.in, sources.in and gmtslice.in files for each profile (Figure A2.5).

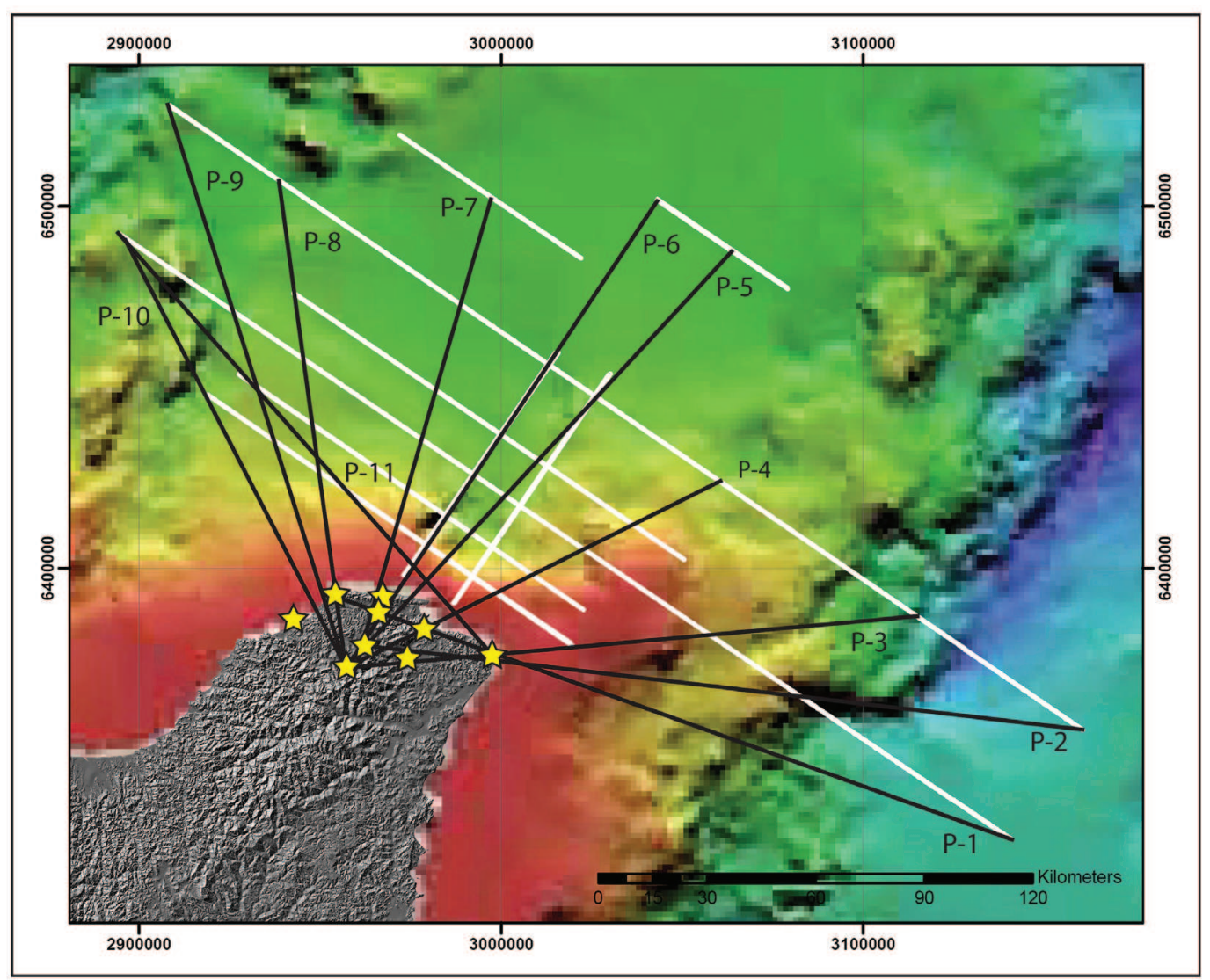

Figure A2.5 - Bathymetric map of the study area illustrating the orientations of cross-sections (black) constructed by the script create_X_sections. White lines show RAU07 seismic reflection profiles and the source of onshore-offshore data. Yellow stars denote onshore seismometers. The cross-section generated for profile 3 is presented below in Figure A2.6. 
Figure A2.6 - Example of cross-section p3 generated by the script create_X_sections.

\section{A2.5 -Model resolution}

The resolution of forward velocity models is assessed through an analysis of raypaths. The number of rays that sample each region of the velocity model effectively measures the degree to which the structures modelled are constrained by refracted and reflected raypaths.

From FMTOMO, it is possible to extract the geometry of synthetic raypaths. Rays can be exported as E-W, N-S, Great Circle and depth projections. These files project all rays within the model region onto a vertical or horizontal plane at an azimuth perpendicular to the profile orientation.

To assess the spatial distribution and density of raypaths in 3-D a $\mathrm{C}++$ script (DSMT, Script A2.9) is executed. This script combines raypoint positions from raysd.xy and raysns.xy exported from FMTOMO (created by gmtslice) into a file containing the complete coordinates of each raypoint in the model. Raypoints associated with discrete rays are separated within the files raysd.xy and raysns.xy 
ray density integer within a particular cell is only incremented for the first raypoint associated with a particular raynumber. Raypoints further along the raypath are ignored until they plot within an unoccupied cell.

The 3-D density grid is exported as a .vtk file which is compatible with the visualisation software package Mayavi2. Within this package it is possible to contour the ray density function and create $3-\mathrm{D}$ shells at each contour interval. It is also possible to observe the 3-D distribution of these shells and view horizontal and vertical slices which are used to analyse the spatial distribution of rays through the model. Due to the difficulty extracting images and contours from Mayavi2, the model resolution plots presented in Figures A4.2.1-4 were created via the development of the scripts vtk2grd.py (Script A2.10) and Make_Contour (Script A2.11). These scripts resample the $v t k$ file at $2 \mathrm{~km}$ depth intervals before using GMT to produce plots of ray density at a variety of azimuths through the model region. These plots should be interpreted as displaying the minimum resolution of velocity models given the influence the velocity field in surrounding areas exerts on the actual path the ray travels. 
large range of depths throughout the model region.

The fundamental limitation of the methodology by which velocity grids are constructed is the inability to introduce lateral velocity variations within layers, other than those accompanying changes in the thickness or geometry of the layer. This limitation requires the assumption that lateral velocity variations within layers are negligible and makes it unlikely a velocity model can be constructed using this methodology, capable of replicating all travel-times within observational error. A large number of layers, each containing small ranges of velocity $(<0.4 \mathrm{~km} / \mathrm{sec})$ may be used minimise the effects of this assumption. Models of this nature however, take a long time to run, can cause complications with $f m 3 d$ and require the specification of detailed (generally underconstrained) ray paths through the model. It is advisable to use the least number of layers possible to adequately replicate the surface velocity structure. These models will be more stable, run faster and require fewer assumptions concerning the phase and thus ray identity of observed travel-times. 


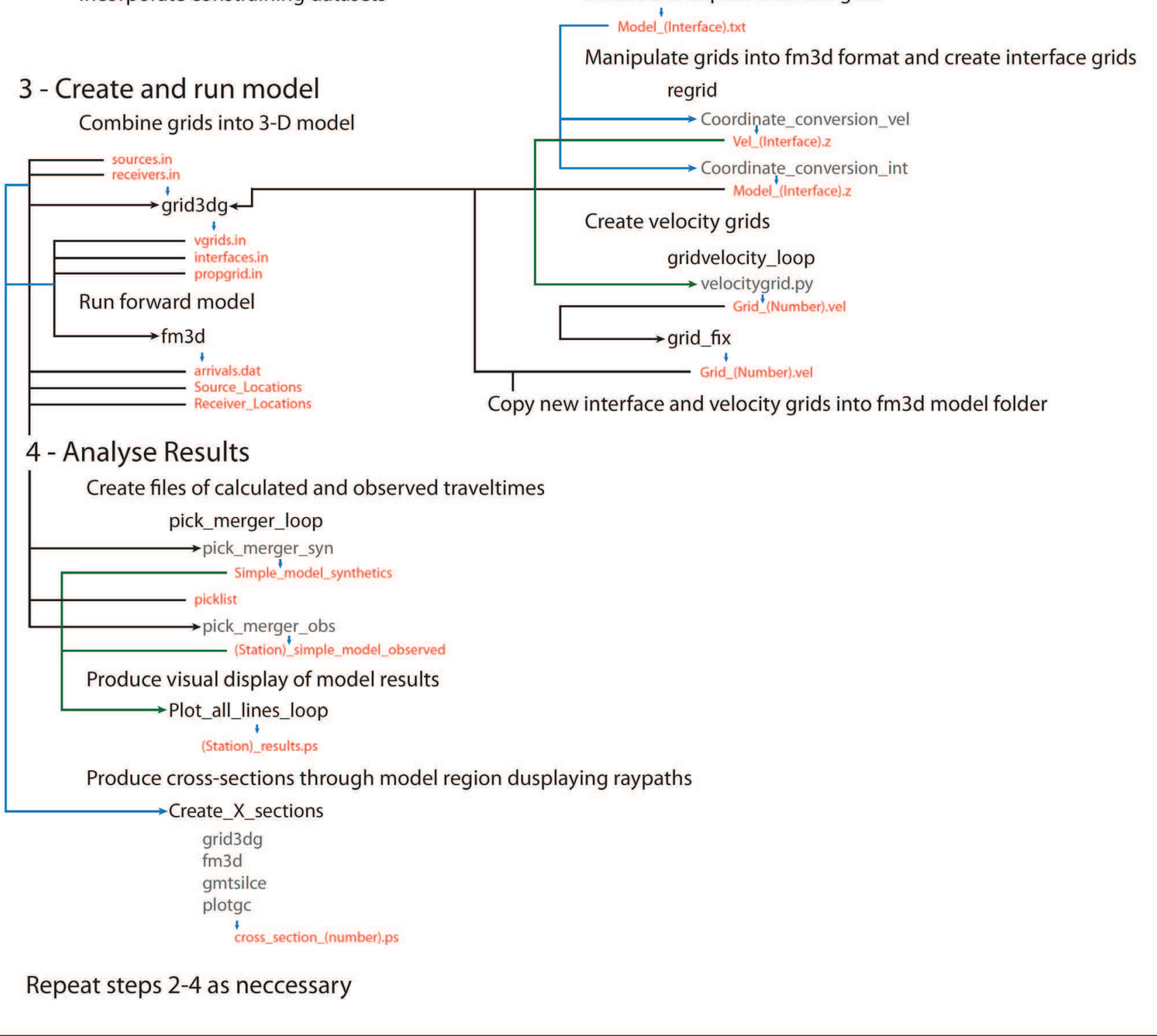

Figure A2.8 - Flow chart detailing the sequential steps within the forward modelling methodology developed in this thesis and the scripts (grey) which should be executed at each stage. Red labels denote the input files required or output files created by a particular script. Green, Blue and Black lines are used to differentiate between file paths. 
A2.3 - Velocitygrid.py .

A2.4 - Grid_velocity_loop

Merging of observed and synthetic traveltime files

A2.6.1 - pick merger obs.py

A2.6.2 - pick_merger_syn.py

A2.6.3 - pick merger_loop

Plotting of observed vs synthetic traveltimes

A2.7 - Plot all Lines_Loop

Visualisation of raypaths

A2.8-Create X sections

Model resolution

A2.9-dsmt.cpp

A2.10 - vtk2grd.py

163

A2.11 - Make Contour . 
\# The grid is resampled in GMT, according to the incruments specified in the first \# several lines of the script with the depth to all nodes within the output region

\# exported to the designated output file.

\#

\# The final stage calculates and prints (to screen) the number of grid nodes and \# some instructions for using these numbers when reading in resampled grids into \# grid3dg.

\#

\# Created by Dan Bassett with the assistance of Adrian Benson

\# December 2009

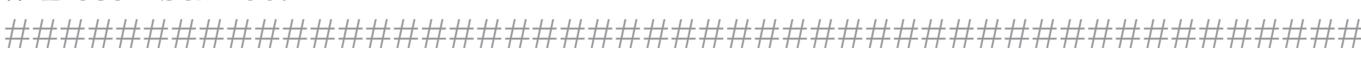

if $[\$ \#$-ne 2]

then

echo "Syntax : ./Coordinate_conversion input_file output_file.z" exit -2

fi

inputfile $=\$ 1$

outputfile $=\$ 2$

fincr $=0.005$

incr $=0.005$

$\min \mathrm{X}=\$($ echo $" 177.2-\$$ fincr" | bc -1$)$

$\max X=\$($ echo $" 180.5+\$$ fincr" $\mid$ bc -1$)$

$\min Y=\$($ echo "-38.2 - \$fincr" | bc -1$)$

$\max Y=\$($ echo "-36.2 + \$fincr" | bc -1$)$

outputregion=" $\$ \min X / \$ \max X / \$ \min Y / \$ \max Y "$

km_per_deg=111.1 
gmtset D_FORMAT $=\% 0.7 \mathrm{f}$

region $=\$(\operatorname{minmax} \$$ tfile $-\mathrm{I} \$$ incr $)$

GRDFILE=tempgrid.grd

blockmean \$tfile \$region -I\$incr |

surface \$region-G\$GRDFILE -I\$incr -T0.35

grdmath \$GRDFILE -0.001 MUL $=$ \$GRDFILE

grd2cpt \$GRDFILE -Chaxby > junky.cpt

grdcut \$GRDFILE -G\$GRDFILE -R \$outputregion

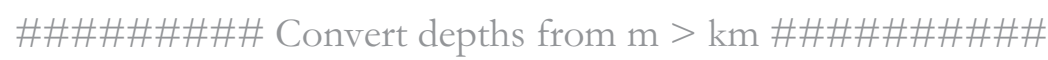

\#Change 0.001 to -0.001 if values below sealevel are + ve

\#grdimage \$GRDFILE -Cjunky.cpt -R\$outputregion -JX15 -Ba2 > junky.ps

\#gv junky.ps

\#RESAMPLE GRID AND PRODUCE .Z FILE FOR INPUT INTO GRID3D\#

echo $=$ =ニ=ニ=ニ=ニ=ニ=ニ=ニ=ニ=ニ=ニ=ニ=

grdinfo \$GRDFILE

echo REGION: \$region

echo OUTPUT: \$outputregion

grd2xyz -V \$GRDFILE -ZBLa > \$outputfile

\section{echo HERE COMES NUMBER OF GRID NODES}

\#\#\#\#\# Calculate and print the number of grid nodes and output region \#\#\#\#\#

grid_information $=(\$($ grdinfo --D_FORMAT $=\% \mathrm{~g}-\mathrm{C}$ tempgrid.grd $))$

echo $\mathrm{x}$ nodes $\$\{$ grid_information[9] $\}$ y nodes $\$\{$ grid_information[10]

echo \#\# take-2 from these for numbers for input into grid3d.in to account for

cushion nodes \#\#

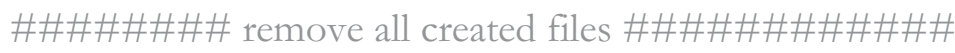

rm \$tfile \$GRDFILE 
\# The grid is resampled in GMT, according to the incruments specified in the first \# several lines of the script with the depth to all nodes within the output region

\# exported to the designated output file. \#

\# The final stage calculates and prints (to screen) the number of grid nodes and \# some instructions for using these numbers when reading in resampled grids into \# grid3dg.

\#

\# Created by Dan Bassett with the assistance of Adrian Benson

\# December 2009

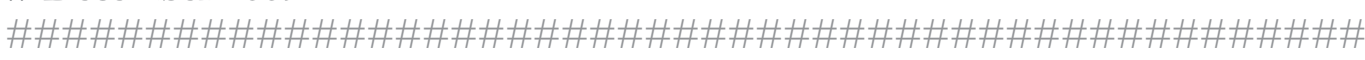

if $[\$ \#$-ne 2]

then

echo "Syntax :./Coordinate_conversion input_file output_file.z" exit -2

fi

inputfile $=\$ 1$

outputfile $=\$ 2$

\section{fincr $=0.025$ \\ incr $=0.025$}

$\min X=\$($ echo $" 177.2-\$$ fincr" | bc -1$)$

$\max X=\$($ echo $" 180.5+\$$ fincr" $\mid$ bc -1$)$

$\min Y=\$($ echo "-38.2 - \$fincr" | bc -1$)$

$\max Y=\$($ echo "-36.2 + \$fincr" | bc -1$)$

outputregion=" $\$ \min X / \$ \max X / \$ \min Y / \$ \max Y "$

km_per_deg=111.1

\# Input txt file from seisware and convert coordinates from UTM50_south to WGS_84 \#

\# Take file and add 360 to all negative values in column $1(-179>181)$ \# 
blockmean \$tfile \$region -I \$incr |

surface \$region-G\$GRDFILE -I\$incr-T0.35

grdmath \$GRDFILE -0.001 MUL = \$GRDFILE

grd2cpt \$GRDFILE -Chaxby > junky.cpt

grdcut \$GRDFILE - G\$GRDFILE - R\$outputregion

\#\#\#\#\#\#\#\#\# Convert depths from $\mathrm{m}>\mathrm{km} \# \# \# \# \# \# \# \# \# \#$

\#Change 0.001 to -0.001 if values below sealevel are + ve

\# grdimage \$GRDFILE -Cjunky.cpt -R\$outputregion -JX15 -Ba2 > junky.ps

\#gv junky.ps

\#RESAMPLE GRID AND PRODUCE .Z FILE FOR INPUT INTO GRID3D \#

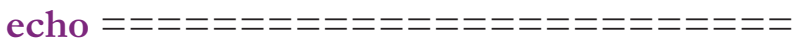

grdinfo \$GRDFILE

echo REGION: \$region

echo OUTPUT: \$outputregion

$\operatorname{grd} 2 x y z-V$ \$GRDFILE -ZBLa > \$outputfile

echo HERE COMES NUMBER OF GRID NODES

\#\#\#\#\# Calculate and print the number of grid nodes and output region \#\#\#\#\#

grid_information $=\left(\$\left(\right.\right.$ grdinfo $--D \_F O R M A T=\% g-C$ tempgrid.grd $\left.)\right)$

echo $\mathrm{x}$ nodes $\$$ \{grid_information[9]\} y nodes $\$$ \{grid_information[10]\}

echo \#\# take-2 from these for numbers for input into grid3d.in to account for

cushion nodes \#\#

\#\#\#\#\#\#\# remove all created files \#\#\#\#\#\#\#\#\#\#\#\#

rm \$tfile \$GRDFILE 
\# The only difference between the Coordinate_converstion scripts called (.vel and .int),

\# is the grid spacing at which the resulting grid is resampled at.

\#

\# The final stage of the script utilises some simple awk commands to ensure no

\# interfaces are interpolated above or below the model region.

\#

\# Created by Dan Bassett

\# December 2009

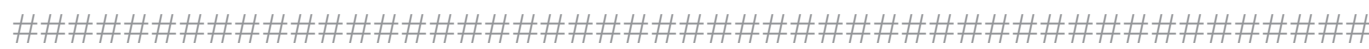

if $((\$ \# !=0))$

then

echo "Syntax : ./ regrid"

exit -1

\#\#\#\#\# List of interfaces for regridding \#\#\#\#\#

interfaces="BaseA Mid_C HorizonE MM_Crust BaseCrust Underplating Top_Slab Base_Slab"

\#\#\#\#\#\# Run both Coordinate_conversion scripts for each interface \#\#\#\#\#\#

for interface in \$interfaces; do

./3D_interfaces/Coordinate_conversion_vel./3D_interfaces/Model_\$interface.txt ./3D_interfaces/Vel_\$interface.zz

./3D_interfaces/Coordinate_conversion_int./3D_interfaces/Model_\$interface.txt ./3D_interfaces/Model_\$interface.zz

echo \$interface

done 
./3D_interfaces/Model_Raukumara_4.zz >

./3D_interfaces/Model_Raukumara_4.z

awk ' $\left\{\right.$ if $\left(\$ 1<==^{\prime}-60 \text { ') \{print '-60'\} else }\{\text { print } \$ 1\}\right\}^{\prime}<$

./3D_interfaces/Model_Mid_C.zz >./3D_interfaces/Model_Mid_C.z

awk $\left\{\right.$ if $\left(\$ 1<==^{\prime}-60 \text { ') }\{\text { print '- } 60 \text { ' }\} \text { else }\{\text { print } \$ 1\}\right\}^{\prime}<$

./3D_interfaces/Model_Raukumara_6.zz $>$

./3D_interfaces/Model_Raukumara_6.z

awk ' $\left\{\text { if }\left(\$ 1<==^{\prime}-60^{\prime}\right)\{\text { print '- } 60 \text { ' }\} \text { else }\{\text { print } \$ 1\}\right\}^{\prime}<$

./3D_interfaces/Model_HorizonE.zz > ./3D_interfaces/Model_HorizonE.z awk ' $\left\{\text { if }\left(\$ 1<==^{\prime}-60^{\prime}\right)\{\text { print '- } 60 \text { ' }\} \text { else }\{\text { print } \$ 1\}\right\}^{\prime}<$

./3D_interfaces/Model_MM_Crust.zz > ./3D_interfaces/Model_MM_Crust.z awk ' $\left\{\text { if }\left(\$ 1<==^{\prime}-60 \text { ') \{print '- } 60 \text { ' }\right\} \text { else }\{\text { print } \$ 1\}\right\}^{\prime}<$

./3D_interfaces/Model_BaseCrust.zz > ./3D_interfaces/Model_BaseCrust.z awk ' $\left\{\right.$ if $\left(\$ 1<==^{\prime}-60\right.$ ') \{print '- 60 ' $\}$ else $\{$ print $\left.\$ 1\}\right\} '<$

./3D_interfaces/Model_Underplating.zz $>$

./3D_interfaces/Model_Underplating.z

awk ' $\left\{\text { if }\left(\$ 1<==^{\prime}-60^{\prime}\right)\{\text { print } '-60 '\} \text { else }\{\text { print } \$ 1\}\right\}^{\prime}<$

./3D_interfaces/Model_Top_Slab.zz > ./3D_interfaces/Model_Top_Slab.z awk ' $\left\{\text { if }\left(\$ 1<==^{\prime}-60 \text { ') \{print '- } 60 \text { ' }\right\} \text { else }\{\text { print } \$ 1\}\right\}^{\prime}<$

./3D_interfaces/Model_Base_Slab.zz > ./3D_interfaces/Model_Base_Slab.z

\#\#\#\#\#\# Ensure no interfaces extend above the model region \#\#\#\#\#\#

awk ' $\left\{\text { if }\left(\$ 1>==^{\prime} 3.0^{\prime}\right)\{\text { print '3.0'\} else \{print } \$ 1\}\right\}^{\prime}<. / 3 \mathrm{D} \_$interfaces/Vel_Seafloor.zz

$>$./3D_interfaces/Vel_Seafloor.z

awk ' $\left\{\right.$ if $\left(\$ 1>=' 3.0^{\prime}\right)\left\{\right.$ print $\left.' 3.0^{\prime}\right\}$ else $\{$ print $\$ 1\}$ \}' <

./3D_interfaces/Vel_Raukumara_1.zz $>$./3D_interfaces/Vel_Raukumara_1.z awk '\{if $\left(\$ 1>=' 3.0^{\prime}\right)\left\{\right.$ print ' $\left.3.0^{\prime}\right\}$ else $\{$ print $\left.\$ 1\}\right\}^{\prime}<. / 3 \mathrm{D} \_$interfaces $/$Vel_BaseA.zz $>$

./3D_interfaces/Vel_BaseA.z

awk ' $\left\{\right.$ if $\left(\$ 1>==^{\prime} 3.0 '\right)\{$ print ' 3.0 ' $\}$ else \{print $\left.\$ 1\right\}$ \}'<

./3D_interfaces/Vel_Raukumara_3.zz > ./3D_interfaces/Vel_Raukumara_3.z awk ' $\left\{\right.$ if $\left(\$ 1>==^{\prime} 3.0^{\prime}\right)\{$ print ' 3.0 ' $\}$ else print $\left.\left.\$ 1\right\}\right\}$ ' <

./3D_interfaces/Vel_Raukumara_4.zz $>$./3D_interfaces/Vel_Raukumara_4.z awk ' $\left\{\text { if }\left(\$ 1>=' 3.0^{\prime}\right)\left\{\text { print } 3.0^{\prime}\right\} \text { else }\{\text { print } \$ 1\}\right\}^{\prime}<. / 3 \mathrm{D} \_$interfaces/Vel_Mid_C.zz

$>$./3D_interfaces/Vel_Mid_C.z

awk ' $\left\{\text { if }\left(\$ 1>==^{\prime} 3.0^{\prime}\right)\left\{\text { print } ' 3.0^{\prime}\right\} \text { else }\{\text { print } \$ 1\}\right\}^{\prime}<$

./3D_interfaces/Vel_Raukumara_6.zz > ./3D_interfaces/Vel_Raukumara_6.z 
echo creating base crust copy to create hanging velocity gradient awk' $\{$ print $\$ 1-30\} '<$./3D_interfaces/Vel_BaseCrust.zz >

./3D_interfaces/Vel_AMantle_VGRAD.z

echo Vel_AMantle_VGRAD.z use to create hanging velocity gradient within

Australian plate mantle

\#\#\#\#\#\# Remove all surplus files \#\#\#\#\#\#

rm./3D_interfaces/Model_Seafloor.zz

$\mathrm{rm}$./3D_interfaces/Model_Raukumara_1.zz

rm./3D_interfaces/Model_BaseA.zz

rm./3D_interfaces/Model_Raukumara_3.zz

rm./3D_interfaces/Model_Raukumara_4.zz

rm./3D_interfaces/Model_Mid_C.zz

rm./3D_interfaces/Model_Raukumara_6.zz

rm./3D_interfaces/Model_HorizonE.zz

rm./3D_interfaces/Model_MM_Crust.zz

rm./3D_interfaces/Model_BaseCrust.zz

rm./3D_interfaces/Model_Underplating.zz

rm./3D_interfaces/Model_Top_Slab.zz

rm./3D_interfaces/Model_Base_Slab.zz

rm./3D_interfaces/Vel_Seafloor.zz

$\mathrm{rm} . / 3 \mathrm{D} \_$interfaces/Vel_Raukumara_1.zz

rm./3D_interfaces/Vel_BaseA.zz

rm./3D_interfaces/Vel_Raukumara_3.zz

rm./3D_interfaces/Vel_Raukumara_4.zz

rm./3D_interfaces/Vel_Mid_C.zz

rm./3D_interfaces/Vel_Raukumara_6.zz

rm./3D_interfaces/Vel_HorizonE.zz

rm./3D_interfaces/Vel_MM_Crust.zz

rm./3D_interfaces/Vel_BaseCrust.zz

$\mathrm{rm} . / 3 \mathrm{D} \_$interfaces/Vel_Underplating.zz

rm./3D_interfaces/Vel_Top_Slab.zz

rm./3D_interfaces/Vel_Base_Slab.zz 
\# as specified by the incrument, and values specified for the geometry of the cube.

\# The script then calculates the positions of all 1D profiles extending down the

\# model region. The intersection point of the top and bottom interface grids with

\# each of these profiles is then determined. The nodes directly overlying the top

\# interface, and underlying the bottom interface are selected with velocities applied

\# to these nodes such that the gradient between them results in the velocity at the

\# top and bottom of the interface are identical to the user specified values.

\#

\# The script iteratively does this for each 1D profile, working from W-E then N-S

\# and results in the formation of a 3D velocity cube, covering the entire model

\# region in which the velocity at the top and bottom of a layer is constant

\# throughout the layers extent with the velocity gradient changing with variations in

\# layer thickness.

\#

\# This script needs to be executed for each layer in the model, changing the system \# arguments as required.

\#

\#Created by Dan Bassett and Adrian Benson

\# December 2009

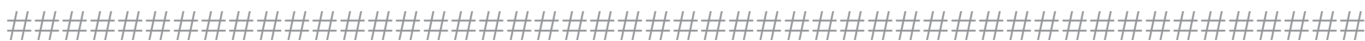

import sys

\#get command line args

if len(sys.argv) $<5$ :

sys.exit("usage: velocitygrid.py top_interface bot_interface top_vel bot_vel [outputfile $] \backslash \mathrm{n} ")$

\#STEP 1 - define geometry of velocity cube and position of nodes

incr $=0.025$

latlon_cushion $=0.05$

Lat0 $=-38.2-$ incr

Lat1 $=-36.2+$ incr

Lon0 $=177.2-$ incr

Lon $1=180.5+$ incr

Zincr $=0.5$

$Z 1=6.5+$ Zincr

$\mathrm{Z} 0=-65.50-$ Zincr 
\#read interface grids

fh1 = open(sys.argv[1], 'r')

\#fh1.readline)

fh2 = open(sys.argv[2], 'r')

\#fh2.readline(

upper $=\left[[] *_{\text {nLat }}\right.$

lower $=\left[\right.$ []] $*_{\text {nLat }}$

for $i$ in range(len(upper)):

upper $[\mathrm{i}]=[0.0] *$ nLon

lower $[\mathrm{i}]=[0.0]^{*}$ nLon

for $\mathrm{j}$ in range(len(upper)):

for $\mathrm{k}$ in range(len(upper[j])):

$\mathrm{u}=$ float $($ fh1.readline ()$\cdot \operatorname{strip}())$

$1=$ float $($ fh 2 .readline $($ strip ()$)$

upper $[\mathrm{j}][\mathrm{k}]=\mathrm{u}$

lower $[\mathrm{j}][\mathrm{k}]=1$

fh1.close 0

fh2.close 0

\# create vel matrix

row $=[0.0] *$ nLon

sheet $=[\mathrm{row}] *$ nLat

velmat $=[[]] * \mathrm{nZ}$

for $\mathrm{i}$ in range(nZ):

velmat $[i]=[\Pi] *$ nLat

for $\mathrm{j}$ in range(len(velmat $[\mathrm{i}]))$ :

velmat $[\mathrm{i}][\mathrm{j}]=[0.0] *$ nLon

zlevels $=$ []

for $\mathrm{z}$ in range( $\mathrm{n} Z)$ :

zlevels.append $\left(Z 1-z^{*}\right.$ Zincr $)$

zlevels.reverse 0

for $j$ in range(len(upper)):

for $\mathrm{k}$ in range(len(upper[j])): 
for $i$ in range $(n Z)$ :

if $\mathrm{i}<=\mathrm{izl}$

velmat $[\mathrm{i}][\mathrm{j}][\mathrm{k}]=\mathrm{vzl}$

elif $i>=$ izu:

velmat $[\mathrm{i}][\mathrm{j}][\mathrm{k}]=\mathrm{vzu}$

else:

$\operatorname{velmat}[\mathrm{i}][\mathrm{j}][\mathrm{k}]=\mathrm{m} *$ zlevels $[\mathrm{i}]+\mathrm{c}$

$\mathrm{fh}="$

if len $($ sys.argv $)==6$ :

else:

$$
\mathrm{fh}=\operatorname{open}\left(\operatorname{sys} \cdot \operatorname{argv}[5], \mathrm{w}^{\prime}\right)
$$

fh $=$ sys.stdout

velmat_i $=$ range $($ len $($ velmat $))$

velmat_j $=$ range $($ len $(\operatorname{velmat}[0]))$

velmat_k $=$ range $(\operatorname{len}(\operatorname{velmat}[0][0]))$

for $i$ in velmat_i:

for $j$ in velmat_

for $\mathrm{k}$ in velmat_k:

fh.write $\left(\% \% 0.3 f \backslash n^{\prime} \%(\operatorname{velmat}[\mathrm{i}][\mathrm{j}][\mathrm{k}])\right)$

if len(sys.argv) $==6$ :

fh.close 0 


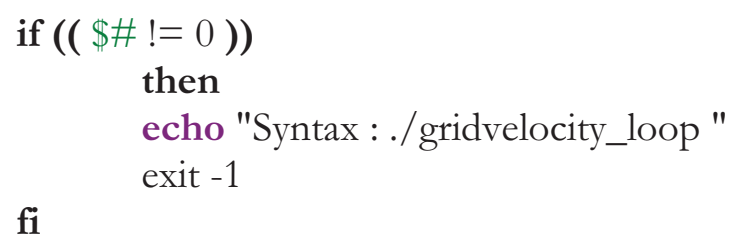

echo \#\#\#\#\#\#\#\#\#\#\# GRIDS FOR SIMPLE MODEL \#\#\#\#\#\#\#\#\#\#\#\#

\# Simple 1 - between top grid and sealevel

SimpleOne_Top="4.0"

SimpleOne_Bottom="5.0"

./velocitygrid.py./3D_interfaces/Vel_TopModel.z./3D_interfaces/Vel_Sealevel.z \$SimpleOne_Top \$SimpleOne_Bottom Simple_Grid_One echo Simple Grid 1

\#\# Simple 2 - between sealevel and seabed

Simple'Two_Top="1.48"

SimpleTwo_Bottom="1.5"

./velocitygrid.py./3D_interfaces/Vel_Sealevel.z./3D_interfaces/Vel_Seafloor.z \$SimpleTwo_Top \$SimpleTwo_Bottom Simple_Grid_Two echo Simple Grid 2

\#\# Simple 3 - between seabed and BaseA

SimpleThree_Top="1.9"

SimpleThree_Bottom="3.3"

./velocitygrid.py./3D_interfaces/Vel_Seafloor.z./3D_interfaces/Vel_BaseA.z \$SimpleThree_Top \$SimpleThree_Bottom Simple_Grid_Three echo Simple Grid 3

\#\# Simple 4 - between BaseA and Mid_C

SimpleFour_Top="3.4"

SimpleFour_Bottom="3.9"

./velocitygrid.py./3D_interfaces/Vel_BaseA.z./3D_interfaces/Vel_Mid_C.z \$SimpleFour_Top \$SimpleFour_Bottom Simple_Grid_Four echo Simple Grid 4 
\#\# Simple 7 - between MM_Crust and Base_Crust

SimpleSeven_Top="6.2"

SimpleSeven_Bottom="7.2"

./velocitygrid.py./3D_interfaces/Vel_MM_Crust.z

./3D_interfaces/Vel_BaseCrust.z \$SimpleSeven_Top \$SimpleSeven_Bottom

Simple_Grid_Seven

echo Simple Grid 7

\#\# Simple 8 - between Base_Crust and Underplating

echo this should be a hanging velocity gradient within Australian Mantle

echo using Vel_AMantle_VGRAD.z to create this

SimpleEight_Top="8.0"

SimpleEight_Bottom="8.5"

./velocitygrid.py./3D_interfaces/Vel_BaseCrust.z

./3D_interfaces/Vel_AMantle_VGRAD.z \$SimpleEight_Top

\$SimpleEight_Bottom Simple_Grid_Eight

echo Simple Grid 8

\#\# Simple 9 - between Underplating and Top_Slab

SimpleNine_Top="5.8"

SimpleNine_Bottom="6.0"

./velocitygrid.py./3D_interfaces/Vel_Underplating.z

./3D_interfaces/Vel_Top_Slab.z \$SimpleNine_Top \$SimpleNine_Bottom

Simple_Grid_Nine

echo Simple Grid 9

\#\# Simple 10 - between Top_Slab and Base_Slab

SimpleTen_Top="6.3"

SimpleTen_Bottom="7.3"

./velocitygrid.py./3D_interfaces/Vel_Top_Slab.z

./3D_interfaces/Vel_Base_Slab.z \$Simple'Ten_Top \$SimpleTen_Bottom

Simple_Grid_Ten

echo Simple Grid 10

\#\# Simple 11 - between Base Slab and bottom grid

SimpleEleven_Top="8.5" 
./velocitygrid.py./3D_interfaces/Vel_Seafloor.z./3D_interfaces/Vel_HorizonE.z

\$Test_One_Top \$Test_One_Bottom Test_One

echo Test One - between seafloor and HorizonE

\#\# TEST TWO - between Base Crust and Top Slab

Test_Two_Top $=" 8.0 "$

Test_Two_Bottom $=" 9.0 "$

./velocitygrid.py./3D_interfaces/Vel_BaseCrust.z

./3D_interfaces/Vel_AMantle_VGRAD.z \$Test_Two_Top

\$Test_Two_Bottom Test_Two

echo Test Two - between Base Crust and Top Slab

\#\# TEST THREE - between Underplating and Top Slab

Test_Three_Top $=" 7.0 "$

Test_Three_Bottom="8.2"

./velocitygrid.py./3D_interfaces/Vel_Underplating.z

./3D_interfaces/Vel_Top_Slab.z \$Test_Three_Top \$Test_Three_Bottom

Test Three

echo Test Three - between Top Slab and Base Slab

\#\# TEST FOUR - between MM Crust and Underplating

Test_Four_Top="6.2"

Test_Four_Bottom="7.0"

./velocitygrid.py./3D_interfaces/Vel_MM_Crust.z

./3D_interfaces/Vel_Underplating.z \$Test_Four_Top \$Test_Four_Bottom

Test_Four

echo Test Four -between Base Slab and Base Grid

\#\#\#\#\# List of outputfiles \#\#\#\#\#

Outputfiles="Grid_Fifteen Grid_Fourteen Grid_Thirteen Grid_Twelve Grid_Eleven Grid_Ten Grid_Nine Grid_Eight Grid_Seven Grid_Six

Grid_Five Grid_Four Grid_Three Grid_Two Grid_One Test_One Test_Two

Test_Three Test_Four Simple_Grid_Eleven Simple_Grid_Ten

Simple_Grid_Nine Simple_Grid_Eight Simple_Grid_Seven Simple_Grid_Six

Simple_Grid_Five Simple_Grid_Four Simple_Grid_Three Simple_Grid_Two

Simple_Grid_One" 
\# Created by Dan Bassett

\# December 2009

\#

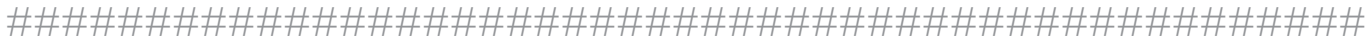

if $((\$ \# !=0))$

then

echo "Syntax : ./ regrid"

exit -1

fi

\#\#\#\#\# List of velocity grids \#\#\#\#\#

Velocity_grids="Grid_One.vel Grid_Two.vel Grid_Three.vel Grid_Four.vel

Grid_Five.vel Grid_Six.vel Grid_Seven.vel Grid_Eight.vel Grid_Nine.vel

Grid_Ten.vel Grid_Eleven.vel Grid_Twelve.vel Grid_Thirteen.vel

Grid_Fourteen.vel Grid_Fifteen.vel Test_One.vel Test_Two.vel Test_Three.vel

Test_Four.vel Simple_Grid_One.vel Simple_Grid_Two.vel

Simple_Grid_Three.vel Simple_Grid_Four.vel Simple_Grid_Five.vel

Simple_Grid_Six.vel Simple_Grid_Seven.vel Simple_Grid_Eight.vel

Simple_Grid_Nine.vel Simple_Grid_Ten.vel Simple_Grid_Eleven.vel"

\#\#\#\#\# Remove velocities smaller than $1.0 \mathrm{~km} / \mathrm{sec} \# \# \# \# \#$

for grid in \$Velocity_grids; do

echo \$grid

awk ' $\left\{\right.$ if $\left(\$ 1<=' 1.0^{\prime}\right)\left\{\right.$ print $\left.11.000^{\prime}\right\}$ else $\{$ print $\left.\$ 1\}\right\}$ ' < \$grid > \$grid"_2"

done

echo Velocities smaller than 1.0 removed

rm Grid_One.vel

rm Grid_Two.vel

rm Grid_Three.vel

rm Grid_Four.vel

rm Grid_Five.vel

rm Grid_Six.vel

rm Grid_Seven.vel 
rm Simple_Grid_Six.vel

rm Simple_Grid_Seven.vel

rm Simple_Grid_Eight.vel

rm Simple_Grid_Nine.vel

rm Simple_Grid_Ten.vel

rm Simple_Grid_Eleven.vel

rm Test_One.vel

rm Test_Two.vel

rm Test_Three.vel

rm Test_Four.vel

Velocity_gridss="Grid_One.vel_2 Grid_Two.vel_2 Grid_Three.vel_2

Grid_Four.vel_2 Grid_Five.vel_2 Grid_Six.vel_2 Grid_Seven.vel_2

Grid_Eight.vel_2 Grid_Nine.vel_2 Grid_Ten.vel_2 Grid_Eleven.vel_2

Grid_Twelve.vel_2 Grid_Thirteen.vel_2 Grid_Fourteen.vel_2

Grid_Fifteen.vel_2 Simple_Grid_One.vel_2 Simple_Grid_Two.vel_2

Simple_Grid_Three.vel_2 Simple_Grid_Four.vel_2 Simple_Grid_Five.vel_2

Simple_Grid_Six.vel_2Simple_Grid_Seven.vel_2Simple_Grid_Eight.vel_2

Simple_Grid_Nine.vel_2 Simple_Grid_Ten.vel_2 Simple_Grid_Eleven.vel_2

Test_One.vel_2 Test_Two.vel_2 Test_Three.vel_2 Test_Four.vel_2"

\#\#\#\#\# Remove velocities greater than $10.0 \mathrm{~km} / \mathrm{sec} \# \# \# \# \#$

for Grid in \$Velocity_gridss ; do echo $\$$ Grid

done

$\operatorname{awk}^{\prime}\left\{\operatorname{if}\left(\$ 1>=' 10.0^{\prime}\right)\{\text { print } 10.000 '\} \text { else }\{\text { print } \$ 1\}\right\}^{\prime}<\$$ Grid > $\$$ Grid"_3"

echo Velocities smaller than 10.0 removed

rm Grid_One.vel_2

rm Grid_Two.vel_2

rm Grid_Three.vel_2

rm Grid_Four.vel_2

rm Grid_Five.vel_2

rm Grid_Six.vel_2

rm Grid_Seven.vel_2

rm Grid_Eight.vel_2 
rm Simple_Grid_Seven.vel_2

rm Simple_Grid_Eight.vel_2

rm Simple_Grid_Nine.vel_2

rm Simple_Grid_Ten.vel_2

rm Simple_Grid_Eleven.vel_2

rm Test_One.vel_2

rm Test_Two.vel_2

rm Test_Three.vel_2

rm Test_Four.vel_2

echo Files copying to .vel files

cp Grid_One.vel_2_3 Grid_One.vel cp Grid_Two.vel_2_3 Grid_Two.vel

cp Grid_Three.vel_2_3 Grid_Three.vel

cp Grid_Four.vel_2_3 Grid_Four.vel

cp Grid_Five.vel_2_3 Grid_Five.vel

cp Grid_Six.vel_2_3 Grid_Six.vel

cp Grid_Seven.vel_2_3 Grid_Seven.vel

cp Grid_Eight.vel_2_3 Grid_Eight.vel

cp Grid_Nine.vel_2_3 Grid_Nine.vel

cp Grid_Ten.vel_2_3 Grid_Ten.vel

cp Grid_Eleven.vel_2_3 Grid_Eleven.vel

cp Grid_Twelve.vel_2_3 Grid_Twelve.vel

cp Grid_Thirteen.vel_2_3 Grid_Thirteen.vel

cp Grid_Fourteen.vel_2_3 Grid_Fourteen.vel

cp Grid_Fifteen.vel_2_3 Grid_Fifteen.vel

cp Simple_Grid_One.vel_2_3 S_Grid_One.vel

cp Simple_Grid_Two.vel_2_3 S_Grid_Two.vel

cp Simple_Grid_Three.vel_2_3 S_Grid_Three.vel

cp Simple_Grid_Four.vel_2_3 S_Grid_Four.vel

cp Simple_Grid_Five.vel_2_3 S_Grid_Five.vel

cp Simple_Grid_Six.vel_2_3 S_Grid_Six.vel

cp Simple_Grid_Seven.vel_2_3 S_Grid_Seven.vel

cp Simple_Grid_Eight.vel_2_3 S_Grid_Eight.vel

cp Simple_Grid_Nine.vel_2_3 S_Grid_Nine.vel

cp Simple_Grid_Ten.vel_2_3 S_Grid_Ten.vel

cp Simple_Grid_Eleven.vel_2_3 S_Grid_Eleven.vel 
rm Grid_Seven.vel_2_3

rm Grid_Eight.vel_2_3

rm Grid_Nine.vel_2_3

rm Grid_Ten.vel_2_3

rm Grid_Eleven.vel_2_3

rm Grid_Twelve.vel_2_3

rm Grid_Thirteen.vel_2_3

rm Grid_Fourteen.vel_2_3

rm Grid_Fifteen.vel_2_3

rm Simple_Grid_One.vel_2_3

rm Simple_Grid_Two.vel_2_3

rm Simple_Grid_Three.vel_2_3

rm Simple_Grid_Four.vel_2_3

rm Simple_Grid_Five.vel_2_3

rm Simple_Grid_Six.vel_2_3

rm Simple_Grid_Seven.vel_2_3

rm Simple_Grid_Eight.vel_2_3

rm Simple_Grid_Nine.vel_2_3

rm Simple_Grid_Ten.vel_2_3

rm Simple_Grid_Eleven.vel_2_3

rm Test_One.vel_2_3

rm Test_Two.vel_2_3

rm Test_Three.vel_2_3

rm Test_Four.vel_2_3 
\# is given at the command line as a system argument.

\# The receiver location (shot location) of picks are matched on the basis of their \# shotnumbers which are saved as the primary key in $S V$ pick files. The source \# (station), line \# and phase \# are given within the name of the $S V$ pick file

\# (e.g.Pakira_Line3_1.pic)

\#

\# Source and Receiver Locations are used to calculate an offset, which along with \# Line num, Shot num, Station name, Phase num and Observed pick time are \# written to the output file specified at the command line.

\# More information regarding the operation of this script and its use within our

\# forward modelling methodology is presented in Appendix 2.

\# Created by Adrian Benson and Dan Bassett

\# Feburary 2009

\#

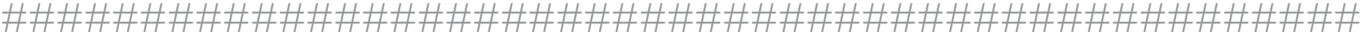

import sys,math

\section{class DanREC:}

def__init__(self):

self.locationfile $=$

"/data/bassetda/data/3D_raytracing/FMTOMO/scripts/Receiver_locations" self.db $=\{\}$

try:

dbfile $=$ open $($ self.locationfile, ' $r$ ')

except:

sys.exit("ERROR: could not open \%s : ABORTING $\backslash n$ " \% self.locationfile)

for 1 in dbfile.readlines $($ :

if 1.startswith('\#'):

continue

la $=1$.strip 0. split 0

rec $=\operatorname{int}(\mathrm{la}[0])$

self.db $[\mathrm{rec}]=$ ]

self.db $[\mathrm{rec}]=[$ float $(\mathrm{x})$ for $\mathrm{x}$ in $\mathrm{la}[1:]]$ 
for 1 in dbfile:

la $=1$.strip 0. split 0

if 1. startswith('\#'):

continue

$\operatorname{src}=\mathrm{la}[0]$

self.db $[\mathrm{src}]=$ ]

self.db $[\mathrm{src}]=[$ float $(\mathrm{x})$ for $\mathrm{x}$ in $\mathrm{la}[1:]]$

dbfile.close 0

\section{class SQCPICS:}

$$
\begin{gathered}
\text { def _init__elf): } \\
\text { self.pic }=\{\}
\end{gathered}
$$

def readClaritasPicFile(self,picfilename, tscale $=0.001$ ):

$\mathrm{pf}=$ open (picfilename.strip $\left({ }^{\prime}{ }^{\prime} \mathrm{r}\right.$ ')

pfbasename $=$ picfilename.split $\left({ }^{\prime} /\right.$ ').pop (

pfbasename $=$ pfbasename.rstrip $\left(' \cdot\right.$ pic' $\left.^{\prime}\right)$

pfbasename $=$ pfbasename.split ('_')

source $=$ pfbasename[0]

try:

phase $=$ int(pfbasename[2])

except:

sys.exit("bad .pic file name: \%s $\backslash \mathrm{n} " \%$ picfilename)

pkey $=-1$

if not self.pic.has_key(source):

self.pic $[$ source $]=\{\}$

for 1 in pf:

$1=1$. strip 0. split 0

if $\operatorname{len}(1)==0$ :

continue

\#update pkey

if $1[0]==$ 'ENSEMBLE':

pkey $=\operatorname{int}(1[3])$ 
def mergeLocations(self,DanSRC,DanREC, xscale $=0.001$ ):

\section{for $\mathrm{S}$ in self.pic.iterkeys $\mathrm{O}$ :}

if not DanSRC.db.has_key(S):

sys.exit('could not find \%s in source locations file. $\backslash \mathrm{n}^{\prime} \% \mathrm{~S}$ )

for $\mathrm{L}$ in self.pic $[\mathrm{S}]$.iterkeys $\mathrm{O}$ :

for $\mathrm{P}$ in self.pic $[\mathrm{S}][\mathrm{L}]$.iterkeys () :

for $\mathrm{i}$ in range(len(self.pic $[\mathrm{S}][\mathrm{L}][\mathrm{P}])$ ):

rn $=$ self.pic $[\mathrm{S}][\mathrm{L}][\mathrm{P}][\mathrm{i}][0]$

obs_tt $=$ self.pic $[\mathrm{S}][\mathrm{L}][\mathrm{P}][\mathrm{i}][1]$

if not DanREC.db.has_key(rn):

\section{continue}

$(\mathrm{sx}, \mathrm{sy})=\operatorname{DanSRC} \cdot \mathrm{db}[\mathrm{S}][0: 2]$

$(\mathrm{rx}, \mathrm{ry})=$ DanREC.db[rn] $[0: 2]$

offset $=$ math.sqrt $\left((\mathrm{sx}-\mathrm{rx})^{* * 2}+(\mathrm{sy}-\mathrm{ry})^{* *} 2\right) *$ xscale

self.pic $[\mathrm{S}][\mathrm{L}][\mathrm{P}][\mathrm{i}]+=$ DanREC.db $[\mathrm{rn}][0: 2]$

self.pic $[\mathrm{S}][\mathrm{L}][\mathrm{P}][\mathrm{i}]+=$ DanREC.db[rn] [4:6]

self.pic $[\mathrm{S}][\mathrm{L}][\mathrm{P}][\mathrm{i}]+=$ DanSRC.db $[\mathrm{S}][0: 2]$

self.pic $[\mathrm{S}][\mathrm{L}][\mathrm{P}][\mathrm{i}]+=\operatorname{DanSRC} \cdot \mathrm{db}[\mathrm{S}][4: 6]$

self.pic $[\mathrm{S}][\mathrm{L}][\mathrm{P}][\mathrm{i}]+=$ [offset $]$

sys.stdout.write("\%02d \%08d \%-10s \%3d \%11.08f \%12.08f $\backslash \mathrm{n} " \%$

(L,rn, S, P, obs_tt, offset) )

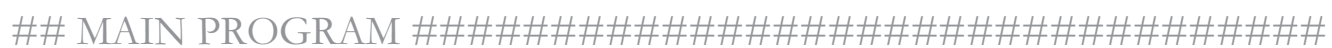

def main () :

obslist $=$ sys.argv $[1]$

\#\# Read in the observed picks

obs_list $=$ []

obslistfile = open (obslist, ' $r$ ')

obspath $=$ obslistfile.readline 0. strip 0

for $\mathrm{fn}$ in obslistfile: 


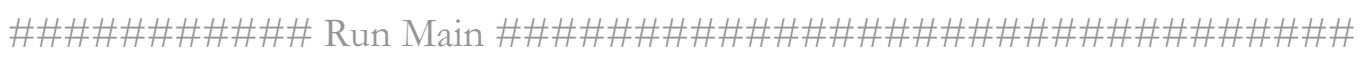

if __name__ = = _ main_": main 0 
\# matched to a specific receiver number within receivers.in on the basis of

\# geographic position. That unique receiver number is then searched for

\# within.arrivals.dat and when located is replaced by the geographic position of the

\# shot.

\#

\# Source locations are determined in a similar manner matching a specific source \# (station) name to each source number within sources.in (again the the basis of \# geographic location). Each source number within arrivals.dat is then replaced \# with the actual station name with the geographic position used in conjunction \# with the receiver locations determined above to calculate an offset for each \# synthetic arrival.

\#

\# As for pick_merger.obs, Line num, Shot num, Station name, Phase num and \# synthetic travel time and offset are written to the output file specified at the \# command line. This script only needs to be executed once after each \# model run with synthetic data for all stations combined into a single file. \#

\# More information regarding the operation of this script and its use within our \# forward modelling methodology is presented in Appendix 2.

\# Created by Adrian Benson and Dan Bassett

\# Feburary 2009

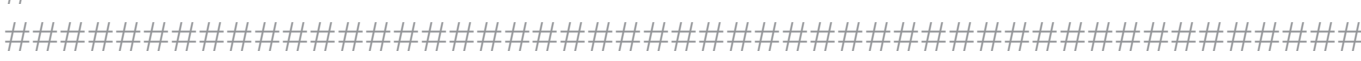

import sys,math

\#get command line args

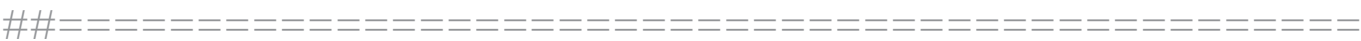

class DanTrueREC:

def__init__self):

self.locationfile $=$

"/data/bassetda/data/3D_raytracing/FMTOMO/scripts/Receiver_locations" self.db $=\{\}$

try:

dbfile $=$ open $($ self.locationfile, ' $r$ ')

except: 


\section{class DanTrueSRC:}

def__init_(self):

self.locationfile $=$

"/data/bassetda/data/3D_raytracing/FMTOMO/scripts/Source_locations"

self.db $=\{\}$

try:

dbfile $=$ open(self.locationfile, ' $r$ ')

except:

sys.exit("ERROR: could not open \%s : ABORTING $\backslash \mathrm{n}$ " \% self.locationfile)

for 1 in dbfile:

if 1.startswith('\#'):

continue

la $=1$. strip 0. split 0

FMTomoSrcFileName $=$ la.pop $(0)$

for $i$ in range(len(la)):

$\mathrm{la}[\mathrm{i}]=$ float $(\mathrm{la}[\mathrm{i}])$

crazykey $=$ "\%09.05f_\%09.05f" \% (la[4],la[5])

self.db [crazykey] $=$ la

self.db [crazykey] $+=$ [FMTomoSrcFileName]

dbfile.close 0

class DanFMTomoSynPick:

$$
\begin{aligned}
& \text { def__init_(self): } \\
& \text { self.k1 = "'" } \\
& \text { self.k2 = "" } \\
& \text { self.Cshotid=-1 } \\
& \text { self.rnum }=-1 \\
& \text { self.snum }=-1 \\
& \text { self.path_id }=-1 \\
& \text { self.path_elem }=[ \\
& \text { self.path_vels }=\square
\end{aligned}
$$


self.scrazykey = "'"

self.rcrazykey $=$ ""

class DanFMTomoRec:

def__init_(self):

self.k1 = "'

self.k2 = ""

self.rnum $=-1$

self.rlon $=-9999.9$

self.rlat $=-9999.9$

self.rx $=-9999.9$

self. ry $=-9999.9$

self.rz $=-9999.9$

self.npath $=0$

self.pathid $=$ ]

self.srcnum $=$ ]

self.crazykey $=$ ""

class DanFMTomoSrc:

def _ init_(self):

self.snum $=-1$

self.typ $=-1$

self.slon $=-9999.9$

self.slat $=-9999.9$

self.sx $=-9999.9$

self.sy $=-9999.9$

self.sz $=-9999.9$

self.npath $=-1$

self.path_elem $=$ []

self.path_vels $=$ []

self.crazykey $=$ ""

\#self.path_elem_str $=$ list 0

\#self.path_vels_str $=$ list 0

def main():

if len(sys.argv) != 4: 


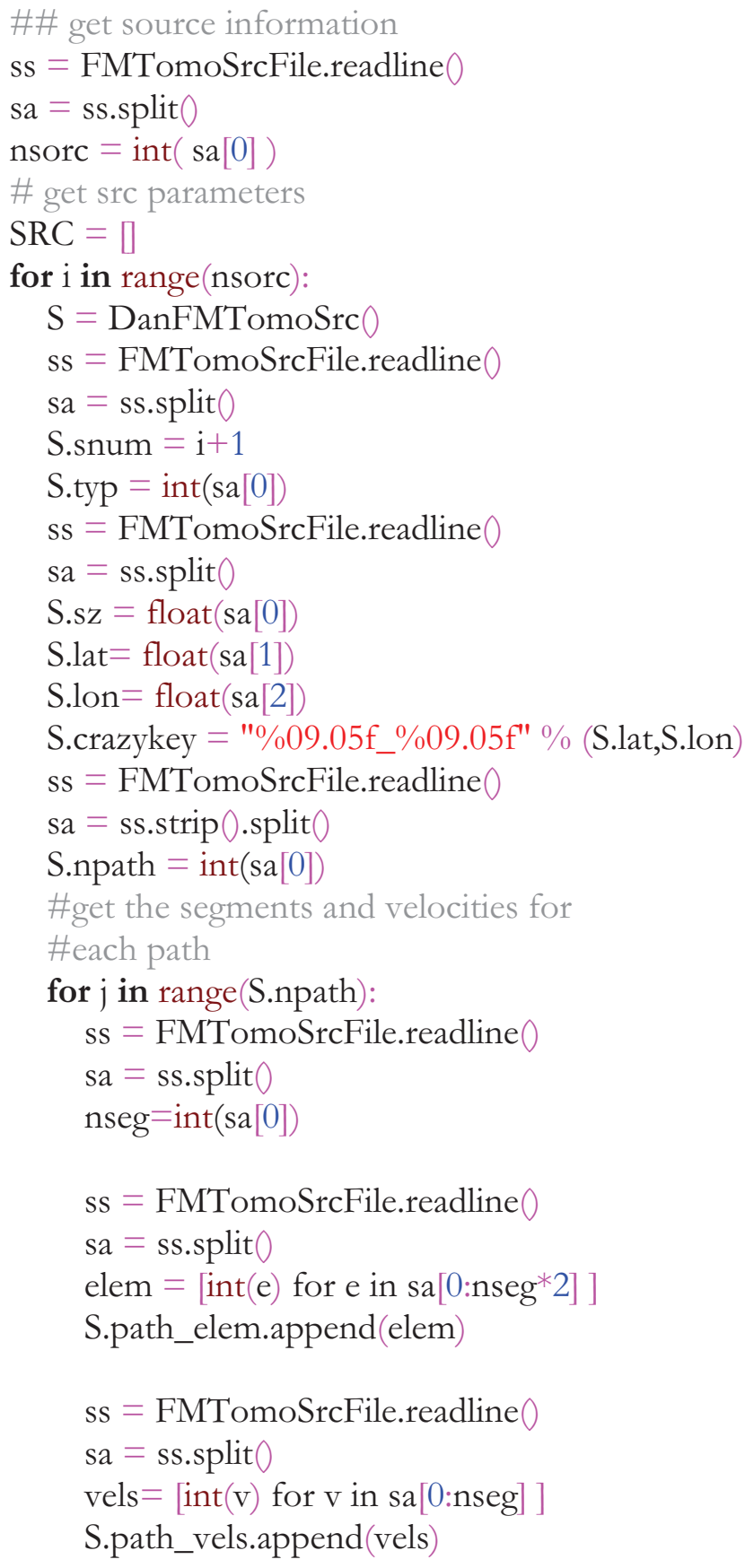


lcount $=0$

while lcount $<$ nrecv:

\#\# create rec object

rec $=$ DanFMTomoRec 0

\# read 11 to get location

$11=$ FMTomoRecFile.readline 0

$11 \mathrm{a}=11$. split 0

rnum $=$ lcount +1

rec.k1 $=11 \mathrm{a}[2]$

rec.k2 $=11 \mathrm{a}[1]$

rec.rz $=$ float $(11 \mathrm{a}[0])$

rec.rlat $=$ float $(11 \mathrm{a}[1])$

rec.rlon $=$ float $(11 \mathrm{a}[2])$

rec.crazykey $=$ "\% $\% 09.05 f \_\% 09.05 f " \%$ (rec.rlat,rec.rlon)

\# read 12 to n paths

12 = FMTomoRecFile.readline 0

$12 \mathrm{a}=12$. split 0

rec.npath $=\operatorname{int}(12 \mathrm{a}[0])$

\#read line3 to src for each path

13 = FMTomoRecFile.readline 0

$13=13$. strip 0

$13 \mathrm{a}=13$.split 0

for $\mathrm{s}$ in range(rec.npath):

rec.srcnum.append(int $(13 \mathrm{a}[\mathrm{s}])$ )

\# read line 4 to geth path id for each path

14 = FMTomoRecFile.readline 0

$14=14 . \operatorname{strip} 0$

$14 \mathrm{a}=14$. split 0

for $\mathrm{p}$ in range(rec.npath):

rec.pathid.append(int $(14 \mathrm{a}[\mathrm{p}]))$

REC.append(rec)

lcount $=$ lcount +1

FMTomoRecFile.close 0 
pid $=\operatorname{int}(\operatorname{arrv}[2])-1$

pick.mt $=$ float $(\operatorname{arrv}[4])$

\#\# get info from receivers

pick.rcrazykey $=$ REC $[$ rn]. crazykey

pick.scrazykey $=$ SRC $[\mathrm{sn}]$.crazykey

if not TrueREC.db.has_key(pick.rcrazykey) or not

TrueSRC.db.has_key(pick.scrazykey):

sys.stderr.write("warning: skipping synpick at arrival number \%d $\ \mathrm{n}$ \% rn )

\section{continue}

pick.rnum $=\mathrm{rn}+1$

pick.snum $=\mathrm{sn}+1$

pick.k1 = REC[rn].k1

pick.k2 = REC [m].k2

pick.rlon $=$ REC $[\mathrm{rn}]$. rlon

pick.rlat $=$ REC $[\mathrm{rn}]$. .rlat

pick.rz $=$ REC[rn].rz

pick.rx $=$ REC $[\mathrm{rn}] . r \mathrm{rx}$

pick.ry $=$ REC[rn].ry

pick.path_id=REC[rn].pathid[pid]

\#\# get info from receivers

pick.slon $=$ SRC $[$ sn $]$. slon

pick.slat $=\mathrm{SRC}[\mathrm{sn}] \cdot$ slat

pick.sz $=$ SRC[sn].sz

pick.sx $=$ SRC $[\mathrm{sn}]$. sx

pick.sy $=$ SRC[sn].sy

pick.path_elem = SRC[sn].path_elem[pick.path_id-1]

pick.path_vels = SRC[sn].path_vels[pick.path_id-1]

$[\mathrm{sx}, \mathrm{sy}]=$ TrueSRC.db[pick.scrazykey $][0: 2]$

$[\mathrm{rx}, \mathrm{ry}]=$ TrueREC.db[pick.rcrazykey] [0:2]

pick.offset $=$ math.sqrt $((\mathrm{sx}-\mathrm{rx}) * * 2+(\mathrm{sy}-\mathrm{ry}) * * 2) * 0.001$

pick.snum $=$ TrueSRC.db[pick.scrazykey $][-1]$

pick.rnum $=$ TrueREC.db[pick.rcrazykey $][-1]$

\#PICK.append(pick)

sys.stdout.write("\%02d \%08d \%-10s \%3d \%11.08f \%12.08f \n" \% (

pick.rnum/1000000, 
Created by Dan Bassett

\# Feburary 2009

\#

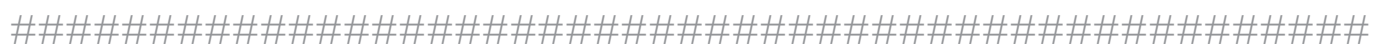

echo Pick Merger

./pick_merger_syn.py $\backslash$

../My_modified_files/3D_simpler_model/sources.in $\backslash$

../My_modified_files/3D_simpler_model/receivers.in \

../My_modified_files/3D_simpler_model/arrivals.dat $>$ Simple_model_synthetics

\section{echo PAKIRA}

./pick_merger_obs.py ../observed_picks/New_pick_files/Pakira/Pakira_picklist > Pakira_simple_model_observed

\section{echo REWETU}

./pick_merger_obs.py ../observed_picks/New_pick_files/Rewetu/Rewetu_picklist $>$ Rewetu_simple_model_observed

echo WAIHAU

./pick_merger_obs.py

../observed_picks/New_pick_files/Waihau/Waihau_picklist >

Waihau_simple_model_observed

echo 0487

./pick_merger_obs.py ../observed_picks/New_pick_files/0487/0487_picklist > 0487_simple_model_observed

echo 0576

./pick_merger_obs.py ../observed_picks/New_pick_files/0576/0576_picklist > 0576_simple_model_observed 
./pick_merger_obs.py ../observed_picks/New_pick_files/0602/0602_picklist > 0602_simple_model_observed

echo 0610

./pick_merger_obs.py ../observed_picks/New_pick_files/0610/0610_picklist > 0610_simple_model_observed

echo COMPLETE 
if $((\$ \# !=4))$
then

echo "Syntax :./plot_all_lines_loop station_number obsPICKfile synPICKfile reduction_velocity"

flipX="1 3 7"

station $=\$ 1$

inputPICKfile $=\$ 2$

inputSYNfile $=\$ 3$

$\mathrm{vl}=\$ 4$

obs_ptsize $=" \mathrm{c} 0.02 "$

syn_ptsize $=" \mathrm{c} 0.01 "$

lines="1 $234567910 "$

DANS_SUPER_CPT="./Dan.cpt"

map_annot="a1000f250g1000/a10f2.5g10/SWne"

map="'\$station"_results.ps"

gmtset ANNOT_OFFSET_PRIMARY $=0.05 \mathrm{c}$

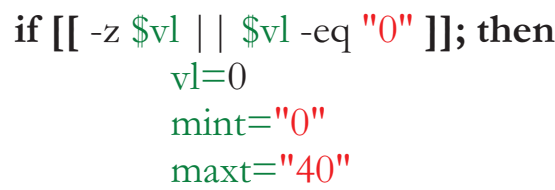

else

fi

$$
\begin{aligned}
& \operatorname{mint}="-5 " \\
& \operatorname{maxt}=" 15 "
\end{aligned}
$$

for $\mathrm{LN}$ in $\$$ lines; do

if [ \$vl -eq "0"]; then

gawk -v SN=\$station -v LN= $\$ \mathrm{LN} '\{\operatorname{if}(\$ 3==\mathrm{SN} \& \& \$ 1==\mathrm{LN})\{$ print $\$ 2, \$ 5, \$ 4\}\}^{\prime} \backslash$ 


\section{done}

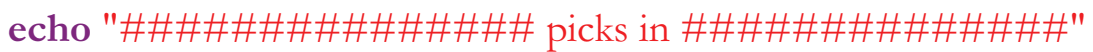

\#\#\#\#\#\#\#\#\#\#\#\# FIRST LINE \#\#\#\#\#\#\#\#\#\#\#\#\#

$>$ \$map

gmtset PAPER_MEDIA = A3

$\mathrm{y} \ln =29.7$

$\mathrm{x} \ln =42.0$

ysep $=1.5$

$\mathrm{xsep}=1$

$\mathrm{xmarg}=1$

ymarg $=1$

yln $=\$($ echo " \$yln-2* $\$$ ymarg" | bc -1)

$\mathrm{x} \ln =\$($ echo " $\$ \mathrm{xln}-2 *$ xmarg" | bc -1$)$

nrows $=3$

linenum $=\left(\begin{array}{lll}1 & 2 & 3\end{array}\right)$

$\min =(100100120010013001001)$

$\max =(100208920025153008915)$

tmin $=($ mint $\$$ mint $\$$ mint $)$

$\operatorname{tmax}=(\$ \operatorname{maxt} \$ \operatorname{maxt} \$ \operatorname{maxt})$

\#=

gmtset X_ORIGIN $=0$ Y_ORIGIN $=0$

$\operatorname{sum} x=0$

for $((\mathrm{i}=0 ; \mathrm{i}<\$\{\# \min [*]\} ; \mathrm{i}++))$; do

$\operatorname{diffx}[\$ i]=\$((\$\{\max [\$ i]\}-\$\{\min [\$ i]\}))$

$\operatorname{sumx}=\$((\$ \operatorname{sumx}+\$\{\operatorname{diffx}[\$ i]\}))$

\section{done}

mappablex $=\$($ echo " \$xln- $(\$\{\# \min [*]\}-1) * \$$ xsep" | bc -1$)$

xscale $=\$($ echo $\$$ mappablex $/ \$$ sumx $\mid$ bc -1$)$ 
xshift $=\$($ echo "\$xsep $+\$$ xaxis" | bc -1$)$

xtotal $=\$($ echo "\$xtotal $+\$ x$ shift" | bc -1$)$

yshift $=0$

fi

overlay="-O -K"

region $=\$\{\min [\$ 1]\} / \$\{\max [\$ 1]\} / \$\{\min [\$ 1]\} / \$\{\max [\$ 1]\}$

xaxis $=\$($ echo $" \$\{\operatorname{diffx}[\$ 1]\} * \$ x s c a l e " \mid$ bc -1$)$

proj=\$xaxis/-\$yaxis

for $\mathrm{j}$ in $\$$ flipX; do

if $((\$ j==$ linenum $[\$ i]))$; then

proj=-\$xaxis/ $-\$$ yaxis

break

fi

done

\#\#\#\#\#\#\#\#\# PLOTTING MAP \#\#\#\#\#\#\#\#\#\#

psbasemap -R \$region -Y\$yshift -X\$xshift -JX\$proj-Ggrey -B0 \$overlay >> \$map

\#obs picks

psxy obs.\$\{linenum[\$i]\}.temp -R -J -O -K -S\$obs_ptsize -Gblack >> \$map

\#syn picks

psxy syn.\$\{linenum[\$i]\}.temp -R -J -O -K -S\$syn_ptsize -

C\$DANS_SUPER_CPT $>>$ map

psbasemap --D_FORMAT $=\% 0.0 f-R-J \quad-B \$$ map_annot $-\mathrm{O}-\mathrm{K}>>$ map

if $((\$\{$ linenum $[\$ 1]\}==3))$; then

xaxis $1=\$($ echo $\$$ xaxis $-14 \mid$ bc -1$)$

yaxis $1=\$($ echo $\$$ yaxis $+0.40 \mid \mathbf{b c}-1)$

xaxis $2=\$($ echo $\$$ xaxis $-6 \mid$ bc -1$)$

yaxis $2=\$($ echo $\$$ yaxis $+0.40 \mid \mathbf{b c}-1)$

xaxis $3=\$($ echo $\$$ xaxis $2-1 \mid$ bc -1$)$

yaxis $3=\$($ echo $\$$ yaxis $2-1.00 \mid$ bc -1$)$

xaxis $4=\$($ echo $\$$ xaxis $3+1.0 \mid$ bc -1$)$

yaxis $4=\$($ echo $\$$ yaxis $3-0.40 \mid$ bc -1$)$ 
pstext -R0/\$xaxis $/ 0 /$ yaxis -JX \$xaxis/\$yaxis -N -O -K $<<$ EOF $>>$ \$map \$xaxis1 \$yaxis1 1200 BL \$inputPICKfile $\quad$ Reduction Velocity $=\$$ v1.0

km.sec@+-1@+

EOF

echo-R0/\$xaxis/0/\$yaxis -JX \$xaxis/\$yaxis

boxX0 $=\$($ echo $" \$$ xaxis $-0.25 " \mid$ bc -1$)$

boxX1 $=\$($ echo "\$xaxis - 6.25" | bc -1)

boxY1 $=\$($ echo "\$yaxis3 + 0.25" | bc -1)

box $Y 0=\$($ echo " $\$$ yaxis11 - 0.25" | bc - 1$)$

psxy -R0/\$xaxis/0/\$yaxis -JX \$xaxis/\$yaxis -L -O -K -Gwhite -W1p $<<$ EOF $>>$

\$map

\$boxX0 \$boxY0

\$boxX1 \$boxY0

\$boxX1 \$boxY1

\$boxX0 \$boxY1

\section{EOF}

pstext -R0/\$xaxis $/ 0 /$ yaxis -JX \$xaxis/\$yaxis $-\mathrm{N}-\mathrm{O}-\mathrm{K}<<\mathrm{EOF}>>$ \$map

\$xaxis4 \$yaxis4 1000 BL Red - Megasequence Z

\$xaxis5 \$yaxis5 1000 BL Green - Aus - Upper crust

\$xaxis6 \$yaxis6 1000 BL Blue - Aus - Lower crust

\$xaxis7 \$yaxis7 1000 BL Yellow - Forearc Mantle Wedge

\$xaxis8 \$yaxis8 1000 BL Purple - Underplated sediment

\$xaxis9 \$yaxis9 1000 BL Pink - Pac - Upper crust (HP)

\$xaxis10 \$yaxis10 1000 BL Tan - Pac - Lower crust

\$xaxis11 \$yaxis11 1000 BL Orange - Pac - Mantle

EOF

fi

done

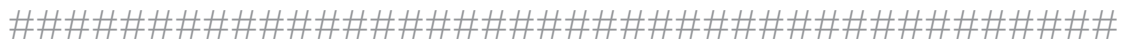

linenum $=\left(\begin{array}{lll}4 & 5 & 6\end{array}\right)$ 
yaxis $=\$($ echo $"(\$ y l n-(\$$ nrows- 1$) *$ ysep $) / \$$ nrows" | bc -1$)$

yorig $=\$($ echo "\$yorig+\$ystep" | bc - 1$)$

ystep $=\$($ echo " $(\$ y s e p+\$ y a x i s) *-1 " \mid$ bc -1$)$

\# gmtset X_ORIGIN = 0 Y_ORIGIN = \$yorig

for $((\mathrm{i}=0 ; \mathrm{i}<\$\{\# \min [*]\} ; \mathrm{i}++))$; do

if $((\$ i==0))$; then

xshift $=\$($ echo $" \$ x$ marg-\$xtotal" | bc - 1$)$

xtotal $=\$$ xmarg

yshift $=\$ y s t e p$

else

xshift $=\$($ echo $" \$$ xsep $+\$$ xaxis" | bc -1$)$

xtotal $=\$($ echo $" \$ x t o t a l+\$ x$ shift" | bc - 1$)$ yshift $=0$

fi

region $=\$\{\min [\$ i]\} / \$\{\max [\$ i]\} / \$\{\operatorname{tmin}[\$ i]\} / \$\{\operatorname{tmax}[\$ 1]\}$

xaxis $=\$($ echo $" \$\{\operatorname{diffx}[\$ 1]\} * \$ x s c a l e " \mid$ bc -1$)$

proj $=\$$ xaxis $/-\$$ yaxis

for $\mathrm{j}$ in $\$$ flipX; do

if $((\$ j==$ linenum $[\$ i]))$; then

proj $=-\$$ xaxis $/$-\$yaxis

break

fi

done

\#\#\#\#\#\#\#\#\# PLOT'TING MAP \#\#\#\#\#\#\#\#\#\#

psbasemap -X \$xshift - Y\$yshift - R \$region -JX \$proj -Ggrey -B0 -O -K >> \$map \#obs picks

psxy obs.\$\{linenum[\$i \}.temp - $\mathrm{R}-\mathrm{J}-\mathrm{O}-\mathrm{K}-\mathrm{S} \$$ obs_ptsize -Gblack

$>>$ \$map

\#syn picks

psxy syn. $\$\{$ linenum $[\$ i]\}$.temp -R -J -O -K -S\$syn_ptsize -

C\$DANS_SUPER_CPT $>$ > \$map

psbasemap --D_FORMAT $=\% 0.0 f-R-J \quad-B$ map_annot $-\mathrm{O}-\mathrm{K}>>$ \$map

done 


\section{for $((\mathrm{i}=0 ; \mathrm{i}<\$\{\# \min [*]\} ; \mathrm{i}++)) ;$ do}

$\operatorname{diffx}[\$ i]=\$((\$\{\max [\$ 1]\}-\$\{\min [\$ 1]\}))$

$\operatorname{sum} x=\$((\$ \operatorname{sum} x+\$\{\operatorname{diffx}[\$ i]\}))$

\section{done}

mappablex $=\$($ echo " \$xln- $(\$\{\# \min [*]\}-1) * \$ \mathrm{xsep} " \mid$ bc -1$)$

xscale $=\$($ echo $\$$ mappablex $/ \$$ sumx $\mid$ bc -1$)$

yaxis $=\$($ echo $"(\$ y l n-(\$$ nrows -1$) *$ \$ysep $) /$ nrows" | bc - 1$)$

yorig2 $=\$($ echo "\$yorig+\$ystep" | bc -1)

ystep $=\$\left(\right.$ echo " $(\text { ysep }+\$ \text { yaxis })^{*}-1 " \mid$ bc -1$)$

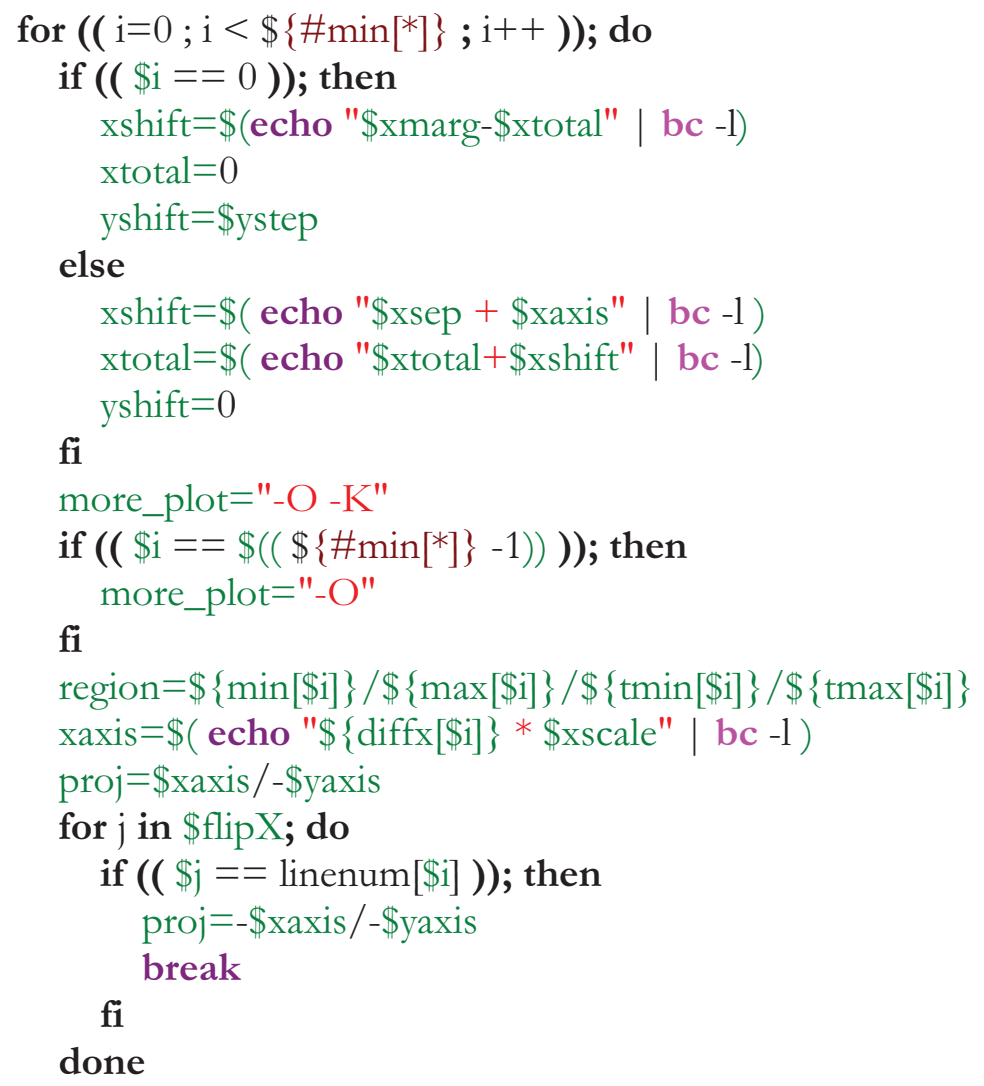


rm -f obs*.temp syn*.temp

gv \$map 
\# Created by Dan Bassett

\# Feburary 2009

\#

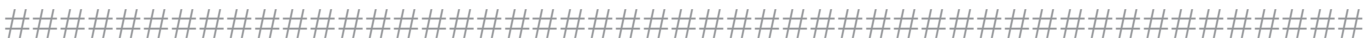

if $((\$ \# !=0))$

then

echo "Syntax : ./create_X_sections" exit -1

fi

\#SET CORRECT DIRECTORY

echo Directory changed to 3D_simpler_raypath

cd ../My_modified_files/3D_simpler_raypath

\#PROFILE 1

echo Profile 1

cp sources.in_1 sources.in

cp receivers.in_1 receivers.in

.$/ \operatorname{grid} 3 \mathrm{dg}$

.$/ \mathrm{fm} 3 \mathrm{~d}$

echo creating $\mathrm{X}$-section

cd gmtfiles

echo directory changed to gmtfiles

cp gmtslice.in_1 gmtslice.in

cp plotgc_1 plotgc

./gmtslice

.$/$ plotgc 
cd gmtfiles

echo directory changed to gmtfiles

cp gmtslice.in_2 gmtslice.in

cp plotgc_2 plotgc

./gmtslice

./plotgc

\#PROFILE 3

echo Profile 3

cd ../

cp sources.in_3 sources.in

cp receivers.in_3 receivers.in

.$/ \operatorname{grid} 3 \mathrm{dg}$

echo creating $\mathrm{X}$-section

cd gmtfiles

echo directory changed to gmtfiles

cp gmtslice.in_3 gmtslice.in

cp plotgc_3 plotgc

./gmtslice

.$/$ plotgc

\# PROFILE 4

echo Profile 4

cd ../ 
cp plotgc_4 plotgc

./gmtslice

./plotgc

\# PROFILE 5

echo Profile 5

cd ../

cp sources.in_5 sources.in

cp receivers.in_5 receivers.in

./grid3dg

.$/ \mathrm{fm} 3 \mathrm{~d}$

echo creating X-section

cd gmtfiles

echo directory changed to gmtfiles

cp gmtslice.in_5 gmtslice.in

cp plotgc_5 plotgc

./gmtslice

./plotgc

\# PROFILE 6

echo Profile 6

cd ../

cp sources.in_6 sources.in

cp receivers.in_6 receivers.in

./grid3dg 
echo Profile 7

cd ../

cp sources.in_7 sources.in

cp receivers.in_7 receivers.in

./grid3dg

.$/ \mathrm{fm} 3 \mathrm{~d}$

\section{echo creating $\mathrm{X}$-section}

cd gmtfiles

echo directory changed to gmtfiles

cp gmtslice.in_7 gmtslice.in

cp plotgc_7 plotgc

./gmtslice

.$/$ plotgc

\# PROFILE 8

echo Profile 8

cd ../

cp sources.in_8 sources.in

cp receivers.in_8 receivers.in

.$/ \operatorname{grid} 3 \mathrm{dg}$

.$/ \mathrm{fm} 3 \mathrm{~d}$

echo creating $\mathrm{X}$-section

cd gmtfiles 
cp sources.in_9 sources.in

cp receivers.in_9 receivers.in

./grid3dg

.$/ \mathrm{fm} 3 \mathrm{~d}$

echo creating X-section

cd gmtfiles

echo directory changed to gmtfiles

cp gmtslice.in_9 gmtslice.in

cp plotgc_9 plotgc

./gmtslice

./plotgc

\# PROFILE 10

echo Profile 10

cd ../

cp sources.in_10 sources.in

cp receivers.in_10 receivers.in

./grid3dg

.$/ \mathrm{fm} 3 \mathrm{~d}$

echo creating $\mathrm{X}$-section

cd gmtfiles

echo directory changed to gmtfiles

cp gmtslice.in_10 gmtslice.in

cp plotgc_10 plotgc 
echo creating $\mathrm{X}$-section

cd gmtfiles

echo directory changed to gmtfiles

cp gmtslice.in_11 gmtslice.in

cp plotgc_11 plotgc

/gmtslice

./plotgc

echo ALL DONE

exit 
int main(int $\operatorname{argc}$, char ** argv $)\{$

double $\mathrm{spc}=\operatorname{atof}(\operatorname{argv}[1])$;

const char* NSFname="raysns.xy";

const char* DFname="raysd.xy";

double $\min Z=1 \mathrm{e} 10, \max Z=-1 \mathrm{e} 10, \mathrm{st} Z=0$;

double minLat $=1 \mathrm{e} 10$, maxLat $=-1 \mathrm{e} 10$, $\mathrm{stLat}=0$;

double $\operatorname{minLon}=1 \mathrm{e} 10, \operatorname{maxLon}=-1 \mathrm{e} 10, \mathrm{stLon}=0$;

ifstream ewFile,dFile;

ofstream ewdFile;

string lineEW,lineD;

double lat1,lat2,lon,depth;

ewFile.open(NSFname);

dFile.open(DFname);

if(!ewFile.is_open 0$)\{$

printf("Cannot open NS file $\backslash \mathrm{n} ")$;

exit(1);

\}

if(!dFile.is_open 0$)\{$

printf("Cannot open D file $\backslash n ") ;$

$\operatorname{exit}(1)$;

\}

int rayCnt $=1$, line $C n t=0$;

ewdFile.precision(10);

char outName[255];

while(getline (ewFile,lineEW) \{

getline(dFile,lineD);

if $\left(\right.$ lineEW $\left.[0] !=^{\prime}>>^{\prime}\right)\{$

rayCnt++;

if $($ rayCnt $\% 100000==0)$ printf("ray number

$\% \mathrm{~d} \backslash \mathrm{n}$ ",rayCnt); 
ewFile.close();

dFile.close ();

$\mathrm{st} Z=\mathrm{spc}$

stLat $=$ spc $/ 111$;

stLon $=\mathrm{spc} / 111 / \cos ((\operatorname{minLat}+\operatorname{maxLat}) / 180 * \operatorname{atan}(1 \mathrm{e} 10))$;

printf("Min Max step_size $\backslash \mathrm{n}$ ");

printf("Lat : \%f \% \% \% $\backslash n$ ",minLat,maxLat,stLat);

printf("Lon : \%f \%f \% $\backslash \mathrm{n}$ ",minLon,maxLon,stLon);

printf("Dep : \%f \%f \%f \n",minZ,maxZ,stZ);

fprintf(stderr,"Min Max step_size $\backslash n ") ;$

fprintf(stderr,"Lat : \%f \%f \%f $\backslash \mathrm{n}$ ",minLat,maxLat,stLat);

fprintf(stderr,"Lon : \% $\%$ f \% $\mathrm{f} \backslash \mathrm{n} "$, minLon,maxLon,stLon);

fprintf(stderr,"Dep : \%f \%f \% $\ \backslash \mathrm{n}$ ", minZ, maxZ,stZ);

int nDepth=(int $)((\operatorname{maxZ}-\min Z) / \mathrm{stZ}+.999)$;

int nLat $=$ (int $)(($ maxLat - minLat $) /$ stLat +.999$)$;

int nLon=(int $)((\operatorname{maxLon}-\mathrm{minLon}) /$ stLon +.999$)$;

int $\mathrm{i}, \mathrm{j}, \mathrm{k}$;

int $* * *$ blkCnt $=$ new int $* *[\mathrm{nLat}]$;

int $* * *$ bufCnt $=$ new int ${ }^{* *}[\mathrm{nLat}]$;

for $(\mathrm{i}=0 ; \mathrm{i}<\mathrm{nLat} ; \mathrm{i}++)\{$

blkCnt $[i]=$ new int*[nLon];

bufCnt[i]=new int*[nLon];

for $(j=0 ; j<$ nLon; $j++)\{$

blkCnt $[\mathrm{i}][\mathrm{j}]=$ new int $[\mathrm{nDepth}]$;

bufCnt [i] [j] = new int [nDepth];

for $(\mathrm{k}=0 ; \mathrm{k}<\mathrm{nDepth} ; \mathrm{k}++)\{$

blkCnt $[\mathrm{i}][\mathrm{j}][\mathrm{k}]=0$;

bufCnt [i] [j] [k]=-1; 
if $($ lineEW[0]!"='>')\{

rayCnt++;

if (rayCnt \%100000 ==0) printf("ray number

$\% \mathrm{~d} \backslash \mathrm{n}$ ",rayCnt);

\}

sscanf(lineEW.c_str $0, " \%$ lf $\% l f ", \& l a t 1, \& d e p t h) ;$

sscanf(lineD.c_str $), " \%$ lf \%lf",\&lon,\&lat2);

if $($ lat $1==$ lat 2$)\{$

$\mathrm{i}=$ (int) $($ (lat1-minLat) $/ \mathrm{stLat})$;

$j=$ (int) $($ (lon-minLon) $/$ stLon);

$\mathrm{k}=$ (int) $(($ depth-minZ) $/ \mathrm{st} Z)$;

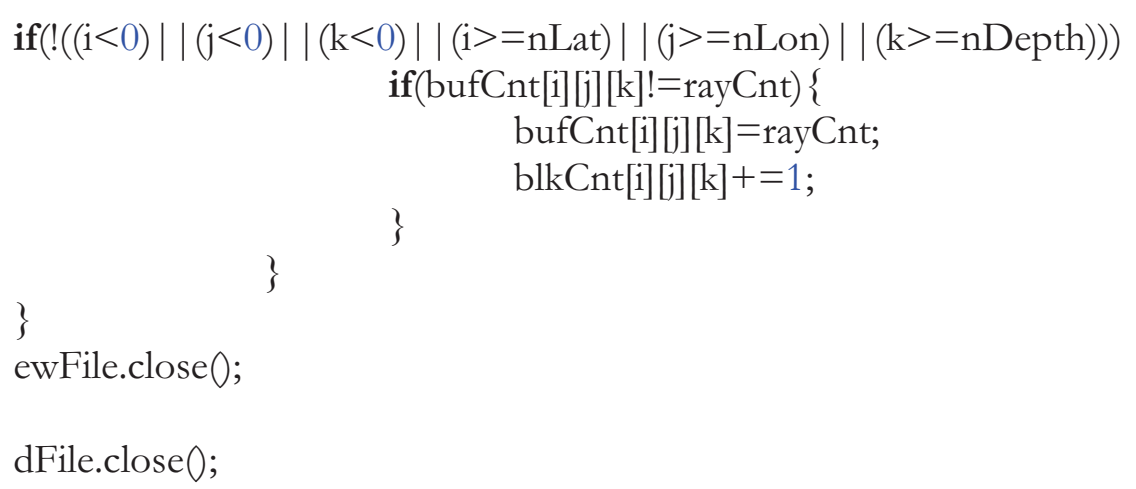


ewdFile.open("dans.vtk");

ewdFile $<<$ "\# vtk DataFile Version 2.0 $\backslash \mathrm{n}$ ";

ewdFile $<<$ "Ray path log density $\backslash \mathrm{n}$ ";

ewdFile $<<$ "ASCII $\backslash n$ ";

ewdFile $<<" \quad \backslash n "$;

ewdFile $<<$ "DATASET STRUCTURED POINTS $\backslash \mathrm{n}$ ";

ewdFile $<<$ "DIMENSIONS $\quad "<<$ nLat $<<" \quad$ "<<nLon $<<" \quad$ "<<nDepth $<<" \backslash n "$;

ewdFile $<<$ "ORIGIN $\quad 0.000 \quad 0.000 \quad 0.000 \backslash n "$;

ewdFile <<"SPACING $\quad "<<$ pst $<<" \quad$ "<< qst $<<" \quad$ "<<stZ $<<" \backslash$ n";

ewdFile $<<" \backslash \backslash \mathrm{n}$ ";

ewdFile $<<$ "POINT_DATA " $<<$ nLat*nLon*nDepth $<<" \backslash n$ ";

ewdFile $<<$ "SCALARS scalars float $\backslash n$ ";

ewdFile $<<$ "LOOKUP_TABLE default $\backslash \mathrm{n}$ ";

ewdFile $<<" \backslash n "$;

for $(\mathrm{k}=0 ; \mathrm{k}<\mathrm{nDepth} ; \mathrm{k}++)\{$

for $(j=0 ; j<n L o n ; j++)\{$

for $(\mathrm{i}=0 ; \mathrm{i}<\mathrm{nLat} ; \mathrm{i}++)\{$

$\mathrm{d}=\log 10(($ double)bufCnt[i] $[\mathrm{j}][\mathrm{k}] / 10.0+1)$;

\}

ewdFile $<<\mathrm{d}<<" \backslash \mathrm{t}$ ";

ewdFile $<<" \backslash \mathrm{n}$;

\}

ewdFile.close ();

for $(\mathrm{i}=0 ; \mathrm{i}<\mathrm{nLat} ; \mathrm{i}++)\{$

for $(j=0 ; j<n L o n ; j++)\{$

delete[ blkCnt[i][j];

delete[ bufCnt[i][j];

delete[ blkCnt[i];

delete[ bufCnt[i];

return 0 ;

\} 
while True:

$1=$ fh.readline 0

if l.startswith('DIMENSIONS'):

$(\mathrm{ny}, \mathrm{nx}, \mathrm{nz})=[\operatorname{int}(\mathrm{x})$ for $\mathrm{x}$ in $1 . \operatorname{strip} 0 . \operatorname{split} \mathrm{O}[1:]]$

elif l.startswith('ORIGIN'):

$(\mathrm{yo}, \mathrm{xo}, \mathrm{zo})=[$ float $(\mathrm{x})$ for $\mathrm{x}$ in 1. strip 0. split $0[1:]]$

elif l.startswith('SPACING'):

$(\mathrm{dy}, \mathrm{dx}, \mathrm{dz})=[$ float $(\mathrm{x})$ for $\mathrm{x}$ in $1 . \operatorname{strip} 0 . \operatorname{split} 0[1:]]$

elif 1.startswith('LOOKUP_TABLE'):

break

$($ xo,yo,zo $)=(176.800000,-38.800000,-38.167351)$

$(\mathrm{dx}, \mathrm{dy}, \mathrm{dz})=(0.022621,0.018018,2$.

\#Lat: -38.050486 -36.363513 0.018018

\#Lon : 177.302200180 .3888020 .022623

\#Dep : -39.732707 0.5400002 .000000

grid $=$ fh.read

grid = re.split("\s+ $\mid \backslash n "$, grid $)$

grid.pop $(0)$

grid.pop 0

nxny $=\mathrm{nx} *$ ny

region $=" \% .9 \mathrm{f} / \% .9 \mathrm{f} / \% .9 \mathrm{f} / \% .9 \mathrm{f} " \%(\mathrm{xo}+\mathrm{dx} / 2, \mathrm{xo}+\mathrm{dx} / 2+(\mathrm{nx}-1) * \mathrm{dx}, \mathrm{yo}+\mathrm{dy} / 2$, yo $+($ ny- 1$) * d y+d y / 2)$

gmtcmd = "xyz2grd -R\%s -I\%.9f/\%.9f xxxxx" \% (region, dx, dy)

$\mathrm{i}=0$

while $\mathrm{i}<\mathrm{nz}$ :

slice $=-39.732707+\mathrm{dz} / 2+\mathrm{i} * \mathrm{dz}$

gridname $=$ "tmpgrd.\%06f.grd" \% slice

gmt $=$ open("xxxxx","w")

tempgrd $=\operatorname{grid}\left[(\mathrm{i}){ }^{*}\right.$ nxny: $(\mathrm{i}+1) *$ nxny $]$

for $j$ in range $(n x)$ :

for $\mathrm{k}$ in range(ny):

gmt.write( "\%0.9f \%0.9f \%s $\backslash \mathrm{n} " \%$

$\left(\mathrm{j}^{*} \mathrm{dx}+\mathrm{xo}+\mathrm{dx} / 2, \mathrm{k} * \mathrm{dy}+\mathrm{yo}+\mathrm{dy} / 2\right.$, tempgrd $\left.\left.\left[\mathrm{j}^{*} \mathrm{ny}+\mathrm{k}\right]\right)\right)$

gmt.close 0 
tmpgrd.-8.732707.grd tmpgrd.-10.732707.grd tmpgrd.-12.732707.grd tmpgrd.-14.732707.grd tmpgrd.-16.732707.grd tmpgrd.-18.732707.grd tmpgrd.-20.732707.grd tmpgrd.-22.732707.grd tmpgrd.-24.732707.grd tmpgrd.-26.732707.grd tmpgrd.-28.732707.grd tmpgrd.-30.732707.grd tmpgrd.-32.732707.grd tmpgrd.-34.732707.grd tmpgrd.-36.732707.grd tmpgrd.-38.732707.grd"

xyfiles="GC_Slice10.txt2 GC_Slice11a.txt2

GC_Slice11b.txt2

GC_Slice11c.txt2

GC_Slice11d.txt2

GC_Slice11.txt2

GC_Slice11_2.txt2

GC_Slice1.txt2

GC_Slice2.txt2

GC_Slice3.txt2

GC_Slice4.txt2

GC_Slice5.txt2

GC_Slice6a.txt2

GC_Slice6.txt2

GC_Slice7.txt2

GC_Slice8a.txt2

GC_Slice8.txt2

GC_Slice9.txt2

GC_Slice_RAU07_05.txt2

GC_Slice_Reyners59.txt2

GC_Slice_Reyners80.txt2" 
\# EW_Slice12.txt2

\# EW_Slice13.txt2

\# EW_Slice14.txt2

\# EW_Slice15.txt2

\# NS_Slice1.txt2

\# NS_Slice2.txt2

\# NS_Slice3.txt2

\# NS_Slice4.txt2

\# NS Slice5.txt2

\# NS_Slice6.txt2

\# NS_Slice7.txt2

\# NS_Slice8.txt2

\# NS_Slice9.txt2

\# NS_Slice10.txt2

\# NS_Slice11.txt2

\# NS Slice12.txt2

\# NS_Slice13.txt2

\# NS_Slice14.txt2

\# NS_Slice15.txt2"

\# CHANGE PAPER MEDIA TO A3 IF PLOTTING GC SLICES

\# CHANGE PAPER MEDIA TO A2 IF PLOT'TING NS SLICES

\# CHANGE PAPER MEDIA TO AO IF PLOTTING EW SLICES

\#\#\#\#\# CREATE SLICE SECTIONS \#\#\#\#\#

map="test.ps"

for $\mathrm{f}$ in $\$ \mathrm{xyfiles}$; do

for $g$ in \$grids; do

$>\$ f . z$

\# $\quad$ grdtrack \$f -Gtmpgrd.-18.732707.grd -Z > > \$f.z

\# grdimage tmpgrd.-18.732707.grd -Jx4 -Ba0.5 -Ctext.cpt > \$map grdtrack $\$ f-G \$ g-Z>>$ f.z

\# gv \$map

echo $\$ \mathrm{f}$

done

done 
$\mathrm{E}=(\$($ tail $-\mathrm{n} 1 \$ \mathrm{f}))$

\# trackfile1=\$( mktemp XXXXXXX)

\# trackfile2=\$( mktemp XXXXXXX)

\# project --D_FORMAT $=\% 00.07 \mathrm{f}-\mathrm{C} \$\{\mathrm{~S}[0]\} / \$\{\mathrm{~S}[1]\}-\mathrm{E} \$\{\mathrm{E}[0]\} / \$\{\mathrm{E}[1]\}-$

$\mathrm{G} \$ \mathrm{x} \_$incr $-\mathrm{Q}$

project --D_FORMAT=\%0.07f -Dg $-\mathrm{C} \$\{\mathrm{~S}[0]\} / \$\{\mathrm{~S}[1]\}-\mathrm{E} \$\{\mathrm{E}[0]\} / \$\{\mathrm{E}[1]\}-$

G\$X_incr $-\mathrm{Q}>$ trackfile1

nline $=(\$($ wc -1 trackfile1 $))$

nline $=\$\{$ nline $[0]\}$

nline $=\$((\$$ nline -1$))$

head $-\mathrm{n} \$$ nline trackfile1 $>$ trackfile2

$\mathrm{S}=(\$($ head $-\mathrm{n} 1$ trackfile 2$))$

$\mathrm{E}=(\$($ tail $-\mathrm{n} 1$ trackfile2 $))$

$\mathrm{X} 0=\$\{\mathrm{~S}[2]\}$

$\mathrm{X} 1=\$\{\mathrm{E}[2]\}$

echo $\$\{\mathrm{~S}[*]\} \$ \mathrm{X} 0$

echo $\left.\$\left\{E^{*}\right]\right\}$

awk '\{print $\$ 1, \$ 2$ ' trackfile $2>$ trackfile1

size $=\$($ echo " $\$$ nline $* 0.0010 " \mid$ bc -1$)$

$>$ trackfile.xyz

for $g$ in \$grids; do

grdtrack trackfile1 $-\mathrm{G} \$ g-\mathrm{Z}>>$ trackfile.xyz

done

xyz2grd trackfile.xyz -ZTL - R \$X0/\$X1/\$Z0/\$Z1 -I\$X_incr/\$Z_incr-G\$f.grd grdmath $\$$ f.grd 1 SUB $=\$$ f.grd

grdsample \$f.grd -I\$(echo "\$X_incr/10" | bc -1)/ \$(echo "\$Z_incr/10" | bc -1) -

Gjunk.grd

grdimage --D_FORMAT=\%0.00f junk.grd $-\mathrm{R} \$ \mathrm{X0} / \$ \mathrm{X} 1 / \mathrm{Z} \mathrm{Z} / \mathrm{ZZ1}$-Jx $\$$ size $/ 0.15$ -

Ctest.cpt -Ba10f250g1000/a10f2.5g10/SWne -K > \$f.ps

pscoast -Jx\$size $/ 0.15-\mathrm{R} \$ \mathrm{X} 0 /$ X1/ $\$ \mathrm{Z} 0 /$ Z $1-\mathrm{Df}-\mathrm{O}-\mathrm{K}>>$ \$f.ps 
concerning the phase of interpreted arrivals and the results generated were encouraging with first order structures, such as the Raukumara sedimentary basin and the East Cape Ridge resolved (Figures A3.1 and A3.3).

Multilayer velocity inversions require detailed a priori information concerning the phase of observed travel-times. This information is often obtained by analyses of apparent velocities, however, in this study such analyses is complicated due to the influence of variations in ray azimuth on apparent velocities. Velocity forward modelling is a viable alternative means of determining phase identity and the final experiment involving tomographic velocity inversion is a complex multilayer inversion, in which, the final 3-D forward model (Section 3.6) developed in this thesis is used to resolve phase identity and then incorporated as the starting model.

The onshore-offshore data analysed in thesis are spatially incomplete with unidirectional shooting and the absence of reversed profiles. The inversion problem is underdetermined and the ray-coverage is insufficient to overcome trade-offs in velocity structure along the ray-path. Within FMTOMO, it is not possible to restrict the inversion to regions unconstrained by other data (e.g. OBS/H profiles) and without this ability, it is difficult to preserve incorporated constraints and produce complete results from tomographic inversion alone 
Spacing page 
This inversion ran for ten iterations and after initial Root Mean Square (RMS) residuals of 10.2 seconds were calculated, RMS residuals stabilised between iterations three and four, reaching a minimum $(1.4 \mathrm{sec})$ after iteration six (Figure A3.2c-d).

In the results of this inversion, the central Raukumara Basin is resolved as a low velocity region $(1.4-4.6 \mathrm{~km} / \mathrm{sec})$ extending on average down to $15 \mathrm{~km}$ depth (Figure A3.1). Along RAU07-09, this low-velocity region dips north from the Raukumara Peninsula reaching a depth of $\sim 20 \mathrm{~km}$ beneath the intersection of this profile with RAU07-05 (Figure A3.2a). The regions flanking the central basin are characterised by higher velocities ( $>4.5$ to $6.5 \mathrm{~km} / \mathrm{sec}$ ) more indicative of basement material than sedimentary basin-fill. At depths $<15 \mathrm{~km}$, the East Cape Ridge region (Figure 3.3) is characterised by low velocities from 1.6-4.0 $\mathrm{km} / \mathrm{sec}$ (Figure 3.9). In the same depth range, low velocities $(\sim 1.8-3.5 \mathrm{~km} / \mathrm{sec})$ are observed onshore at the East Cape and are considered the onshore continuation of the low-velocity anomaly observed offshore. 

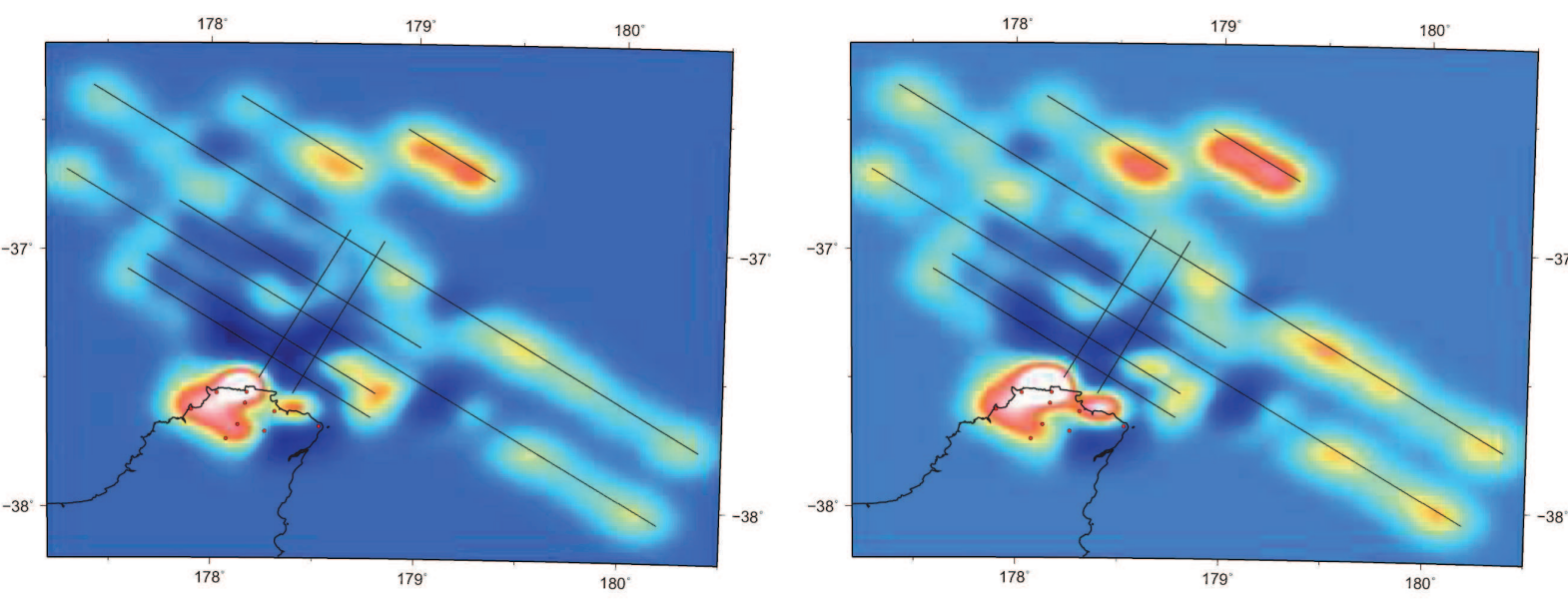

$\mathrm{DEPTH}=5.0 \mathrm{~km}$

$\mathrm{DEPTH}=7.5 \mathrm{~km}$

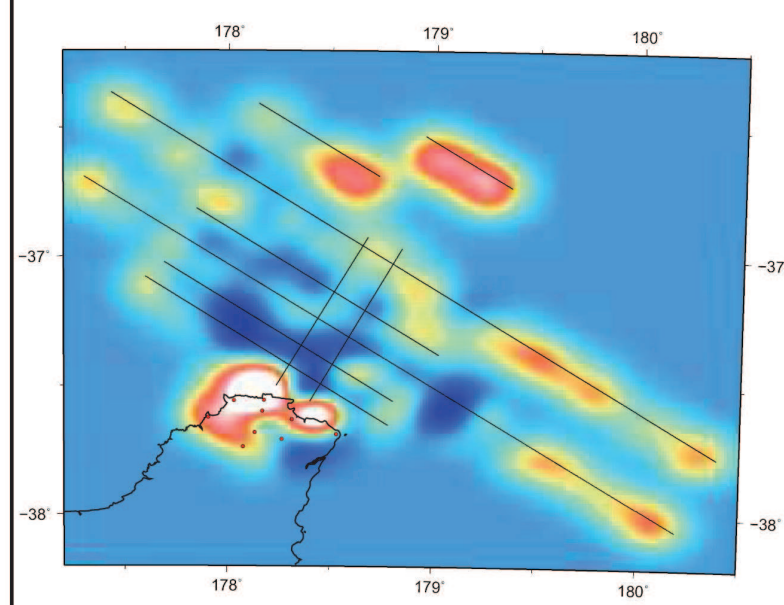

$\mathrm{DEPTH}=10.0 \mathrm{~km}$

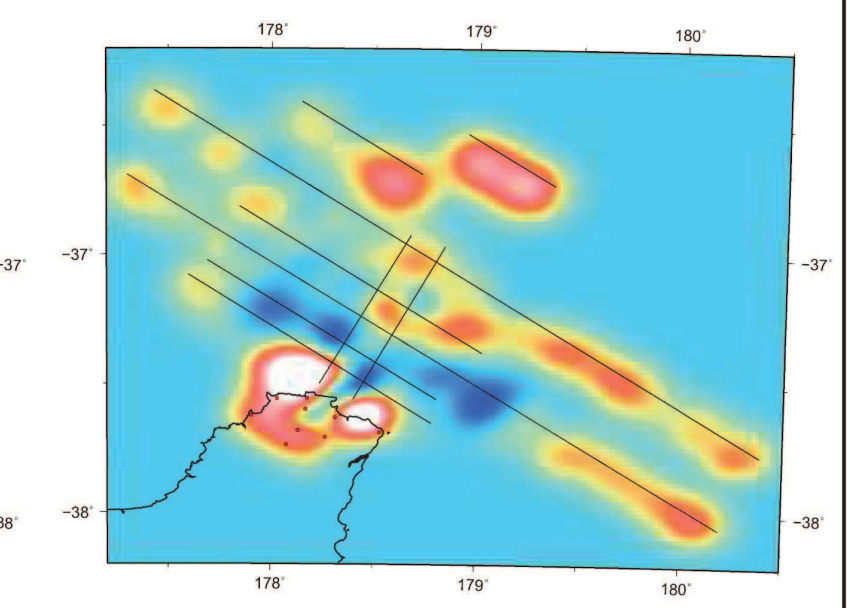

$\mathrm{DEPTH}=15.0 \mathrm{~km}$

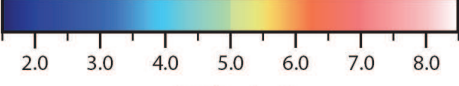

Vel $(\mathrm{km} / \mathrm{sec})$

Figure A3.1 - Depth slices (as labelled) displaying the distribution of Vp velocities generated by the unconstrained tomographic inversion of all interpreted first arrival travel-times. Black lines offshore display RAU07 reflection profiles and the source of observational data. Coastline of the Raukumara Peninsula is displayed in Black. Continued overleaf. 


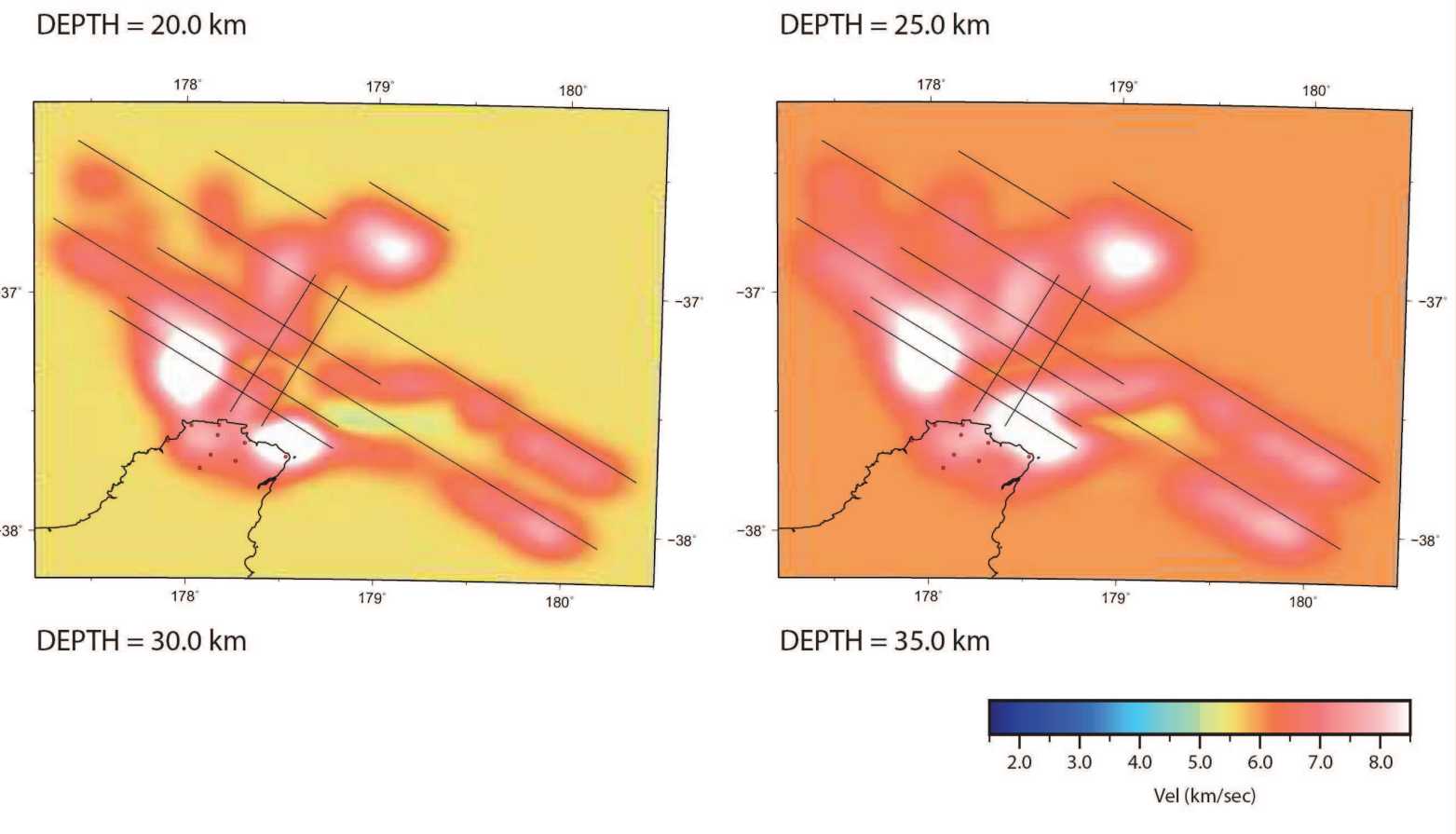

Figure A3.1 - continued

At depths $>10 \mathrm{~km}$, velocities exceeding $6.0 \mathrm{~km} / \mathrm{sec}$ are observed beneath the East Cape. The central and western regions of the Raukumara Peninsula display velocities in excess of $7.0 \mathrm{~km} / \mathrm{sec}$ at depths $<15 \mathrm{~km}$. Beneath the central region of the northern Raukumara Peninsula, a low-velocity ( $\mathrm{Vp}<4.5 \mathrm{~km} / \mathrm{sec}$ ) anomaly is observed at depths from $15-25 \mathrm{~km}$, which appears to extend offshore to the northeast. 


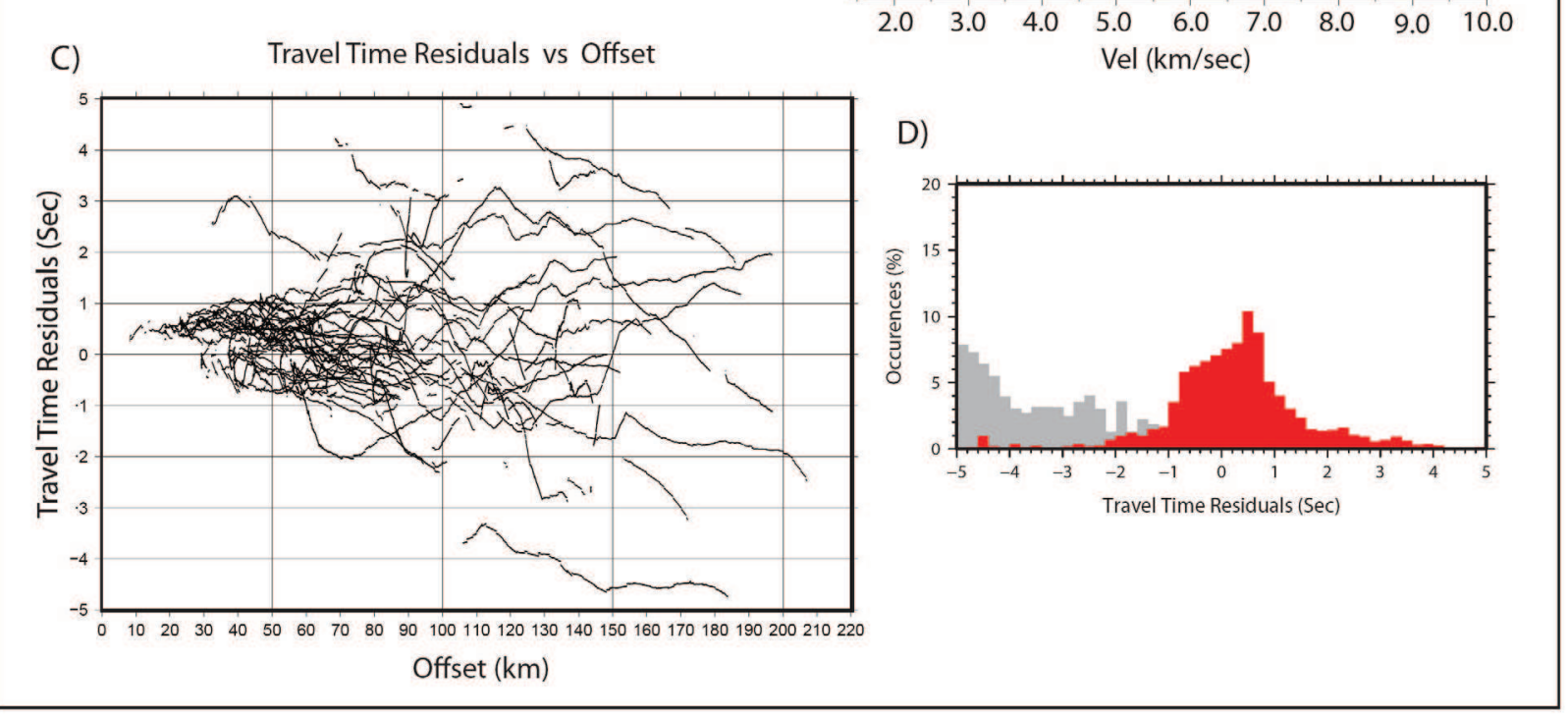

Figure A3.2 - a) Cross-section along profile 6 presenting the depth distribution of P-wave velocities along RAU07-09 and its onshore projection generated by the unconstrained inversion. b) Bathymetric map displaying the orientations of cross-sections generated to analyse model results (Black) and RAU07 seismic reflection lines (Blue/White) The profile presented in (a) is thick and white. c) Plot of travel-time residuals ( $\mathrm{T}$ obs $-\mathrm{T}$ calc) vs offset observed at the completion of this inversion. d) Histogram displaying the distribution of residual travel-times observed before (grey) and after (red) tomographic inversion.

This inversion appears to resolve the Raukumara Basin with a depth and location approximately consistent with observations from MCS reflection data. Low velocities display a spatial correlation with the topographic crest and are observed beneath the East Cape Ridge, East Cape and central Raukumara Peninsula at greater depth (Figure A3.1). The low velocities resolved in each region are considered to be related and these observations could be reconciled by a curved low velocity anomaly parallel to the topographic crest, which becomes localised beneath the central Raukumara Peninsula with depth. 
limit imposed in this inversion [Reyners et al., 1999] and the crustal transition may thus be resolved as lower velocities (most likely above $17 \mathrm{~km}$ ) attempting to compensate for the underestimated forearc crustal thickness in the starting model.

The starting model for this inversion consisted of four layers representing subaerial land $(4.0-5.5 \mathrm{~km} / \mathrm{sec})$, the water column $(1.48-1.5 \mathrm{~km} / \mathrm{sec})$, forearc crust $(2.5-5.5 \mathrm{~km} / \mathrm{sec})$, and the mantle wedge $(7.0-8.5 \mathrm{~km} / \mathrm{sec})$.

The introduction of multiple layers in which refracted arrivals turn required $a$ priory assumptions to be made concerning the phase of arrivals. For this reason, observations included in the inversion are limited to first-arrivals originating from shot-points within the Raukumara Plain. Information from preliminary forward-modelling is used to segment these arrivals into two discrete phases, turning within the forearc crust (Layer three, offsets $<50 \mathrm{~km}$ ) and mantle wedge (Layer four, offsets $>50 \mathrm{~km}$ ). Excluding arrivals from the East Cape Ridge region and areas farther east prevent smearing associated with these arrivals from perturbing the velocity field beneath the Raukumara Peninsula. Arrivals from these regions sample unique structures (e.g. the subducting slab) and are too complex to resolve with a four layer model.

This model ran for ten iterations, in which RMS residuals decrease monotonically from 12.6 seconds through the first seven iterations to a value of 1.48 seconds (Figure A3.4c-d). 

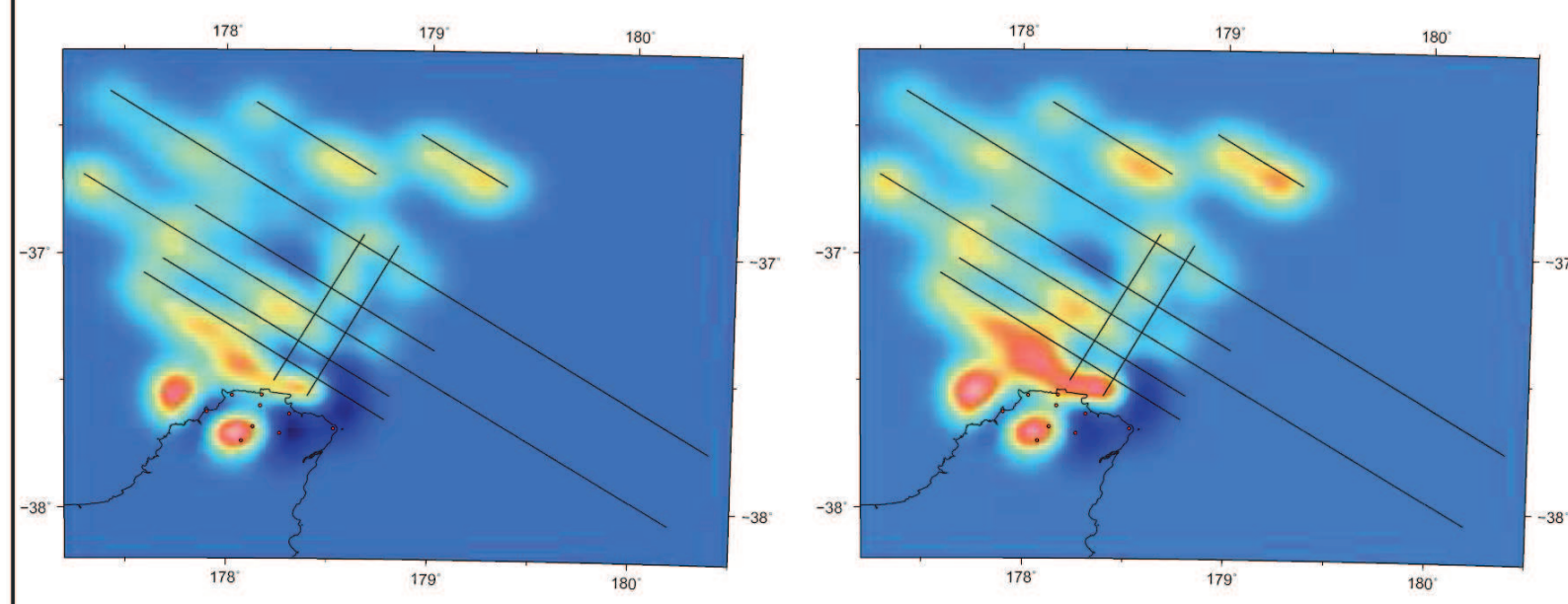

DEPTH $=5.0 \mathrm{~km}$

DEPTH $=7.5 \mathrm{~km}$

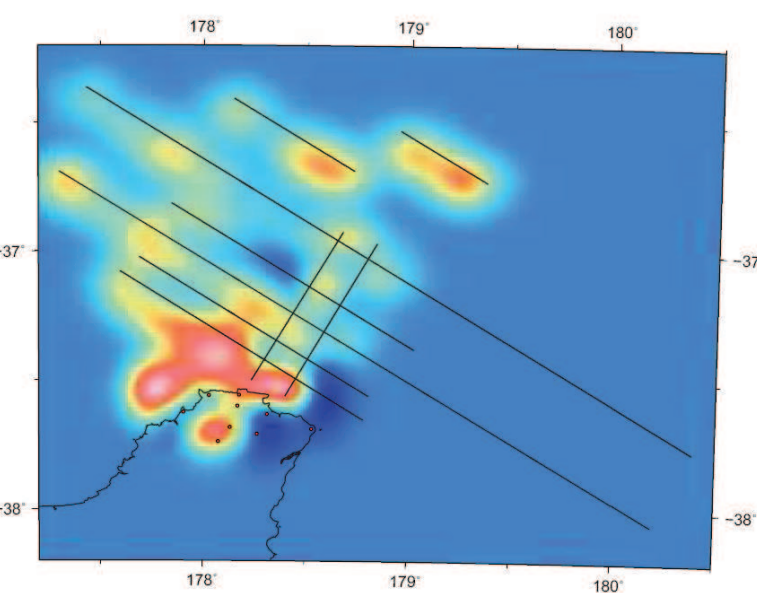

DEPTH $=10.0 \mathrm{~km}$

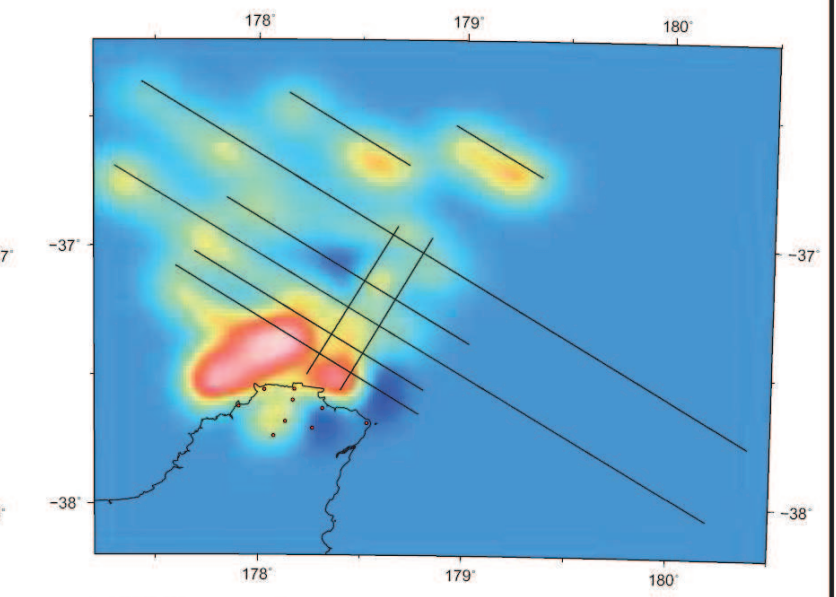

DEPTH $=15.0 \mathrm{~km}$

$\begin{array}{llllllllll}2.0 & 3.0 & 4.0 & 5.0 & 6.0 & 7.0 & 8.0 & 9.0 & 10.0\end{array}$ Vel $(\mathrm{km} / \mathrm{sec})$

Figure A3.3 - Depth slices (as labelled) displaying the distribution of Vp velocities generated by the constrained tomographic inversion of all interpreted first arrival travel-times originating from shotpoints within the Raukumara Plain. Black lines offshore display RAU07 reflection profiles and the source of interpreted arrivals. Coastline of the Raukumara Peninsula is displayed in Black. Continued overleaf. 


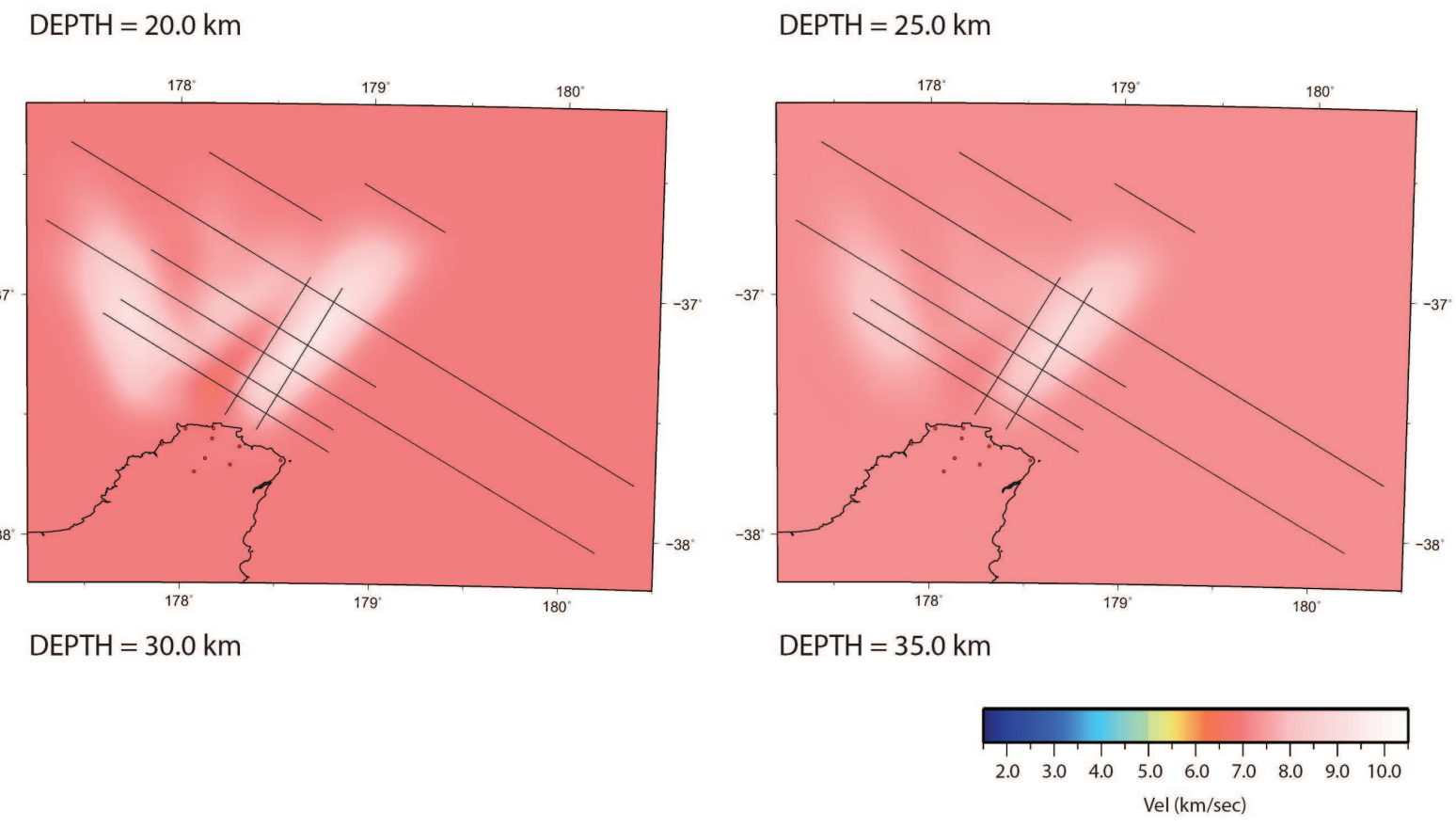

Figure A3.3 - continued

This model consists of two refracting layers and one must be mindful of the velocity trade-off between these layers when interpreting results (Figure A3.4a).

At depths between 5 and $20 \mathrm{~km}$, the continental shelf is modelled with velocities from 6.0-7.5 km/sec (Figure A3.3). These velocities are notably higher than those observed for the coastal regions of the Raukumara Peninsula $(\mathrm{Vp}<5.0$ $\mathrm{km} / \mathrm{sec}$ ). The velocity contrast between the continental shelf and the northern Raukumara Peninsula is observed at all depths shallower than the Moho (fixed at $17 \mathrm{~km})$. 
continental shelf, an inference consistent with the results of velocity forward modelling (Figure 4.3).

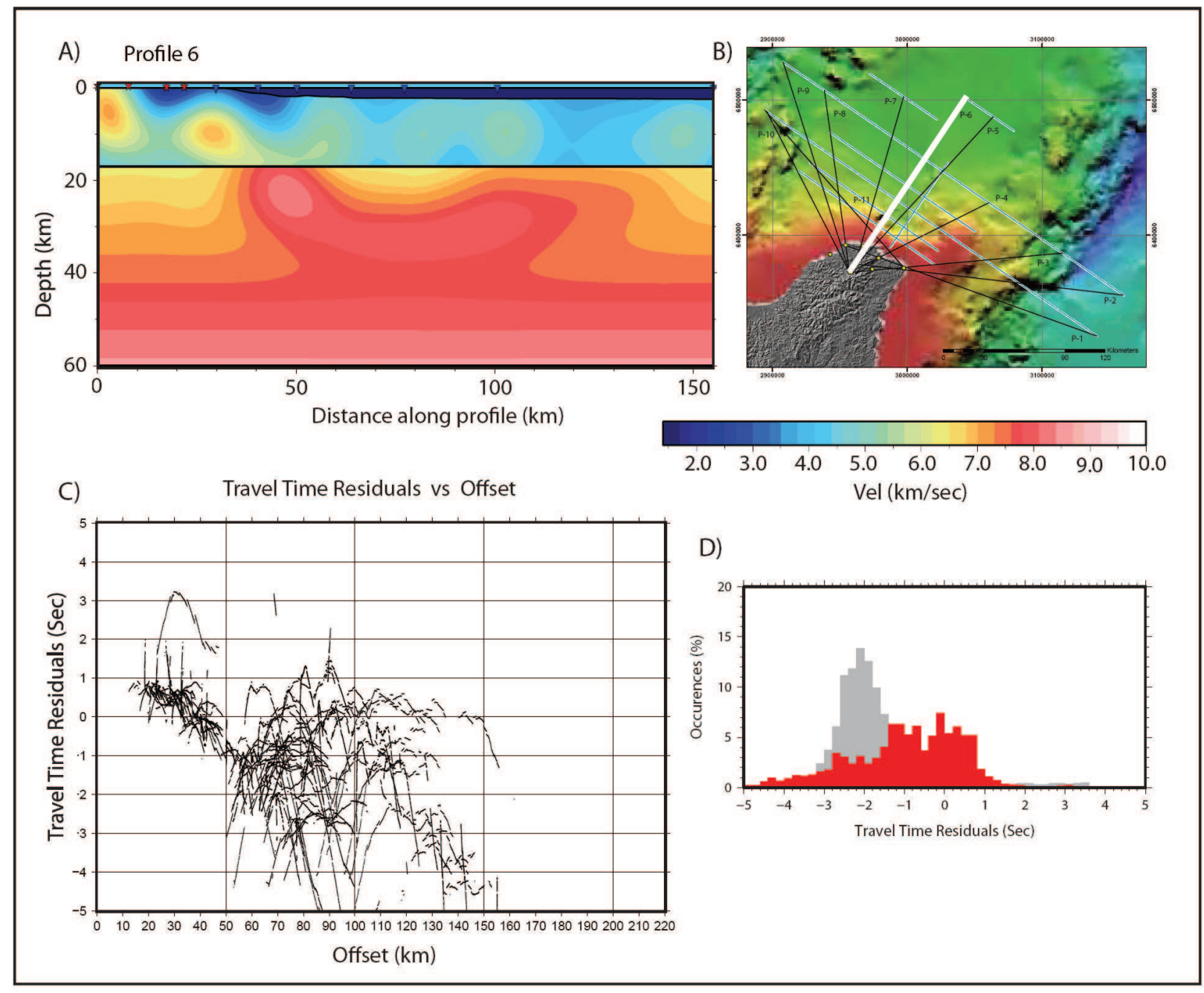

Figure A3.4 - a) Cross-section along profile 6 presenting the depth distribution of Vp velocities generated by the constrained inversion along RAU07-09 and its onshore projection. b) Bathymetric map displaying the orientations of cross-sections generated to analyse model results (Black) and RAU07 seismic reflection lines (Blue/White) The profile presented in (a) is thick and white c) Plot of travel-time residuals $(\mathrm{T}$ obs $-\mathrm{T}$ calc) vs offset observed at the completion of the constrained inversion. d) Histogram displaying the distribution of residual travel-times observed before (grey) and after (red) tomographic inversion. Note the prevalence of negative residual travel-times implying the generated velocity model remains too slow. 
The large number (14) and complexity of layers in the starting model made this a complicated inversion to perform and the results of forward modelling were used to discern the discrete phase of each observed travel-time. Arrivals were excluded where an anomalously large $(>1 \mathrm{sec})$ residual travel-time remained after forward modelling.

Velocity forward models were constructed assuming negligible lateral velocity variations within layers and are comprised of velocity grids derived by linear interpolation between constant velocities specified for upper and lower layer boundaries. It is anticipated that the majority of travel-time residuals can be reconciled by deviating from this assumption and introducing velocity perturbations within layers. The degree of geometrical constraint on subsurface interfaces exceed constraints placed on the velocity structure and for these reasons, this inversion is performed exclusively solving for velocity structure.

In contrast to earlier inversions, large variations in RMS residuals were not observed between iterations (Table 3.1, Figure A3.6c-d) and the nature and location of velocity perturbations introduced are highly dependent on the velocity structure of the starting model. The results of this inversion should thus be interpreted as representing the best fitting velocity structure, subject to the interface geometries as constrained in the starting model. 

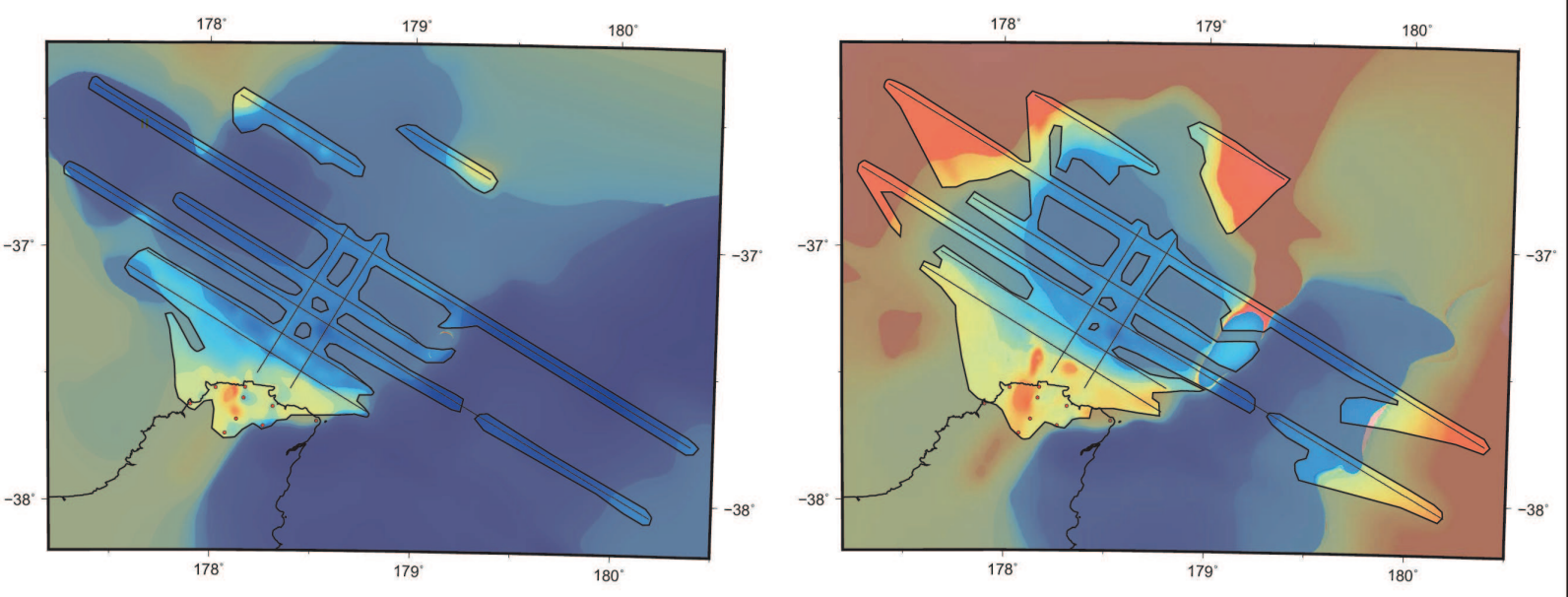

$\mathrm{DEPTH}=5.0 \mathrm{~km}$

$\mathrm{DEPTH}=7.5 \mathrm{~km}$

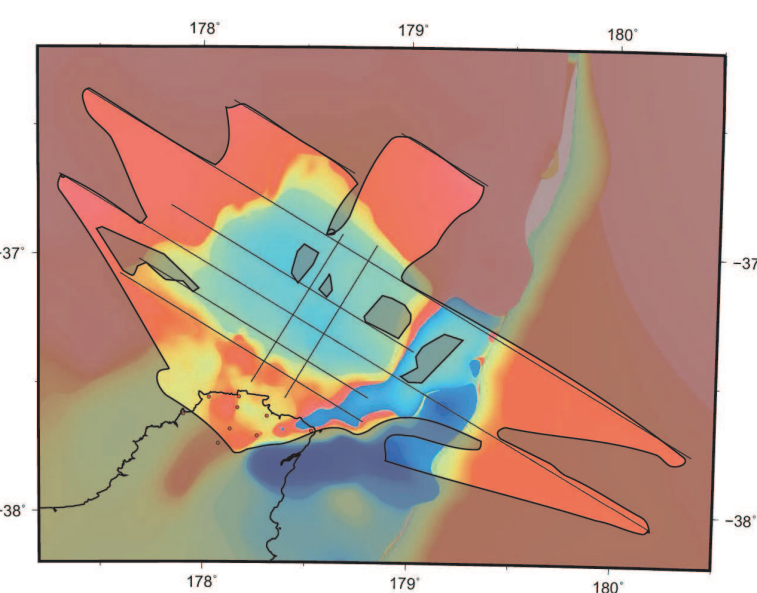

$\mathrm{DEPTH}=10.0 \mathrm{~km}$

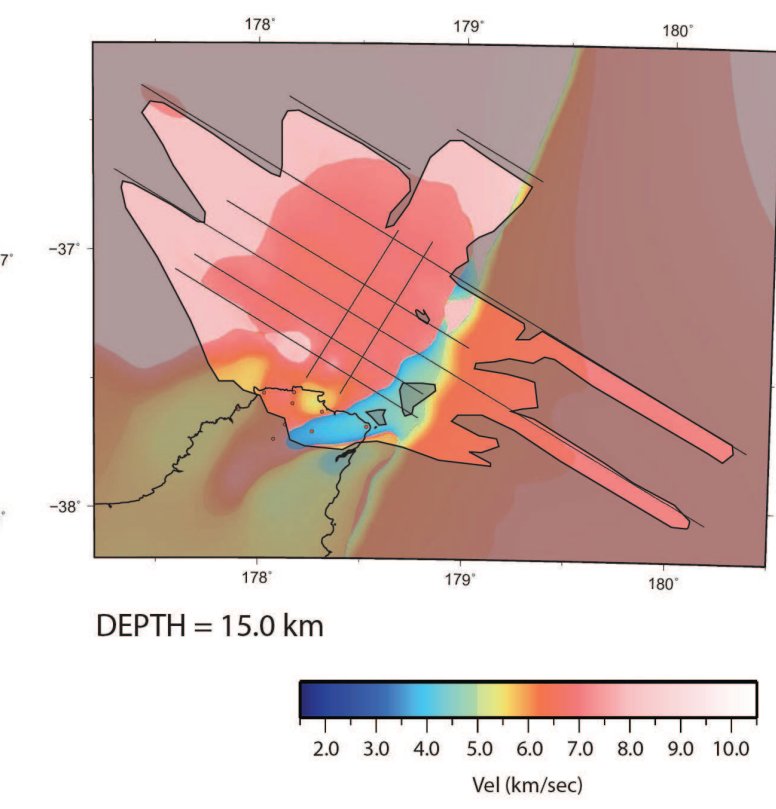

Figure A3.5 - Depth slices (as labelled) displaying the distribution of P-wave velocities after the tomographic inversion for travel-time residuals persisting after forward modelling. The final forward velocity model was used as the starting model for this inversion. Darker areas represent regions not sampled by seismic data (Figure A5.2.2). Black lines offshore display RAU07 reflection profiles and the source of interpreted arrivals. Coastline of the Raukumara Peninsula displayed in Black. Continued overleaf. 

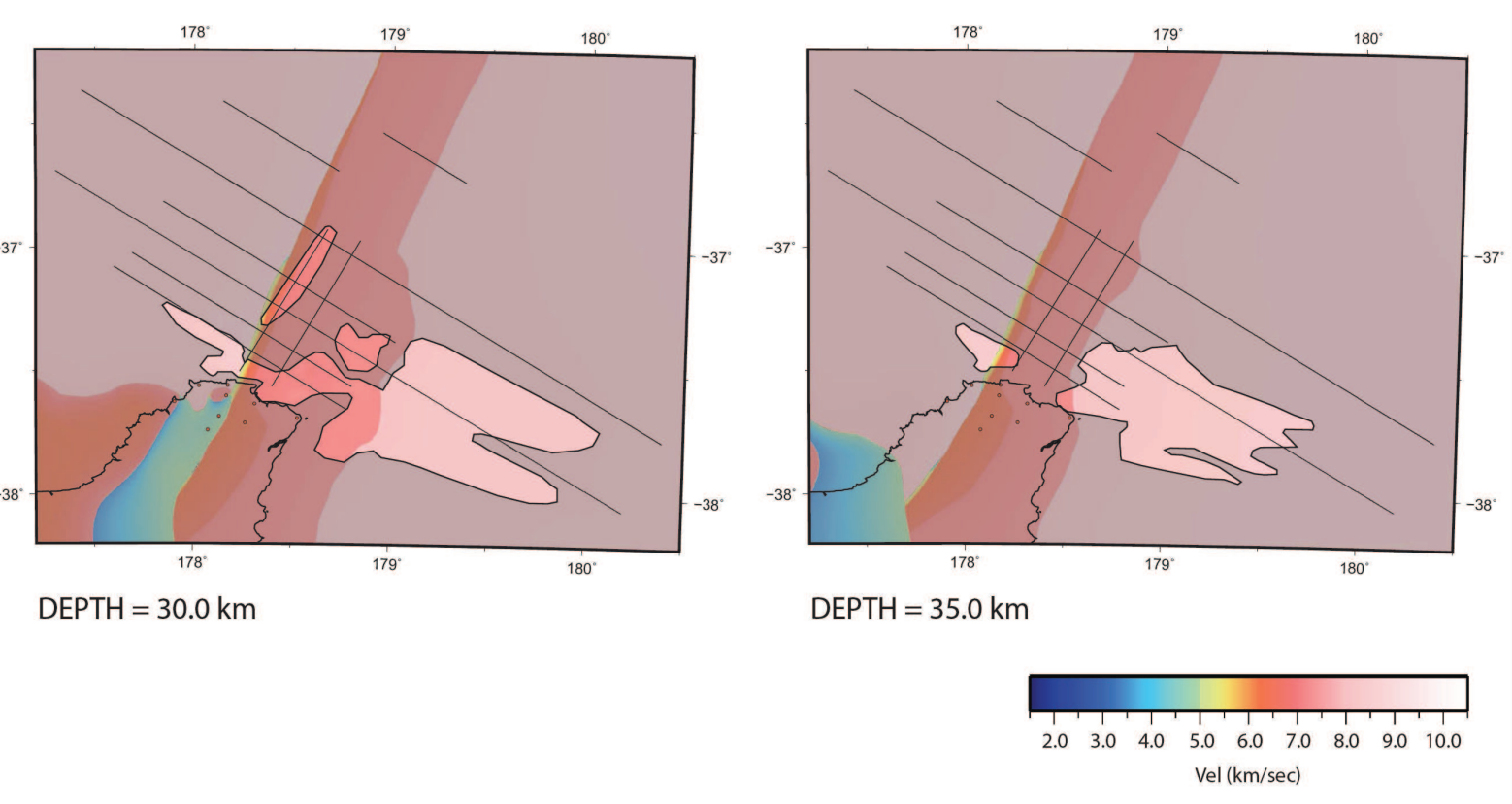

Figure A3.5 - Continued

The velocity structure resolved by forward methods is preserved after this inversion. The only notable velocity perturbation introduced is an $(0.5 \mathrm{~km} / \mathrm{sec})$ increase in the shallow $(<3 \mathrm{~km})$ velocity structure of the northern Raukumara Peninsula. This perturbation may be interpreted as suggesting an underestimated thickness for the Matakaoa Volcanics within the starting model.

The raypath limitations which rendered the initial inversions as underdetermined problems persist within this inversion and analysis of the differential velocity structure (which reveals velocity perturbations) displays residuals predominantly being smeared along raypaths rather than being focussed within specific regions. 


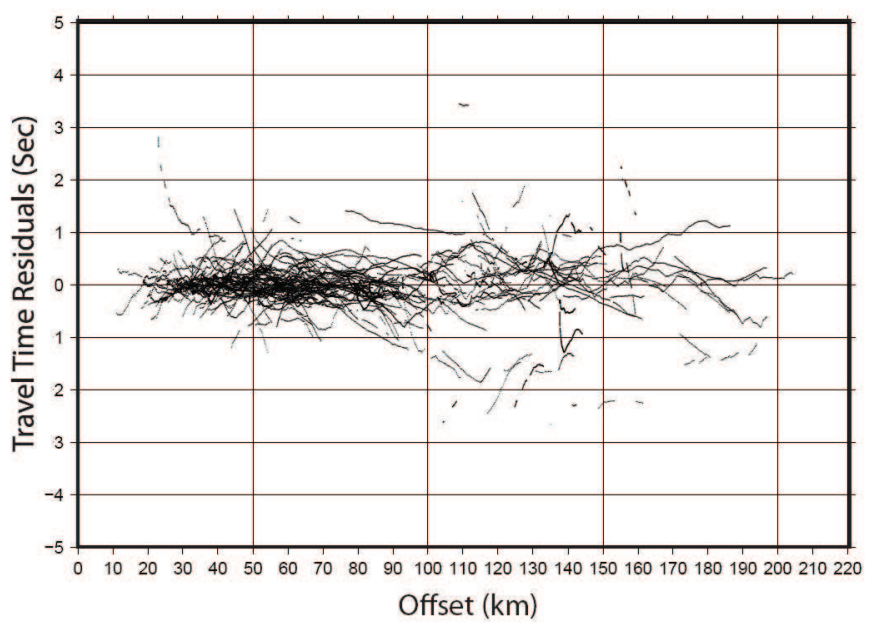

D)

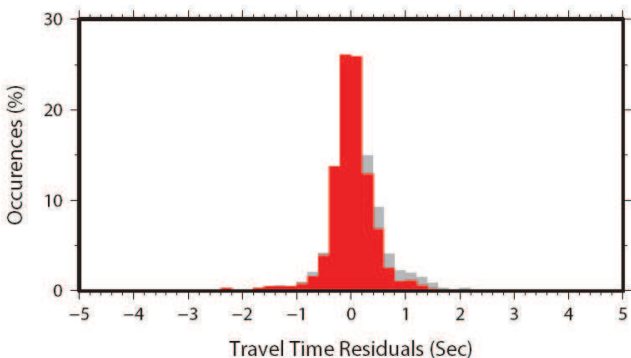

Travel Time Residuals (Sec)

Figure A3.6 - a) Cross-section along profile 6 presenting the depth distribution of Vp velocities generated by the inversion of the final forward model along RAU07-09 and its onshore projection. b) Bathymetric map displaying the orientations of cross-sections generated to analyse model results (Black) and RAU07 seismic reflection lines (Blue/White) The profile presented in (a) is thick and white. c) Plot of travel-time residuals (T obs - T calc) vs offset observed at the completion of this inversion. d) Histogram displaying the distribution of residual travel-times observed before (grey) and after (red) tomographic inversion. Note the general consistency between residual travel-times and offset (c) and the approximately normal distribution of residual values centred at 0 .

To produce a robust result from tomographic inversion using onshore-offshore data, a larger range of ray-azimuths and the acquisition of reversed profiles are required. Complete onshore-offshore experiments often supplement the acquisition of onshore-offshore data with OBS/H deployments and land-based refraction profiling. These additional data increase the ray-coverage and make robust analysis using tomographic inversion possible, as documented within the literature [e.g. Rawlinson \& Urvoy 2006]. 
Figure A4.1 (Overleaf) - Station plots (as labelled) displaying observed (black) and synthetic travel-times calculated through the forward model (coloured). Each block represents arrivals from a discrete RAU07 profile with the first digit of the shot-number representing the RAU07 line-number. Plotted behind each observed travel-time is a white line displaying the estimated error associated with each interpreted travel-time. The vertical scale is total travel time with no reduction velocity applied. 


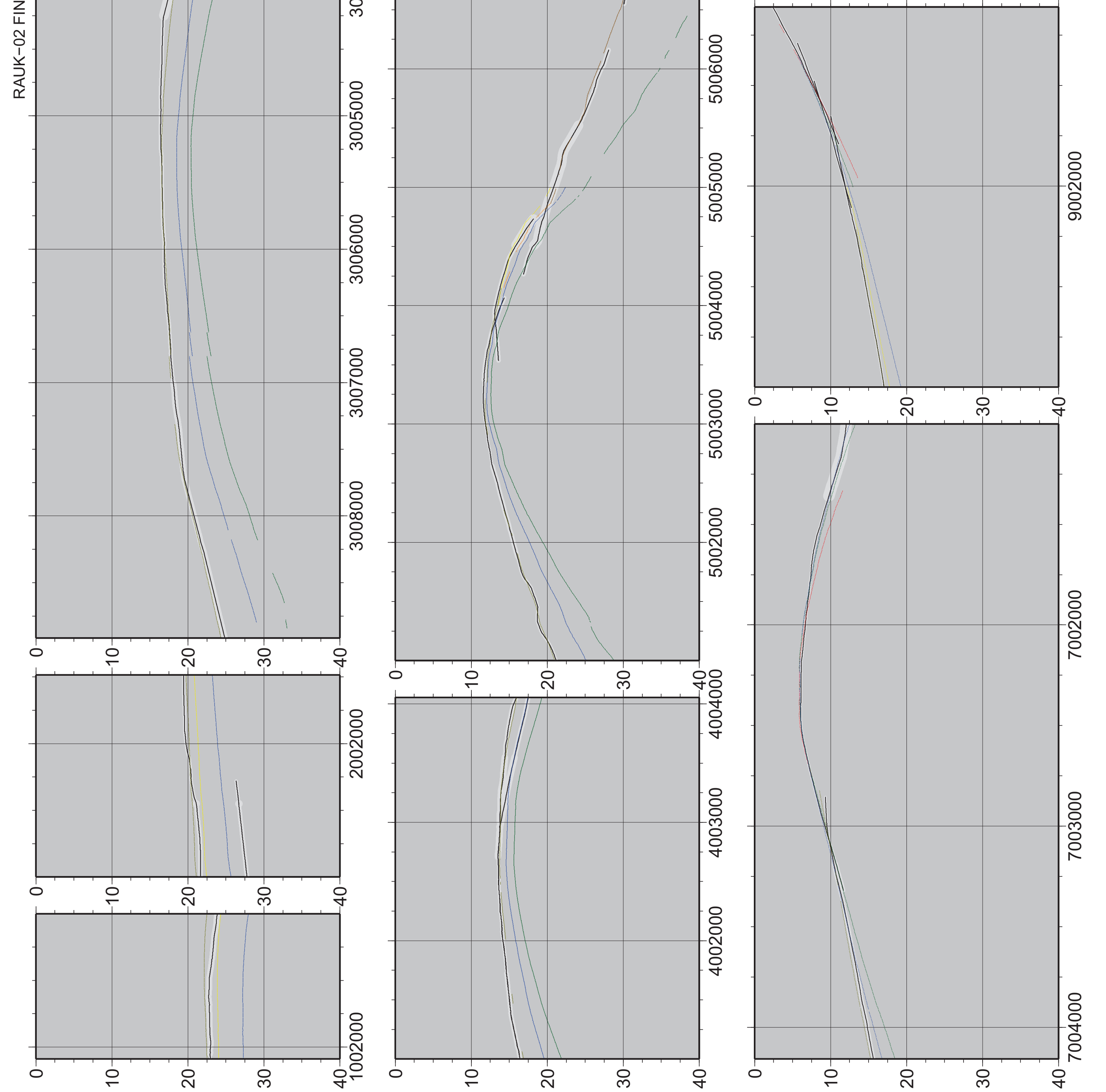




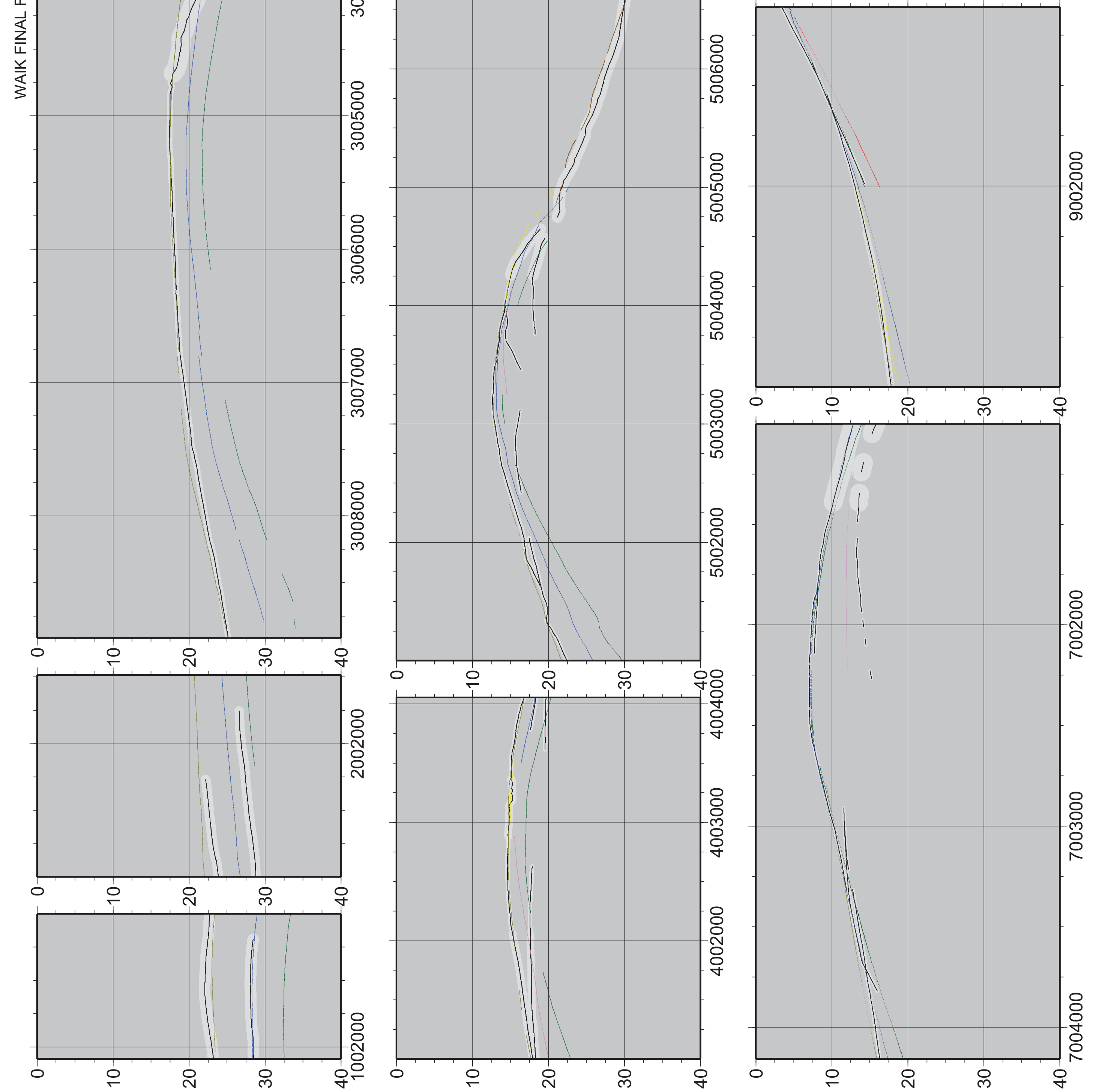




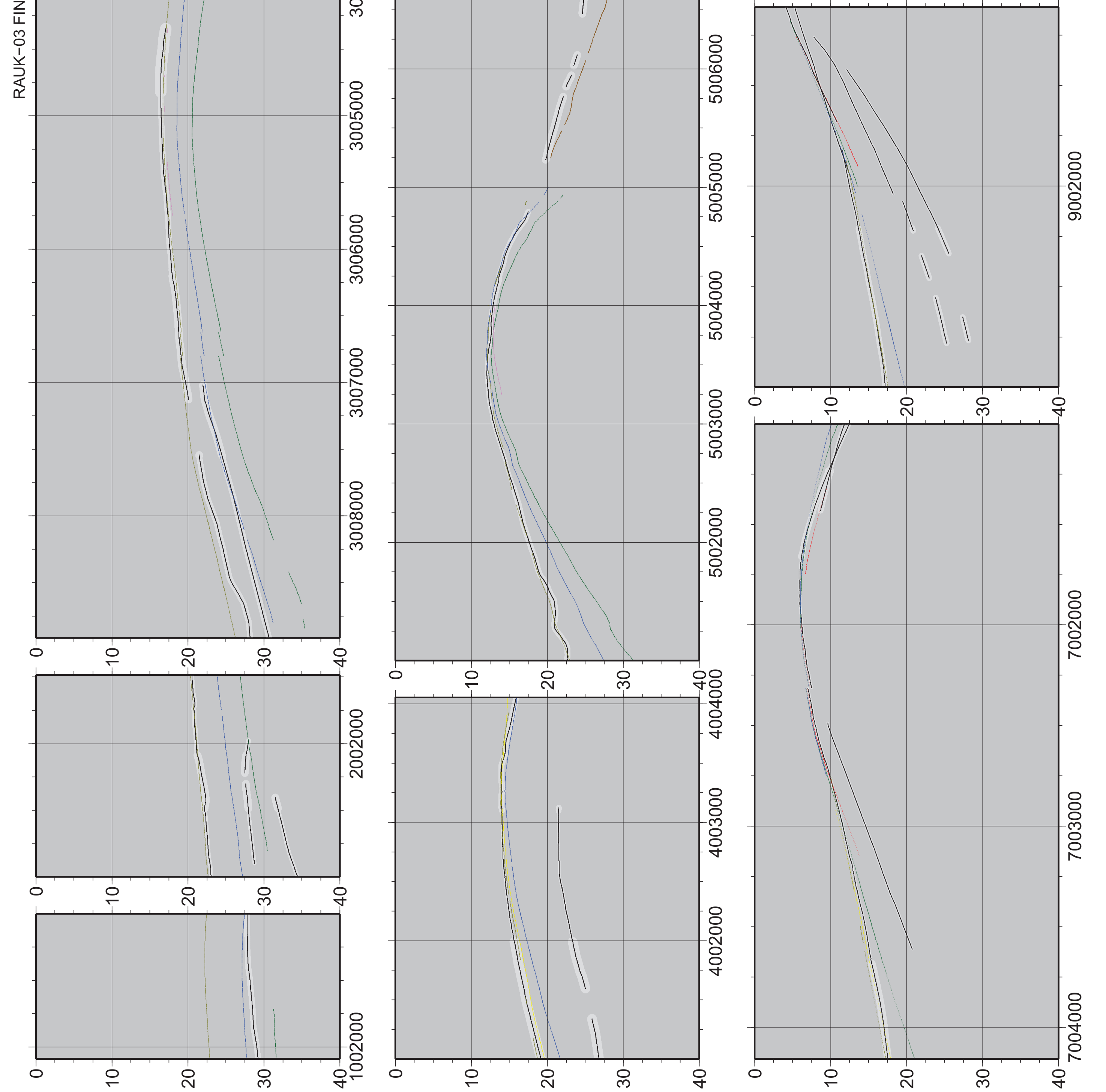




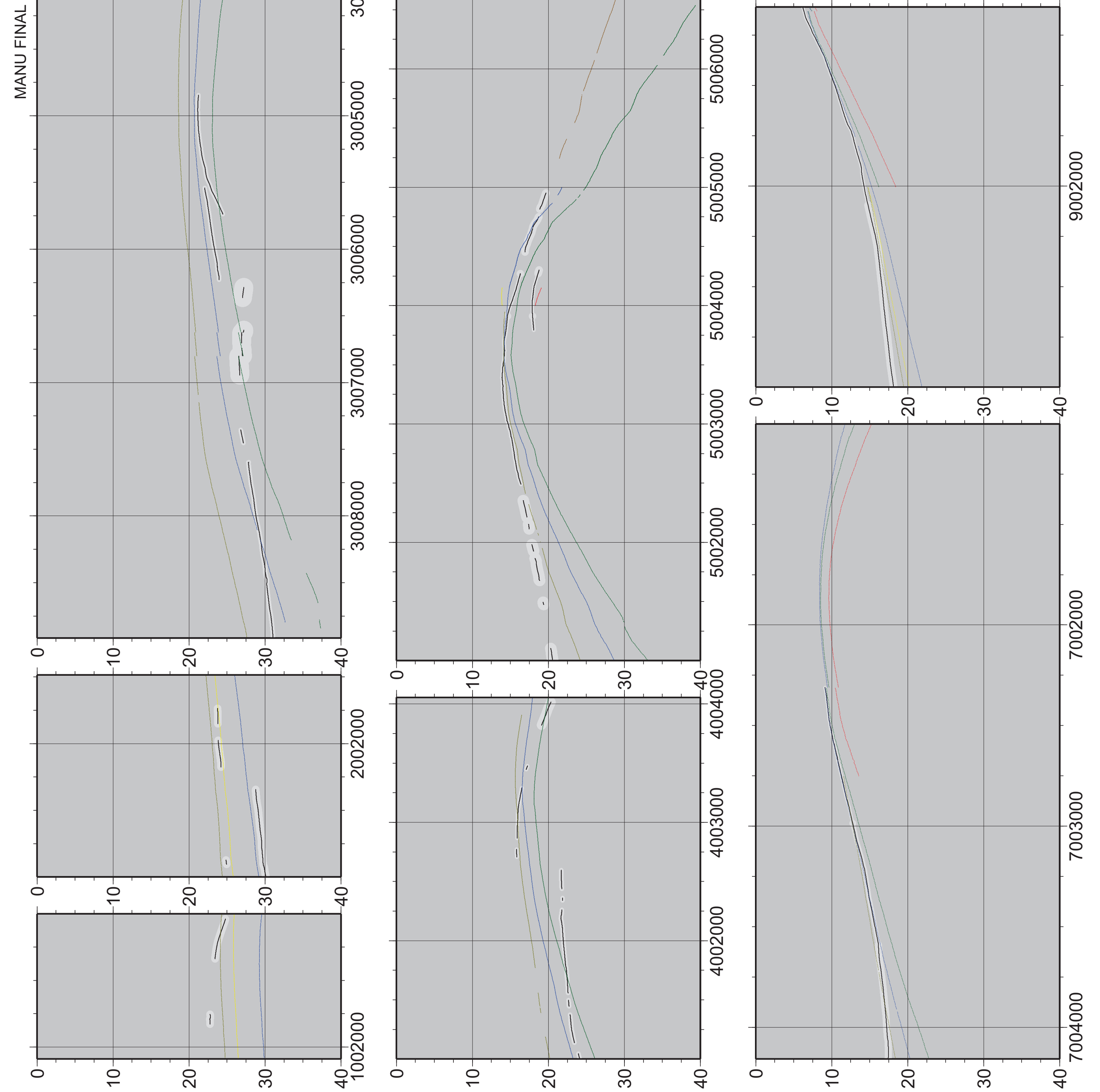




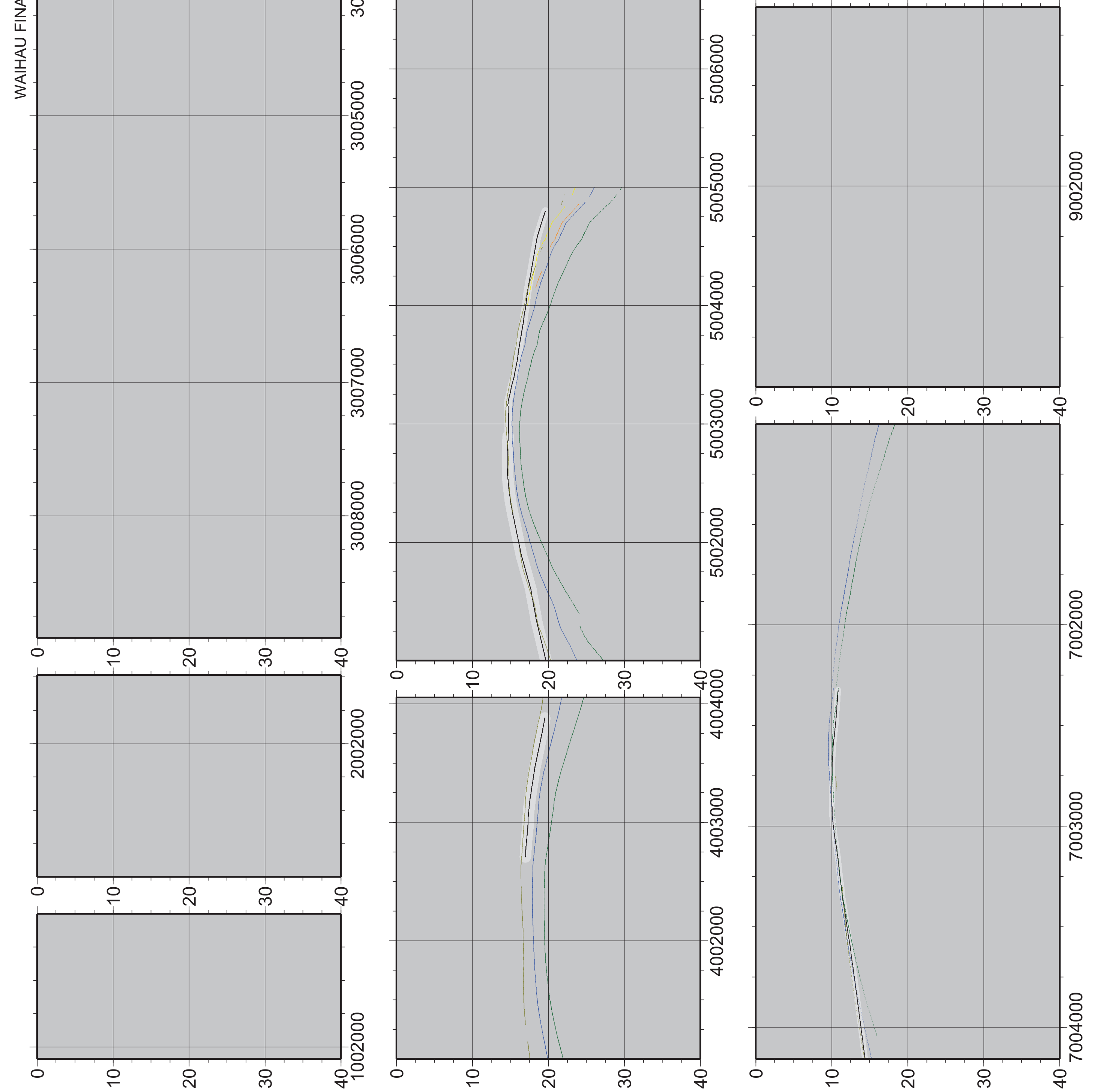




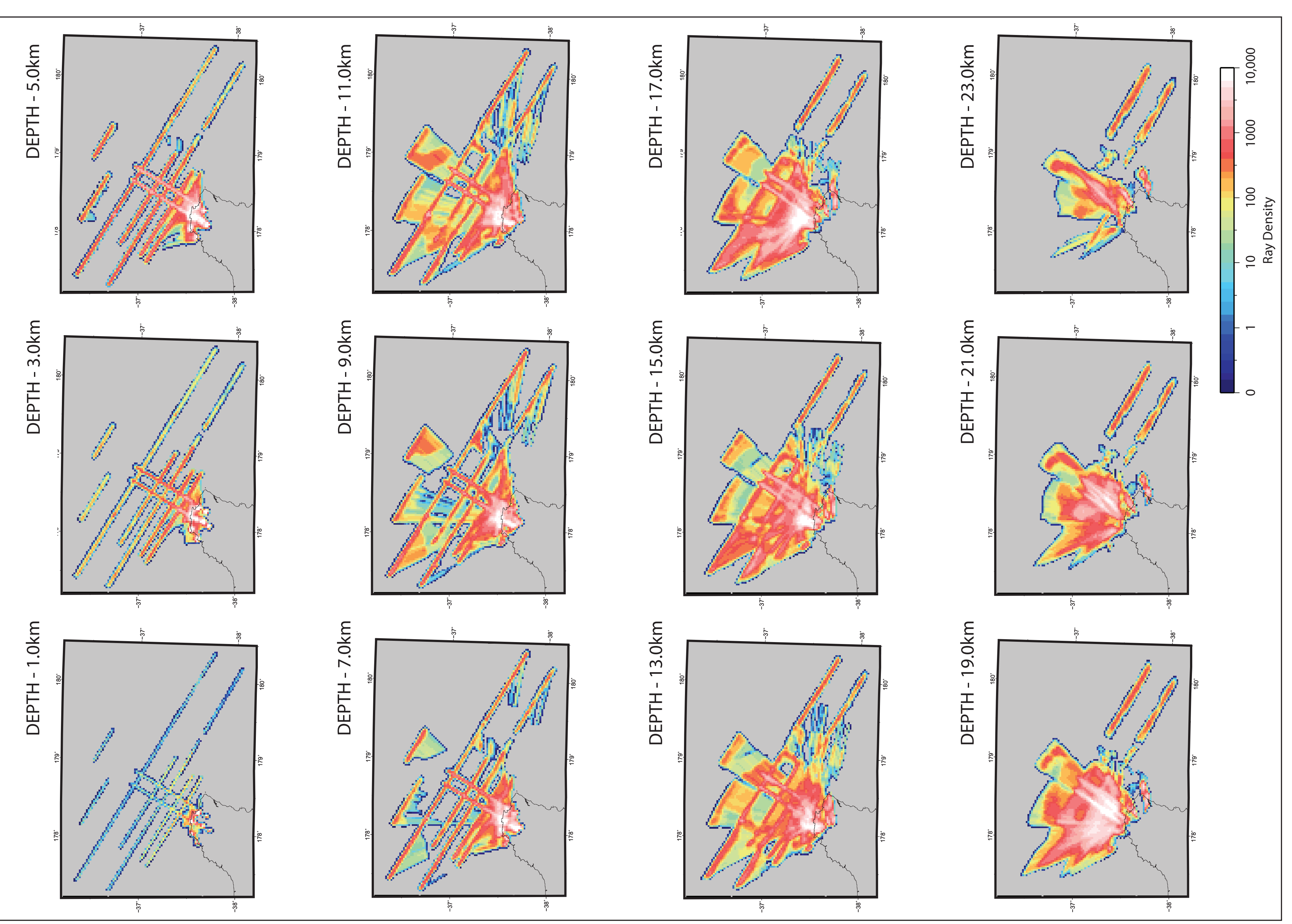


